\title{
Development of Enhanced Emission Factor Through the Identification of an Optimal Combination of Input Variables Using Artificial Neural Network
}

Tse-Huai Liu

Follow this and additional works at: https://researchrepository.wvu.edu/etd

\section{Recommended Citation}

Liu, Tse-Huai, "Development of Enhanced Emission Factor Through the Identification of an Optimal Combination of Input Variables Using Artificial Neural Network" (2018). Graduate Theses, Dissertations, and Problem Reports. 6104.

https://researchrepository.wvu.edu/etd/6104

This Thesis is protected by copyright and/or related rights. It has been brought to you by the The Research Repository @ WVU with permission from the rights-holder(s). You are free to use this Thesis in any way that is permitted by the copyright and related rights legislation that applies to your use. For other uses you must obtain permission from the rights-holder(s) directly, unless additional rights are indicated by a Creative Commons license in the record and/ or on the work itself. This Thesis has been accepted for inclusion in WVU Graduate Theses, Dissertations, and Problem Reports collection by an authorized administrator of The Research Repository @ WVU. For more information, please contact researchrepository@mail.wvu.edu. 


\title{
Economic and Environmental Analyses of Biomass Utilization for Bioenergy Products in the Northeastern United States
}

\author{
Weiguo Liu
}

\author{
Dissertation submitted \\ to the Davis College of Agriculture, Natural Resources and Design \\ at West Virginia University \\ in partial fulfillment of the requirements for the degree of \\ Doctor of Philosophy in \\ Forest Resources Science \\ Jingxin Wang, Ph.D., Chair \\ Debangsu Bhattacharyya, Ph.D. \\ Kara Cafferty, M.S. \\ Shawn Grushecky, Ph.D. \\ Jamie Schuler, Ph.D. \\ Kaushlendra Singh, Ph.D. \\ Sabrina Spatari, Ph.D
}

School of Natural Resources

Morgantown, West Virginia

2015

Keywords: Carbon Sequestration, CBTL, Woody Biomass, Energy Crop, Life Cycle Assessment, Modeling and Optimization 


\title{
ABSTRACT \\ Economic and Environmental Analyses of Biomass Utilization for Bioenergy Products in the Northeastern United States
}

\author{
Weiguo Liu
}

A mixed-integer programming model was developed to optimize forest carbon sequestration considering carbon price, biomass price, harvest area restriction, and harvest method. The model was applied to examine the harvest scheduling strategies and carbon sequestration in a mixed central Appalachian hardwood forest. Sensitivity analyses were conducted over a range of carbon and biomass to timber price ratios, harvest area limitations and harvest methods. The results showed that the carbon sequestration rate of the central Appalachian hardwood forests could gradually increase as the carbon to timber price ratio changed from 0.0 to 1.0 with an average sequestration rate of $0.917 \mathrm{Mg} \cdot \mathrm{ha}^{-1} \cdot \mathrm{year}^{-1}$. The rise of biomass to timber price ratio reduces the carbon sequestration potential. Additionally, the carbon sequestration potential would decrease when harvest area limitation varied from 0 (no harvest) to 100 ha. The decrease could be $97.4 \%$ and $70.8 \%$ respectively when the carbon to timber price ratios were 0.0 and 0.25 . Low intensity partial cut could have a higher carbon sequestration rate comparing with clearcutting when the carbon to timber price ratio was low.

We analyzed the economic feasibility and environmental benefits of an alternative technology that converts coal and biomass to liquid fuels (CBTL), using West Virginia as a real case scenario with considerations of woody biomass harvest scheduling optimization, feedstock transportation and siting options of potential CBTL plants. Sensitivity analyses on required selling price (RSP) were conducted according to feedstock availability and price, biomass to coal mix ratio, liquid fuel yield, IRR, capital cost, operational and maintenance cost. A cradleto-grave life cycle assessment (LCA) model was also developed to analyze the environment benefits of the CBTL processes. The study of siting and capacity showed that feedstock mixed ratio limited the CBTL production. Sensitivity analysis on RSP showed the price of coal had more dominant effect than that of biomass. Different biomass mixed ratio in the feedstock and liquid fuel yield led to RSP ranging from $\$ 104.3$ - $\$ 157.9 / \mathrm{bbl}$. LCA study indicated that greenhouse gas (GHG) emissions ranged from $80.62 \mathrm{~kg} \mathrm{CO}_{2}$ eq to $101.46 \mathrm{~kg} \mathrm{CO}_{2} \mathrm{eq} / 1,000 \mathrm{MJ}$ at various biomass to coal mix ratios and liquid fuel yield if carbon capture and storage (CCS) was applied. Most of water and fossil energy were consumed in conversion process at a CBTL facility. Compared to petroleum-derived-liquid fuels, the reduction in GHG emissions in West Virginia was estimated to be between -162 and 555 million tons over a 30-year period.

A mixed integer linear programming (MILP) model and life cycle assessment (LCA) model were developed to analyze economic and environmental benefits by utilizing forest residues for small scale production of bioenergy in West Virginia. The MILP was developed to optimize the costs and required selling price of biofuels under different strategies. The cradle- 
to-gate LCA was developed to examine the greenhouse gas emissions, blue water and fossil energy consumption associated with the biomass utilization. The RSP in base case was $\$ 90.87 / \mathrm{bbl}$ ethanol and $\$ 126.08 / \mathrm{bbl}$ for diesel and gasoline. The sensitivity analysis on RSP showed that liquid fuel yield had most prominent effect and followed by internal rate of return (IRR) and feedstock price. The LCA showed that the GHG emissions from the production of $1,000 \mathrm{MJ}$ energy equivalent ethanol was $9.72 \mathrm{~kg} \mathrm{CO}_{2}$ eq which was lower than fast pyrolysis (9.72 $\mathrm{kg} \mathrm{CO} 2 \mathrm{eq})$. Fast pyrolysis had high water and energy consumption. The uncertainty analysis showed the change of environmental impact by the change of liquid fuel yield. The risk of biomass to liquid via fast pyrolysis (BLFP) to have a negative energy output was expected when the liquid fuel yield was low. The production of ethanol required lower cost and had lower environmental impact, that is to say, the costs for reducing $1 \mathrm{~kg} \mathrm{CO}_{2}$ eq GHG emissions was low in biomass to ethanol (BTE), but more biomass was required to produce same amount of energy equivalent liquid fuels.

Finally, a modeling process was developed to examine the economic and environmental benefits of utilizing energy crops for biofuels and bio-products. Three energy crops (hybrid willow, switchgrass and miscanthus) that can potentially grow on marginal agricultural land or abandoned mine land in the Northeastern United States were considered in the analytical process for the production of biofuels, biopower and pellet fuel. The supply chain components for both the economic and life cycle modeling processes include feedstock establishment, harvest, transportation, storage, preprocessing, energy conversion, distribution and final usage. Sensitivity analysis was also conducted to assess the effects of energy crop yield, transportation distance, bioproduct yield, different pretreatments, facility capacity and internal rate of return (IRR) on the production of bioenergy products. The RSPs were ranged from $\$ 7.39 / \mathrm{GJ}$ to $\$ 23.82 / \mathrm{GJ}$ for different bioproducts. The production of biopower had the higher required selling price (RSP) where pellet fuel had the lowest. The results also indicated that bioenergy production using hybrid willow demonstrated lower RSP than the two perennial grass feedstocks. Biopower production presented the lowest $\mathrm{GHG}$ emissions (less than $10 \mathrm{~kg} \mathrm{CO} 2 \mathrm{eq}$ per 1,000 MJ) and fossil energy consumption (less than $160 \mathrm{MJ}$ per 1,000 MJ) but with the highest water consumption. The production of pellet fuel resulted in the highest GHG emissions. Sensitivity analysis indicated that bioproduct yield was the most sensitive factor to RSP and followed by transportation distance for biofuel and biopower production. Bioproduct yield and transportation distance of feedstock presented great effects on environmental impact for the production of liquid fuels and biopower. 


\section{Acknowledgements}

This dissertation is a long journey to work at West Virginia University with Dr. Jingxin Wang's guidance. First, I would like to thank my major professor Dr. Jingxin Wang for providing me with this opportunity and his patient guidance that brings my learning to the current level. He continuously provided opportunity to improve my professional knowledge and skill. He also helped me to navigate through my course works and research projects. I would also like to thank my committee members: Dr. Debangsu Bhattacharyya, Ms. Kara Cafferty, Dr. Shawn Grushecky, Dr. Jamie Schuler, Dr. Kaushlendra Singh, and Dr. Sabrina Spatari for their precious time, valuable comments and suggestions.

Additionally, I would like to thank my parents for their support during my study at WVU. They provided endless encouragement and reassurance during the last five years. I would also like to thank my friends I have made in WVU who brought a lot joy and made my life easier. 


\section{Table of Contents}

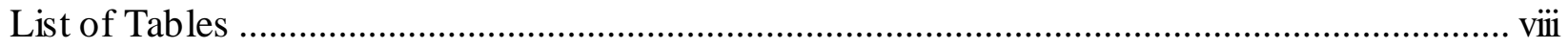

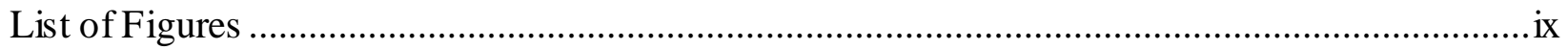

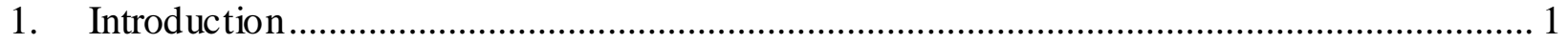

2. Modeling of Forest Harvest Scheduling and Carbon Sequestration in Central Appalachian

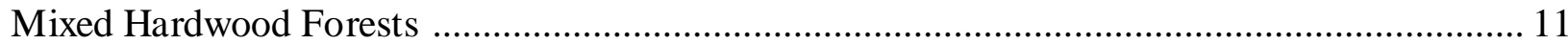

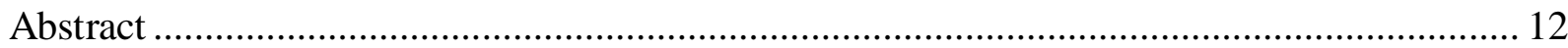

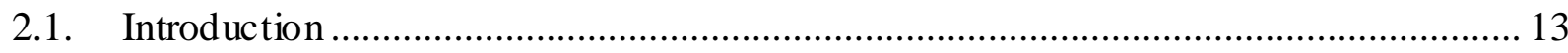

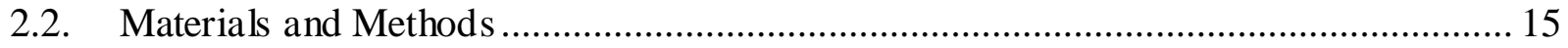

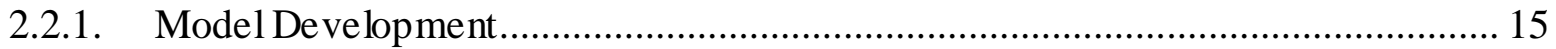

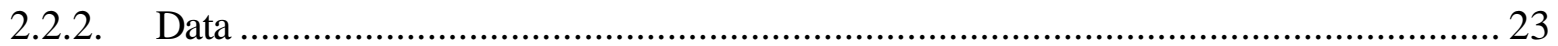

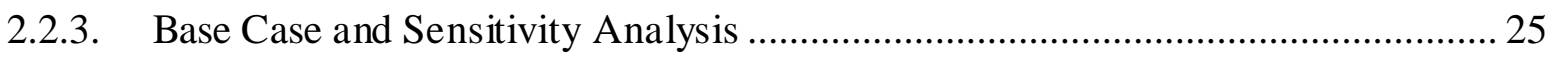

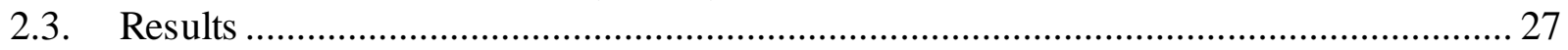

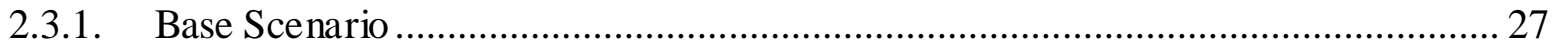

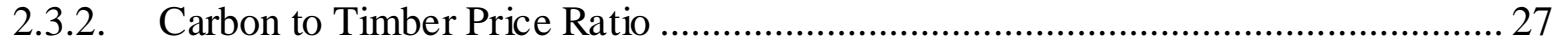

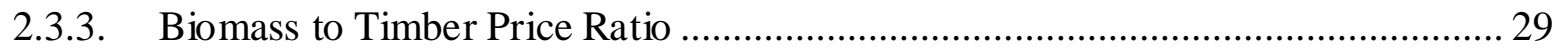

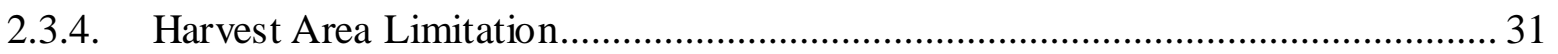

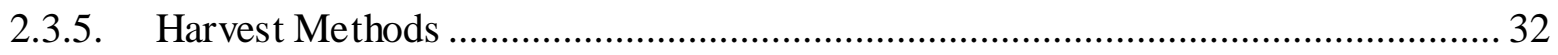

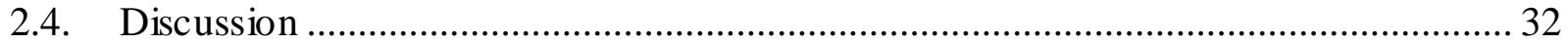

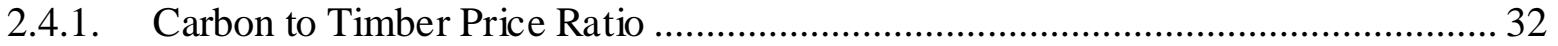

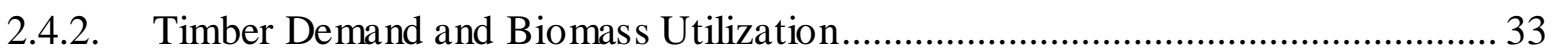

2.4.3. Harvest Area Limitation and Harvest Methods ...................................................... 34

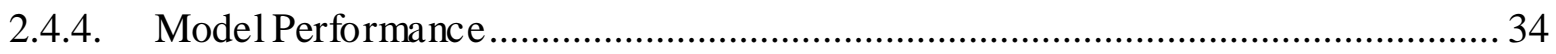

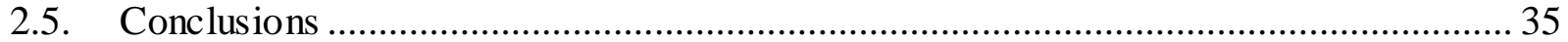

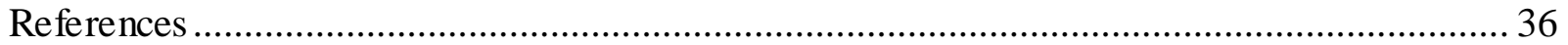

3. Economic and Environmental Analyses of Coal and Biomass to Liquids Plants ................. 40

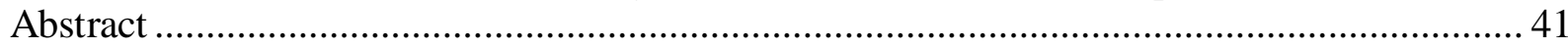

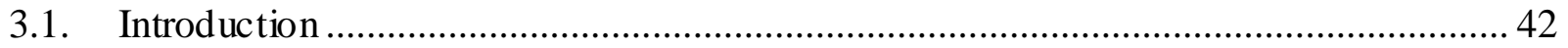

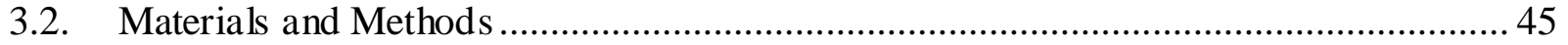

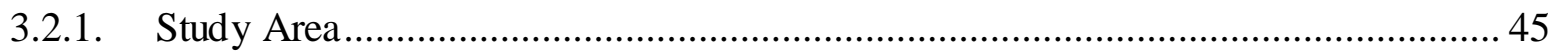

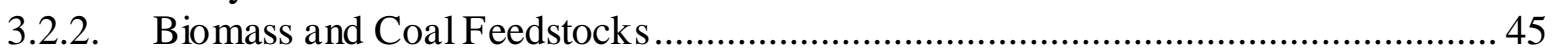

3.2.3. Process model of the CBTL plant ....................................................................... 49

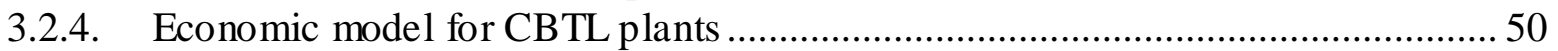

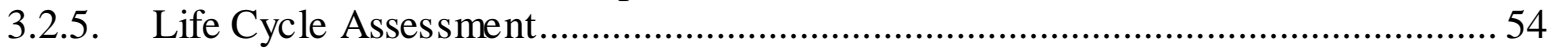

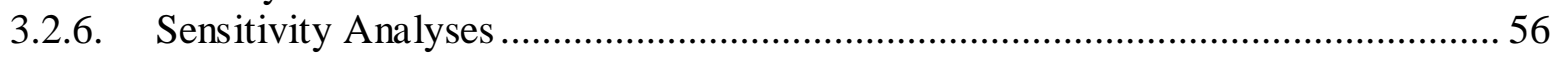

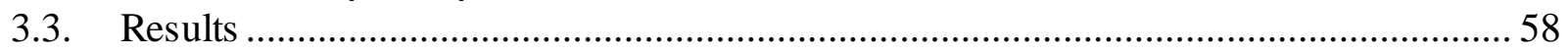

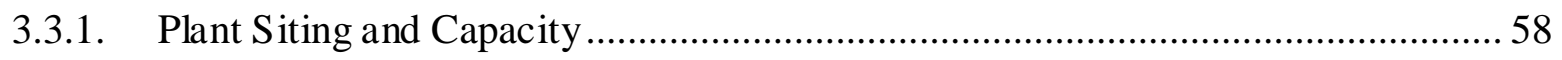

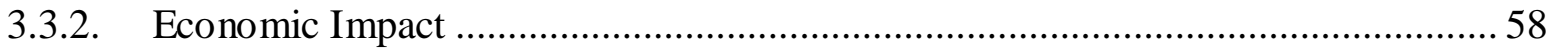

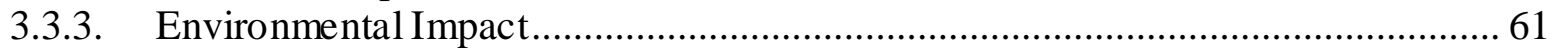

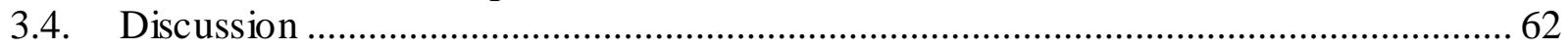

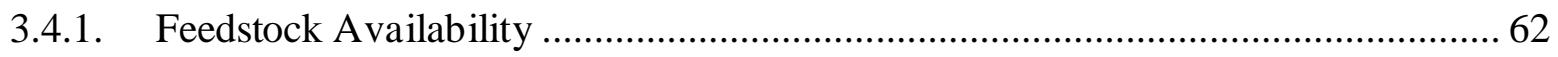

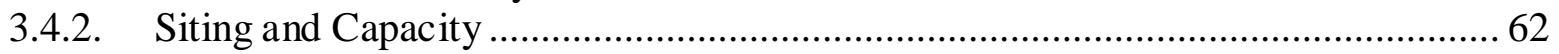

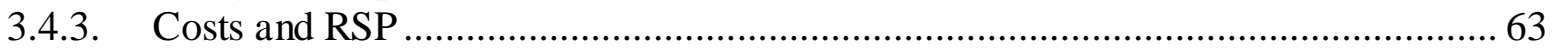

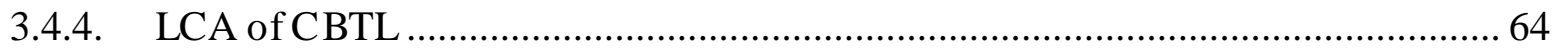




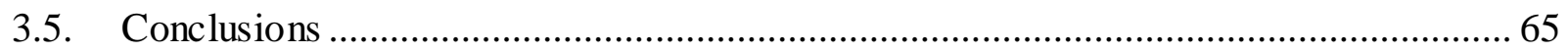

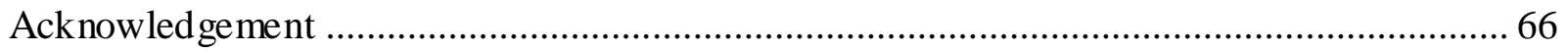

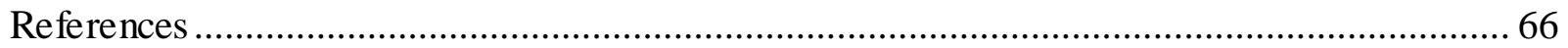

4. Economic and Life Cycle Analyses of Small-Scale Woody Biomass Utilization for

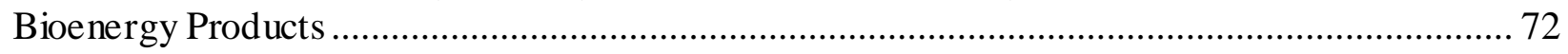

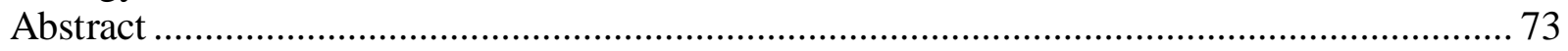

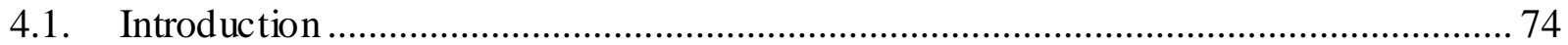

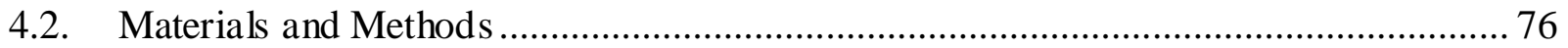

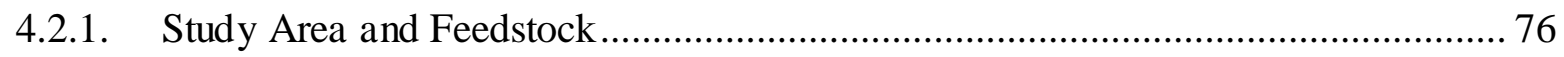

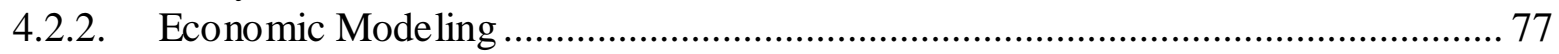

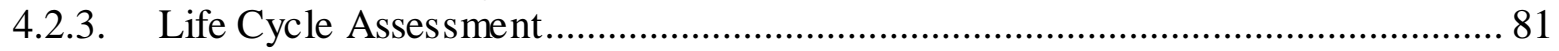

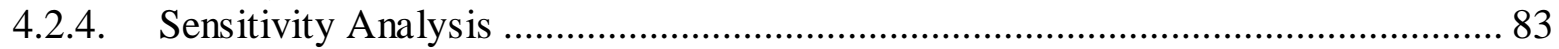

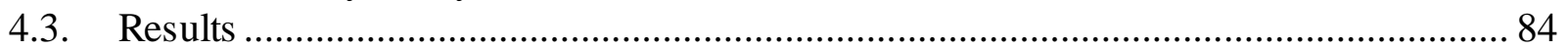

4.3.1. Production and Required Selling Price of Biofuels ............................................... 84

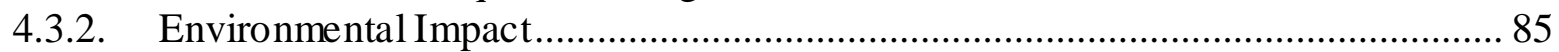

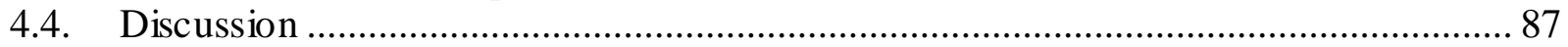

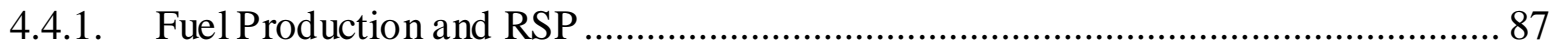

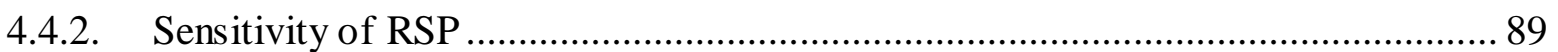

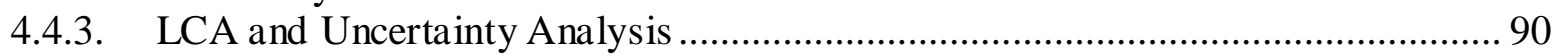

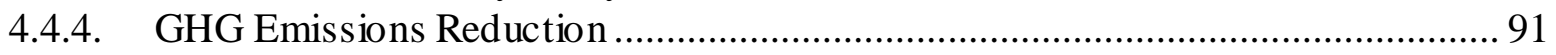

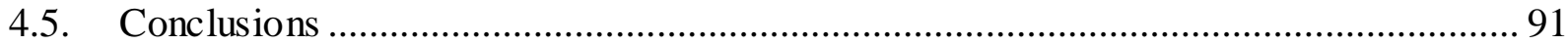

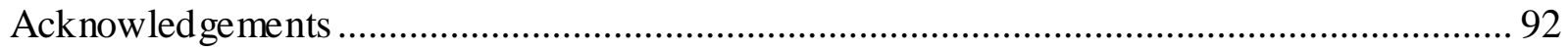

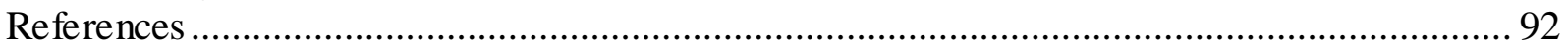

5. Economic and Life Cycle Analyses of Biomass Utilization for Bioenergy and Bioproducts 99

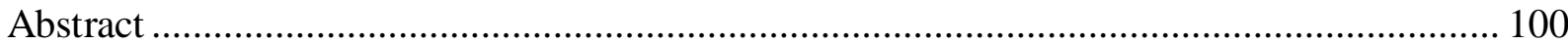

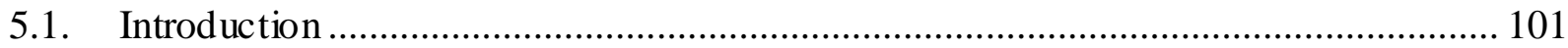

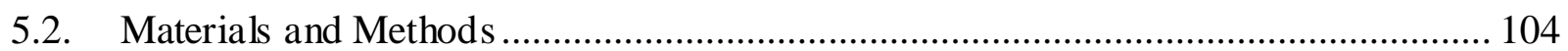

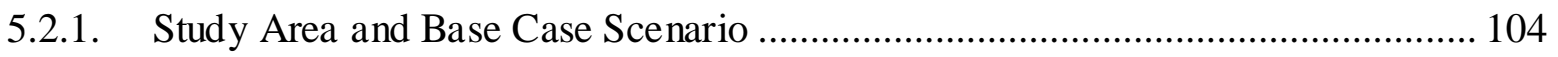

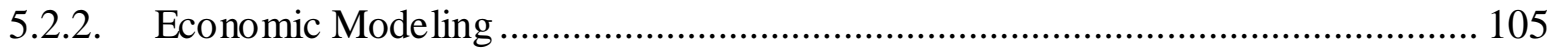

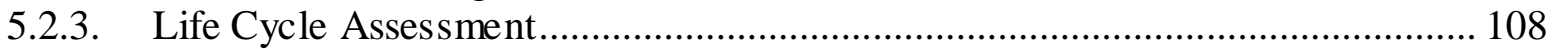

5.2.4. Sensitivity and Uncertainty Analyses …………............................................. 111

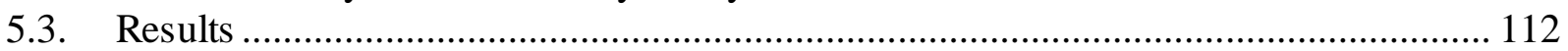

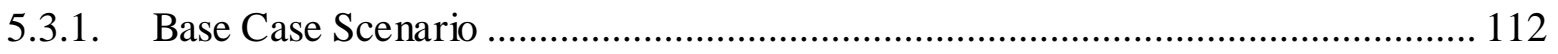

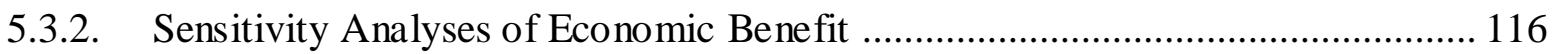

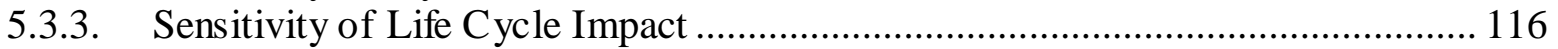

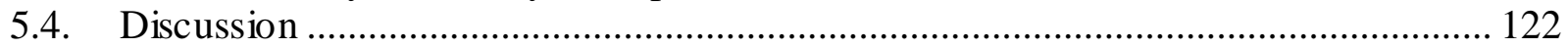

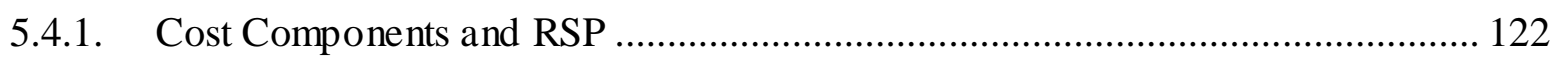

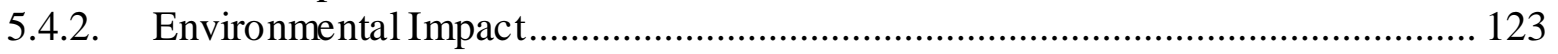

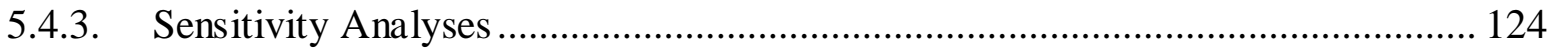

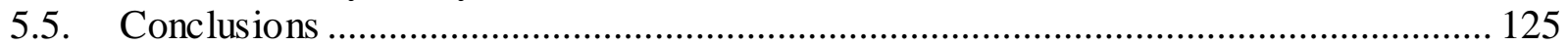

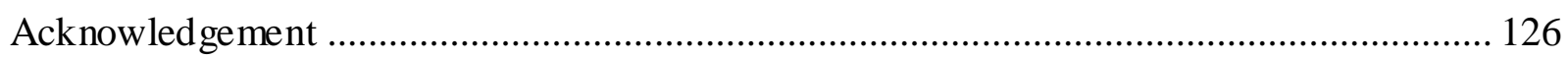

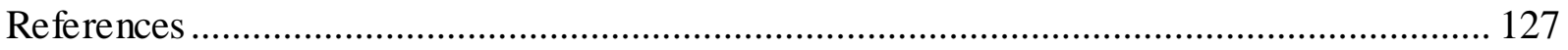

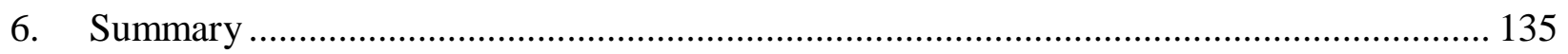

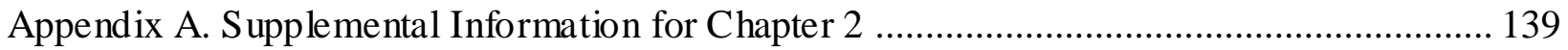

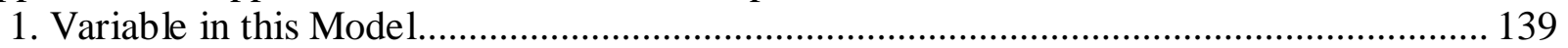


2. The Parameters Used in This Model........................................................................... 140

3. JAVA Code to Solve the Problem ............................................................................... 142

Appendix B. Supplemental Information for Chapter 3 ..................................................... 150

1. Variables and Parameters in the Economic Model ...................................................... 150

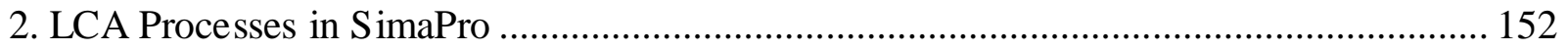

Appendix C. Supplemental Information for Chapter 4 ..................................................... 158

1. Variables and Parameters in the Economic Model .......................................................... 158

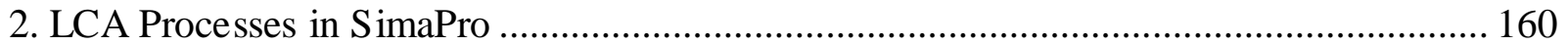

Appendix D. Supplemental Information for Chapter 5 ................................................... 169

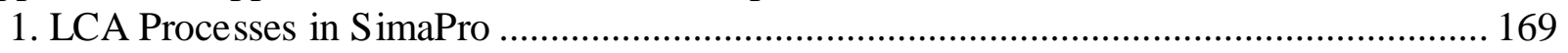

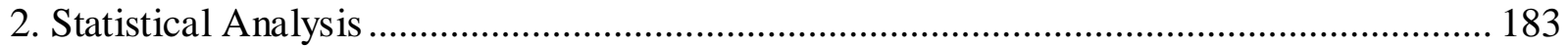




\section{LIST OF TABLES}

Table 2-1 Descriptive statistic s of the inventoried stands used in the case study..................... 22

Table 2-2. Parameter configuration for the base case.......................................................... 24

Table 2-3. Description of parameter configurations in each case scenario. ............................. 25

Table 2-4. Optimized results of carbon sequestration, timber and revenue by carbon to timber

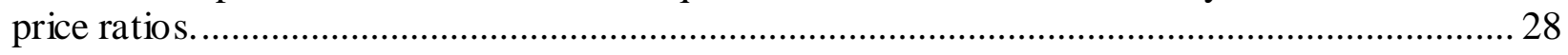

Table 3-1. Base case configuration of the CBTL process. ........................................................ 51

Table 3-2 Percentage change of RSP according change of capital cost and operation and

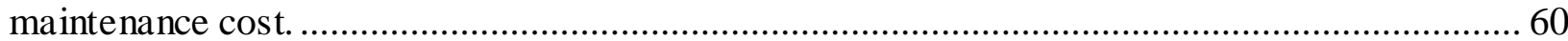

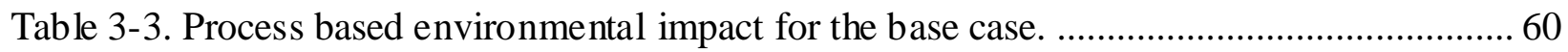

Table 4-1. Configurations of case scenarios of biomass to ethanol and biomass to liquids via fast

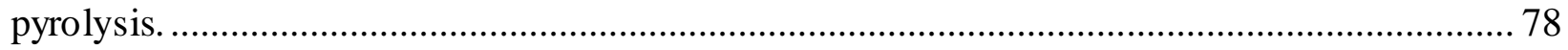

Table 4-2. Computational results from the economic model............................................... 84

Table 4-3. Environmental impact of LCA by bioenergy products and processes. ....................... 86

Table 4-4. Efficiency of reduction of $1 \mathrm{~kg} \mathrm{CO}_{2}$ eq $\mathrm{GHG}$ emissions........................................ 86

Table 5-1. Physical properties and requirements of three energy crops for three bioenergy

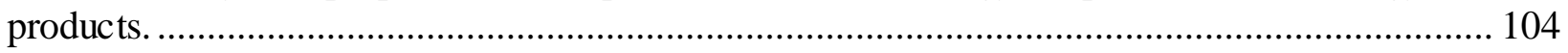

Table 5-2. Parameters for base case and sensitivity analysis........................................... 111

Table 5-3. Required selling price of bioenergy products by energy crops. ............................... 113

Table 5-4. GHG emissions for the production of the three energy products by energy crops. .. 113 


\section{LIST OF FIGURES}

Fig. 2-1 Representations and application procedures of stand adjacencies for a maximum permissible contiguous harvest area

Fig. 2-2 Illustrations of stand age constraints over a planning horizon

Fig. 2-3 Quadratic functions for stand age vs. (a) total carbon and (b) carbon in above ground biomass

Fig. 2-4. Different carbon components of the forest at different carbon to timber price ratio, (a) 0.1 , (b) 0.5 , (c) 1.0 ..

Fig. 2-5. Variations of (a) carbon sequestration rate and (b) total forest revenue by carbon to timber price ratio.

Fig. 2-6. Method for choosing a suitable carbon price by considering timber demand and carbon sequestration. 30

Fig. 2-7 Carbon sequestration rate by (a) biomass to timber price ratio; (b) harvest area size (ha); (c) management strategies. 31

Fig. 3-1. Distributions of logging residue (a), mill residue (b), coal production level (c), and locations of candidate CBTL plants (d) in the study area.

Fig. 3-2. Block flow diagram of the ind irect CBTL plant with CCS ....................................... 48

Fig. 3-3. System boundary of the CBTL LCA framework model. 55

Fig. 3-4. Sensitivity analyses by liquid fuel yield and biomass to coal mix ratio for CBTL fuel production in thousand bbl/day (a); required selling price of CBTL fuels $\$ / b b l(b)$, GHG emission $\mathrm{kg} \mathrm{CO} 2$ eq/f.u. (c), and $\mathrm{GHG}$ reduction compared to petroleum derived diesel in thousand tons $\mathrm{CO}_{2}$ eq/year $(\mathrm{d})$. 57

Fig. 3-5 Change of RSP based on different IRR at different mix ratio and liquid fuel yield. ..... 59

Fig. 4-1. System boundary of LC A model for biomass to bioenergy products. ........................ 82

Fig. 4-2. Sensitivities of feeds tock price, liquid fuel yield, IRR on RSP. .............................. 85

Fig. 4-3. Monte Carlo simulations of the environmental impact by bioenergy products: (a) GHG

emissions, (b) blue water consumption, and (c) fossil energy consumption. 88

Fig. 5-1. System boundary and processes of the three energy crops for three bioenergy products.

Fig. 5-2. Cost components of the biomass supply chain by energy crops and bioenergy products: (a) biofuel; (b) biopower; (c) pellet.

Fig. 5-3. LCA impact of GHG emissions, fossil energy consumption, blue water consumption and human health impact by energy crops: (a) willow by bioenergy products; (b) switchgrass by bioenergy products and (c) miscanthus by bioenergy products.

Fig. 5-4. Sensitivities of crop yield, transportation distance, facility capacity and IRR by energy crops and bioenergy products: (a) willow; (b) switchgrass; (c) miscanthus. 117

Fig. 5-5. Sensitivities of LCA impact by energy crops and bioenergy products: (a) willow; (b) switchgrass and (c) miscanthus. 


\section{INTRODUCTION}


The amount of carbon dioxide $\left(\mathrm{CO}_{2}\right)$, one of the major greenhouse gases (GHGs), has increased from $315 \mathrm{ppm}$ to $400 \mathrm{ppm}$ since 1959 (Tans and Keeling 2015). Terrestrial uptake of $\mathrm{CO}_{2}$ has a significant role in the overall carbon budget (Fan et al. 1998; Schimel 1995), and terrestrial forests are the major carbon sink. Forests have a great potential of absorbing atmospheric carbon dioxide. Their efficiency has been estimated by previous studies which were begotten in response to global climate change (Richards and Stokes 2004, Pan et al. 2011, Hardiman et al. 2013). Additionally, carbon prices can effectively motivate carbon mitigation (McCarl and Schneider 2001). A higher carbon price could result in a longer forest rotation (Asante et al. 2011).

Though the best strategy to sequester carbon is never to harvest forest, harvesting is considered to be one of the most important forest management practices, which provides timber for commercial usage and brings financial benefits to landowners. Clearcutting has the lowest harvest cost comparing to partial cut (Gutrich and Howarth 2007), but it increases the potential of land erosion and reduces shelter for some wildlife. The limitation of open area through environmentally sound management has been addressed (Thompson et al. 1973), and well defined (O’Hara et al. 1989, Murray and Church 1996). According to those concerns and requirements, Murray (1999) developed an area restriction model (ARM) to maximize the economic benefit from harvest with the limitation of open area. Sharma (2010) analyzed the carbon sequestration potential based on the area restriction model and found high potential of carbon sequestration in center Appalachian hardwood forest. The increase of carbon subsidy could effectively increase carbon sequestration (McCarl and Schneider 2001) and Sharma (2010) indicated the necessity to study this effect with consideration of open area. 
Besides the carbon sequestration by forest growth, the utilization of biomass has also been given a high priority to substitute fossil fuels and reduce the carbon emissions. Woody biomass is an abundant clean energy resource that could bring lots of environmental benefits. In the study of the Union of Concerned Scientists (UCS 2012), total estimated sustainable available biomass resources are just under 680 million tons each year within the U.S. As one of the largest underexploited energy resources, woody biomass is identified as a potentially important feedstock for biofuels and bioproducts (Perlack et al. 2005). The production of bioproducts from biomass usually has much less GHG emissions compared to fossil fuel (Mann and Spath 1997, Hsu et al. 2010, Guest et al. 2011).

There are several pathways to convert biomass to biofuels and bioproducts. Fast pyrolysis is a thermal decomposition process in the absence of oxygen to upgrade biomass to valuable high energy density liquid fuels. The dark liquid yields could be $30 \mathrm{wt} \%$ - $70 \mathrm{wt} \%$ depending on the feedstock (Bridgwater 2012). The pyrolysis-derived-liquid fuels need to be upgraded and can be blended with petroleum-derived-liquid fuels. The introduction of biomass into coal to liquid technology (CTL) known also as coal and biomass to liquids (CBTL) can further reduce GHG emissions. Generally, biomass as a single feedstock could bring more reduction of GHG emissions, but it typically requires higher procurement cost and lower energy conversion efficiency (Bartis et al. 2008). The mix of coal or natural gas and biomass effectively solves this dilemma - the tradeoff between GHG reduction and cost. Recently, the economic feasibility of CBTL or natural gas and biomass to liquids (GBTL) has been studied extensively to address the potentials of bioenergy production based on these processes (Marano and Ciferno 2001; Tarka 2009; Van Bibber et al. 2007; Wu et al. 2012). 
Both economic and environmental analyses have been extensively conducted on biomass utilization in terms of feedstock delivered costs, capital, operation and maintenance costs of conversion facilities. Economic analyses were conducted on biomass utilization to determine the feasibility of bioproducts. Studies conducted on CBTL from 2001 to 2011 showed that the required selling price (RSP) of CBTL was higher than the price of petroleum-derived fuels (Marano and Ciferno 2001; Van Bibber et al. 2007; Tarka 2009; Wu et al. 2012). With the increase of petroleum-derived-fuels price and carbon price, the CBTL plant could be feasible under certain scenarios. The economic analyses conducted on ethanol resulted lower RSP (from \$1/gal to \$1.49/gal) than CBTL (Phillips et al 2007, Gnansounou and Dauriat 2010). The estimation of RSP of liquid fuel by fast pyrolysis was from $\$ 1.93 /$ gal - $\$ 3.7 /$ gal according to the techno-economic analysis conducted by Brown (2015). Previous techno-economic analysis had lower RSP (\$0.40/gal - \$3.07/gal) than that in Brown's study (Ringer et al. 2006; Wright et al. 2010). The production of pellets had large variation in RSP according to the logistics cost of feedstock. Its RSP ranged from $\$ 122 /$ ton to $\$ 170 /$ ton (Sultana et al. 2010) and eancould be as high as $\$ 199 /$ ton (Pirraglia et al. 2013). The production of biopower usually had high cost which is difficult to compete with electricity from coal. The analysis conducted by the International Renewable Energy Agency (IRENA) had capital cost of \$1.8-\$5.7 million/MW (2012).

Life Cycle Assessment (LCA) is a standardized method to systematically evaluate the environmental impact of a product or service throughout its full life cycle (ISO 2006). Four general steps are typically required to finish a proper LCA study: scope and goal definition which defines the system boundary, life cycle inventory which provides material input and output for every process, impact assessment which usually summarizes the impact based on available data and analyzes the method, and interpretation which discusses the results. Currently, 
LCA is a mainstream environmental analysis tool to evaluate the impact of bioenergy products, such as pellets, biopower, ethanol, biodiesel and other liquid fuels.

The first biomass fired power plant was available in the U.S. in 1989 (U.S. DOE 1992). The study on the production of biopower showed that GHG emissions were $49 \mathrm{~g} \mathrm{CO}_{2} \mathrm{eq} / \mathrm{kWh}$ which was 95\% reduction comparing to coal fired power plant (Mann and Spath 1997). A LCA study in New York showed that, by combining biomass and coal at power plant, a reduction of GHG by $7-10 \%$ was achieved with only $10 \%$ biomass mixed with coal (Heller et al. 2004). A recent LCA study conducted on biomass based combined heat and power plant (CHP) showed higher thermal efficiency and more reduction of GHG (Guest et al. 2011).

Although some studies have been conducted on economic analysis and life cycle assessments of biomass utilization, there is a necessity to further examine the economics and life cycle impact of biomass utilization for bioenergy products in the northeastern United States. Therefore, this dissertation targeted the optimization of the forest harvest scheduling, and biomass utilization for bioenergy products by specifically including the following four objectives: (1) Modeling the forest carbon sequestration in mixed hardwood forests, (2) Analyzing economic and environmental impact of transforming coal and biomass to liquids, (3) Conducting economic input/output life cycle assessment of woody biomass utilization for bioenergy products, and (4) Assessing economic and life cycle impact of energy crops for bioenergy products in the northeastern U.S.

\section{REFERENCES}

Asante, P., Armstrong, G.W., and Adamowicz, W.L. 2011. Carbon sequestration and the optimal 
forest harvest decision: A dynamic programming approach considering biomass and dead organic matter. Journal of Forest Economics 17(1): 3-17.

Bartis, J.T., Camm, F.A., and Ortiz, D.S. 2008. Producing liquid fuels from coal: prospects and policy issues. Rand Corporation.

Boustead, I. 1996. LCA - How it came about - the beginning in the U.K. The International Journal of Life Cycle Assessment 1(3): 147-150.

Bridgwater, A.V. 2012. Review of fast pyrolysis of biomass and product upgrading. Biomass \& Bioenergy 38: 68-94.

Brown, T.R. 2015. A techno-economic review of thermochemical cellulosic biofuel pathways. Bioresource Technology 178: 166-176.

Constantino, M., Martins, I., and Borges, J.G. 2008. A new mixed-integer programming model for harvest scheduling subject to maximum area restrictions. Operations Research 56(3): $542-551$.

U.S.Department of Energy 1992. Electricity from biomass: a development strategy. U.S. DOE, Solar Thermal and Biomass Power Divison.

Fan, S., Gloor, M., Mahlman, J., Pacala, S., Sarmiento, J., Takahashi, T., and Tans, P. 1998. A large terrestrial carbon sink in North America implied by atmospheric and oceanic carbon dioxide data and models. Science 282(5388): 442-446.

Fargione, J., Hill, J., Tilman, D., Polasky, S., and Hawthorne, P. 2008. Land clearing and the biofuel carbon debt. Science 319(5867): 1235-1238.

Gecan, R., and Johansson, R. 2010. Using biofuel tax credits to achieve energy and environmental policy goals. DIANE Publishing.

Gnansounou, E., and Dauriat, A. 2010. Techno-economic analysis of lignocellulosic ethanol: A 
review. Bioresource Technology 101(13): 4980-4991.

Guest, G., Bright, R.M., Cherubini, F., Michelsen, O., and Stromman, A.H. 2011. Life Cycle Assessment of Biomass-based Combined Heat and Power Plants. Journal of Industrial Ecology 15(6): 908-921.

Gutrich, J., and Howarth, R.B. 2007. Carbon sequestration and the optimal management of New Hampshire timber stands. Ecological Economics 62(3-4): 441-450.

Hardiman, B.S., Gough, C.M., Halperin, A., Hofmeister, K.L., Nave, L.E., Bohrer, G., and Curtis, P.S. 2013. Maintaining high rates of carbon storage in old forests: A mechanism linking canopy structure to forest function. Forest Ecology and Management 298: 111119.

Heller, M.C., Keoleian, G.A., Mann, M.K., and Volk, T.A. 2004. Life cycle energy and environmental benefits of generating electricity from willow biomass. Renewable Energy 29(7): 1023-1042.

Herrmann, I.T., Jorgensen, A., Bruun, S., and Hauschild, M.Z. 2013. Potential for optimized production and use of rapeseed biodiesel. Based on a comprehensive real-time LCA case study in Denmark with multiple pathways. International Journal of Life Cycle Assessment 18(2): 418-430.

Hsu, D.D., Inman, D., Heath, G.A., Wolfrum, E.J., Mann, M.K., and Aden, A. 2010. Life cycle environmental impact of selected US ethanol production and use pathways in 2022. Environmental science \& technology 44(13): 5289-5297.

IRENA. 2012. Renewable energy technologies: cost analysis series. Volume 1 issue 1/5: Biomass for power generation. International Renewable Energy Agency.

ISO. 2006. Environmental Management: Life Cycle Assessment: Principles and Framework. 
International Organization for Standardization.

Mann, M.K., and Spath, P.L. 1997. Life cycle assessment of a biomass gasification combinedcycle system. National Renewable Energy Laboratory.

Marano, J.J., and Ciferno, J.P. 2001. Life-cycle greenhouse-gas emissions inventory for FischerTropsch fuels. Report Prepared for the US Department of Energy, Energy and Environmental Solution, LLC, Gaithersburg, MD, USA.

McCarl, B.A., Schneider, U.A. 2001. Greenhouse gas mitigation in U.S. agriculture and forestry. Sci. 294: 2481-2482.

Murray, A.T. 1999. Spatial restrictions in harvest scheduling. Forest Science 45(1): 45-52.

Murray, A.T., and Church, R.L. 1996. Analyzing cliques for imposing adjacency restrictions in forest models. Forest Science 42(2): 166-175.

O'Hara, A.J., Faaland, B.H., and Bare, B.B. 1989. Spatially Constrained Timber Harvest Scheduling. Canadian Journal of Forest Research-Revue Canadienne De Recherche Forestiere 19(6): 715-724.

Pan, Y.D., Birdsey, R.A., Fang, J.Y., Houghton, R., Kauppi, P.E., Kurz, W.A., Phillips, O.L., Shvidenko, A., Lewis, S.L., Canadell, J.G., Ciais, P., Jackson, R.B., Pacala, S.W., McGuire, A.D., Piao, S.L., Rautiainen, A., Sitch, S., and Hayes, D. 2011. A Large and Persistent Carbon Sink in the World's Forests. Science 333(6045): 988-993.

Perlack, R.D., Wright, L.L., Turhollow, A.F., Graham, R.L., Stokes, B.J., and Erbach, D.C. 2005. Biomass as feedstock for a bioenergy and bioproducts industry: the technical feasibility of a billion-ton annual supply. DTIC Document.

Phillips, S., Aden, A., Jechura, J., Dayton, D., and Eggeman, T. 2007. Thermochemico ethanol via indirect gasification and mixed alcohol synthesis of lignocellulosic biomass. NREL. 
Pirraglia, A., Gonzalez, R., Saloni, D., and Denig, J. 2013. Technical and economic assessment for the production of torrefied ligno-cellulosic biomass pellets in the US. Energy Conversion and Management 66: 153-164.

Richards, K.R., and Stokes, C. 2004. A review of forest carbon sequestration cost studies: A dozen years of research. Climatic Change 63(1-2): 1-48.

Ringer, M., Putsche, V., and Scahill, J. 2006. Large-scale pyrolysis oil production: a technology assessment and economic analysis. NETL.

Schimel, D.S. 1995. Terrestrial Ecosystems and the Carbon-Cycle. Global Change Biology 1(1): $77-91$.

Sharma, B.D. 2010. Modeling of forest harvest scheduling and terrestrial carbon sequestration. $\mathrm{PhD}$ thesis, Division of Forestry and Natural Resources, West Virginia University, Morgantown, WV, U.S.

Skone, T.J. 2011. Case Study: Interagency workgroup on life cycle GHG emissions of alternative aviation fuels. National Energy Technology Laboratory.

Sultana, A., Kumar, A., and Harfield, D. 2010. Development of agri-pellet production cost and optimum size. Bioresource Technology 101(14): 5609-5621.

Tans, P., and Keeling, R. 2015. Trends in Atmospheric [accessed July 7 2015].

Tarka, T.J., Wimer, J.G., Balash, P.C., Skone, T.J., Kern, K.C., Vargas, M.C., Morreale, B.D., White III, C.W., and Gray, D. 2009. Affordable, low-carbon diesel fuel from domestic coal and biomass. In Proc. 25th Annual Pittsburgh Coal Conf., Pittsburgh, PA.

Thompson, E.F., Halterma.Bg, Lyon, T.J., and Miller, R.L. 1973. Integrating Timber and Wildlife Management Planning. Forestry Chronicle 49(6): 247-250.

UCS. 2012. The promise of biomass: clean power and fuel - if handled right. Union of 


\section{Concerned Scientists.}

Van Bibber, L., Thomas, C., and Chaney, R. 2007. Alaska coal gasification feasibility studiesHealy coal-to-liquids plant. National Energy Technology Laboratory (United States).

Wright, M.M., Daugaard, D.E., Satrio, J.A., and Brown, R.C. 2010. Techno-economic analysis of biomass fast pyrolysis to transportation fuels. Fuel 89: S11-S19.

Wu, J.Z., Wang, J.X., Cheng, Q.Z., and DeVallance, D. 2012. Assessment of coal and biomass to liquid fuels in central Appalachia, USA. International Journal of Energy Research 36(7): 856-870. 


\section{Modeling OF Forest HARveSt SCHEdUling AND Carbon Sequestration in Central Appalachian MiXed HaRdWOOd FORESTS ${ }^{1}$}

\footnotetext{
${ }^{1}$ Submitted to Canadian Journal of Forest Research.
} 


\section{AbSTraCt}

A mixed-integer programming model was developed to optimize forest carbon sequestration considering carbon price, biomass price, harvest area restriction, and harvest method. The model was applied to examine the harvest scheduling strategies and carbon sequestration in a mixed central Appalachian hardwood forest. Sensitivity analyses were conducted over a range of carbon and biomass to timber price ratios, harvest area limitations and harvest methods. The results showed that the carbon sequestration rate of the central Appalachian hardwood forests could gradually increase as the carbon to timber price ratio changed from 0.0 to 1.0 with an average sequestration rate of $0.917 \mathrm{Mg} \cdot \mathrm{ha}^{-1} \cdot \mathrm{year}^{-1}$. The rise of biomass to timber price ratio reduces the carbon sequestration potential. Additionally, the carbon sequestration potential would decrease when harvest area limitation varied from 0 (no harvest) to 100 ha. The decrease could be $97.4 \%$ and $70.8 \%$ respectively when the carbon to timber price ratios were 0.0 and 0.25 . Low intensity partial cut could have a higher carbon sequestration rate comparing with clearcutting when the carbon to timber price ratio was low. 


\subsection{INTRODUCTION}

Carbon dioxide plays a vital role in global warming, along with other greenhouse gases (GHGs), such as water vapor, methane, nitrous oxide, ozone and chlorofluoromethane (Mitchell 1989). Since 1959, the concentration of $\mathrm{CO}_{2}$ in atmosphere has increased $25 \%$ (Tans and Keeling 2014). The increase of atmospheric carbon has led to increased scrutiny of the global carbon budget. One of the factors that could significantly mitigate atmospheric carbon is the terrestrial uptake of $\mathrm{CO}_{2}$, in which terrestrial forests are a major carbon sink (Fan et al. 1998; Schimel 1995).

In response to global climate change, more attention has been paid to find ways to slow down or reverse the trend of global warming. One of the approaches examined is the efficiency of forest carbon sequestration through appropriate forest management activities. Spring et al. (2005) analyzed the carbon sequestration benefits of forests around Thomson catchment in southeastern Australia using stochastic dynamic programming and found that the optimal decision depends on the change of fire frequency and water availability. Sharma (2010) developed a model that simultaneously optimized sustainable biomass utilization and carbon emission reduction. By solving this model, Sharma et al. (2011) reported that forest carbon sequestration potential could be enhanced through using efficient forest management strategies to increase the mean annual carbon sequestration rate between $6 \%$ and $79 \%$ for central Appalachian hardwood forests.

Carbon subsidy has been found to be a driver that increases the motivation of landowners to manage their forests for carbon sequestration (McCarl and Schneider 2001). The subsidy is typically financially incentivized policies that encourage the employment of GHG offset activities, with the aim of influencing management decisions. As the amount of subsidy 
increases, it has been shown that the optimal management alternative in terms of economic benefit is to tend away from harvest activities (Van Kooten et al. 1995). A simulation of response of management policies to price changes for $\mathrm{CO}_{2}$ storage suggested that a higher carbon price could result in a longer rotations and no harvest would occur when carbon price was higher than $\$ 35 /$ ton (Asante et al. 2011).

However, forests are also managed for both ecological and societal services. Harvesting is one of the most commonly used management practices in forest operations. Although partial cut or selective harvesting has been used for years, they might result in an increase of management costs (Gutrich and Howarth 2007). Clearcutting could possibly reduce management costs. To conform to harvesting and sustainability requirements and regulations, clearcutting typically requires a limitation on maximum open area. The applications of harvesting carry some inherent risks of land erosion and disruption of wildlife habitats (Barahona et al. 1992). However, these risks could be effectively mitigated through careful planning and implementation of forest best management practices (BMPs, WVDOF 2014), such as harvest area limit and buffer size of streamside management zones (SMZs). Murray (1999) proposed an area restriction model (ARM) using mixed-integer nonlinear programming with consideration of the maximum permissible contiguous harvest area. This area could be different in different forests but the average size must not exceed 120 acres (Murray et al. 2004). An even flow of timber supply was also considered in the model because a consistent supply of timber is always a mandate requirement (Vielma et al. 2007).

Many of the previous forest harvest scheduling and carbon sequestration studies usually considered either timber values or carbon values but neither took into account the 
potential biomass utilization, nor multi-time periods of harvests. As a result, there appears to be an opportunity to advance the knowledge of harvest scheduling and forest carbon sequestration through optimizing scheduling scenarios with considering carbon sequestration rate, harvest area limitation relative to BMPs, even flow of timber supply, biomass production and harvest methods. Specifically, the objectives of this study were to: (1) model forest harvest scheduling and carbon sequestration to maximize the total revenue of forests from timber, biomass, and carbon, and (2) apply the model to a mixed hardwood forest in the central Appalachian region to analyze the effects of carbon to timber price ratio, biomass to timber price ratio, harvest area and harvest method on carbon sequestration.

\subsection{MATERIALS AND METHODS}

\subsubsection{Model Development}

The objective of the model is to maximize the total revenue (z) of the forests in terms of carbon (C), timber (W), and biomass (B) values. The objective function of the model is formulated as:

$\max \quad z=C+W+B$

Where $C$ is the monetary value of carbon sequestered and is calculated by equation (2-2).

$C=r_{C O_{2}} p^{C O_{2}} \sum_{i=1}^{S} \sum_{t=1}^{T}\left\{f_{c i}\left(a_{i t}\right)-r_{d r y} \delta x_{i t}\left[G_{i, t-1}+f_{b i}\left(a_{i, t-1}\right)\right]\right\}$

A harvest decision for a stand at a given time is denoted by a binary variable:

$x_{i t}=\left\{\begin{array}{l}1, \text { if stand } i \text { is harvested at period } t \\ 0, \text { otherwise }\end{array}\right.$

Where, $t=1 \ldots \mathrm{T}$, and $i=1 \ldots \mathrm{S}$. T is the total management periods. $\mathrm{S}$ is the total number of stands. An integer variable $a_{i t}$ represents stand age of stand $i$ at time period $t$. A continuous variable $G_{i t}$ is the above-ground dry biomass in metric tons $(\mathrm{Mg})$ of stand $i$ at period $t$. 
$f_{b i}\left(a_{i t}\right)=$ Growth function of the aboveground dry biomass of stand $i$ at period $t(\mathrm{Mg})$;

$f_{c i}\left(a_{i t}\right)=$ Stand carbon storage function of stand $i$ at period $t(\mathrm{Mg})$;

$p^{C O_{2}}=$ The present carbon price in term of carbon dioxide $\left(\$ \cdot \mathrm{CO}_{2} \mathrm{Mg}^{-1}\right) ;$

$r_{\mathrm{CO}_{2}}=$ Coefficient used to convert Carbon into $\mathrm{CO}_{2}$ equivalent;

$r_{d r y}=$ Coefficient used to convert dry biomass into carbon;

$\delta=$ Percentage of wood products other than long lived wood products;

Similarly, $\mathrm{W}$ is the value of timber and B is the value of biomass. They can be computed by equations (2-3) and (2-4), respectively.

$W=p^{T} \sum_{i=1}^{S} \sum_{t=1}^{T} \eta_{T} x_{i t}\left[G_{i, t-1}+f_{b i}\left(a_{i, t-1}\right)\right]$
$B=\rho \cdot p^{B} \sum_{i=1}^{S} \sum_{t=1}^{T} \eta_{B} x_{i t}\left[G_{i, t-1}+f_{b i}\left(a_{i, t-1}\right)\right]$

Where:

$p^{B}=$ The present price of biomass $\left(\$ \cdot \mathrm{Mg}^{-1}\right)$;

$p^{T}=$ Average present price of timber, $\left(\$ \cdot \mathrm{dry}^{\mathrm{Mg}}{ }^{-1}\right) ;$

$\eta_{B}=$ Percentage of wood residue which includes logging and mill residues;

$\eta_{T}=$ Percentage of timber in total aboveground biomass;

$\rho=$ Percentage of biomass that is economically available.

The objective function is subject to the following constraints: 


\section{Harvest area restrictions}

A symmetric adjacency $(A D J)$ matrix is constructed to describe the adjacency of every two stands:

$A D J_{i j}=\left\{\begin{array}{l}1, \text { if stand } i \text { and stand } j \text { are physically adjacent or } i=j \\ 0, \text { otherwise. }\end{array}\right.$

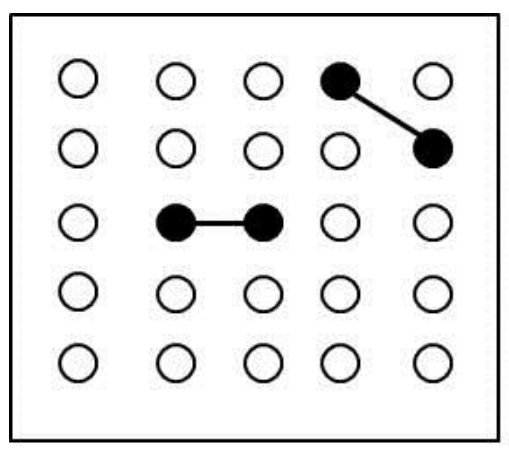

(a)

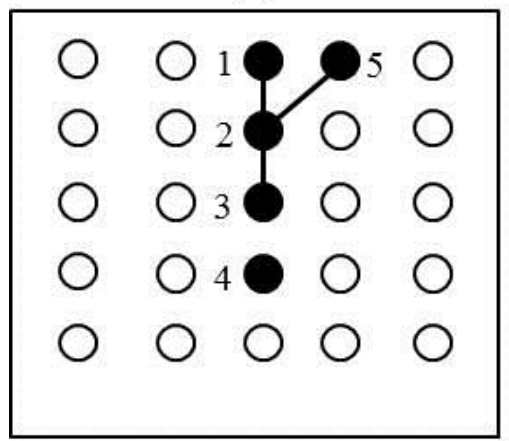

(d)

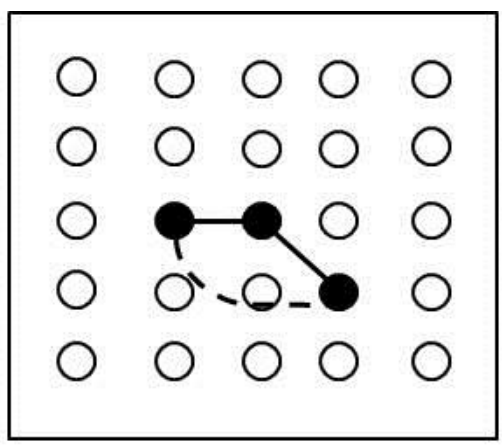

(b)

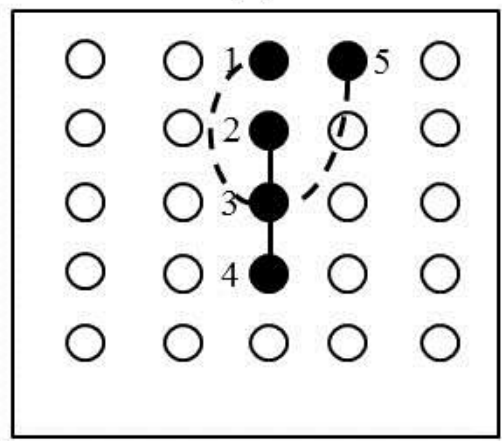

(e)

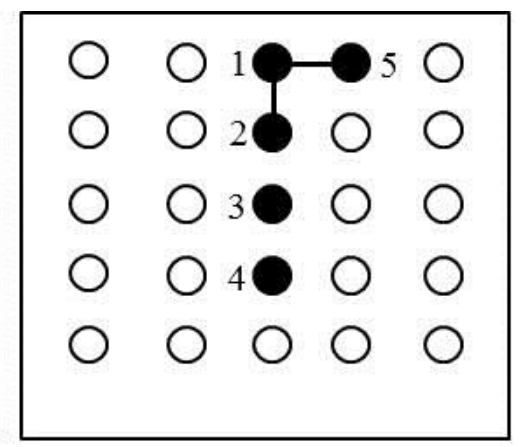

(c)

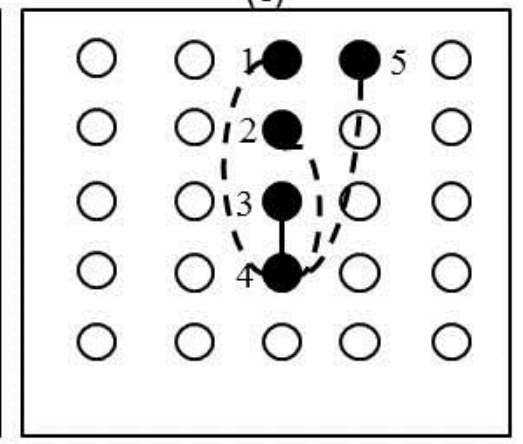

(f)

Fig. 2-1 Representations and application procedures of stand adjacencies for a maximum

permissible contiguous harvest area. Each circle represents a managed stand and two stands are physically adjacent if they are next to each other. Solid black circles represent stands that can be potentially harvested at the same time and the dotted lines represent the virtual adjacency. (a) no virtual adjacency; (b) virtual adjacency; $(c),(d),(e)$, and $(f)$ procedures that can be applied to form a maximum permissible contiguous harvest area. 
Another binary variable is defined to represent the harvest of two stands at the same time:

$y_{i j t}=\left\{\begin{array}{l}1, \text { if stand } i \text { and stand } j \text { are havested at the same time period } t \\ \text { and they are virtually adjacent or } i=j ; \quad \mathrm{j}=1 \ldots \mathrm{S} ; \\ 0, \text { otherwise. }\end{array}\right.$

Virtual adjacency is defined when two stands are harvested at the same time period and located in the same contiguous harvest area. The decision of harvesting a stand is based on a virtual adjacency matrix (Fig. 2-1a,b).

Equations (2-5) and constraints (2-6) ensure that every contiguous harvest area does not exceed the maximum permissible contiguous harvest area (Murray 1999). Fig. 1c-f show the procedures to check if a continuous harvest area exceeds the maximum permissible contiguous area. To illustrate the procedures, we define that the stands represented by solid circles are harvested at period 1, stands 1-5 are harvested in period 1 and belong to the same contiguous area, $y_{m n 1}=1$ for $m, n=1,2,3,4,5$. If the total size of this harvest area consisting of stands $1,2,3,4$ and 5 exceeds $A R$, the area constraint (6) is violated.

$$
\begin{aligned}
& \left\{\begin{array}{l}
y_{i j t}=x_{i t} \cdot x_{j t} \cdot A D J_{i j}, \forall i, j=1 \ldots S \wedge \forall t=1 \ldots T \wedge A D J_{i j}=1 \\
y_{i j t}=\sum_{k=1}^{S} x_{i t} \cdot x_{j t} \cdot y_{i k t} \cdot A D J_{j k}, \forall i, j=1 \ldots S \wedge \forall t=1 \ldots T \wedge A D J_{i j} \neq 1
\end{array}\right. \\
& \sum_{j=1}^{S} y_{i j t} A_{j}+x_{i t} \sum_{j=1}^{S} A_{j} \leq A R+\sum_{j=1}^{S} A_{j}, \forall i=1 \ldots S, \forall t=1 \ldots T
\end{aligned}
$$

Where:

$A_{j}=$ The area of stand $j$ (ha);

$A R=$ The maximum permissible contiguous harvest area (ha); 


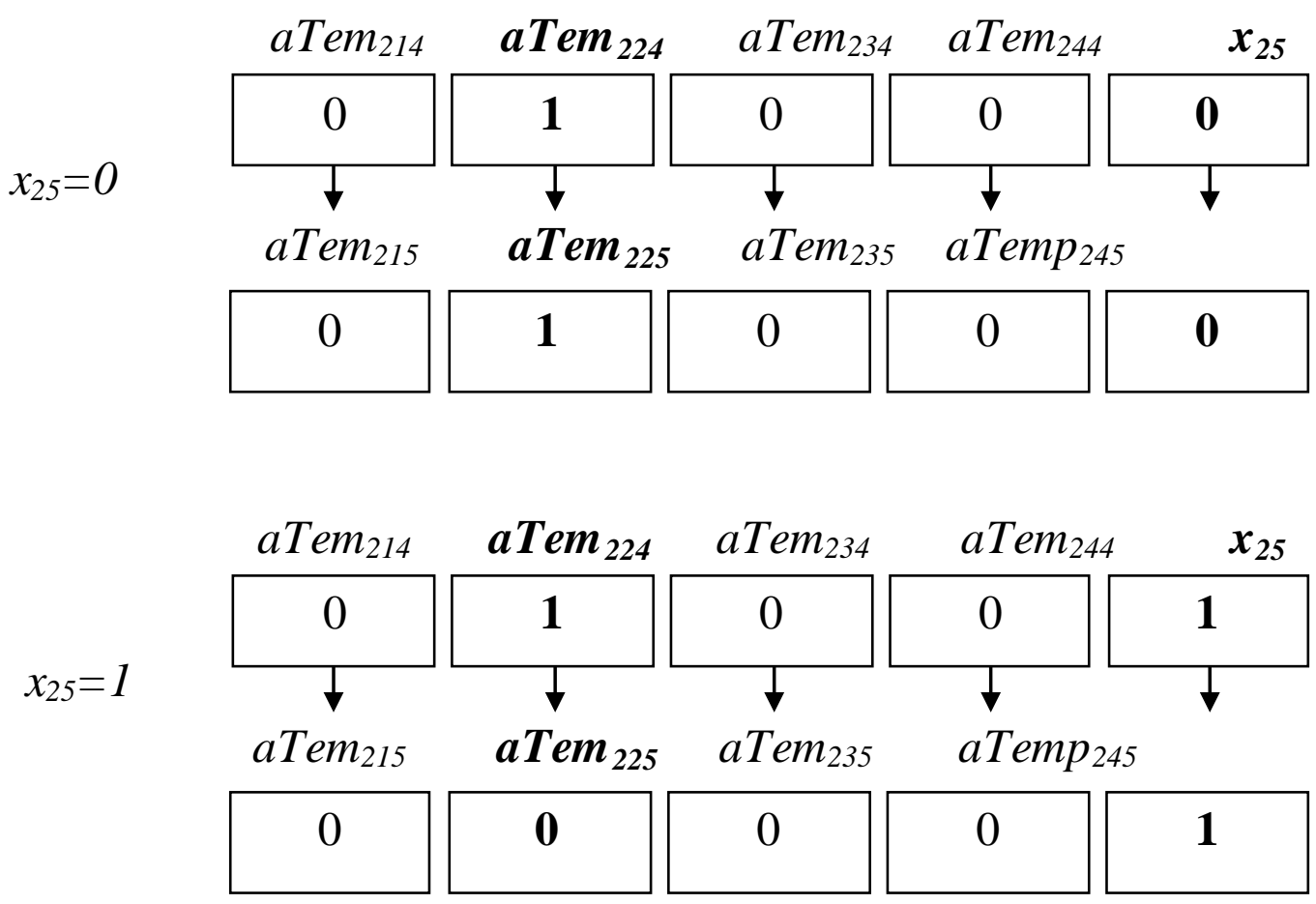

Fig. 2-2 Illustrations of stand age constraints over a planning horizon. This figure assumes two cases when $x_{25}=0$ and 1 to illustrate the value of aTem 225 according to $x_{25}$.

Stand age and even flow of timber supply

Constraint (2-7) imposes the restriction of average ending stand age for harvest, which means the average stand age at the end of a planning horizon should be greater than the minimum permissible stand age for harvest. Constraint (2-8) ensures even flow of timber supply among planning periods.

$$
\begin{aligned}
& \sum_{i=1}^{S} A_{i} \cdot\left(a_{i T}-A g e R\right) \geq 0 \\
& (1-\Delta) \sum_{i}^{S} x_{i t}\left[G_{i, t-1}+f_{b i}\left(a_{i, t-1}\right)\right] \leq \sum_{i}^{S} x_{i, t+1}\left[G_{i t}+f_{b i}\left(a_{i t}\right)\right] \\
& \leq(1+\Delta) \sum_{i}^{S} x_{i t}\left[G_{i, t-1}+f_{b i}\left(a_{i, t-1}\right)\right], \forall t=1 \ldots T-1
\end{aligned}
$$


Where:

AgeR $=$ The minimum permissible average ending stand age .

$\Delta=$ Allowable variation of timber supply in even flow constraint.

A binary variable aTem $_{i k t}(k \leq t)$ is used to calculate stand age and is defined as:

$$
\text { aTem }_{i k t}=\left\{\begin{array}{l}
1, \text { if }\left(x_{i k} \neq x_{i t} \wedge x_{i t}=0\right) \vee\left(x_{i k}=1 \wedge k=t\right) \\
0, \text { otherwise. }
\end{array}\right.
$$

Equations (2-9) and (2-10) compute the stand age at each period over the planning horizon. These two equations ensure that $a$ Tem $m_{i k t}$ will be set to 1 when $x_{i t}$ is 1 , and aTem $_{i k t}$ will also be set to 1 if $x_{i t}$ is not 1 but $a T e m_{i k, t-1}$ is 1 . We take stand 2 in time period 5 as an example (Fig. 2-2). If $x_{25}=0$, all the aTems for that stand are kept the same as they are in the previous planning period. If $x_{25}=1$, all the aTems, except for aTemp 255 , should be 0 . Equations (2-11) initialize the stand age at the beginning of harvest schedule. Equations (2-12) calculate the stand age in each time period. Constraints (2-13) mandate stands that are qualified to be harvested when they are older than a certain age $a h$.

Equations (2-14) and (2-15) compute the amount of above-ground dry biomass of every stand in each planning period.

$$
\begin{aligned}
& \operatorname{aTem}_{i k t}=a T e m_{i k, t-1}\left(1-x_{i t}\right), \forall i=1 \ldots S \wedge \forall t=2 \ldots T \wedge k<t ; \\
& a T e m_{i k t}=x_{i t}, \forall i=1 \ldots S \wedge \forall t=1 \ldots T \wedge k=t ; \\
& a_{i 0}=a g e_{i}, \forall i=1 \ldots S ; \\
& a_{i t}=a g e_{i}+t Y-\sum_{k=1}^{t} a T e m p_{i k t}\left(a g e_{i}+k Y\right), \forall i=1 \ldots S \wedge \forall t=1 \ldots T ; \\
& a_{i t} \geq x_{i t}(a h-\mathrm{Y}), \quad \forall i=1 \ldots S \wedge \forall t=1 \ldots T ; \\
& \mathrm{G}_{\mathrm{i} 1}=\mathrm{G}_{\mathrm{i} 0}, \forall i=1 \ldots S ; \\
& G_{i t}=\left(1-x_{i t}\right)\left[G_{i, t-1}+f_{b i}\left(a_{i, t-1}\right)\right], \forall i=1 \ldots S \wedge \forall t=1 \ldots T ;
\end{aligned}
$$


Where:

$a g e_{i}=$ The initial stand age of stand $i$;

$a h=$ The minumum allowed age of a stand could be harvested;

$G_{i 0}=$ The initial aboveground biomass of stand $i$ (dry tonnes);

$Y=$ The length of each planning period (years);

\section{Linearization}

A linearization process was adopted to simplify the quadratic formulations of the model in order to improve its solving and computing efficiency. Specifically, the expression $x_{i t}\left[G_{i, t-1}+f_{b i}\left(a_{i, t-1}\right)\right]$ is linearized as $\left[G_{i, t-1}+f_{b i}\left(a_{i, t-1}\right)-G_{i t}\right]$. This is because $G_{i, t-1}+$ $f_{b i}\left(a_{i, t-1}\right)$ represents the accumulated biomass of stand $i$ in time $t$ if this stand is not harvested in time $t$. If it is harvested in time $\mathrm{t}, G_{i t}$ will be 0 . Therefore, the objective function (equations 2-1, 2-2, 2-3, 2-4), and constraints/equations 2-5, 2-8, 2-9, 2-14 can be expressed as equations 2-16, 2-17, 2-18, 2-19, and 2-20.

$$
\begin{gathered}
\max z=r_{C O_{2}} p^{c o_{2}} \sum_{i=1}^{S} \sum_{t=1}^{T}\left\{f_{c i}\left(a_{i t}\right)-r_{d r y} \delta\left[G_{i, t-1}+f_{b i}\left(a_{i, t-1}\right)-G_{i t}\right]\right\} \\
+p^{T} \sum_{i=1}^{S} \sum_{t=1}^{T} \eta_{T} x_{i t}\left[G_{i, t-1}+f_{b i}\left(a_{i, t-1}\right)-G_{i t}\right] \\
+p^{B} \sum_{i=1}^{S} \sum_{t=1}^{T} \eta_{B} x_{i t}\left[G_{i, t-1}+f_{b i}\left(a_{i, t-1}\right)-G_{i t}\right]
\end{gathered}
$$

S.t. 


$$
\begin{aligned}
& \left\{\begin{array}{l}
y_{i j t} \geq\left(x_{i t}+x_{j t}-1\right), \forall i, j=1 \ldots S \wedge \forall t=1 \ldots T \wedge A D J_{i j}=1 \\
y_{i j t} \leq \frac{x_{i t}+x_{j t}}{2}, \forall i, j=1 \ldots S \wedge \forall t=1 \ldots T \wedge A D J_{i j}=1 \\
y_{i j t} \geq x_{i t}+x_{j t}-2+\frac{\sum_{k=1}^{S} y_{i k t} A D J_{j k}}{2 S}, \forall i, j=1 \ldots S \wedge \forall t=1 \ldots T \wedge A D J_{i j} \neq 1 \\
y_{i j t} \leq \frac{(S-0.5)\left(x_{i t}+x_{j t}\right)}{2 S}+\frac{\sum_{k=1}^{S} y_{i k t} A D J_{j k}}{2 S}, \forall i, j=1 \ldots S \wedge \forall t=1 \ldots T \wedge A D J_{i j} \neq 1
\end{array}\right. \\
& \left(\begin{array}{l}
1-\Delta) \sum_{\mathrm{i}}^{S}\left[G_{i, t-1}+f_{b i}\left(a_{i, t-1}\right)-G_{i t}\right] \leq \sum_{\mathrm{i}}\left[\mathrm{G}_{\mathrm{it}}+\mathrm{f}_{\mathrm{bi}}\left(\mathrm{a}_{\mathrm{it}}\right)-G_{i, t+1}\right] \\
\leq(1+\Delta) \sum_{\mathrm{i}}\left[G_{i, t-1}+f_{b i}\left(a_{i, t-1}\right)-G_{i t}\right], \forall t=1 \ldots T-1
\end{array}\right. \\
& \left\{\begin{array}{l}
a T e m_{i k t} \geq a T e m_{i k, t-1}-x_{i t}, \forall i=1 \ldots S \wedge \forall t=2 \ldots T \wedge k<t \\
a T e m_{i k t} \leq \frac{1+a T e m_{i k, t-1}-x_{i t}}{2}, \forall i=1 \ldots S \wedge \forall t=2 \ldots T \wedge k<t
\end{array}\right. \\
& \left\{\begin{array}{l}
G_{i t} \leq M\left(1-x_{i t}\right), \forall i=1 \ldots S \wedge \forall t=2 \ldots T \\
G_{i t} \leq G_{i, t-1}+f_{i}\left(a_{i, t-1}\right), \forall i, k=1 \ldots S \wedge \forall t=2 \ldots T \\
G_{i t} \geq G_{i, t-1}+f_{i}\left(a_{i, t-1}\right)-M x_{i t}, \forall i, k=1 \ldots S \wedge \forall t=2 \ldots T
\end{array}\right.
\end{aligned}
$$

Where, $M$ is a large constant that $M \gg G_{i t}$

Table 2-1 Descriptive statistics of the inventoried stands used in the case study.

\begin{tabular}{lcccccc}
\hline & $\mathrm{N}$ & Mean & StdDev & Maximum & Minimum & Median \\
\hline Number of measurement points & 92 & 21 & 6 & 31 & 5 & 22 \\
Tree height $(m)$ & 14008 & 18 & 11 & 44 & 2 & 22 \\
Diameter at breast height (DBH) $(\mathrm{cm})$ & 14008 & 36 & 15 & 132 & 3 & 36 \\
Quadratic mean diameter $(\mathrm{cm})$ & 14008 & 28 & 3 & 36 & 21 & 28 \\
Trees per ha & 92 & 497 & 210 & 1505 & 232 & 439 \\
Basal area $\left(\mathrm{m}^{2} \cdot h \mathrm{~h}^{-1}\right)$ & 92 & 30 & 11 & 72 & 11 & 28 \\
Merchantable volume $\left(\mathrm{m}^{3} \cdot h \mathrm{a}^{-1}\right)$ & 92 & 1784 & 625 & 4802 & 557 & 1668 \\
Forest C stock $\left(M g \cdot h a^{-1}\right)$ & 92 & 147 & 49 & 363 & 74 & 136 \\
Merchantable C stock $\left(M g \cdot h a^{-1}\right)$ & 92 & 69 & 24 & 170 & 21 & 64 \\
\hline
\end{tabular}




\subsubsection{Data}

Data for a case study of the model application were from an inventory conducted in 2000 for West Virginia University Research Forest, a mixed hardwood forest of 3,042 ha, located approximately at $39.66^{\circ} \mathrm{N}, 79.78^{\circ}$ near Morgantown, West Virginia, USA. The forest has 92 cutting units (i.e. equivalent to stands) with area varying from 7 to 41 ha. Recent forest inventory data were acquired from West Virginia University Division of Forestry and Natural Resources. Each stand had at least 5 cruise points and altogether 14,008 tree records were available for this study. A description of these stand parameters is given in Table 2-1.

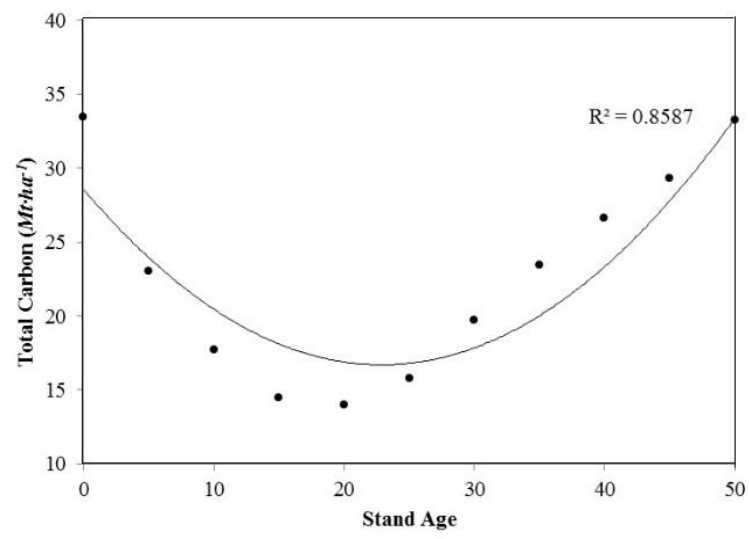

(a)

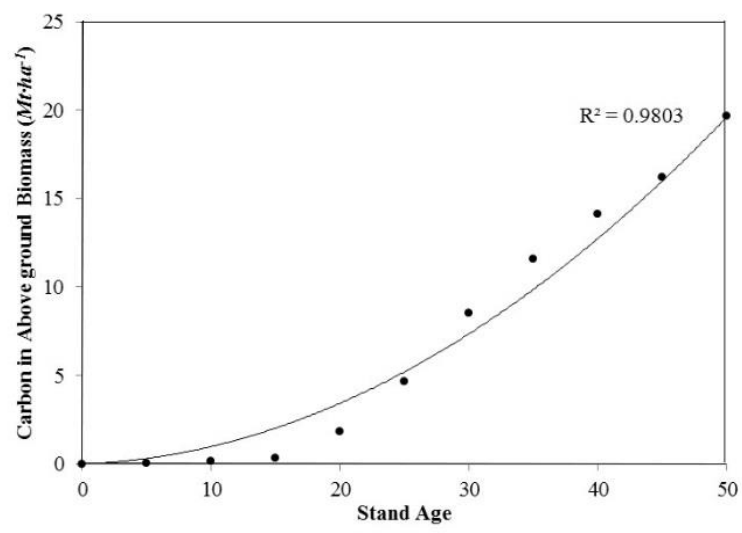

(b)

Fig. 2-3 Quadratic functions for stand age vs. (a) total carbon and (b) carbon in above ground

biomass. The decrease of total carbon in the first few years after harvest is because the decomposition of dead root and release of soil carbon.

The Forest Vegetation Simulator (FVS) (Dixon 2013; Stage 1973) Northeast Variant (NE) with Fire and Fuels Extension (FFE) was used on the inventoried stand data to simulate the growth and yield, harvest impact, carbon stocks, and biomass production at each time period of 5 years over a planning horizon of 50 years. A quadratic relationship between stand age and growth rate as well as between stand age and the total carbon accumulation, was developed for each stand (Fig. 2-3). Then $f_{b i}\left(a_{i t}\right)$ and $f_{c i}\left(a_{i t}\right)$ were calculated as increment of biomass accumulation and carbon sequestration between planning periods. 
Table 2-2. Parameter configuration for the base case.

\begin{tabular}{|c|c|c|c|}
\hline Name & Definition & Value & Reference \\
\hline$\overline{A_{j}}$ & The area of stand $j(h a)$ & & Inventory \\
\hline$A D J$ & describe the adjacency of every two stands & & Inventory \\
\hline AgeR & The minimum permissible average ending stand age & 40 & Sharma et al. 2011 \\
\hline$a g e_{i}$ & The initial stand age of stand $i$ & 80 & Inventory \\
\hline$a h$ & The minumum allowable age of a stand could be harvested & 20 & \\
\hline$A R$ & The maximum permissible contiguous harvest area $(h a)$ & 40 & Sharma et al. 2011 \\
\hline$f_{b i}\left(a_{i t}\right)$ & $\begin{array}{l}\text { Growth function of the aboveground dry biomass of stand } i \\
\text { at period } t(M g)\end{array}$ & Simulation & \\
\hline$f_{c i}\left(a_{i t}\right)$ & Stand carbon storage function of stand $i$ at period $t(\mathrm{Mg})$ & Simulation & \\
\hline$G_{i 0}$ & The initial aboveground biomass of stand $i$ (dry tonnes) & & Inventory \\
\hline$r_{\mathrm{CO}_{2}}$ & Coefficient used to convert Carbon into $\mathrm{CO}_{2}$ equivalent & 3.667 & \\
\hline$r_{d r y}$ & Coefficient used to convert dry biomass into carbon & 0.5 & de Wit et al. 2006 \\
\hline Y & The length of each planning period (years) & 5 & \\
\hline$\rho$ & Percentage of biomass that is economically available & 0.65 & Wu et al. 2012 \\
\hline$\delta$ & Percentage of wood product other than long lived wood product & $82 \%$ & Sharma et al. 2011 \\
\hline$\eta_{B}$ & Percentage of wood residue which includes logging and mill residues & $60 \%$ & Sharma et al. 2011 \\
\hline$\eta_{T}$ & Percentage of timber in total aboveground biomass & $60 \%$ & Sharma et al. 2011 \\
\hline$\Delta$ & Allowable variation of timber supply in even flow constraint & 0.15 & $\begin{array}{l}\text { Goycoolea et al. } \\
2005\end{array}$ \\
\hline
\end{tabular}


Table 2-3. Description of parameter configurations in each case scenario.

\begin{tabular}{|c|c|c|c|c|c|c|c|}
\hline \multirow{2}{*}{ Description } & \multirow{2}{*}{$\begin{array}{l}\text { Clearcutting } \\
\text { Base Case }\end{array}$} & \multirow{2}{*}{$\begin{array}{l}\text { Clearcutting } \\
\text { Sensitivity } 1\end{array}$} & \multirow{2}{*}{$\begin{array}{l}\text { Clearcutting } \\
\text { Sensitivity } 2\end{array}$} & \multirow{2}{*}{$\begin{array}{l}\text { Clearcutting } \\
\text { Sensitivity } 3\end{array}$} & \multicolumn{3}{|c|}{ Partial-cut: basal area removal } \\
\hline & & & & & $25 \%$ & $50 \%$ & $75 \%$ \\
\hline $\begin{array}{l}\text { Enforce Area } \\
\text { Restriction }\end{array}$ & $\mathrm{Y}$ & $\mathrm{Y}$ & $\mathrm{Y}$ & $\mathrm{Y}$ & $\mathrm{N}$ & $\mathrm{N}$ & $\mathrm{N}$ \\
\hline Enforce Even Flow & $\mathrm{Y}$ & $\mathrm{Y}$ & $\mathrm{Y}$ & $\mathrm{Y}$ & $\mathrm{Y}$ & $\mathrm{Y}$ & $\mathrm{Y}$ \\
\hline $\begin{array}{c}\text { Enforce Minimum } \\
\text { Permissible Stand } \\
\text { Age }\end{array}$ & $\mathrm{Y}$ & $\mathrm{Y}$ & $\mathrm{Y}$ & $\mathrm{Y}$ & $\mathrm{N}$ & $\mathrm{N}$ & $\mathrm{N}$ \\
\hline $\begin{array}{l}\text { Number of Planning } \\
\text { Periods }\end{array}$ & 10 & 10 & 10 & 10 & 10 & 10 & 10 \\
\hline $\begin{array}{l}\text { Carbon to Timber } \\
\text { Price Ratio }\end{array}$ & 0.05 & $\begin{array}{c}0-1, \\
\text { increased by } \\
0.05\end{array}$ & 0.05 & 0.05 & $\begin{array}{c}0-1, \\
\text { increased } \\
\text { by } 0.05\end{array}$ & $\begin{array}{c}0-1, \\
\text { increased } \\
\text { by } 0.05\end{array}$ & $\begin{array}{c}0-1, \\
\text { increased } \\
\text { by } 0.05\end{array}$ \\
\hline $\begin{array}{l}\text { Biomass to Timber } \\
\text { Price Ratio }\end{array}$ & 0.005 & 0.005 & $\begin{array}{c}0-1, \\
\text { increased by } \\
0.05\end{array}$ & 0.005 & 0.005 & 0.005 & 0.005 \\
\hline $\begin{array}{c}\text { Permissible Harvest } \\
\text { Area }\end{array}$ & 40 & 40 & 40 & $\begin{array}{c}0-100 \text { ha, } \\
\text { increased by } \\
10\end{array}$ & - & - & - \\
\hline
\end{tabular}

\subsubsection{Base Case and Sensitivity Analysis}

The base case scenario of this study is to schedule the harvest of the above mentioned mixed hardwood forest of 3,042 ha. A clearcutting with an area limit of 40 ha was used in the base case management scenario. We assumed the timber product price at $\$ 100 /$ dry $M g$ according to a timber market report (AHC 2014), carbon price at $\$ 5 / \mathrm{Mg} \mathrm{CO}_{2}$ eq based on the historical data by Chicago Climate Exchange (2011), and average woody residue price at $\$ 2 / \mathrm{dry} \mathrm{Mg}$ (Wu et al. 2011). The configurations of all other parameters are listed in Table 2-2. 


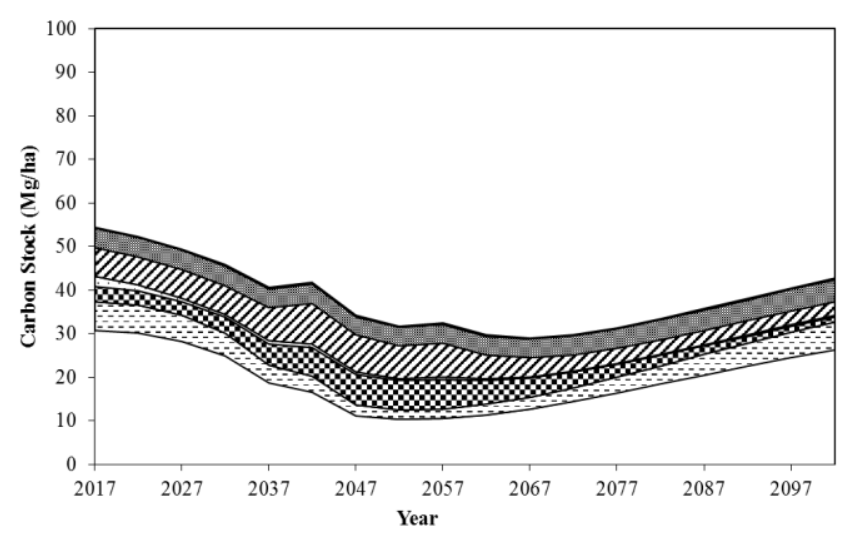

(a)

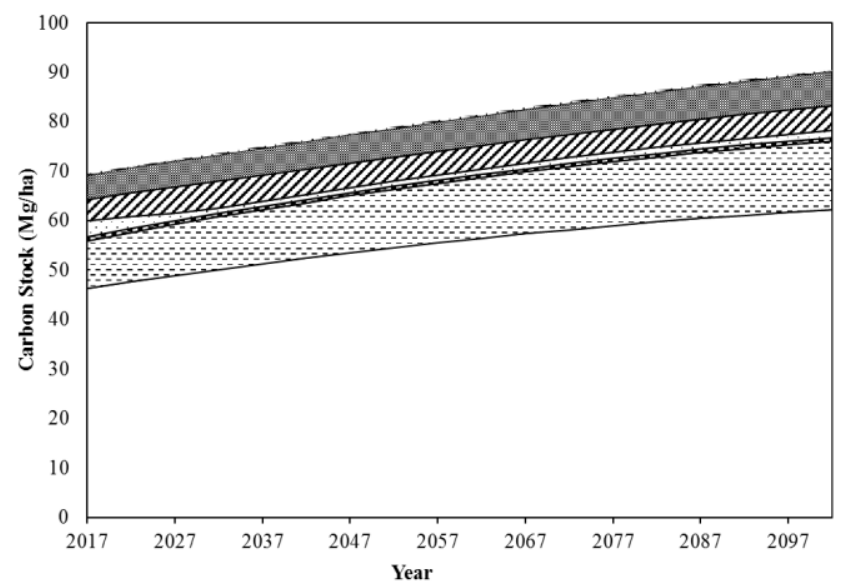

(c)

$\square$ Standing Live $\quad \square$ Belowground Live $\quad$ Belowground Dead $\square$ Standing Dead $\quad$ aDown Dead Wood

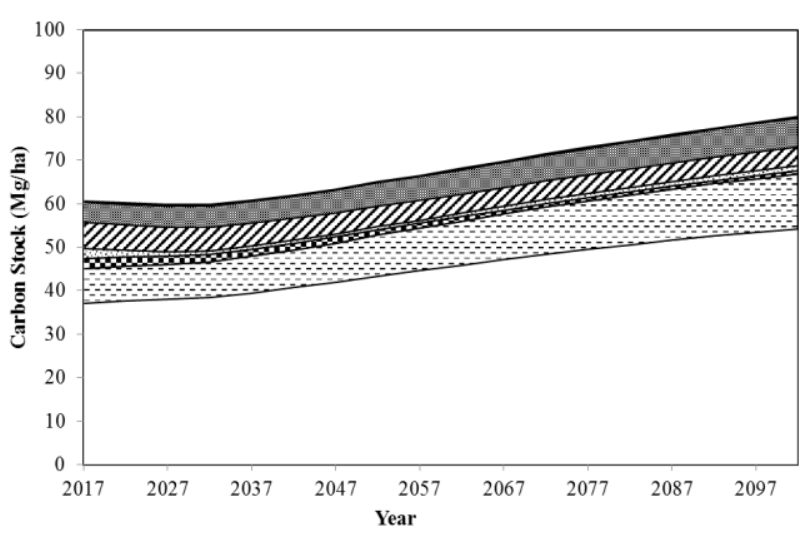

(b)

Fig. 2-4. Different carbon components of the forest at different carbon to timber price ratio, (a) 0.1, (b) 0.5, (c) 1.0. Growth of 100 years was simulated in FVS.

The sensitivity of carbon sequestration was analyzed over a range of carbon to timber price ratio, biomass to timber price ratio, harvest area limit, and harvest method (Table 2-3). The partial cut was set at removal levels of $25 \%, 50 \%$, and $75 \%$ of the stand's basal area. The carbon to timber price ratio varied from 0 to 1 at the increment of 0.05 (from $\$ 0-\$ 100 / \mathrm{CO}_{2} \mathrm{eq} \mathrm{Mg}$ ). The biomass (wood residue) to timber price ratio ranged from 0 to 0.7 at the increment of 0.05 (from $\$ 0-\$ 70 /$ dry Mg of biomass). The carbon sequestration potential was also examined with consideration of a permissible harvest area ranging from 0 to $100 \mathrm{ha}$ at an increment of $10 \mathrm{ha}$. 
The model in this case study was solved using ILOG CPLEX 12.5 on a computer with 8GB memory and $2.93 \mathrm{GHz}$ processor. Necessary programs were written in JAVA to implement the model and a 5000-second time limit was set to achieve a convergence gap of less than $1 \%$.

\subsection{RESULTS}

\subsubsection{Base Scenario}

The optimized carbon sequestration rate of the base case scenario over the planning horizon of 50 years was $0.408 \mathrm{Mg} \cdot \mathrm{ha}^{-1} \cdot \mathrm{year}^{-1}$. Among different carbon components of the forest (Fig. 2-4a), aboveground living stands were the major contributor (59.6\%) to the total carbon storage, followed by belowground living component (15.6\%). The forest carbon sequestration rate drastically decreased right after each harvest. However, it will gradually return to pre-harvest rate with enough time for new growth (20-50 years). The revenue could be up to $\$ 21.2 \mathrm{ha}^{-1} \cdot$ year $^{-1}$ where carbon sequestration accounts for $40 \%$, timber and biomass account for $59 \%$ and $1 \%$, respectively.

\subsubsection{Carbon to Timber Price Ratio}

Most of the case scenarios at different carbon prices were solved with a convergence gap of less than $1 \%$ (Table 2-4). A noticeable increase of carbon sequestration rate was generally observed as carbon to timber price ratio increased. The sequestration rate of mixed Appalachian hardwood forests ranged from 0.325 to $1.253 \mathrm{Mg} \cdot \mathrm{ha}^{-1} \cdot \mathrm{year}^{-1}$ with an average of $0.917 \mathrm{Mg}$. $\mathrm{ha}^{-1} \cdot$ year $^{-1}$ as the carbon to timber price ratio increased from 0.0 to 1.0 . The carbon storage of the forest could be sustained in a planning horizon when the carbon to timber price ratio was higher than 0.5 (Fig. 2-4b, c). Consequently, the total revenue from the forest grew steadily from 
Table 2-4. Optimized results of carbon sequestration, timber and revenue by carbon to timber price ratios.

\begin{tabular}{|c|c|c|c|c|c|}
\hline $\begin{array}{l}\text { Carbon to Timber } \\
\text { Price Ratio }\end{array}$ & $\begin{array}{c}\text { Carbon }(\mathrm{Mg} \cdot \\
\left.\text { ha }^{-1} \cdot \text { year }^{-1}\right)\end{array}$ & $\begin{array}{c}\text { Timber (Mg. } \\
\text { ha }^{-1} \cdot \\
\left.\text { year }^{-1}\right)\end{array}$ & $\begin{array}{c}\text { Revenue }(\$ \cdot \\
\left.\text { ha }^{-1} \cdot \text { year }^{-1}\right)\end{array}$ & $\begin{array}{c}\text { Harvest } \\
\text { Area (ha } \\
\text { year }^{-1} \text { ) }\end{array}$ & Final convergence Gap ${ }^{a}$ \\
\hline 0 & 0.325 & 0.796 & 20.386 & 55.7 & $0.02 \%$ \\
\hline 0.05 & 0.405 & 0.782 & 21.198 & 54.9 & $-b$ \\
\hline 0.1 & 0.408 & 0.766 & 22.531 & 54.9 & $0.09 \%$ \\
\hline 0.15 & 0.413 & 0.764 & 24.150 & 54.1 & $0.10 \%$ \\
\hline 0.2 & 0.411 & 0.769 & 25.503 & 54.0 & $0.17 \%$ \\
\hline 0.25 & 0.540 & 0.698 & 26.646 & 49.3 & - \\
\hline 0.3 & 0.624 & 0.633 & 28.051 & 47.2 & - \\
\hline 0.35 & 0.655 & 0.576 & 29.829 & 44.5 & - \\
\hline 0.4 & 0.803 & 0.504 & 32.186 & 37.3 & - \\
\hline 0.45 & 1.125 & 0.235 & 34.833 & 22.6 & - \\
\hline 0.5 & 1.195 & 0.162 & 37.808 & 15.8 & - \\
\hline 0.55 & 1.211 & 0.140 & 40.929 & 14.3 & - \\
\hline 0.6 & 1.216 & 0.132 & 44.135 & 14.1 & - \\
\hline 0.65 & 1.228 & 0.114 & 47.389 & 13.4 & - \\
\hline 0.7 & 1.230 & 0.109 & 50.656 & 12.8 & - \\
\hline 0.75 & 1.230 & 0.109 & 53.935 & 12.8 & - \\
\hline 0.8 & 1.231 & 0.103 & 57.231 & 12.8 & - \\
\hline 0.85 & 1.253 & 0.000 & 60.466 & 0 & - \\
\hline 0.9 & 1.253 & 0.000 & 64.023 & 0 & - \\
\hline 0.95 & 1.253 & 0.000 & 67.580 & 0 & - \\
\hline 1 & 1.253 & 0.000 & 71.137 & 0 & - \\
\hline
\end{tabular}

Note:

${ }^{a}$ Final gap for sub-optimal solution when the optimal solution was not achieved;

${ }^{b}$ A hyphen indicated an optimal solution was obtained.

$\$ 20.8$ to $\$ 71.2 \mathrm{ha}^{-1} \cdot$ year $^{-1}$. The number of stands harvested would be reduced as the carbon to timber price ratio increased.

The peak of the increment of carbon sequestration rate (marginal rate) was located when the carbon to timber price ratio was at 0.45 (Fig. 2-5a). The rate reached 0 when the carbon to timber price ratio was greater than or equal to 0.8 . Accordingly, the revenue steadily increased from $\$ 0.8$ to $\$ 3.6 \mathrm{ha}^{-1} \cdot \mathrm{year}^{-1}$ as the carbon to timber price ratio increased from 0.0 to 1.0. When 


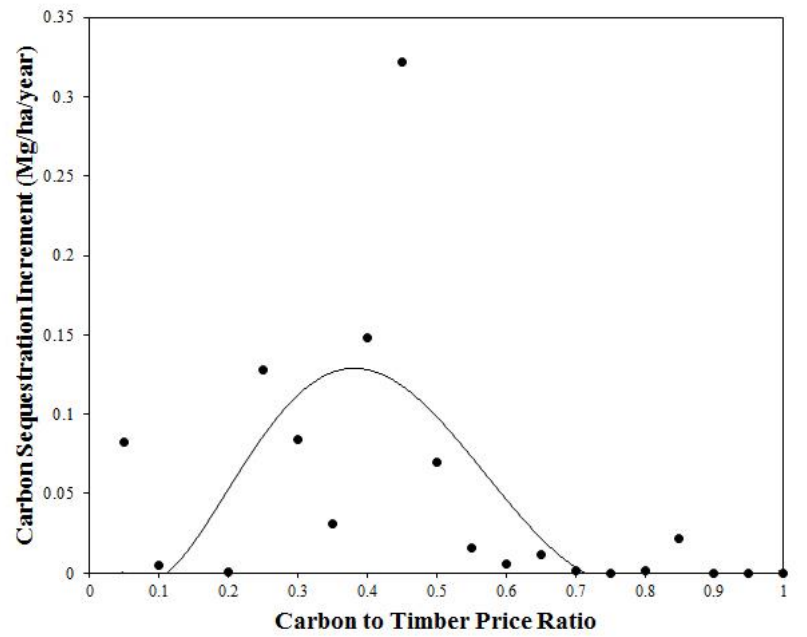

(a)

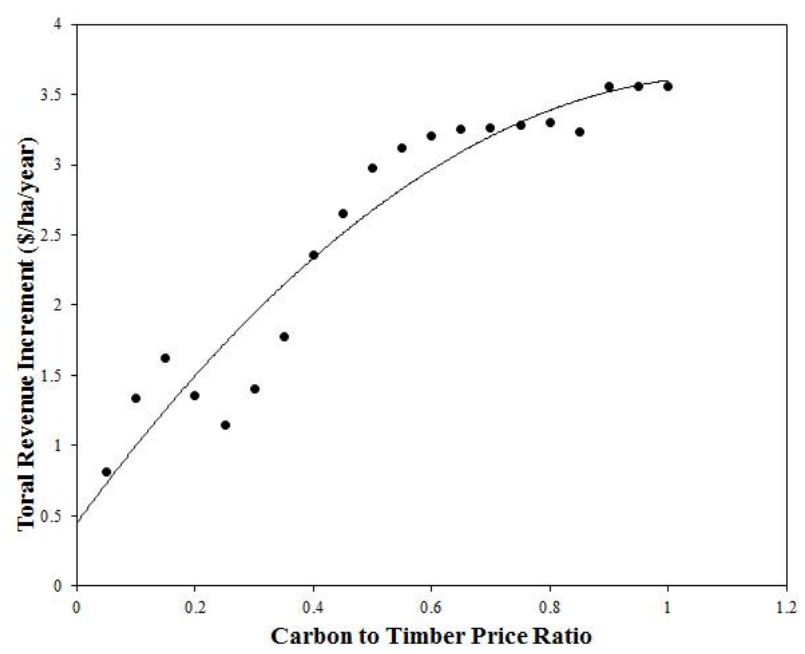

(b)

Fig. 2-5. Variations of (a) carbon sequestration rate and (b) total forest revenue by carbon to timber price ratio $(\Delta=\mathbf{0 . 0 5})$.

the price ratio was greater than or equal to 0.8 , the increment of forest revenue attained a flat plateau.

The clear increasing trend of carbon sequestration rate and decreasing trend of timber harvest intensity were observed when the carbon to timber price ratio was between 0.2 and 0.5 . When carbon price was higher than or equal to 0.8 , the carbon sequestration rate was flatted out while timber production was dramatically dropped (Fig. 2-6). The carbon to timber price ratio is a tradeoff between carbon stock and timber demand. As shown in Fig. 6, to achieve a carbon sequestration rate of $\mathrm{C}(0.64) \mathrm{Mg} \cdot \mathrm{ha}^{-1} \cdot$ year $^{-1}$, a carbon to timber price ratio should be $\mathrm{P}$ (0.33), then $\mathrm{M}(0.6) \mathrm{Mg} \cdot \mathrm{ha}^{-1} \cdot \mathrm{year}^{-1}$ is determined as the amount of raw timber products available for the market.

\subsubsection{Biomass to Timber Price Ratio}

If the carbon to timber price ratio was 0.0 , the carbon sequestration rate slightly varied from 0.325 to $0.323 \mathrm{Mg} \cdot \mathrm{ha}^{-1} \cdot$ year $^{-1}$ as biomass to timber price ratio increased from 0.0 to 0.7 (Fig. 2-7a). As woody biomass price increased, the carbon sequestration rate declined. When a 
carbon to timber price ratio of either 0.0 or 1.0 , the carbon sequestration rate would decline approximately $2 \%$. But an obvious decline of carbon sequestration rate was noticed when the carbon to timber price ratio was $0.5(63.4 \%$, Fig. $2-7 a)$.
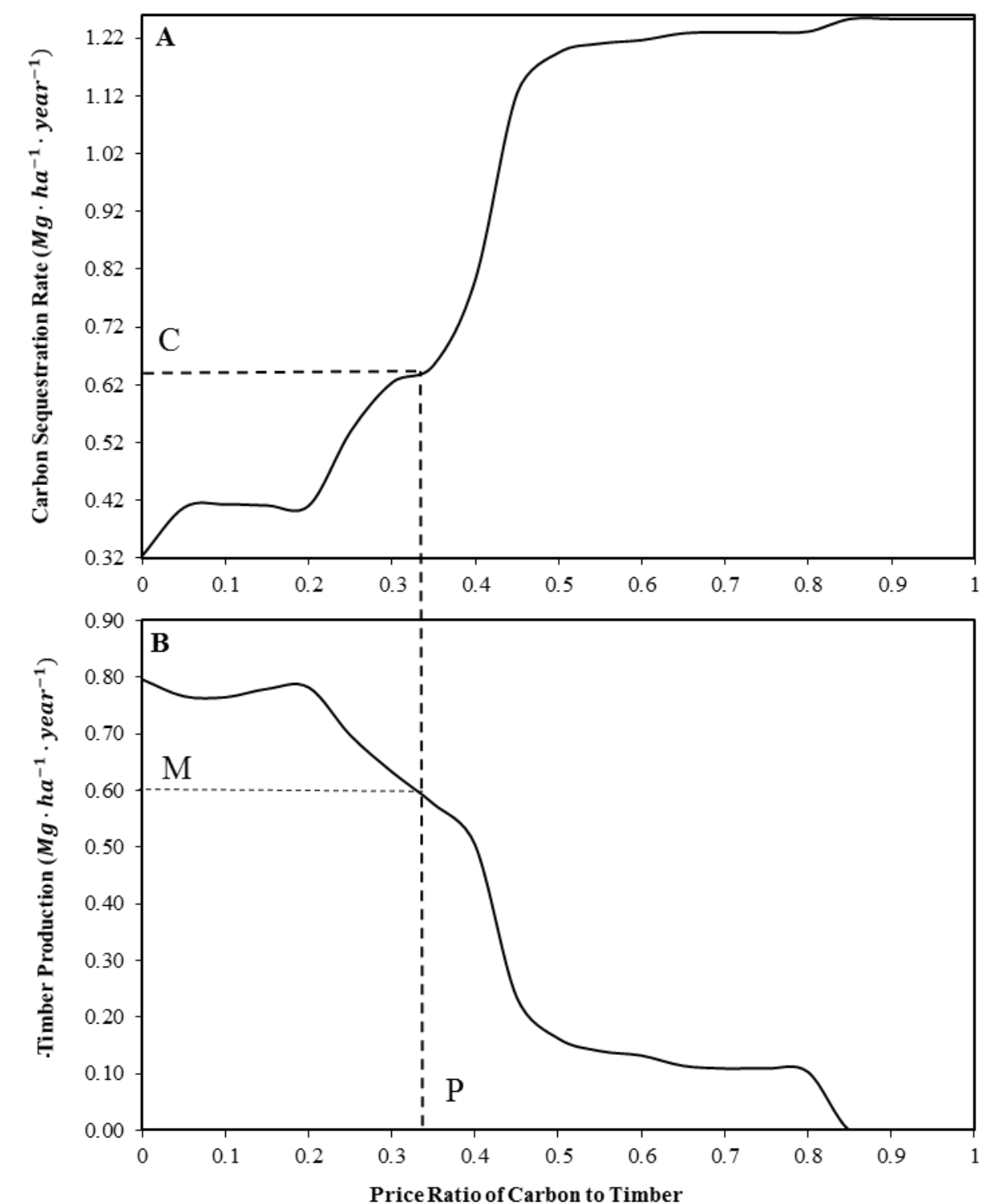

Fig. 2-6. Method for choosing a suitable carbon price by considering timber demand and carbon sequestration. Note: C: carbon sequestration; M: Raw timber; P: Carbon to Timber price ratio. 


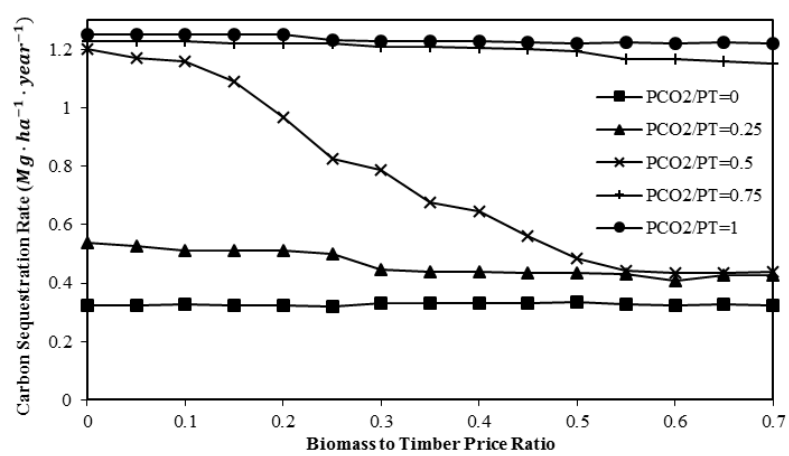

(a)

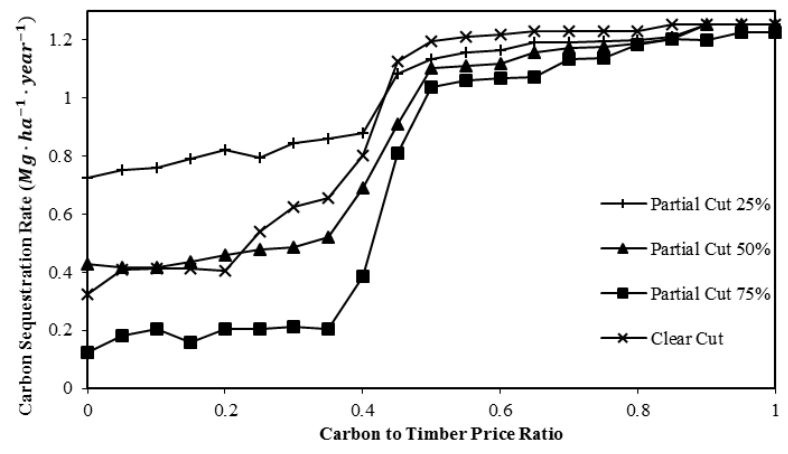

(c)

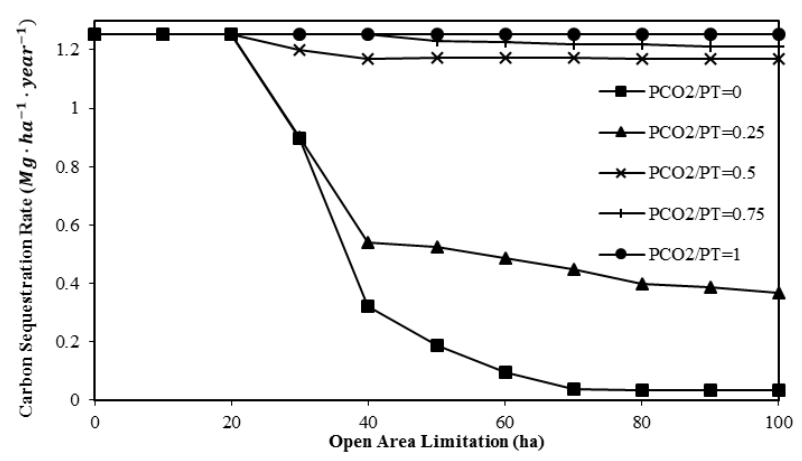

(b)

Fig. 2-7 Carbon sequestration rate $\left(\boldsymbol{M g} \cdot \boldsymbol{h a ^ { - 1 }} \cdot \boldsymbol{y e a r ^ { - 1 }}\right)$ by (a) biomass to timber price ratio; (b) harvest area size (ha); (c) management strategies: partial-cut vs. clearcutting.

\subsubsection{Harvest Area Limitation}

Limitation of the harvest area is important to prevent wildlife habitat in the forest from disruption and fragmentation, it reduces soil erosion, and ensures a sustainable manner of forest resource management. For a given carbon to timber price ratio, the size restriction of continuous harvest areas becomes a primary factor affecting the amount of carbon sequestrated in a forest stand. The maximum potential carbon sequestration rate of $1.253 \mathrm{Mg} \cdot \mathrm{ha}^{-1} \cdot$ year $^{-1}$ was achieved when the harvest area was limited to less than 20 ha for lower carbon to timber price ratio (Fig. 2-7b). Assuming the carbon to timber price ratio was 0.0, the carbon sequestration rate steadily declined from 1.253 to $0.03 \mathrm{Mg} \cdot \mathrm{ha}^{-1} \cdot$ year $^{-1}$ with the harvest area changed from 
0 to 100 ha. When the carbon to timber price ratio was high, the carbon sequestration rate changed slightly as the harvest area varied.

\subsubsection{Harvest Methods}

Generally, the carbon sequestration of clearcutting was higher than that of partial cut; specifically, when the carbon to timber price ratio was higher than 0.4. Without carbon credit, the carbon sequestration rate of the partial cuts of $75 \%$ and $25 \%$ of stand basal area removal scenarios was $165.7 \%$ lower and $55 \%$ higher than clearcutting, respectively (Fig. 2-7c). All stands would be reserved for carbon storage when the carbon to timber price ratio was 1.0 for partial cuts of $50 \%$ and $25 \%$ basal area removal scenarios. If the carbon to timber price ratio remained the same, as the removal intensity of partial cuts increased, the carbon sequestration rate generally decreased (Fig.2- 7c). The sequestration potential among various harvest methods could be largely differentiated when the carbon to timber price ratio was lower than 0.45 . However, this difference became smaller when the carbon to timber price ratio was higher (Fig. $2-7 c)$.

\subsection{DISCUSSION}

\subsubsection{Carbon to Timber Price Ratio}

Carbon price could substantially affect the potential of forest carbon sequestration rate. For the Appalachian mixed hardwood forests, the carbon sequestration rate could be up to $1.253 \mathrm{Mg}$. $\mathrm{ha}^{-1} \cdot$ year $^{-1}$ when the carbon to timber price ratio was over 0.8. As Asante et al. (2011) indicated, forest might never be harvested if carbon price was high enough. In this study, for example, forest stands might not need to be harvested when the carbon to timber price ratio was higher than 0.8 . 
A noticeable change of carbon sequestration rate was observed when the carbon to timber price ratio was between $0.4-0.5$. This was because a stand would not be treated as 'no harvest' at a lower carbon price unless the economic benefit of reserving the stand for carbon was higher than its harvest revenue. This threshold was dependent on growth and management strategies of forest stands and most thresholds were around 0.4-0.5 in our case. As the further increase of carbon price, carbon sequestration rate became stable and the increment reached 0 eventually. When the carbon to timber price ratio was near 0 , because most of the stands would be harvested, a reduction of carbon storage in the forest was expected within the planning horizon. An increase of carbon to timber price ratio allowed less cut and more sustainable carbon storage.

\subsubsection{Timber Demand and Biomass Utilization}

If the amount of timber harvested is lower than the market demand, timber price would increase until the demand is met. To maintain a certain level of carbon sequestration rate, an increase of carbon price is needed. If timber demand is not a driving factor of the supply, then the carbon to timber price ratio could become a major factor motivating forest managers and landowners to manage their forests for carbon sequestration.

Biomass is considered as a carbon neutral energy resource, so the benefit from forest carbon sequestration can be further enhanced, if the reduction of GHG emissions is considered through utilizing woody biomass such as residues for bioenergy (Fantozzi and Buratti 2010; Perilhon et al. 2012; Augustínová et al. 2013). Any increase of biomass price can affect the carbon sequestration and forest management decision as well (Saud et al. 2013; Wu et al. 2011). In this study, the price of woody biomass was assumed to be a ratio of timber price ranging from 0 to 0.7 . Biomass production would affect carbon sequestration as the biomass to timber price ratio increased. Biomass utilization for bioenergy would generally encourage more harvest as 
biomass price increased. Biomass price did not have any noticeable effect when the carbon to timber price ratio was either high or low, due to price of biomass being considered as part of benefit from harvest and have little effect on the carbon to timber price ratio.

\subsubsection{Harvest Area Limitation and Harvest Methods}

Harvest area limitation, related BMPs regulations and harvest site terrain conditions, all affect carbon sequestration. Clearcutting with appropriate area limitation could enhance carbon sequestration of the forest compared to partial cuts. When the carbon to timber price ratio is low, most stands will be profitable if be harvested rather than reserved for carbon storage, thus lower area limitation could ensure more carbon can be stored in forest stands. In this study, harvest intensity of a partial cut presented a direct effect on the carbon sequestration rate. High intensity of partial cut will allow more removal of timber and biomass, and reduce the carbon sequestration rate. But when the carbon to timber price ratio is low, more stands would be harvested in clearcutting scenario. When the carbon to timber price ratio rises, the advantage of clearcutting becomes prominent because area limitation restricts the feasible harvest decision and responses to the rise quickly.

\subsubsection{Model Performance}

Few approaches were previously discussed for modeling harvesting area restrictions (Constantino et al. 2008; Goycoolea et al. 2005; McDill et al. 2002 ), and the cluster packing formulation could be an efficient approach (Goycoolea et al. 2009). However, it could not be used directly in this case study because multiple harvesting for a stand needs to be considered during multiple planning horizons. Thus some of the stands in a feasible cluster might need to be harvested at different time periods to achieve an optimal solution. The approach developed in this study can be intentionally used to schedule harvest of a stand multiple times during different 
planning horizons. The CPLEX solver was used to optimize the scenarios in this case study with 3,207 rows, 1,536 columns, and 11,478 non-zero elements contained in the modelling matrix.

Five types of variables were defined in the model, including $x_{i t}, y_{i j t}, a_{i t}, \mathrm{G}_{\mathrm{it}}$ and aTem $\mathrm{ikt}_{\mathrm{t}}$, and they made the computing a very complex task. Solving a larger optimization problem is always challenging. However, the modeling approach developed in this study proved to be useful and efficient in making decision in sustainable forest management. Modeling process and algorithms could be further improved to reduce the number of variables and to enhance solving efficiency for larger problems.

\subsection{CONCLuSiOnS}

Harvest area restriction, carbon price, biomass price, and harvest method all affected the carbon sequestration rate of the central Appalachian mixed hardwood forests to some extent. Carbon price was the most sensitive factor to the carbon sequestration rate, followed by harvest intensity. The average carbon sequestration potential was $0.408 \mathrm{Mg} \cdot \mathrm{ha}^{-1} \cdot \mathrm{year}^{-1}$ in the central Appalachian hardwood forests at a carbon price of $\$ 5 / \mathrm{Mg} \mathrm{CO}$ eq. This potential could be enhanced as carbon price increased. The marginal revenue for carbon sequestration and timber demand also affect the sequestration strategies. Increased biomass utilization for bioenergy would encourage more harvest to promote the long-term carbon sequestration. Larger area limitation could encourage more harvest when carbon price is low. When the carbon to timber price ratio is low, lower harvest intensity of partial cut would allow more carbon storage compared to clearcutting. 


\section{REFERENCES}

Appalachia Hardwood Center. 2014. WV timber market report [online]. Available from http://ahc.caf.wvu.edu/ahc-resources-mainmenu-45/timber-market-report-mainmenu-62 [accessed 15 October 2014].

Asante, P., Armstrong, G.W., Adamowicz, W.L. 2011. Carbon sequestration and the optimal forest harvest decision: a dynamic programming approach considering biomass and organic matter. J. For. Econ. 17: 3-17.

Augustíno vá, J., Cvengrošová, Z., Mikulec, J., Vasilkovová, B., Cvengroš, J. 2013. Upgrading of bio-oil from fast pyrolysis. $46^{\text {th }}$ International Conference on Petroleum Processing, Bratislava, Slovak Republic.

Barahona, F., Weintraub, A., Epstein, R., 1992. Habitat dispersion in forest planning and stable set problem. Oper. Res. 40(1): 14-21.

Chicago Climate Exchange. 2011. CCX historical price and volume [online]. Available from: https://www.theice.com/ccx.jhtml[accessed in 2 September 2013].

Constantino, M., Martins, I., Borges, J.G., 2008. A New Mixed-Integer Programming Model for Harvest Scheduling Subject to Maximum Area Restrictions. Oper. Res. 56(3): 542-551.

Dixon G.E. 2013. Essential FVS: A User's Guide to the Forest Vegetation Simulator. USDA Forest Service, Fort Collins, CO.

Fan, S., Gloor, M., Mahlman, J., Pacala, S., Sarmiento, J., Takahashi, T., Tans, P. 1998. A Large Terrestrial Carbon Sink in North America Implied by Atmospheric and Oceanic Carbon Dioxide Data and Models. Sci. 282: 442-446. 
Fantozzi, F., Buratti, C. 2010. Life cycle assessment of biomass chains: wood pellet from short rotation coppice using data measured on a real plant. Biomass and Bioenergy, 34: 17961804.

Goycoolea, M., Murray, A.T., Barahona, F., Epstein, R., Weintraub, A. 2005. Harvest scheduling subject to maximum area restrictions: exploring exact approaches. Oper. Res. 53(3): 490500.

Goycoolea, M., Murray, A., Vielma, J.P., Weintraub, A. 2009. Evaluating approaches for solving the area restriction model in harvest scheduling. For. Sci. 55(2): 149-165.

Gutrich, J., Howarth, R.B. 2007. Carbon sequestration and the optimal management of New Hampshire timber stands. Ecol. Econ. 62(3): 441-450.

McCarl, B.A., Schneider, U.A. 2001. Greenhouse gas mitigation in U.S. agriculture and forestry. Sci. 294: 2481-2482.

McDill, M.E., Rebain, S.A., Braze, J. 2002. Harvest scheduling with area-based adjacency constraints. For. Sci. 48(4): 631-642.

Mitchell J. 1989. The "Greenhouse" Effect and Climate Change. Rev. Geophys. 27: 115-139.

Murray, A.T. 1999. Spatial Restrictions in Harvest Scheduling. For. Sci. 45(1): 45-52.

Murray, A.T., Goycoolea, M., Weintraub, A. 2004. Incorporating average and maximum area restrictions in harvest scheduling models. Canadian Journal of Forest Research, 34: 456464.

Perilhon, C., Alkadee, D., Descombes, G., Lacour, S. 2012. Life cycle assessment applied to electricity generation from renewable biomass. Energy Procedia, 18: 165-176. 
Saud, P., Wang, J., Lin, W., Sharma, B.D., Hartley, D.S. 2013. A life cycle analysis of forest carbon balance and carbon emissions of timber harvesting in West Virginia. Wood Fiber Sci. 45(3): 250-267.

Schimel, D.S. 1995. Terrestrial ecosystems and the carbon cycle. Glob. Change Biol. 1:77-91.

Sharma, B.D., Wang, J., Liu, S. 2011. Modeling of sustainable biomass utilization and carbon emission reduction. Sens. Lett. 9: 1175-1179.

Sharma, B.D. 2010. Modeling of forest harvest scheduling and terrestrial carbon sequestration. $\mathrm{PhD}$ thesis, Division of Forestry and Natural Resources, West Virginia University, Morgantown, WV, U.S.

Stage, A.R. 1973. Prognosis model for stand development. Research Paper INT-137. Ogden, Utah: U.S. Dept. of Agriculture, Forest Service, Intermountain Forest and Range Experiment Station. $32 \mathrm{p}$.

Spring, D.A., Kennedy, J. O.S., Nally, R.M. 2005. Optimal management of a forested catchment providing timber and carbon sequestration benefits: climate change effects. Glob. Environ. Chang. 15: 281-292.

Tans, P., Keeling, R. 2014. Trends in Atmospheric [online]. Available from: http://www.esrl.noaa.gov/gmd/ccgg/trends/[accessed 2 September 2014].

Vielma, J.P., Murray, A.T., Ryan, D.M., Weintraub, A. 2007. Improving computational capabilities for addressing volume constraints in forest harvest scheduling problems. Eur. J. Oper. Res. 176(2): 1246-1264.

Van Kooten, G.C., Binkley, C.S., Delcourt, G. 1995. Effect of carbon taxes and subsidies on optimal forest rotation age and supply of carbon services. Am. J. Agric. Econ. 77: 365 374. 
West Virginia Division of Forestry. 2009. West Virginia silvicultural best management practices for controlling soil erosion and sedimentation from logging operations. Charleston, WV. de Wit, H.A., Palosuo, T., Hylen, G., Liski, J. 2006. A carbon budget of forest biomass and soils in southeast Norway calculated using a widely applicable method. Forest Ecology and Management, 225: 15-26.

Wu, J., Wang, J., Cheng, Q. and DeVallance, D. 2011. Assessment of coal and biomass to liquid fuels in central Appalachia, USA. Int. J. Energ. Res. 36(7): 856-870. 


\section{Economic AND ENVIRonmental ANALySES OF COAL AND Biomass to LiQuids Plants ${ }^{2}$}

\footnotetext{
${ }^{2}$ Prepared for International Journal of Energy Research.
} 


\section{AbSTRACT}

We analyzed the economic feasibility and environmental benefits of an alternative technology that converts coal and biomass to liquid fuels (CBTL), using West Virginia as a real case scenario with considerations of woody biomass harvest scheduling optimization, feedstock transportation and siting options of potential CBTL plants. Sensitivity analyses on required selling price (RSP) were conducted according to feedstock availability and price, biomass to coal mix ratio, liquid fuel yield, IRR, capital cost, operational and maintenance cost. A cradle-tograve life cycle assessment (LCA) model was also developed to analyze the environment benefits of the CBTL processes. The study of siting and capacity showed that feedstock mixed ratio limited the CBTL production. Sensitivity analysis on RSP showed the price of coal had more dominant effect than that of biomass. Different biomass mixed ratio in the feedstock and liquid fuel yield led to RSP ranging from $\$ 104.3$ - \$157.9/bbl. LCA study indicated that greenhouse gas (GHG) emissions ranged from $80.62 \mathrm{~kg} \mathrm{CO} 2$ eq to $101.46 \mathrm{~kg} \mathrm{CO} 2 \mathrm{eq} / 1,000 \mathrm{MJ}$ at various biomass to coal mix ratios and liquid fuel yield if carbon capture and storage (CCS) was applied. Most of water and fossil energy were consumed in conversion process at a CBTL facility. Compared to petroleum-derived-liquid fuels, the reduction in GHG emissions in West Virginia was estimated to be between -162 and 555 million tons over a 30-year period. 


\subsection{INTRODUCTION}

Uncertain supplies of oil, climate change and attempts to increase the nation's fossil fuel independence are concerns that has evoked a renewed interest in alternative sources of energy. Substitutes for traditional fossil fuels could be liquid fuels produced from coal or biomass which enables the USA to reduce its reliance on foreign oil (Paul 2009). Since the Fischer-Tropsch (FT) technology was first developed in Germany in the 1920s, it has been popularly used for producing synthetic fuels (Höök and Aleklett 2010; Bartis and Van Bibber 2011). There are two processes that could be developed to produce liquid fuels from coal: direct and indirect (Paul 2009; Jiang and Bhattacharyya 2014,2015). Direct approach has higher product yield compared to indirect approach, but the product quality is lower and the operating conditions are severe (Bellman et al. 2007).

Both direct and indirect coal-to-liquids (CTL) methods have been commercialized in South Africa and China. Sasol in Africa was able to produce 27\% of the total liquid fuel produced in 2012 (Tennant 2014). Five CTL projects processing a total of 930,000 ton coal per year were planned in China in 2013 and two will completed in 2015 (Li et al. 2013). Currently, there is no CTL plant in the U.S. because liquid fuels derived from coal cannot compete on price with the fuels derived from crude oil (Van Bibber et al. 2007; Tarka 2009). Additionally, another main drawback of CTL is the high carbon footprint in the conversion processes, which is more than twice of petroleum-derived-fuels (Tarka 2009). Carbon capture and storage (CCS) is an approach to capture carbon emission during the production of liquid fuels at facility, which can efficiently reduce greenhouse gas (GHG) emissions. If a simple CCS is considered (91\% carbon captured), a 5-12\% reduction in life cycle emission can be achieved in comparison to the petroleumderived-diesel (Tarka 2009). 
Biomass has always been considered as a carbon neutral energy resource. The introduction of biomass to CTL, known as coal and biomass to liquids (CBTL) process, can further reduce GHG emissions (Gray et al. 2007; Tarka 2009). Biomass-to-liquids (BTL) processes have very low GHG emissions and most emissions are associated with harvesting, collection and transportation of biomass feedstock, but they usually associate with high costs (Bartis et al. 2008). Combination of coal and biomass allows biomass to offset the emissions in the CTL process. Inclusion of CCS in the CBTL process can maintain the total emissions at a lower level. A study from the U.S. Department of Energy's National Energy Technology Laboratory (DOE NETL) reported that a mixture of $8 \%$ biomass and $92 \%$ coal (by weight) can produce fuels which have $20 \%$ lower life cycle GHG emissions than petroleum-derived diesel fuel (Tarka et al. 2009).

Life Cycle Assessment (LCA) has been considered as a good tool to analyze GHG emissions since it was first proposed in 1970 (Hunt and Franklin 1996) and fully developed in the early 1990s (Boustead 1996). The International Organization for Standardization (ISO) accredited LCA when the process was completed and published between 1996 and 1998. A second edition of this standardization has become available since 2006 (ISO 14040 2006). Many studies have been conducted on LCA of biofuel, CTL, and CBTL fuel productions. A study of CTL by Marano and Ciferno (2001) reported $18.7 \mathrm{~kg} \mathrm{CO}_{2}$ eq GHG emissions per gal of liquid fuels produced from coal. GHG emission of $16.4-58.9 \mathrm{~kg} \mathrm{CO} 2 \mathrm{eq}$ per 1,000 MJ ethanol produced from biomass is 43-57\% lower than those of petroleum-derived-gasoline (Hsu et al. 2010). Kumar and Murthy (2012) found that fossil energy consumption for ethanol production from grass straw is $57.43-112.67 \%$ lower than that of gasoline. Compared to the traditional jet fuel, CBTL can result in up to $30 \%$ lower GHG emissions when $31 \%$ switchgrass is mixed with coal 
(Skone 2011). Wu et al. (2012) reported a 27\% lower GHG emissions with a biomass to coal mix ratio of $15 / 85$.

Economic feasibility of CBTL were studied by considering siting optimization, delivered costs of feedstocks and techno-economic analysis. Wu et al. proposed a two-stage GIS suitability model for deciding the suitable site for biomass to liquid fuel facility which considered topography condition, biomass handling cost and environmental impact (Wu et al. 2011). The CBTL plant could become economically feasible if the prices of petroleum-derived-fuels keep rising or the price of carbon is quite high (Marano and Ciferno 2001; Van Bibber et al. 2007; Tarka 2009; Wu et al. 2012). Marano and Ciferno (2001) estimated the price of FT liquid fuels for a 50,000 bpd CBTL plant to be $\$ 52.8 \mathrm{bbl}^{-1}-\$ 96.6 \mathrm{bbl}^{-1}$ in $1998 \$ \mathrm{~s}$ based on the amount of biomass content in the feedstock. This price was not competitive with petroleum derived gasoline and diesel. In the work of Van Bibbler et al. (2007), the average FT liquid fuels price was reported to be $\$ 81.5 \mathrm{bbl}^{-1}$. Tarka (2009) reported that the CBTL plant becomes feasible when the price of crude oil is higher than $\$ 100 \mathrm{bbl}^{-1}$ and when less than $30 \%$ of biomass is added to the mixture. Based on Wu et al.'s study (2012) conducted for the central Appalachia, the price was $\$ 84.19$ bbl $^{-1}-\$ 86.74 \mathrm{bbl}^{-1}$ in $2009 \$$ s and was able to compete with petroleum derived fuels with high government subsidy.

The abundant coal and biomass resources in West Virginia provide a compelling opportunity for the production of liquid fuels using CBTL technologies, but it is imperative that these resources can reach the facility at a reasonable price. There are many factors that influence the delivered cost to a facility, including but not limited to, the abundance of feedstock, presence of an infrastructure to handle the feedstock, and existing competing uses. There appears a necessity to further examine both environmental and economic benefits of the CBTL processes. 
Hence, the objectives of this study are to: (1) examine the economic efficiency of CBTL processes by developing a mixed integer linear programming model; (2) perform a life cycle assessment to analyze the environmental benefits of CBTL; and (3) conduct sensitivity analysis of economic and environmental impact of the CBTL applications in terms of feedstock availability, feedstock price, liquid fuel yield, biomass to coal mix ratio and plant capacity.

\subsection{Materials ANd MethodS}

\subsubsection{Study Area}

Our study area is the state of West Virginia (WV). West Virginia extends from $37^{\circ} 12^{\prime} \mathrm{N}$ to $40^{\circ} 39^{\prime} \mathrm{N}$ and from $77^{\circ} 43^{\prime} \mathrm{W}$ to $82^{\circ} 39^{\prime} \mathrm{W}$ in the U.S. More than $80 \%$ of the total land area is covered with forests, which makes it the third most heavily forested state in term of coverage. The total forest area is 4.9 million $h a$ of which $98 \%$ is timber land. The annual yield of woody residue is approximately 2.19 million dry tons according to information on timber products output, published by US Department of Agriculture (USDA TPO 2009).

The state of West Virginia (WV) is the nation's second largest coal-producing state, producing more than 143 million metric tons of coal in 2010, about $13 \%$ of the U.S. total (National Mining Association 2011, West Virginia Coal Association 2011). The majority of the coal in the state is produced in the southern half of the state. Eight counties in the southern central part of the state (Boone, Kanawha, Logan, McDowell, Mercer, Mingo, Raleigh and Wyoming) produce approximately $55 \%$ of the state's coal.

\subsubsection{Biomass and Coal Feedstocks}

An area restriction model (Murrary 1999) was used to estimate the biomass in West Virginia. The planning horizon was 80-year with planning period of five years. The forest 
inventory data were downloaded from the Forest Inventory \& Analysis database (USDA FIA 2012). The growth of forest stands was simulated by the Forest Vegetation Simulator (FVS) Northeast Variant (NE) with Fire and Fuels Extension (FFE) (Dixon 2013). The land cover data were obtained from the United States Geological Survey National Gap Analysis Program - Land Cover Data 2006 (USGS 2012).

It was assumed that a total of $10 \%$ of the timberland would not be harvested because of landowners' preferences to maintain forests for future values, aesthetics and other reasons. The amount of logging residues left in the forests was $2 / 3$ of the raw timber and mill residues was $1 / 3$ of the raw timber (Sharma 2010). The availability of mill residue was estimated based on the amount of timber harvested and capacity of sawmills. The location of sawmills in West Virginia were obtained from the Appalachian Hardwood Center (AHC) at West Virginia University. A total of 171 sawmills were recorded. The distances from logging sites to sawmills were calculated based on the 2010 road network downloaded from TIGER/Line Shape files of the U.S. Census Bureau.

The costs of handling biomass were based on a study by Wu et al. (2012). All costs are in 2012 dollars and all the tons are metric tons. The harvest costs were $\$ 12.92$ dry ton ${ }^{-1}$ using grapple skidder-chips system and the price of logging residue was set to be $\$ 1$ dry ton $^{-1}$ as the average price in the base case, although some logging residues could be obtained free from some landowners (Wu et al. 2012). We assumed that $65 \%$ of total logging residue is economically available. The purchase price of mill residue was assumed to be $\$ 50$ dry ton ${ }^{-1}$. We also assumed that $40 \%$ of the total woody residue from sawmill was economically available. The round-trip transportation costs was $\$ 0.23$ dry ton ${ }^{-1} \cdot \mathrm{km}^{-1}$ for logging residue and $\$ 0.15$ dry ton ${ }^{-1} \mathrm{~km}^{-1}$ for wood chips (Kerstetter and Lyons 2001). All the biomass was assumed to be evenly supplied to 
the CBTL plants and no storage occurred at plant sites from previous year. The distribution of logging and sawmill residues in 2012 are shown in Fig. 3-1a and b.

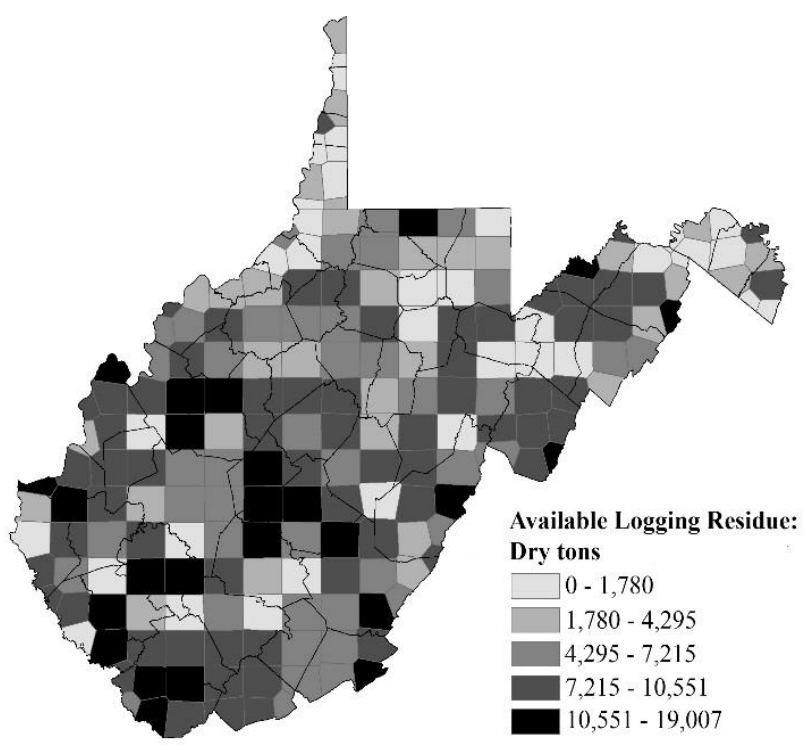

(a)

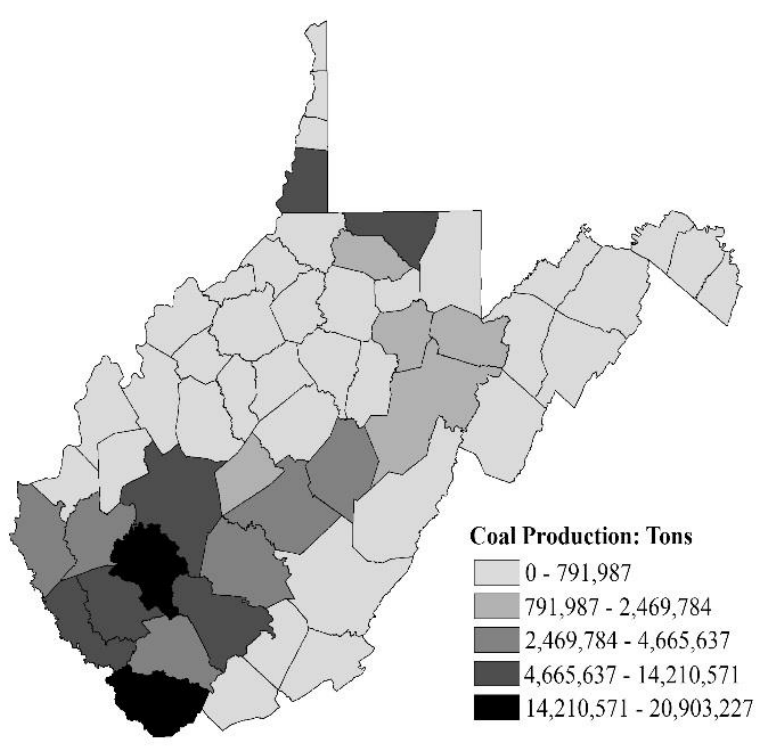

(c)

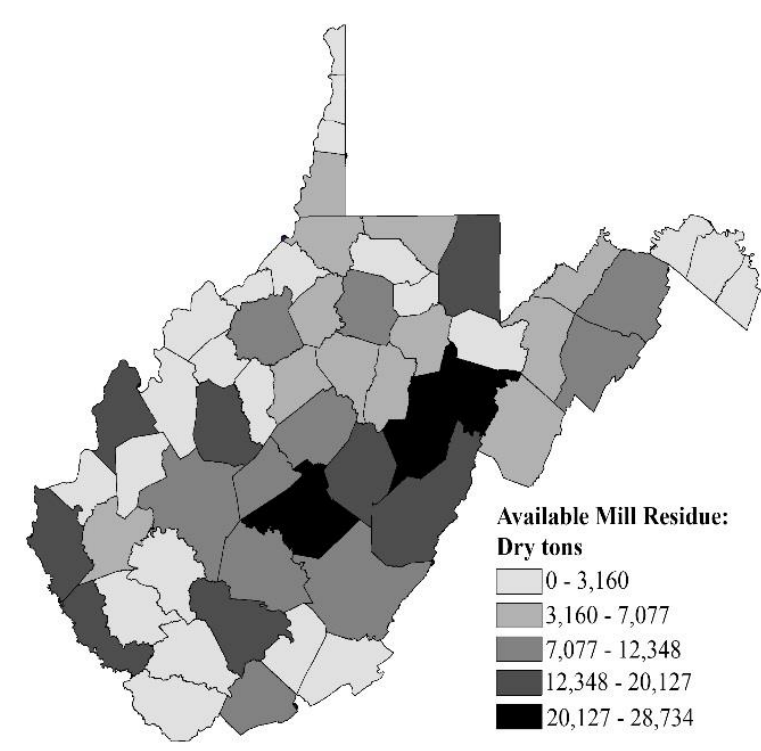

(b)

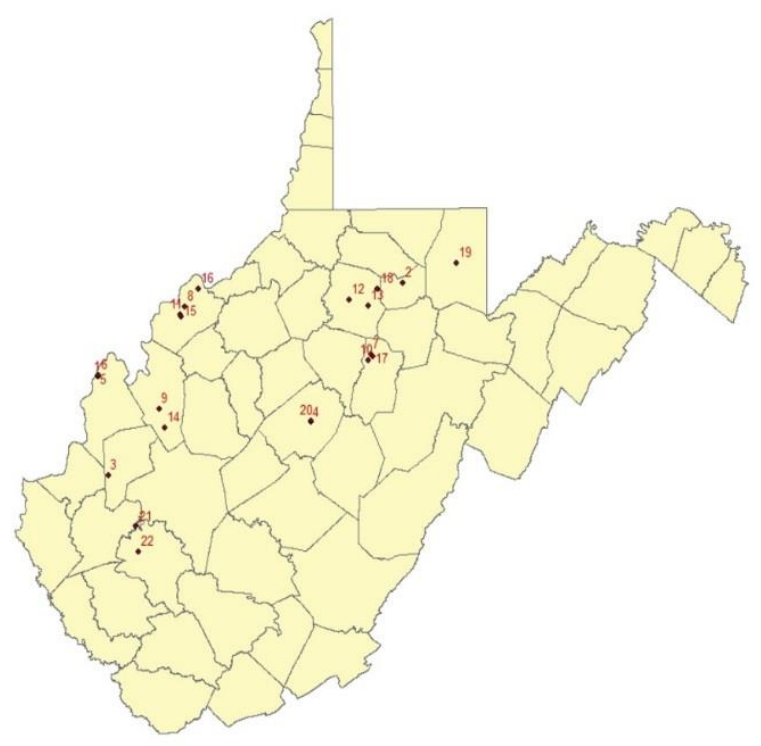

(d)

Fig. 3-1. Distributions of logging residue (a), mill residue (b), coal production level (c), and locations of candidate CBTL plants (d) in the study area. 


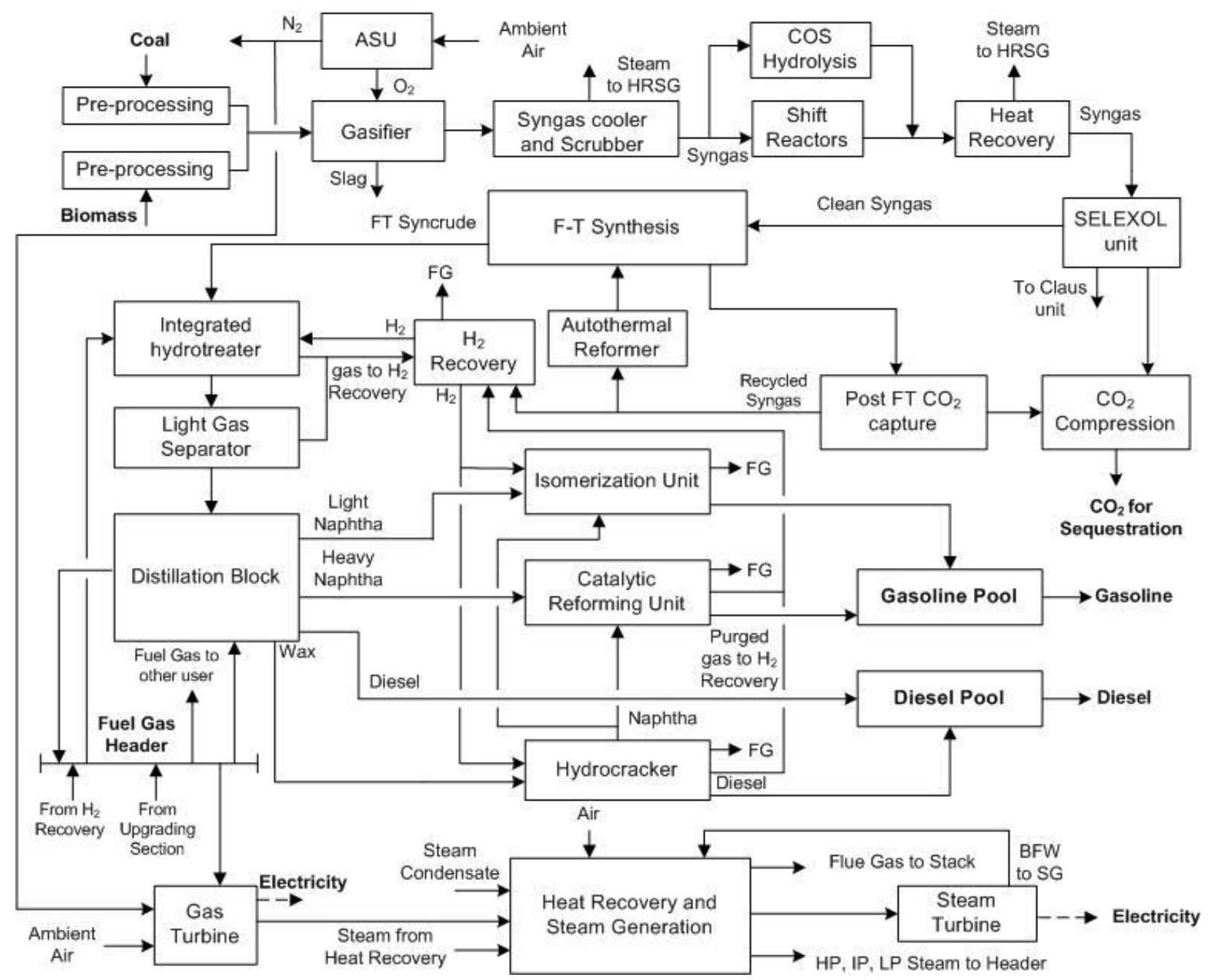

Fig. 3-2. Block flow diagram of the indirect CBTL plant with CCS

The regional coal production data are available in Annual Coal Report by the U.S. Energy Information Administration (Harris et al. 2013). The average sales price was $\$ 90.17$ ton $^{-1}$. The locations of coal mines were obtained from the West Virginia Department of Environmental Protection Technical Applications \& GIS Unit. We assumed a round-trip transportation cost of coal at $\$ 0.1$ ton $^{-1} \cdot \mathrm{km}^{-1}$ for the base case. Coal was primarily consumed for coal-fired power generation that provided approximately $99 \%$ of the electricity in West Virginia and the total amount of coal used for power generation is 29.52 million tons in 2012 in West Virginia (EIA 2013). A consistent and sufficient supply of coal was assumed over the next 30 years in this 
region, while over half of this production potential could be used to meet the feedstock request of CBTL plants (Fig. 3-1c). Distances between coal miles to CBTL facilities were calculated in the same way as we did for biomass feedstock.

\subsubsection{Process model of the CBTL plant}

A block flow diagram of the indirect CBTL plant is shown in Fig. 3-2. In the indirect CBTL plant, pre-treated coal and biomass are sent to the gasifier producing raw syngas, consisting mainly of $\mathrm{H}_{2}, \mathrm{CO}, \mathrm{H}_{2} \mathrm{O}, \mathrm{CO}_{2}, \mathrm{COS}, \mathrm{H}_{2} \mathrm{~S}$. The raw syngas is then cooled and sent to the COS hydrolysis unit and water gas shift unit to convert $\mathrm{COS}$ to $\mathrm{H}_{2} \mathrm{~S}$ and adjust the $\mathrm{H}_{2} / \mathrm{CO}$ ratio in the stream. Then the syngas is sent to the heat recovery unit, where most of the $\mathrm{H}_{2} \mathrm{O}$ is condensed. After that it is sent to the acid gas removal (AGR) unit where the physical solvent Selexol is used for selective capture of $\mathrm{CO}_{2}$ and $\mathrm{H}_{2} \mathrm{~S}$. The physical absorption process is preferred to remove $\mathrm{CO}_{2}$ from syngas because the syngas from gasification unit is available at high pressure, which can provide enough driving force for absorption, while the $\mathrm{CO}_{2}$ released from the solvent regeneration is also available at high pressure, which can reduce the penalty of the downstream $\mathrm{CO}_{2}$ compressor. The clean syngas from the AGR unit and the recycle stream from the autothermal reformer, containing mainly $\mathrm{H}_{2}$ and $\mathrm{CO}$, are sent to the Fischer-Tropsch (FT) unit to produce syncrude, where additional $\mathrm{CO}_{2}$ is produced. The vapor product from the FT unit is sent to the post-FT $\mathrm{CO}_{2}$ removal unit, using chemical absorption technology, to remove $\mathrm{CO}_{2}$ from unreacted syngas and light hydrocarbons. The advantage of using chemical absorption process for post-FT $\mathrm{CO}_{2}$ remove is that it can avoid hydrocarbon loss, which is significant in a physical absorption unit. The liquid product is sent to the product upgrading section, including hydrotreating, isomerization, catalytic reforming and hydrocracking unit, to produce on-spec gasoline and diesel. The $\mathrm{H}_{2}$ required for product upgrading is generated from 
the recycled syngas in the $\mathrm{H}_{2}$ recovery unit using pressure swing adsorption. A portion of the fuel gas generated in the FT unit and product upgrading unit is used as utility in the furnaces, while the remaining portion is sent to the gas turbine for power generation. Steam generated at multiple pressure levels in the syngas cooler, heat recovery and FT synthes is units is either directly utilized in various unit operations or sent to the heat recovery and steam generation section for superheating. Superheated steam is sent to the steam turbine for power generation. Some amount of steams is also extracted from the steam turbine for being utilized in the process (Jiang and Bhattacharyya, 2014, 2015)

\subsubsection{Economic model for CBTL plants}

An economic model is developed to maximize the total profit of the CBTL process. The liquid fuel yield from biomass to liquid fuels is $1.53 \mathrm{bbl} \cdot$ ton $^{-1}$ and from coal to liquid fuels is 2.38 bbl $\cdot$ ton $^{-1}$ (Wu et al. 2012, Jiang and Bhattacharyya 2014, 2015). The base case conditions for this CBTL process are reported in Table 1. The cost components consist of feedstock purchase cost, transportation, facility construction, operational and maintenance costs. Capital costs and operation and maintenance costs of different plant sizes are estimated in Aspen Process Economic Analyzer $^{\circledR}$ (APEA) based on a steady-state process model developed in Aspen Plus ${ }^{\circledR}$. All of the distillation columns are sized in Aspen Plus ${ }^{\circledR}$. All of the heat exchangers are sized in Exchanger Design and Rating ${ }^{\circledR}$. Reactors are specified as quoted equipment in APEA, of which the costs are estimated from the throughput (Jiang and Bhattacharyya, 2015; Baliban et al., 2010). The main outside battery limit (OSBL) equipment is the cooling water system, which is designed by Analyzer Utility Modules (AUM) available in APEA. The remaining project components are designed in APEA. Other than reactors, the capital cost of each sized equipment is estimated in APEA $^{\circledR}$ based on Aspen Icarus database. The costs are then scaled to different capacity based on 
Table 3-1. Base case configuration of the CBTL process.

\begin{tabular}{lc}
\hline Parameters & Assumptions \\
\hline Plant capacity (bpd) & 10,000 \\
Conversion method & Indirect liquefaction \\
Carbon capture and storage $(\%)$ & 88 \\
Liquid fuels yield - Coal (bbl·ton ${ }^{-1}$ ) & $2.38^{1}$ \\
Liquid fuels yield - Biomas ( $\left(\mathrm{bbl} \cdot \mathrm{ton}^{-1}\right)$ & $1.53^{1}$ \\
Price of logging residues $\left(\$ \cdot\right.$ dry ton $\left.^{-1}\right)$ & 2 \\
Price of sawmill residues $\left(\$ \cdot\right.$ dry ton $\left.^{-1}\right)$ & 50 \\
Price of Coal $\left(\$ \cdot\right.$ ton $\left.^{-1}\right)$ & 90.17 \\
Biomas to coal mix ratio: mass & $8 / 92$ \\
Plant life (years) & 30 \\
Equity proportion $(\%)$ & 40 \\
Cost of Equity $(\%)$ & 15 \\
Cost of Debt $(\%)$ & 8 \\
Operating time (days/year) & 350 \\
Internal Rate of Return $(\%)$ & 15 \\
Federal tax $(\%)$ & 40 \\
\hline
\end{tabular}

${ }^{1}$ Cited from Jiang and Bhattacharyya 2014.

NETL report (Gray et al. 2007). A set of candidate locations (Fig. 3-1d) were selected using a twostage GIS-based suitability model by Wu et al. $(2011,2012)$.

The high heating value (HHV) of FT liquid fuels (diesel equivalence) is $44.7 \mathrm{MJ}^{\mathrm{kg}} \mathrm{kg}^{-1}$ while for petroleum-derived diesel it is $43.1 \mathrm{MJ} \cdot \mathrm{kg}^{-1}$ (Jiang and Bhattacharyya 2014, 2015). An incremental cost of $\$ 2.95 \mathrm{bbl}^{-1}$ would incur for applying CCS (Tarka 2009). We assume a $15 \%$ internal rate of return (IRR) on equity in the base case in order to make the project economically feasible. The RSP was calculated according to feedstock costs, liquid fuel yield, mix ratio of biomass to coal, and the internal rate of return on equity. The model is shown as follows (The configurations and explanations of other necessary parameters considered in the model are in Appendix B):

$\operatorname{Max} z=R v-T C$ $(3-1)$

where:

$T C=F C+T r+\psi \cdot O M+\zeta \cdot T P C$. 
$\zeta=\sum_{t}^{T 2} \frac{1}{(1+W A C C)^{t}}$

$W A C C=w_{e} \cdot R_{e}+\left(1-w_{e}\right) \cdot R_{d} \cdot\left(1-f_{t}\right)$.

$\psi=\sum_{t}^{T 2} r_{O M}^{t}$

$R v=p_{f} \times \sum_{t}^{T 2}\left(\sum_{c}^{C} \sum_{p}^{P} \operatorname{Covs}_{c} \cdot x C_{c p t}+\sum_{i}^{I} \sum_{p}^{P} \operatorname{Covs}_{b} \cdot x I_{i p t}+\sum_{s}^{S} \sum_{p}^{P} \operatorname{Covs}_{b} \cdot x S_{s p t}\right) . \quad(3-6)$

$F C=\sum_{t}^{T 2}\left(\sum_{c}^{C} \sum_{p}^{P} P_{c} \cdot x C_{c p t}+\sum_{i}^{I} \sum_{p}^{P}\left(P_{l}+H C\right) \cdot x I_{i p t}+\sum_{s}^{S} \sum_{p}^{P} P_{s} \cdot x S_{s p t}\right)$.

$\operatorname{Tr}=\sum_{t}^{T 2}\left(\sum_{c}^{C} \sum_{p}^{P} T R_{c} \cdot d C_{c p} \cdot x C_{c p t}+\sum_{i}^{I} \sum_{p}^{P} T R_{l} \cdot d I_{i p} x I_{i p t}\right.$

$\left.+\sum_{s}^{S} \sum_{p}^{P} T R_{s} \cdot d S_{s p} x S_{s p t}\right)$

$O M=\sum_{p}^{P} \sum_{l}^{L} o_{p l} \cdot o m_{l}$.

$T P C=\sum_{p}^{P} \sum_{l}^{L} o_{p l} \cdot t p c_{l}$.

S.t.:

$\sum_{l}^{L} o_{p l} \leq 1, \forall p \in P$.

$\sum_{p}^{P} x C_{c p t} \leq A C_{c}, \forall c \in C, \forall t \in T 2$. 


$$
\begin{aligned}
& \sum_{p}^{P} x I_{i p t} \leq A I_{i}, \forall i \in I, \forall t \in T 2 \\
& \sum_{p}^{P} x S_{s p t} \leq A S_{s}, \forall s \in S, \forall t \in T 2 \\
& \sum_{i}^{I} x I_{i p t}+\sum_{S}^{S} x S_{s p t}=\eta \cdot \sum_{c}^{C} x C_{c p t}, \forall p \in P, \forall t \in T 2 . \\
& \sum_{c}^{C} \operatorname{Covs}_{s} \cdot x C_{c p t}+\sum_{i}^{I} \operatorname{Covs}_{b} \cdot x I_{i p t}+\sum_{S}^{S} \operatorname{Covs}_{b} \cdot x S_{s p t} \leq 365 \times 10^{4} \sum_{l}^{L} l \cdot o_{p l}, \forall p \in P, \forall t \\
& \in T 2 . \\
& (3-16) \\
& x I_{\text {ipt }}, x S_{s p t}, x C_{c p t} \geq 0, \forall c \in C, \forall i \in I, \forall s \in S, \forall t \in T 2 . \\
& o_{p l}=\left\{\begin{array}{c}
1, \text { if plant } p \text { is operated at capacity level } l \\
0, \text { otherwise. }
\end{array}\right.
\end{aligned}
$$

Equations (3-2) to (3-10) compute the related cost components, amortization factor $(\zeta)$, weighted average cost of capital (WACC), plant maintenance factor $(\psi)$, total revenue $(R v)$, feedstock costs $(F C)$, transportation costs $(T r)$, operation \& maintenance $(O M)$ and capital costs $(T P C)$, respectively. Constraints (3-11) ensure a consistent capacity of a CBTL plant over its entire operational period. Constraints (3-12)-(3-14) impose the condition that the total amount of feedstocks transported from a feedstock location cannot be greater than its availability in that location. Equations (3-15) ensure that the amounts of biomass and coal transported to a CBTL plant equal to the required mix ratio of biomass to coal under difference case scenarios. Constraints (3-16) limit the total production of a plant that cannot exceed its designed capacity.

All the models were solved using the program ILOG CPLEX 12.2, Academic Version on a computer with $16 \mathrm{G}$ memory and $1.8 \mathrm{GHz} 8 \mathrm{CPUs}$. Required programs to implement the model were written in the JAVA programming language and 5000 seconds was set as a time limit. 


\subsubsection{Life Cycle Assessment}

\subsubsection{Goal and Scope}

A cradle-to-grave life cycle assessment model was developed to examine the CBTL process with a focus on global warming potential, blue water and fossil energy consumption. The reduction potential in GHG emissions through using woody biomass in the CBTL process over the next 30 years was assessed. The functional unit was defined as 1,000 MJ energy equivalent FT liquid fuels. All energy inputs and outputs were calculated in HHV. The system boundary of this CBTL process is described in Fig. 3-3.

\subsubsection{2. $\quad$ Life Cycle Inventory (LCI)}

This LCA model included seven basic processes consisting of biomass collection, coal mining, transportation of coal, transportation of biomass, thermo-chemical conversion, liquid fuels distribution and final combustion. Feedstock included logging residue, mill residue and coal. Mill residue did not require any specific harvests since they were already available at sawmills. The extraction of logging residue involved grapple skidder, chipper and grapple loader. Data on processes of coal mining were obtained from the US LCI database provided by National Renewable Energy Laboratory (NREL). The transportation related processes were also derived from the US LCI database. Hauling distances of feedstocks were obtained through solving the economic model in the previous section.

The emissions in the conversion process were adapted from the inventory data by Marano and Ciferno (2001). A simple CCS was considered to reduce $\mathrm{CO}_{2}$ emission in the thermoschemical conversion process. It was assumed that $88 \%$ of $\mathrm{CO}_{2}$ was captured (Jiang and Bhattacharyya 2014, 2015). At the distribution stage, we assumed an average transportation distance of $100 \mathrm{~km}$ from plants to refueling stations. We also assumed that the FT liquid fuels of 
CBTL were combusted in a flex-fuel passenger car (Wang 2009). All other background processes were based on Ecoinvent 2.2 database. GHG emissions of $98.8 \mathrm{~kg} \mathrm{CO}_{2}$ eq per 1,000 $\mathrm{MJ}$ of petroleum-derived-diesel were used as a base reference for comparison (Keesom and Unasch, 2009). All the detailed processes were in Appendix B.

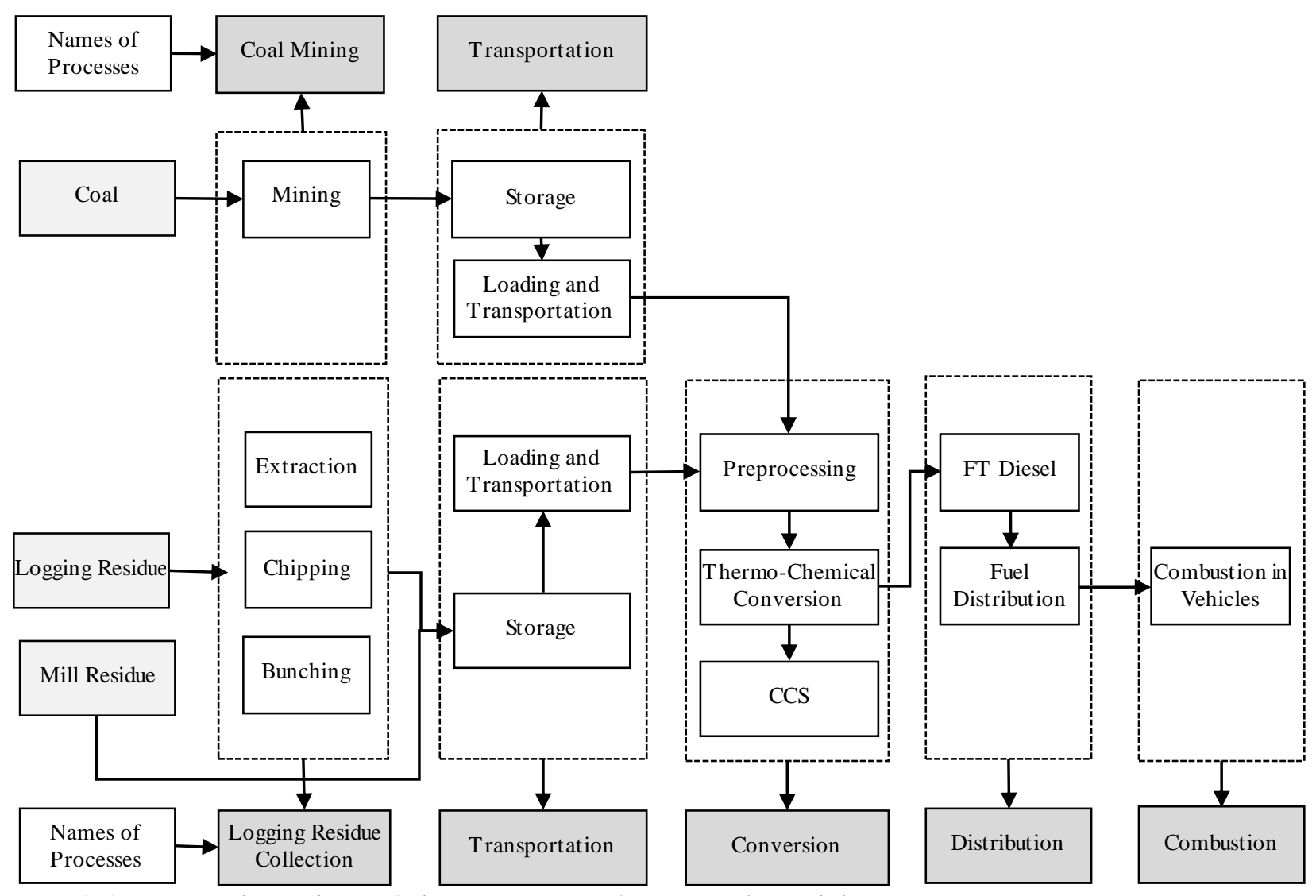

Fig. 3-3. System boundary of the CBTL LCA framework model.

\subsubsection{Life Cycle Impact Assessment}

The LCA model was developed by the environmental modeling tool SimaPro 8 (PRé Consultants 2011). The impact of GHG emissions was calculated using 100-year global warming potentials (Forster et al. 2007). All emissions were converted to $\mathrm{CO}_{2}$ equivalent ( $\mathrm{kg} \mathrm{CO}_{2} \mathrm{eq}$ ). The reduction of GHG emissions was calculated as the difference between the emissions from petroleum-derived-diesel and the emissions from coal and biomass derived liquid fuels. The 
calculation of blue water consumption (BWC: $\mathrm{kg}$ ) was done following Boulay et al.'s method (2011). Fossil energy consumption (FEC: MJ) was calculated based on Frischknecht et al.'s work (2007).

\subsubsection{Sensitivity Analyses}

Sensitivity analyses on RSP was conducted by changing price of coal and biomass, biomass to coal mix ratio, liquid fuel yield, plant capacity and internal rate of return (IRR). The price range of coal and biomass were $\$ 40$ ton $^{-1}-\$ 100$ ton $^{-1}$ and $\$ 40$ ton $^{-1}-\$ 140$ ton $^{-1}$, respectively. The liquid fuel yield ranged from 1.36 to $1.7 \mathrm{bbl} \cdot$ ton $^{-1}$ for biomass to liquid fuels and from 2.22 to $2.54 \mathrm{bbl} \cdot$ ton $^{-1}$ for coal (Edwards et al. 2011; Jiang and Bhattacharyya 2014, 2015; Liu et al, 2011; Wu et al. 2011). The energy efficiency ranged from 40\%-50\%. The liquid fuel yield for different mix ratio were linear combinations of liquid fuel yield of coal and biomass (Andre et al., 2005). The IRR was set to $20 \%$ and $10 \%$ to test its effect on RSP. The effects of $20 \%$ change of capital cost and operation and maintenance cost were studied. The sensitivity analysis of liquid fuel yield and mix ratio on GHG emissions was studied in the same way as on RSP. 


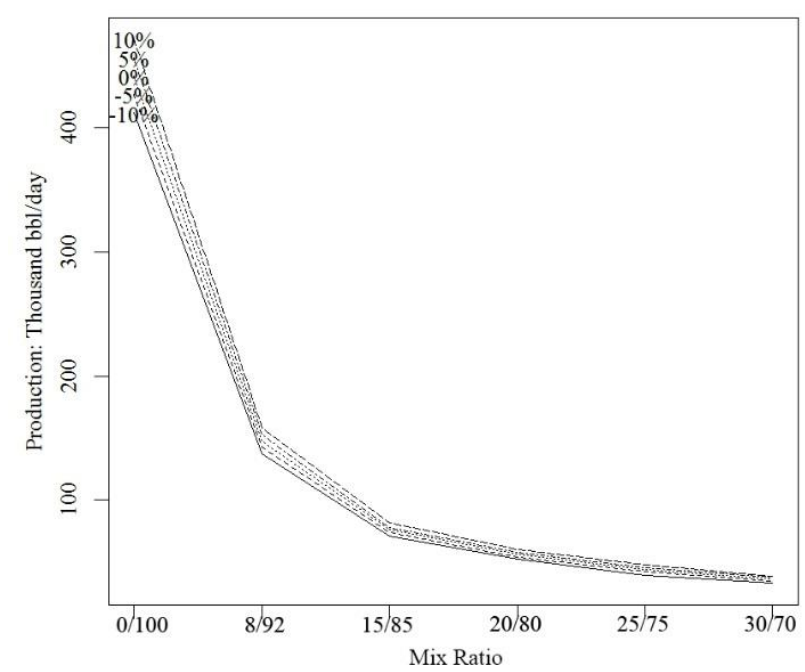

(a)

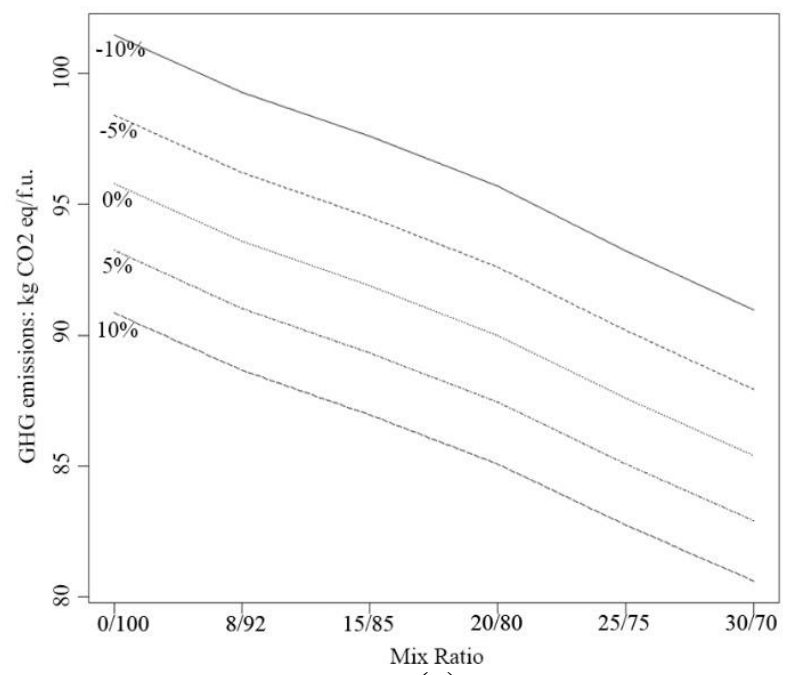

(c)

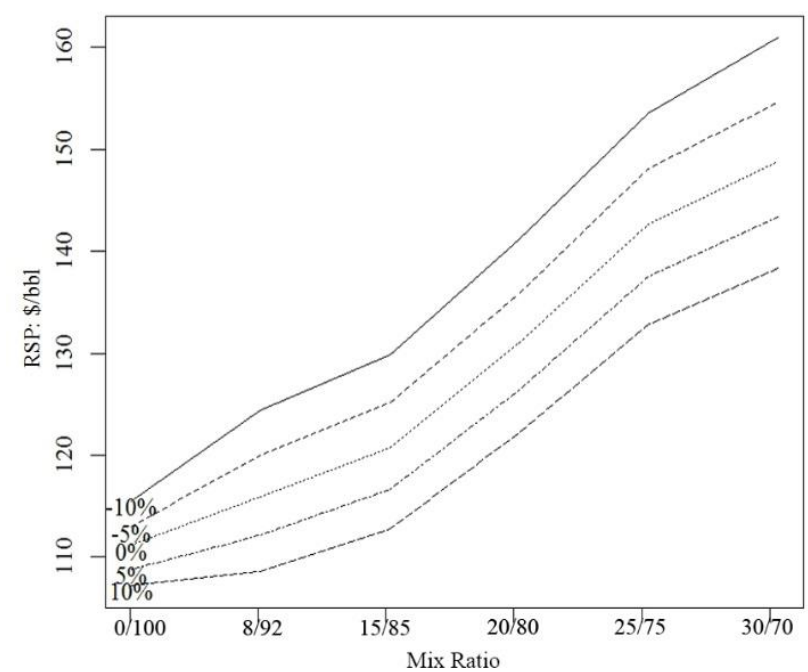

(b)

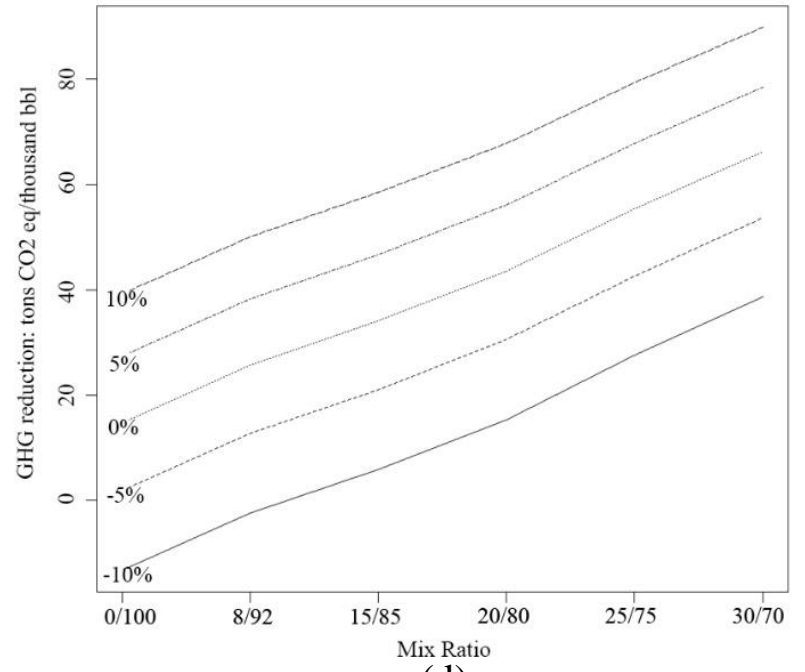

(d)

Fig. 3-4. Sensitivity analyses by liquid fuel yield and biomass to coal mix ratio for CBTL fuel production in thousand bbl/day (a); required selling price of CBTL fuels $\$ / b b l(b), G H G$ emission $\mathrm{kg} \mathrm{CO}_{2}$ eq/f.u. (c), and $\mathrm{GHG}$ reduction compared to petroleum derived diesel in thousand tons $\mathrm{CO}_{2}$ eq/year (d). 


\subsection{RESUltS}

\subsubsection{Plant Siting and Capacity}

The siting and capacity of a CBTL plant were typically determined by several major factors such as availability of feedstocks, infrastructure, and others. The total production of all open plants decreased with a decrease in liquid fuel yield and an increase in mix ratio (Fig. 3-4a). Differences among the various mix ratios showed a greater effect than that among the various liquid fuel yield. The highest production was 471,223 bbl/day (bpd) with highest liquid fuel yield and no biomass was mixed with coal. When the biomass to coal mix ratio was 30/70 and the liquid fuel yield a minimum, the overall production was 27,971 bpd.

A total of 22 potential CBTL plant site candidates were considered under different availability of feedstock, infrastructure and biomass to coal mix ratios. Most candidate sites were not suitable for CBTL plants. The number of CBTL plants, as well as their production, decreased

as the liquid fuel yield declines. In the case where the mix ratio was 8/92 and the liquid fuel yield changed from 2.473 to $2.151 \mathrm{bbl} \cdot$ ton $^{-1}$, the production changed from $157,805 \mathrm{bpd}$ to 137,261 bpd. Multiple plants were operated if the amount of available biomass increased and the capacity of plant did not increase.

\subsubsection{Economic Impact}

Cost analysis indicated that the purchase of coal and operational and maintenance cost accounted most of the total cost. In the base case (defined in Table 3-1), the purchase of coal accounted $60.7 \%$ of the total cost. Operational and maintenance cost accounted $17 \%$. The transportation of biomass cost more than purchasing them. When the mix ratio increased, which meant more biomass mixed with coal, the unit transportation cost of biomass became to decrease and unit transportation cost of coal increased. 
The RSP of liquid fuels was calculated based on all the cost components in the project. The RSP in the base case was $\$ 113.01$ bbl $^{-1}$ with a payback period of 7 years for the project. The RSP rose with the increase in the price of feedstock, where the RSP was calculated when the mix ratio was $8 / 92$ and the liquid fuel yield was $1.53 \mathrm{bbl} \cdot \operatorname{ton}^{-1}$ for biomass and $2.38 \mathrm{bbl} \cdot \operatorname{ton}^{-1}$ for coal. The effect of coal on RSP was more pronounced than that of biomass. The RSP was $\$ 91.9 \mathrm{bbl}^{-1}$ when the price of coal and biomass were $\$ 40 \cdot$ ton $^{-1}$. The RSP increased to $\$ 115.8 \mathrm{bbl}^{-1}$ when the price of coal was $\$ 100$ ton $^{-1}$, and increased to $\$ 94.7 \mathrm{bbl}^{-1}$ when the price of biomass was $\$ 100$ $\operatorname{ton}^{-1}$.

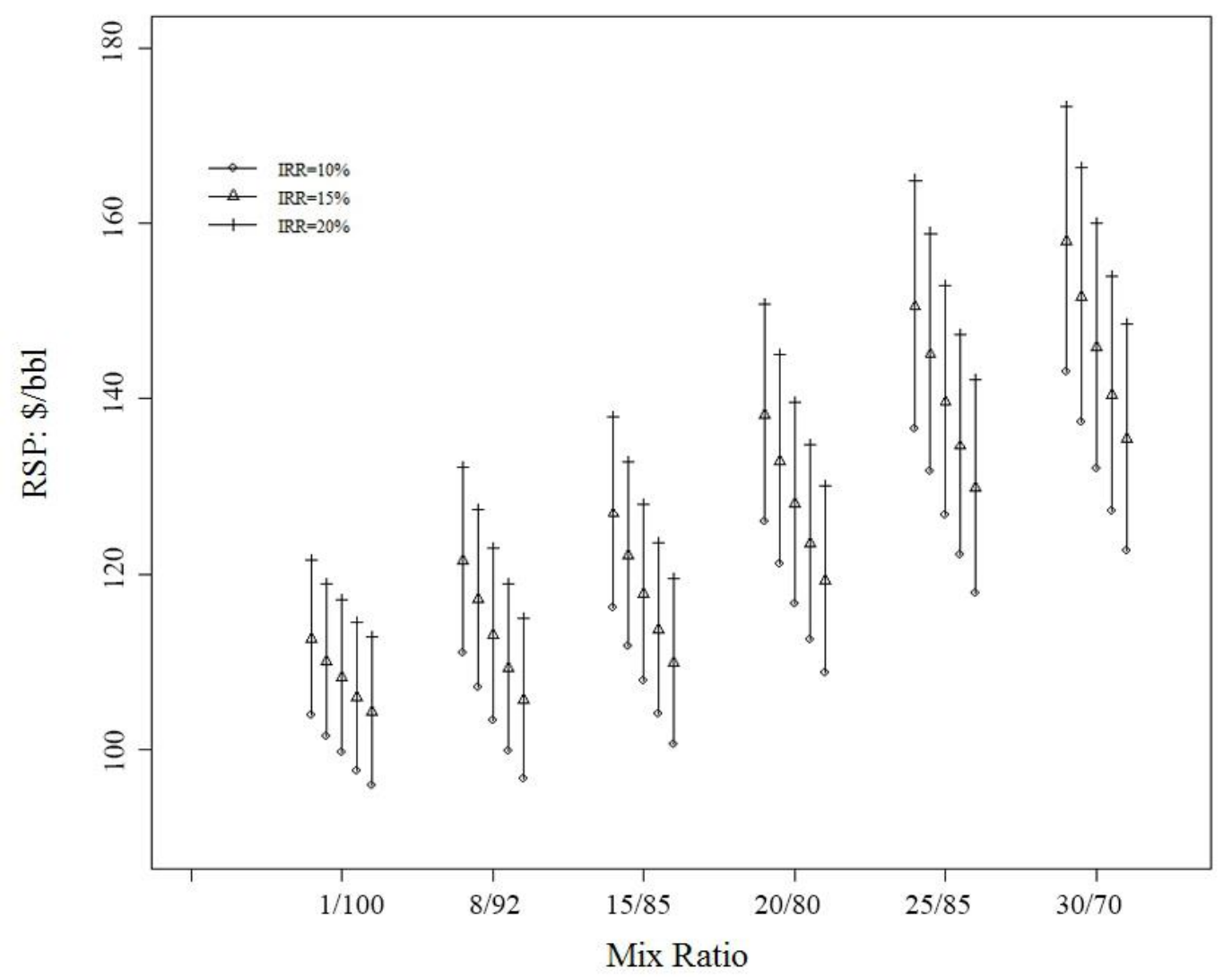

Fig. 3-5 Change of RSP based on different IRR at different mix ratio and liquid fuel yield. 
Table 3-2 Percentage change of RSP according change of capital cost and operation and

maintenance cost.

\begin{tabular}{crrrrrrrrrr}
\hline \multirow{2}{*}{$\begin{array}{c}\text { Mix } \\
\text { Ratio }\end{array}$} & \multicolumn{4}{c}{ Capital Cost } & \multicolumn{4}{c}{ Operation \& Maintenance } \\
\hline $0 / 100$ & $10.01 \%$ & $10.05 \%$ & $10.16 \%$ & $10.19 \%$ & $10.29 \%$ & $2.12 \%$ & $2.14 \%$ & $2.20 \%$ & $2.21 \%$ & $2.26 \%$ \\
$8 / 92$ & $10.75 \%$ & $10.96 \%$ & $10.96 \%$ & $11.14 \%$ & $11.14 \%$ & $2.09 \%$ & $2.15 \%$ & $2.15 \%$ & $2.21 \%$ & $2.21 \%$ \\
$15 / 85$ & $10.84 \%$ & $10.84 \%$ & $10.84 \%$ & $10.84 \%$ & $10.84 \%$ & $2.12 \%$ & $2.12 \%$ & $2.12 \%$ & $2.12 \%$ & $2.12 \%$ \\
$20 / 80$ & $11.30 \%$ & $11.30 \%$ & $11.30 \%$ & $11.30 \%$ & $11.30 \%$ & $2.04 \%$ & $2.04 \%$ & $2.04 \%$ & $2.04 \%$ & $2.04 \%$ \\
$25 / 75$ & $11.78 \%$ & $11.75 \%$ & $11.75 \%$ & $11.75 \%$ & $11.75 \%$ & $2.02 \%$ & $2.01 \%$ & $2.01 \%$ & $2.01 \%$ & $2.01 \%$ \\
$30 / 70$ & $11.97 \%$ & $11.97 \%$ & $11.97 \%$ & $11.97 \%$ & $11.97 \%$ & $1.93 \%$ & $1.93 \%$ & $1.93 \%$ & $1.93 \%$ & $1.93 \%$ \\
\hline
\end{tabular}

The RSP was $\$ 104.3 \mathrm{bbl}^{-1}$ when no biomass was used at the maximum liquid fuel yield when the prices of coal and biomass were same as the base case. The highest RSP was $\$ 157.9$ bbl $^{-1}$ when the mix ratio was $30 / 70$ with the minimum liquid fuel yield. The RSP kept increasing when more biomass was mixed with the coal and lower liquid fuel yield was assumed (Fig. 3-4b). When the mix ratio was low, the RSP changed with a change of liquid fuel yield than when more biomass was mixed. The reduction of IRR significantly reduced the RSP, especially when more biomass was mixed with coal (Fig. 3-5). The change in capital cost by $20 \%$ would change the RSP by $10 \%-12 \%$. The change in operation and maintenance cost by $20 \%$ would change the RSP by $1.93 \%-2.26 \%$. (Table 3-2).

Table 3-3. Process based environmental impact for the base case.

\begin{tabular}{lllllllll}
\hline \multirow{2}{*}{ Impact } & $\begin{array}{l}\text { Coal } \\
\text { Mining }\end{array}$ & $\begin{array}{l}\text { Transport- } \\
\text { Coal }\end{array}$ & $\begin{array}{l}\text { Residue } \\
\text { Collection }\end{array}$ & $\begin{array}{l}\text { Transport- } \\
\text { Residue }\end{array}$ & Conversion & Distribution & Combustion & Total \\
\hline \multirow{2}{*}{ GHG } & 12.6 & 0.1 & 0.17 & 0.06 & 17.17 & 0.64 & 62.86 & 93.6 \\
& $13.46 \%$ & $0.11 \%$ & $0.18 \%$ & $0.06 \%$ & $18.34 \%$ & $0.68 \%$ & $67.16 \%$ & $100 \%$ \\
& 0.632 & 0.838 & 0.0721 & 0.998 & 44.46 & 2.21 & 0.09 & 49.3 \\
BWC & $1.28 \%$ & $1.70 \%$ & $0.15 \%$ & $2.02 \%$ & $90.18 \%$ & $4.48 \%$ & $0.18 \%$ & $100 \%$ \\
& 1.05 & 1.31 & 0.101 & 1.639 & 34 & 0.584 & 0.016 & 38.7 \\
FEC & $2.71 \%$ & $3.39 \%$ & $0.26 \%$ & $4.24 \%$ & $87.86 \%$ & $1.51 \%$ & $0.04 \%$ & $100 \%$ \\
& & & & & & & &
\end{tabular}




\subsubsection{Environmental Impact}

There were seven major processes in the LCA model. For the base case, the GHG emissions, water and fossil energy consumption of each process and the percentage of their total amount of emission were shown in Table 3-3. Most emissions originated from the combustion in vehicles and thermos-chemical conversion, which contribute $62.86 \%$ and $17.17 \%$ to the overall GHG emissions, respectively. The portion of FT fuels derived from biomass was considered as carbon neutral. The emissions from $1,000 \mathrm{MJ}$ of products ranged from $80.62 \mathrm{~kg} \mathrm{CO}_{2}$ eq to $101.46 \mathrm{~kg}$ $\mathrm{CO}_{2}$ eq for various mix ratio and liquid fuel yield. The CBTL facility consumed over $80 \%$ of the water and fossil energy in the system.

Fig. 3-4c shows the GHG emissions at each mix ratio are a function of liquid fuel yield. GHG emissions are lower when more biomass is mixed with coal. Given the same mix ratio, more GHG emissions occur when the liquid fuel yield is low. The mix ratio and liquid fuel yield also affect the transportation distance of the feedstock, but the emissions due to transportation only account for a low percentage in the entire life cycle.

By producing FT liquid fuels, the total reduction in GHG emissions over 30 years is estimated to range from -162 to 555 million tons $\mathrm{CO}_{2}$ eq for various liquid fuel yield and mix ratios in our simulation (Fig. 3-4d). The reduction in emissions is calculated by considering the emissions due to production and combustion of the equal amount (in energy) of petroleumderived-fuel minus the emissions due to coal and biomass derived liquid fuels. 


\subsection{DISCUSSION}

\subsubsection{Feedstock Availability}

A constant growth of forest was simulated using the FVS over a relatively short term (i.e., 60 years). Wildfire was included in the simulation but its intensity was low and no other natural disturbance was simulated. This allowed a constant increment of the available biomass before the forests reach maturity. The availability of woody biomass could reach its peak as the timber production could not exceed the capacity of sawmills in our model. However, this availability of biomass could be changed due to other uncertain factors such as growth of short rotation woody crops on marginal agricultural land and abandoned mine land, natural disturbances or increment of carbon subsidies (Asante et al. 2011). There usually was abundant coal available in West Virginia. We had, in general, assumed that the supply of coal will not decline over the next 30 years. Coal was also easy to handle with and always have lower transportation cost than biomass.

\subsubsection{Siting and Capacity}

The optimal location of CBTL plants was based on a set of candidate locations and the availability of feedstock (Wu et al. 2011, Hartley 2014). Candidate location was selected by considering many criteria such as cost, environmental impact, site physical condition and human society (Wu et al. 2011, Hartley 2014). The best locations were those surrounded by coal mines since coal was the dominant feedstock for CBTL plants. When more biomass was mixed with coal, smaller CBTL plant was operated, and hauling distance of biomass was decreased and hauling distance of coal was increased. This is because biomass is difficult to handle with and cost more than coal in transport.

When only coal was used as feedstock to produce FT fuels, the total productivity was not limited by biomass and could be very high. When biomass was involved, production will decline 
because of limited biomass availability. The decision of operating one large scale plant or several small plants also depended on the capital and operational costs besides the distribution of feedstocks. Coal was more concentrated in Southern West Virginia than biomass. So if only coal was used as feedstock, the best location was the candidate location in Boone county.

\subsubsection{Costs and RSP}

The feasibility of CBTL is largely depended on the total costs. Costs were low when only coal was supplied as feedstock and increased when biomass was mixed with coal. This is because higher cost is always expected to handle biomass (Ruiz et al. 2013). The feasibility is also depended on the price of crude oil. Tarka (2009) shows that CBTL (with 30\% biomass or lower) was feasible when the price of crude oil was over $\$ 100 \mathrm{bbl}^{-1}$. As the average crude oil price in 2012 was $\$ 94 \mathrm{bbl}^{-1}$, CBTL could be feasible if the required internal rate of return is allowed to be lower than $10 \%$. But the low price of fossil fuels from the end of 2014 till date has made CBTL hard to compete with conventional petroleum-derived fuels (EIA 2015).

By changing the price of coal and biomass, our investigation showed close relationship of RSP and the price of feedstock. The price of coal had a more pronounced effect because coal is always the dominant feedstock in a CBTL plant. Because the price of coal for our investigation were higher than in previous studies and because we also considered lower liquid fuel yield, the RSP in our study could be higher than the feasible price. The liquid fuel yield is one important factor because this rate may vary due to coal type, tree species and other factors. The rise in the RSP did not linearly follow increases of mix ratio and decreases in liquid fuel yield. This is because the CBTL plant is operated under its capacity in some scenarios. So a more sophisticated biomass supply chain is needed to be developed and the improvement of conversion efficiency was required to reduce the high RSP of CBTL. IRR had significant effect on RSP especially 
when more biomass was mixed with coal because higher capital cost was usually required. Wu et al. (2011) assumed 5\% and 10\% change in capital cost which changed the RSP by $2 \%$ and 5\%, respectively. The results on the sensitivity of capital cost in this study were consistent with $\mathrm{Wu}$ et al.'s study (2011).

\subsubsection{LCA of CBTL}

This study showed that the major contribution to GHG emissions was from the thermochemical conversion of FT fuels and their final combustion in vehicles. The emissions released in land use changes were neglected because the candidate sites were selected from pre-existing industrial sites. We also did not consider the environmental impact of waste since the slag can be used as a concrete mix where it performs well (Slag Cement Association 2013). Differences in GHG emissions at the same mix ratio were caused by various liquid fuel yield. The location and size of CBTL plants had a direct influence on the distance for transporting feedstock. But this did not change the life cycle emissions to any great extent because transportation accounts for less than $0.5 \%$ of the overall emissions. The electricity required in conversion process was provided by waste heat and light hydrocarbons, so the fossil energy consumption was low in CBTL plant. But the water consumption could be high to generate power from coal.

When the liquid fuel yield increased, the reduction in GHG emissions to produce same amount of liquid fuels was higher because less coal and biomass were required. Improvements in the liquid fuel yield and capture of carbon dioxide can further benefit the environment, such as aggressive CCS is able to capture 95\% of the total emissions (Tarka 2009). But aggressive CCS will dramatically increase the cost (Jiang and Bhattacharyya 2015). The contribution of GHG emission reduction from biomass utilization may be overestimated because we did not include most natural disturbances, such as extreme weather, wild fire, insect and disease, which will 
disturb the growth of forest. The LCA model also will systematically underestimated environmental impact by ignoring some less important processes and information gap. High ratios of biomass was only preferred when biomass was abundant. This implied that the option of relatively lower amount of biomass in feedstock was chosen if high GHG emission reduction was expected when biomass availability was low.

\subsection{CONCLuSiOnS}

In this study, we analyzed the economic and environmental effect of coal and biomass utilization for production of liquid fuels. The location of CBTL facility preferred the site surround with coal mines. If there was abundant biomass and the biomass ratio in feedstock was low, large plant sizes should be selected and high overall liquid fuel production was expected. RSP was calculated by changing biomass to coal mix ratio, liquid fuel yield, price of coal and biomass, IRR, capital cost, and operational and maintenance costs. The price of feedstock directly affected RSP. Coal had more pronounced effect than biomass on RSP. RSP increased when more biomass was mixed and liquid fuel yield was low. Lower IRR could obviously reduce RSP. Thermo-chemical conversion and combustion in vehicles account for most GHG emissions. Most of blue water and fossil energy were consumed in conversion process at CBTL facility. The effects of biomass to coal mix ratio and liquid fuel yield on GHG emissions were assessed in this study. High biomass ratio in the feedstock will reduce the GHG emissions, but GHG emission reduction will also decline because of limited biomass availability. The improvement of liquid fuel yield consistently reduced the GHG emissions. 


\section{ACKNOWLEDGEMENT}

The authors would like to thank the US Department of Energy National Energy Technology Laboratory for providing funding support to this study (DE-FE0009997). We thank IBM for providing an academic version of the ILOG CPLEX solver. We are also grateful to few individuals for providing us data on biomass and coal.

\section{REFERENCES}

Andre, R.N., Pinto, F., Franco, C., Dias, M., Gulyurtlu, I., Matos, M.A.A., and Cabrita, I. 2005. Fluidised bed co-gasification of coal and olive oil industry wastes. Fuel 84(12-13): 16351644.

Asante, P., Armstrong, G.W., and Adamowicz, W.L. 2011. Carbon sequestration and the optimal forest harvest decision: A dynamic programming approach considering biomass and dead organic matter. Journal of Forest Economics 17(1): 3-17.

Baliban, R.C., Elia, J.A., and Floudas, C.A. 2010. Toward Novel Hybrid Biomass, Coal, and Natural Gas Processes for Satisfying Current Transportation Fuel Demands, 1: Process Alternatives, Gasification Modeling, Process Simulation, and Economic Analysis. Industrial \& Engineering Chemistry Research 49(16): 7343-7370.

Bartis, J.T., Camm, F.A., and Ortiz, D.S. 2008. Producing liquid fuels from coal: prospects and policy issues. Rand Corporation.

Bartis, J.T., and Van Bibber, L. 2011. Alternative fuels for military applications. DTIC Document. 
Bellman, D.K. 2007. Coal to liquids and Gas. Working Document of the NPC Global Oil and Gas Study. American Electric Power Co., Inc.

Board, T.S.S.E. 2006. Building a bridge to energy independence and to a sustainable energy future. The American Energy Security. Southern States Energy Board Norcross.

Boulay, A.M., Bulle, C., Bayart, J.B., Deschenes, L., and Margni, M. 2011. Regional Characterization of Freshwater Use in LCA: Modeling Direct Impact on Human Health. Environmental science \& technology 45(20): 8948-8957.

Boustead, I. 1996. LCA - How it came about - the beginning in the U.K. The International Journal of Life Cycle Assessment 1(3): 147-150.

Dixon, G.E. 2013. Essential FVS: A User's Guide to the Forest Vegetation Simulator. USDA Forest Service.

Edwards, R., Larivé, J.-F.o., and Beziat, J.-C. 2011. Well-to-wheels analysis of future automotive fuels and powertrains in the European context. European Commission Joint Research Centre, Institute for Energy and Transport.

EIA. Fossil fuel consumption for electricity generation by year, industry type and state [accessed $82013]$.

EIA. 2015. Gasoline and diesel fuel update. Available from http//www.eia.gov/petroleum/gasdiesel/ [accessed March 24 2015].

Forster, P., Ramaswamy, V., Artaxo, P., Berntsen, T., Betts, R., Fahey, D.W., Haywood, J., J., L., Lowe, D.C., Myhre, G., Nganga, J., Prinn, R., Raga, G., Schul, M., and Van Dorland, R. 2007. Changes in Atmospheric Constituents and in Radiative Forcing. In Climate 
change 2007-the physical science basis: Working group I contribution to the fourth assessment report of the IPCC. Edited by S. Solomon, D. Qin, M. Manning, Z. Chen, M. Marquis, K. B. Averyt, M. Tignor, and H. L. Miller. Cambridge University Press.

Frischknecht, R., Jungbluth, N., Althaus, H.-J., Hischier, R., Doka, G., Bauer, C., Dones, R., Nemecek, T., Hellweg, S., and Humbert, S. 2007. Implementation of life cycle impact assessment methods. Data v2. 0 (2007). Ecoinvent report No. 3. Ecoinvent Centre, Swiss Federal Laboratories for Materials Testing and Research (EMPA), Duebendorf (Switzerland).

Gray, D., White, C., and Tomlinson, G. 2007. Increasing security and reducing carbon emissions of the US transportation sector: a transformational role for coal with biomass.

Harris, L., Paduano, N. Raghuveer, T., Thapa, S. 2013. Annual coal report 2012. U.S. Energy Information Administration.

Hartley, D.S. 2014. Modeling and Optimization of Woody Biomass Harvest and Logistics in the Northeastern United States. WEST VIRGINIA UNIVERSITY, Morgantown, WV.

Höök, M., and Aleklett, K. 2010. A review on coal-to-liquid fuels and its coal consumption. International Journal of Energy Research 34(10): 848-864.

Hsu, D.D., Inman, D., Heath, G.A., Wolfrum, E.J., Mann, M.K., and Aden, A. 2010. Life cycle environmental impact of selected US ethanol production and use pathways in 2022. Environmental science \& technology 44(13): 5289-5297. 
Hunt, R.G., Franklin, W.E. 1996. LCA-How it came about-personal reflections on the origin and the development of LCA in the USA. International Journal of Life Cycle Assessment, 1(1):4-7.

ISO. 2006. Environmental Management: Life Cycle Assessment: Principles and Framework. International Organization for Standardization.

Jiang, Y., and Bhattacharyya, D. 2014. Plant-wide modeling of an indirect coal-biomass to liquids (CBTL) plant with CO2 capture and storage (CCS). International Journal of Greenhouse Gas Control 31: 1-15.

Jiang, Y., and Bhattacharyya, D. 2015. Modeling and Analysis of an Indirect Coal Biomass to Liquids Plant Integrated with a Combined Cycle Plant and CO2 Capture and Storage. Energy \& Fuels 29(8): 5434-5451.

Keesom, W., Unnasch, S., Moretta, J., and Consultancy, J. 2009. Life cycle assessment comparison of North American and imported crudes. Alberta Energy Research Institute.

Kerstetter, J.D., and Lyons, J.K. 2001. Logging and agricultural residue supply curves for the Pacific Northwest. Washington State University Energy Program.

Kumar, D., and Murthy, G.S. 2012. Life cycle assessment of energy and GHG emissions during ethanol production from grass straws using various pretreatment processes. International Journal of Life Cycle Assessment 17(4): 388-401.

Li, W., Men, Z., and Bu, Y. 2013. The momentum of Chinese-derived indirect coal-to-liquids technologies. Cornerstone 1(3): 49-53. 
Liu, G.J., Larson, E.D., Williams, R.H., Kreutz, T.G., and Guo, X.B. 2011. Making FischerTropsch Fuels and Electricity from Coal and Biomass: Performance and Cost Analysis. Energy \& Fuels 25: 415-437.

Marano, J.J., and Ciferno, J.P. 2001. Life-cycle greenhouse-gas emissions inventory for FischerTropsch fuels. Report Prepared for the US Department of Energy, Energy and Environmental Solution, LLC, Gaithersburg, MD, USA.

Murray, A.T. 1999. Spatial restrictions in harvest scheduling. Forest Science 45(1): 45-52.

Paul, A.D. 2009. A Fresh Look at Coal-Derived Liquid Fuels. Power 153(1): 46-51.

Ruiz, J.A., Juárez, M.C., Morales, M.P., Muñoz, P., and Mendívil, M.A. 2013. Biomass logistics: Financial \& environmental costs. Case study: $2 \mathrm{MW}$ electrical power plants. Biomass \& Bioenergy 56: 260-267.

SCA. Does slag cement change the hardened properties of concrete. Available from <http://www.slagcement.org/News/FAQ_HardenedProperties.html> [accessed 8 2014].

Sharma, B.D. 2010. Modeling of forest harvest scheduling and terrestrial carbon sequestration. West Virginia University.

Skone, T.J. 2011. Case Study: Interagency workgroup on life cycle GHG emissions of alternative aviation fuels. National Energy Technology Laboratory.

Tarka, T.J., Wimer, J.G., Balash, P.C., Skone, T.J., Kern, K.C., Vargas, M.C., Morreale, B.D., White III, C.W., and Gray, D. 2009. Affordable, low-carbon diesel fuel from domestic coal and biomass. In Proc. 25th Annual Pittsburgh Coal Conf., Pittsburgh, PA. 
Tennant, J.B. 2014. Overview of coal and coal-biomass to liquids (C\&CBTL) program. National Energy Technology Laboratory.

USDA. 2009. Timber Products Output Map Maker (Version 1.0). U.S. Department of Agriculture, Forest Service.

USGS. 2012. Download land cover data. Available from http•/gapanalysis.usgs.gov/gaplandcover/data/download/ [accessed June 4 2013].

Van Bibber, L., Thomas, C., and Chaney, R. 2007. Alaska coal gasification feasibility studiesHealy coal-to-liquids plant. National Energy Technology Laboratory (United States).

Wang, M. 2009. The GREET spreadsheet model: greenhouse gases and regulated emissions and energy use in transportation, Version 1.8 c. Center for Transportation Research, Energy Systems Division, Argonne National Laboratory.

Wu, J., Wang, J., and Strager, M.P. 2011. A Two-Stage GIS-Based Suitability Model for Siting Biomass-to-Biofuel Plants and its Application in West Virginia, USA. International Journal of Forest Engineering 22(2): 28-38.

Wu, J.Z., Wang, J.X., Cheng, Q.Z., and DeVallance, D. 2012. Assessment of coal and biomass to liquid fuels in central Appalachia, USA. International Journal of Energy Research 36(7): 856-870. 


\section{Economic and Life Cycle Analyses of SMall-Scale WOODY BIOMASS UTILIZATION FOR BIOENERGY

\author{
Products $^{3}$
}

\footnotetext{
${ }^{3}$ Prepared for International Journal of Forest Research.
} 


\section{Abstract}

A mixed integer linear programming (MILP) model and life cycle assessment (LCA) model were developed to analyze economic and environmental benefits by utilizing forest residues for small scale production of bioenergy in West Virginia. The MILP was developed to optimize the costs and required selling price of biofuels under different strategies. The cradle-togate LCA was developed to examine the greenhouse gas emissions, blue water and fossil energy consumption associated with the biomass utilization. The RSP in base case was $\$ 90.87 / \mathrm{bbl}$ ethanol and $\$ 126.08 / \mathrm{bbl}$ for diesel and gasoline. The sensitivity analysis on RSP showed that liquid fuel yield had most prominent effect and followed by internal rate of return (IRR) and feedstock price. The LCA showed that the GHG emissions from the production of 1,000 MJ energy equivalent ethanol was $9.72 \mathrm{~kg} \mathrm{CO} 2 \mathrm{eq}$ which was lower than fast pyrolysis $(9.72 \mathrm{~kg}$ $\mathrm{CO} 2$ eq). Fast pyrolysis had high water and energy consumption. The uncertainty analysis showed the change of environmental impact by the change of liquid fuel yield. The risk of biomass to liquid via fast pyrolysis (BLFP) to have a negative energy output was expected when the liquid fuel yield was low. The production of ethanol required lower cost and had lower environmental impact, that is to say, the costs for reducing $1 \mathrm{~kg} \mathrm{CO} 2$ eq GHG emissions was low in biomass to ethanol (BTE), but more biomass was required to produce same amount of energy equivalent liquid fuels. 


\subsection{INTRODUCTION}

Biomass is a carbon neutral energy resource which can be utilized as a feedstock for bioenergy and bioproducts and has a great potential to reduce the carbon emissions from fossil fuels. The interest in the use of cellulosic biomass as feedstock for biofuels has been increased to reduce energy dependence on fossil fuels. As one of the largest unexploited sources of cellulosic biomass, woody biomass is identified as a potentially important feedstock for biofuels (Perlack et al. 2005). Current biofuels are typically converted from energy crops which require change of land covers and introduce carbon debt that needs a considerable amount of time to pay back (Fargione et al. 2008). Woody biomass is given high priority to produce biofuels in terms of effectively managing land cover changes and carbon emissions. There are several pathways to convert biomass to biofuels or bioproducts, including biomass-to-ethanol (BTE) and biomass to liquids via fast pyrolysis (BLFP). Many analyses have been conducted on these approaches in terms of economic analysis and environmental or life cycle assessments.

Ethanol is one of the biofuels which currently widely produced in the United States, 10.8 billion gallon of ethanol was produced in 2009 (Renewable Fuels Association Statistics 2014) and most of them were from corn grain (Gecan and Johansson 2010). The production of ethanol has increased to 13.3 billion gallon in 2013 (Renewable Fuels Association Statistics 2014). The required selling price (RSP) of ethanol from biomass was around \$1.00/gal (Gnansounou and Dauriat 2010). Phillips et al. (2007) studied the hybrid poplar chips to ethanol and reported a RSP of $\$ 1.07 /$ gal. An estimation of the global ethanol program cost target in 2012 showed \$1.49/gal in US\$ of 2007 (EIA 2009). The Economic Research Service (2015) summarized a historical survey of corn derived ethanol showed that the price of ethanol was peaked in 2006 (\$3.58/gal) and reduced to $\$ 1.67 /$ gal in 2015 . The average price was $\$ 1.91 /$ gal from 2005 to 
2015. Kocoloski et al. (2010) indicated that larger facilities would be able to decrease ethanol cost by $\$ 0.20-0.30 /$ gal by analyzing the impact of facility size and location on ethanol cost. Although the improvement of biomass derived liquid fuel production, the low price of fossil fuels from the end of 2014 till date has made biomass derived liquid fuel hard to compete with conventional petroleum-derived fuels (EIA 2015).

Fast pyrolysis is a good approach to produce reliable higher energy density liquid fuels from biomass. The energy density of pyrolysis-derived diesel and gasoline can be $40.6 \mathrm{MJ} / \mathrm{kg}$ and $42.3 \mathrm{MJ} / \mathrm{kg}$, respectively (Wang 2009). In fast pyrolysis, biomass is quickly heated to $400^{\circ} \mathrm{C}$ to $500^{\circ} \mathrm{C}$ in the absence of oxygen and the biomass decomposes very rapidly. Dark brown liquid fuel is generated after cooling and condensation of the pyrolysis vapours (Bridgwater 2012; Hsu 2012). The liquid fuel needs to be upgraded by hydrotreating and hydrocracking before using as transportation fuels (Augustínová et al. 2013). The pyrolysis-derived-liquid fuels also can be blended with petroleum-derived-liquid fuels and filled in passenger vehicle. Some economic analysis conducted in recent years found that these biofuels had economic advantages to compete with other alternative fuels and the estimated costs ranged from $\$ 0.40 /$ gal to $\$ 3.07 /$ gal (Ringer et al. 2006; Wright et al. 2010).. A review of recently techno-economic analysis on fast pyrolysis found the RSP changed from $\$ 1.93-\$ 3.70 /$ gal of gasoline equivalent (Brown 2015).

Life cycle assessments (LCA) were conducted separately to analyze environmental impact of biomass utilization. Kumar and Murthy found $15 \mathrm{~kg}$ to $57 \mathrm{~kg} \mathrm{CO}_{2}$ eq GHG emissions and $57 \%-113 \%$ reduction in fossil energy consumption to produce $1,000 \mathrm{MJ}$ of ethanol from grass straws (2012). The LCA study of biodiesel from rapeseeds showed that the climate change potential was 73\% lower than petroleum derived diesel (Herrmann et al. 2013). The study of different agricultural feedstock (corn stover, sugarcane and sugar beet) to produce ethanol showed a reduction of GHG emissions from $46 \%$ to $65 \%$ compared to fossil based ethanol 
(Munñz et al. 2013). However, because ethanol has lower energy density which is $26.8 \mathrm{MJ} / \mathrm{kg}$ (Edwards et al. 2011) and the possible damage of engine (Lavelle 2010), the manufacturers have no willing to increase the blending percentage of ethanol. Hertel et al. (2010) also argued that the change of land use may eliminate the benefit of ethanol on global warming. The lab research of fast pyrolysis generally brings more reduction in GHG emissions comparing to ethanol. Fan et al. (2011) studied the GHG emissions for pyrolysis oil to generate electricity and found it can saving $77 \%-99 \%$ of GHG emissions relative to fossil fuels combustion. GHG emissions could be reduced 56-77\% from pyrolyzed biofuels compared to fossil fuels (Snowden-Swan and Male 2012, Hsu 2012).

Located in the central Appalachian region, West Virginia is the third most heavily forested state in the U.S. and can produce roughly 2.5 million dry tons of biomass annually. This biomass resource can definitely be used as a feedstock for biofuels or bioproducts to benefit the environment. There appears a necessity to analyze the economic and environmental impact of increased woody biomass utilization at a regional scale. The objectives of this study were to: (1) develop an economic model to optimize and analyze the conversions of forest residues to bioenergy through both biological and thermos-chemical pathways; (2) develop LCA model to analyze the environmental impact of biomass utilization.

\subsection{MATERIALS AND MethodS}

\subsubsection{Study Area and Feedstock}

This study area is located in West Virginia, of the United States with more than $80 \%$ of total land area covered with forest. The total forest area in West Virginia is 4.9 million hectares and $98 \%$ of them are timber land. The annual yield of wood residue is approximately 2.19 
million dry tons in this region according to the timber products output by the US Department of Agriculture (USDA TPO 2009). This biomass resource can be utilized as a feedstock for BTE and BLFP of up to 10,000 barrels per day, respectively.

\subsubsection{Economic Modeling}

\subsubsection{Feedstock handling costs}

The availability of forest residues was derived from the Bioenergy Knowledge Discovery Framework (KDF) by U.S. Department of Energy. The monthly availability of biomass (from Jan. to Dec.) was assumed to be $8.3,8.3,8.3,8.3,7.5,7.5,7.5,7.5,9.2,9.2,9.2$ and $9.2 \%$ of the yearly available forest residues. The logging residue availability was based on the historic harvest activities and the impact of monthly precipitation on the accessibility to harvested sites in West Virginia (US DOS 2014). The stumpage price of logging residue was set to be $\$ 2$ dry ton ${ }^{-1}$ as average price for the base case in spite some logging residue could be free from land owners. Grapple skidder-chips system was used to collect logging residues. The harvest costs were $\$ 13.19$ dry ton ${ }^{-1}$ according to $\mathrm{Wu}$ et al. (2012). It was assumed that $65 \%$ of total logging residue was economically available. The purchase costs of mill residue were assumed to be $\$ 50$ dry ton${ }^{1}$. It was also assumed that $40 \%$ of total mill residue in sawmill was economically available. The round-trip transportation costs for logging residue and wood chips are $\$ 0.23$ dry ton ${ }^{-1} \cdot \mathrm{km}^{-1}$ and $\$ 0.15$ dry ton ${ }^{-1} \cdot \mathrm{km}^{-1}$ respectively (Kerstetter and Lyons 2001). 
Table 4-1. Configurations of case scenarios of biomass to ethanol and biomass to liquids via fast pyrolysis.

\begin{tabular}{|c|c|c|c|c|}
\hline $\begin{array}{l}\text { Conversion } \\
\text { pathways }\end{array}$ & Parameters & Base case & $\begin{array}{l}\text { Sensitivity and } \\
\text { uncertainty }\end{array}$ & References \\
\hline \multirow{2}{*}{$\begin{array}{l}\text { Biomass to } \\
\text { ethanol }\end{array}$} & Liquid fuel yield: bbl·ton ${ }^{-1}$ & 1.99 & $1.7-2.1$ & Hsu et al. 2010; Wang, 2009. \\
\hline & Conversion Method & Fermentation & & \\
\hline \multirow{11}{*}{$\begin{array}{l}\text { Fast pyrolysis } \\
\text { derived liquid } \\
\text { fuels }\end{array}$} & Liquid fuel yield: bbl.ton ${ }^{-1}$ & 2.44 & $1.95-2.6$ & Hsu 2012. \\
\hline & Conversion Method & Pyrolys is & & \\
\hline & Price of logging residues & $\$ 1 /$ dry ton & & Wu et al. 2012 \\
\hline & Price of sawmill residues & $\$ 50 /$ dry ton & & \\
\hline & Plant life & 30 years & & \\
\hline & Operating time & $\begin{array}{l}350 \\
\text { days/year }\end{array}$ & & \\
\hline & Internal Rate of Return & $15 \%$ & & \\
\hline & Equity proportion (\%) & 40 & & \\
\hline & Cost of Equity (\%) & 15 & & \\
\hline & Cost of Debt (\%) & 8 & & \\
\hline & Federal tax $(\%)$ & 40 & & \\
\hline \multirow{3}{*}{$\begin{array}{l}\text { Energy density } \\
\text { (HHV } \mathrm{MJ} / \mathrm{kg} \text { ) }\end{array}$} & Ethanol & 26.8 & & WTT Report 2011 \\
\hline & $\begin{array}{l}\text { Fast Pyrolysis derived } \\
\text { diesel }\end{array}$ & 40.6 & & Wang 2009 \\
\hline & $\begin{array}{l}\text { Fast Pyrolysis derived } \\
\text { gasoline }\end{array}$ & 42.3 & & Wang 2009 \\
\hline
\end{tabular}

\subsubsection{Economic Model Development}

This economic model is to maximize the total profit of biofuel production. In the base case, the capacity, liquid fuel yield, and other parameters are listed Table 4-1. The total costs include feedstock harvest, purchase, transportation, storage, facility construction and operation \& maintenance. Capital costs of different plant capacities were adjusted from a study by Kocoloski 
et al. (2011) for BTE and a study by Shackley et al. (2011) for BLFP. The siting of the bioenergy candidate plants (Fig. 4-1) was optimized by Wu et al. (2011, 2012) and Hartley (2014). The plant life was assumed to be 30 years. The distances between the sites of residues and the candidate locations of bioenergy product plants were calculated based on the 2010 road network downloaded from the U.S. Census Bureau's TIGER/Line Shape files. In this study, a 15\% internal rate of return on equity was assumed for the base case. The RSP for two conversion pathways was calculated based on the total costs and internal rate of return on equity.

The objective function of the mixed integer linear programming model consists of two major components (total revenue and total cost), which is expressed as follows (The definitions and configurations of variables and parameters considered in the model are in Appendix C):

$\operatorname{Max} z=R v-T C$

Where:

$$
\begin{aligned}
& R v=P \cdot \operatorname{cov} \cdot \sum_{j=1}^{J} \sum_{m=1}^{12} x P_{j m} ; \\
& T C=F+O M+\zeta \cdot T P C \\
& \zeta=\psi \cdot\left[\frac{q^{N+p}-1}{(q-1) \cdot q^{N+p}}-\frac{q^{p}-1}{(q-1) \cdot q^{p}}\right]^{-1} ; \\
& q=(1+W A C C) \cdot(1+r) ; \\
& W A C C=w_{e} \cdot R_{e}+\left(1-w_{e}\right) \cdot R_{d} \cdot\left(1-f_{t}\right) ; \\
& O M=\sum_{j=1}^{J} \sum_{l=1}^{L} y_{j l} \cdot o m_{l}
\end{aligned}
$$


$T P C=\sum_{j=1}^{J} \sum_{l=1}^{L} y_{j l} \cdot t p c_{l}$

S. t.:

$$
\begin{aligned}
& F=\sum_{i=1}^{I} \sum_{j=1}^{J} \sum_{m=1}^{12}\left(H C+P C L+T C L \cdot D_{i j}+L D L\right) \cdot x L_{i j m} \\
&+\sum_{i=1}^{I} \sum_{j=1}^{J} \sum_{m=1}^{12}\left(P C M+T C M \cdot D_{i j}+L D M\right) \cdot x M_{i j m}+\sum_{j=1}^{J} \sum_{m=1}^{12} x S_{j m} \cdot S C ;(4-9)
\end{aligned}
$$

$$
\sum_{l=1}^{L} y_{j l} \leq 1, \forall j ;
$$

$\sum_{j=1}^{J} x L_{i j m} \leq A L_{i m}, \forall i, m$

$\sum_{j=1}^{J} x M_{i j m} \leq A M_{i m}, \forall i, m ;$

$\sum_{i=1}^{I}\left(x L_{i j m}+x M_{i j m}\right)+x S_{j, m-1}-x P_{j m}-x S_{j m}=0, \forall j, m ;$

$x P_{j m}=\sum_{l=1}^{L}\left(y_{j l} \cdot R B_{l}\right), \forall j, m ;$

$x S_{j 0}=0, \forall j$

$x P_{j m}, x L_{i j m}, x M_{i j m}, x S_{j m} \geq 0, \forall j \in J, \forall i \in I, \forall m \in\{1, \ldots, 12\}$.

$y_{j l}=\left\{\begin{array}{l}1, \text { if plant } j \text { is operated in level } l, \\ 0, \text { otherwise. }\end{array}\right.$

Expressions $(4-2)-(4-8)$ compute the total revenue $(R v)$, total costs $(T C)$, amortization factor $(\zeta)$, weighted average cost of capital (WACC), operation and maintenance costs $(O M)$, and 
total capital costs (TPC), respectively. Equation (4-9) calculates the handling costs of feedstock including feedstock purchase cost, harvest, transport, loading and storage. Constraints (4-10) are to ensure that a candidate site can only have at most one facility and only be operated in one of certain capacity. Constraints (4-11) and (4-12) impose that the amount of feedstock transported from a supply location cannot be greater than the total available amount at that location. Constraints (4-13) balance the storage at a bioenergy product facility. The amount of biomass being transported to a facility plus the storage from previous period should be equal to the biomass processed and stored in this time period. Equations (4-14) initialize the amount of biomass being processed at each time period at each facility. Equations (4-15) ensure no storage before the facility is opened.

All the models were solved using the IBM ILOG CPLEX 12.2, academic version on a computer with $16 \mathrm{~GB}$ memory and $1.8 \mathrm{GHz} 8 \mathrm{CPU}$. Required programs to implement the model were written in JAVA and 5000 seconds was set as a time limit of solution convergence.

\subsubsection{Life Cycle Assessment}

\subsubsection{Scope definition}

The cradle-to-gate life cycle assessment included feedstock collection, transportation, preprocessing and storage, liquid fuel production, distribution, final usage and waste disposal in terms of GHG emissions, blue water consumption, and fossil fuel consumption (Fig. 4-1). The functional unit (f.u.) of the biomass supply chain system was 1,000 MJ of biofuel produced. 


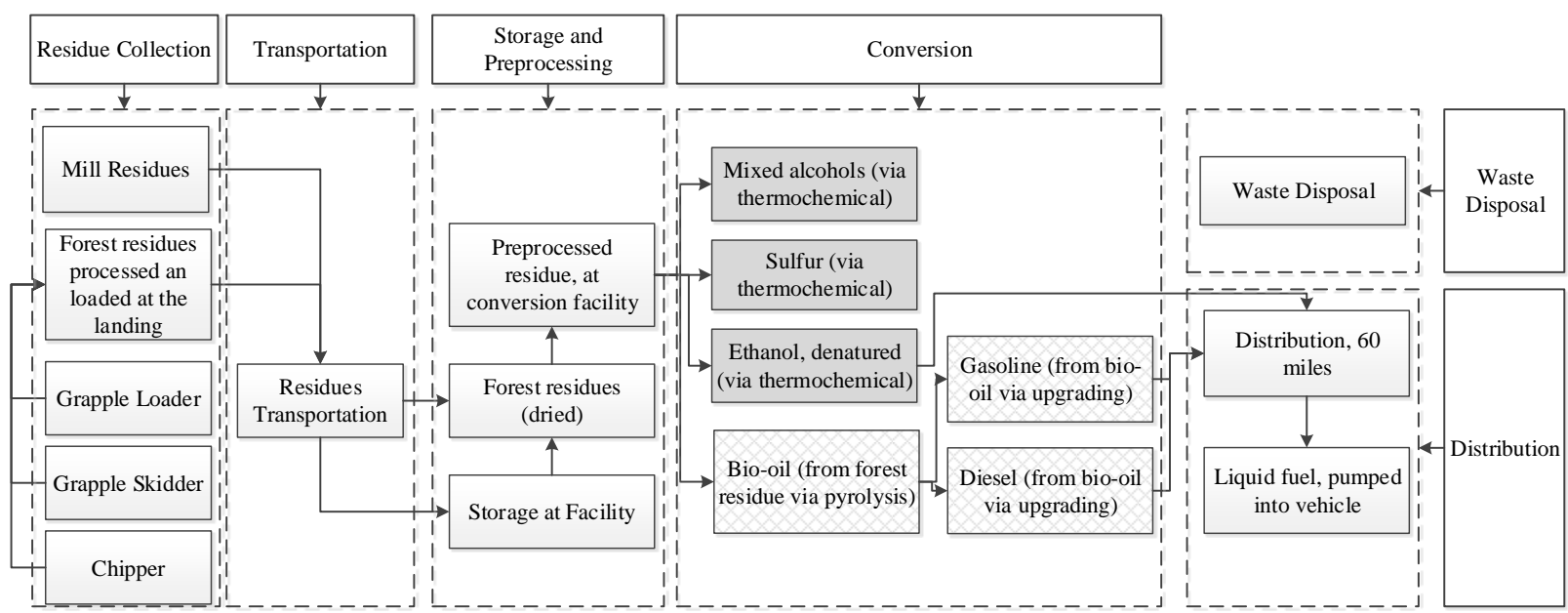

Process only included in Ethanol

Process only included in Fast Pyrolysis

Fig. 4-1. System boundary of LCA model for biomass to bioenergy products.

\subsubsection{Life cycle inventory}

Feedstock collection included the collection of logging and mill residues. Specifically, logging residue was collected using mechanized harvesting system and chipped on site. The fuel consumption of this harvest system was based on Wu et al.'s study (2012). Data on transportation process were primarily adapted from the US LCI database. The liquid fuel yield of BTE and BLFP were adjusted according to Hsu's studies $(2010,2012)$, respectively. A hauling distance of $100 \mathrm{~km}$ was used in the base case as an average transportation distance from bioenergy plant to refueling station (Marano and Ciferno 2001). The liquid fuels were finally combusted in a flex-fuel passenger car (GREET 1.8c). All the other background processes were based on the processes defined in Ecoinvent 2.2. The GHG emissions of $98.8 \mathrm{~kg} \mathrm{CO}_{2}$ eq per 1,000 MJ for petroleum-derived-diesel were used as a base reference for comparisons (Keesom and Unasch, 2009). All the detailed processes were in Appendix C. 


\subsubsection{Impact Assessment}

The environmental impact of each process were assessed using the environmental modeling tool SimaPro v8 (PRé Consultants 2011). The impact of GHGs was calculated using 100-year global warming potentials (Forster et al. 2007). All the emissions were converted into the carbon dioxide equivalent amount $\left(\mathrm{kg} \mathrm{CO}_{2} \mathrm{eq}\right)$. The reduction of $\mathrm{GHG}$ emissions was calculated as the difference between the emissions from petroleum-derived-diesel and the emissions from liquid fuels produced using BTE and BLFP. The calculation of blue water consumption (BWC: kg) was based on the method by Boulay et al. (2011). Fossil energy consumption (FEC: MJ) was calculated based on Frischknecht et al. (2007). The economic input/output LCA (EIO-LCA) model was also examined on the processes based LCA model to estimate the overall environmental impact of the biomass utilization (Suh 2004, Jiang et al. 2011, Cooper et al. 2013). An input-output matrix of physical flows $\boldsymbol{A}$ was created for each pathway. This matrix indicated quantitative relationship between each two processes. The environmental impact (GHG, BWC, FEC) for each process was represented as a row vector $\boldsymbol{b}$ which was derived from SimaPro based on the functional unit. The total demand of each processes was represented as a column vector $\boldsymbol{y}$. Amount of liquid fuel in $\boldsymbol{y}$ was given based on the functional unit and all the other processes in $\boldsymbol{y}$ was set to zero. The total life cycle environmental impact $(E)$ was calculated by:

$E=b A^{-1} y$

\subsubsection{Sensitivity Analysis}

Sensitivity analyses on RSP and environmental impact were conducted according to feedstock price of biomass, liquid fuel yield, plant capacity and internal rate of return (IRR) 
(Table 4-1). The delivery cost of biomass was examined by changing from $\$ 40 /$ dry ton $\$ 140 /$ dry ton. Sensitivity analyses of liquid fuel yield were conducted by testing the maximum and minimum liquid fuel yield. The IRR was set from $10 \%$ to $20 \%$ to test its effect on RSP. The Monte Carlo uncertainty analysis for environmental impact focused on the liquid fuel yield. Triangular distribution was assumed on each liquid fuel yield according to Hsu's studies (2010, 2012). A total of 1,000 random trials were conducted to study the effect of uncertainty.

\subsection{RESUlts}

\subsubsection{Production and Required Selling Price of Biofuels}

Three and seven small scale facilities can be supported for BTE and BLFP, respectively (Table 4-2). The production for both BTE and BLFP was at 10,000 bpd. The biomass consumption as feedstock was at 1.91, 1.95 million dry tons for BTE, BLFP, respectively. The procurement radius of forest residues were slightly longer for producing ethanol than for diesel and gasoline. Among the cost components, the operation and maintenance accounted for $30.4 \%$ $38.8 \%$ of the total cost, and it was followed by feedstock handling costs $(35.8 \%-37.8 \%)$. The RSP of ethanol $(\$ 90.87 / \mathrm{bbl})$ was lower than that of diesel and gasoline, but the energy based RSP of ethanol was higher.

Table 4-2. Computational results from the economic model.

\begin{tabular}{|c|c|c|c|c|c|c|}
\hline \multirow{2}{*}{ Technology } & \multicolumn{2}{|c|}{$\begin{array}{l}\text { Average transportation distance } \\
\text { of feedstock (km/ton) }\end{array}$} & \multirow{2}{*}{$\begin{array}{l}\text { \# of } \\
\text { facilities }\end{array}$} & \multirow{2}{*}{$\begin{array}{l}\text { Productivity: } \\
\text { (bbl/day: bpd) }\end{array}$} & \multirow{2}{*}{$\begin{array}{l}\mathrm{RSP} \\
(\$ / \mathrm{bbl})\end{array}$} & \multirow{2}{*}{$\begin{array}{l}\text { RSP } \\
(\$ / 1,000 \mathrm{MJ})\end{array}$} \\
\hline & Logging residue & Mill residue & & & & \\
\hline BTE & 86.928 & 73.824 & 3 & 10,437 & 90.87 & 38.06 \\
\hline BLFP & 71.952 & 67.408 & 7 & 13,048 & 126.08 & 21.95 \\
\hline
\end{tabular}


Sensitivity analyses were conducted according to the price of feedstock, liquid fuel yield and IRR (Fig. 4-2). The biomass price affected the RSP of both BTE and BLFP. An increase of $10 \%$ delivered cost of biomass would increase the RSP by $2.68 \%$ and $1.57 \%$ for BTE and BLFP, respectively. The liquid fuel yield was a factor that affected the overall costs and RSP. The RSP would reduce $5.98 \%$ for BTE and $6.94 \%$ for BLFP if the liquid fuel yield would be improved $10 \%$. A required IRR of $15 \%$ was set in base case. A change of IRR to $10 \%$ or $20 \%$ would reduce or increase the RSP up to $9.26 \%$ or $10.50 \%$ for BTE and $8.65 \%$ or $9.57 \%$ for BLFP, respectively.

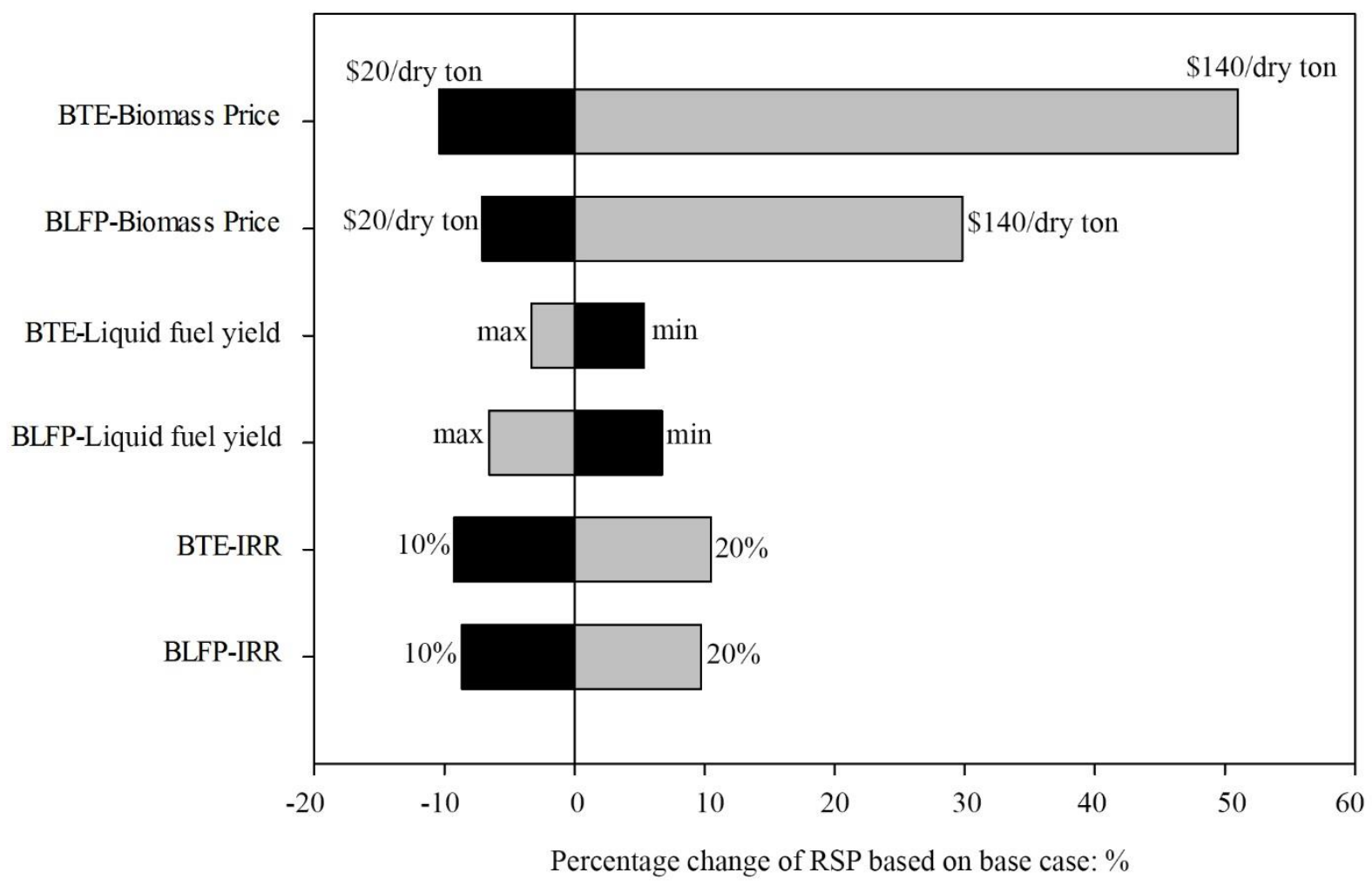

Fig. 4-2. Sensitivities of feedstock price, liquid fuel yield, IRR on RSP.

\subsubsection{Environmental Impact}

The GHG emissions of BTE were lower than that of BLFP. Most of the GHG emissions in BTE were accounted in biomass collection and transportation processes. The conversion 
process accounted most of the GHG emissions in BLFP (80.26\%). For the same amount of energy equivalent liquid fuel produced, the BLFP consumed higher amount of water and fossil energy. The processes of transportation, storage and preprocessing and conversion together accounted for more than $80 \%$ of the total water or fossil fuel consumptions. Table $4-3$ also showed the analysis of biogenic GHG emissions from the biomass to liquid fuels system. The biogenic GHG emissions were very high in BTE and BLFP. Almost all the emissions were from conversion process.

Table 4-3. Environmental impact of LCA by bioenergy products and processes.

\begin{tabular}{|c|c|c|c|c|c|c|c|c|}
\hline \multirow{2}{*}{$\begin{array}{l}\text { Bioenergy } \\
\text { product }\end{array}$} & \multirow{2}{*}{$\begin{array}{l}\text { Impact } \\
\text { Factors }\end{array}$} & \multicolumn{6}{|c|}{ LCA impact of each process, $\%$} & \multirow[b]{2}{*}{ Total } \\
\hline & & $\begin{array}{l}\text { Feedstock } \\
\text { Collection }\end{array}$ & Transportation & $\begin{array}{l}\text { Storage and } \\
\text { Preprocessing }\end{array}$ & Conversion & Distribution & $\begin{array}{l}\text { Waste } \\
\text { Disposal }\end{array}$ & \\
\hline \multirow{4}{*}{ Ethanol } & GHG & 28.41 & 45.18 & 8.92 & 13.09 & 4.02 & 0.38 & 9.72 \\
\hline & BWC & 2.07 & 54.56 & 9.63 & 32.02 & 1.23 & 0.49 & 254.61 \\
\hline & FEC & 0.72 & 12.87 & 10.29 & 75.01 & 0.81 & 0.3 & 125.24 \\
\hline & $\begin{array}{l}\text { Biogenic } \\
\text { GHG }\end{array}$ & 0 & 0.02 & 0 & 99.98 & 0 & 0 & 190 \\
\hline \multirow{4}{*}{$\begin{array}{l}\text { Pyrolyzed } \\
\text { fuel }\end{array}$} & GHG & 6.41 & 10.15 & 2.17 & 80.26 & 0.96 & 0.05 & 30.5 \\
\hline & BWC & 0.3 & 8.18 & 1.41 & 89.79 & 0.28 & 0.04 & 711.72 \\
\hline & FEC & 0.18 & 3.18 & 2.54 & 93.95 & 0.11 & 0.04 & 589.13 \\
\hline & $\begin{array}{l}\text { Biogenic } \\
\text { GHG }\end{array}$ & 0 & 0.03 & 0 & 99.97 & 0 & 0 & 68.59 \\
\hline
\end{tabular}

Table 4-4. Efficiency of reduction of $1 \mathrm{~kg} \mathrm{CO}_{2}$ eq $\mathrm{GHG}$ emissions.

\begin{tabular}{lrr}
\hline & BTE & BLFP \\
\hline Cost, \$ & 0.48 & 0.95 \\
Fossil Energy input, $M J$ & 1.343 & 7.951 \\
Blue Water Consumption, $k g$ & 2.671 & 9.752 \\
Biomass Requirement, $\mathrm{kg}$ & 1.84 & 0.805 \\
\hline
\end{tabular}


The GHG reduction was $89.08,68.3 \mathrm{~kg} \mathrm{CO}_{2}$ eq for BTE, BLFP, respectively, compared to petroleum derived diesel. The costs, fossil energy, blue water and biomass input per $\mathrm{kg} \mathrm{CO}_{2}$ eq $\mathrm{GHG}$ reduction were used to determine the efficiency of $\mathrm{GHG}$ emissions reduction (Table 4-4). BTE required lower cost to reduce GHG emission but it required more biomass as feedstock compared to BLFP. BLFP was a more energy and water intensive technology comparing to the BTE.

Uncertainty analysis of Monte Carlo simulation indicated the comparative results of the environmental impact (Fig. 4-3). It can be noticed that there was no overlap between the BTE and BLFP technologies. However, the right tail of BTE and the left tail of BLFP were closer to each other (18 $\mathrm{kg} \mathrm{CO}_{2}$ eq to $21 \mathrm{~kg} \mathrm{CO}_{2} \mathrm{eq}$ ). The highest possible values of the three impact factors were $59.8 \mathrm{~kg} \mathrm{CO}_{2}$ eq $\mathrm{GHG}$ emissions, $1,914 \mathrm{~kg}$ for water consumption and 1,525 $\mathrm{MJ}$ for fossil energy consumption to produce gasoline and diesel. There was possibility that the energy consumption larger than the energy output in the simulation of BLFP, but the possibility was lower than $2.5 \%$.

\subsection{DiscuSSION}

\subsubsection{Fuel Production and RSP}

There were more than one facility for BTE and BLFP opened and they were operated at smaller scale $(<5,000 \mathrm{bpd})$. This was because a larger facility typically demands more biomass and accordingly increases the biomass handling cost (Sultana et al. 2010). Few small scale facilities would be able to reduce the transportation distance of biomass. Unlike a fossil fuel facility, handling cost of biomass is usually higher (Sharma et al. 2013). 

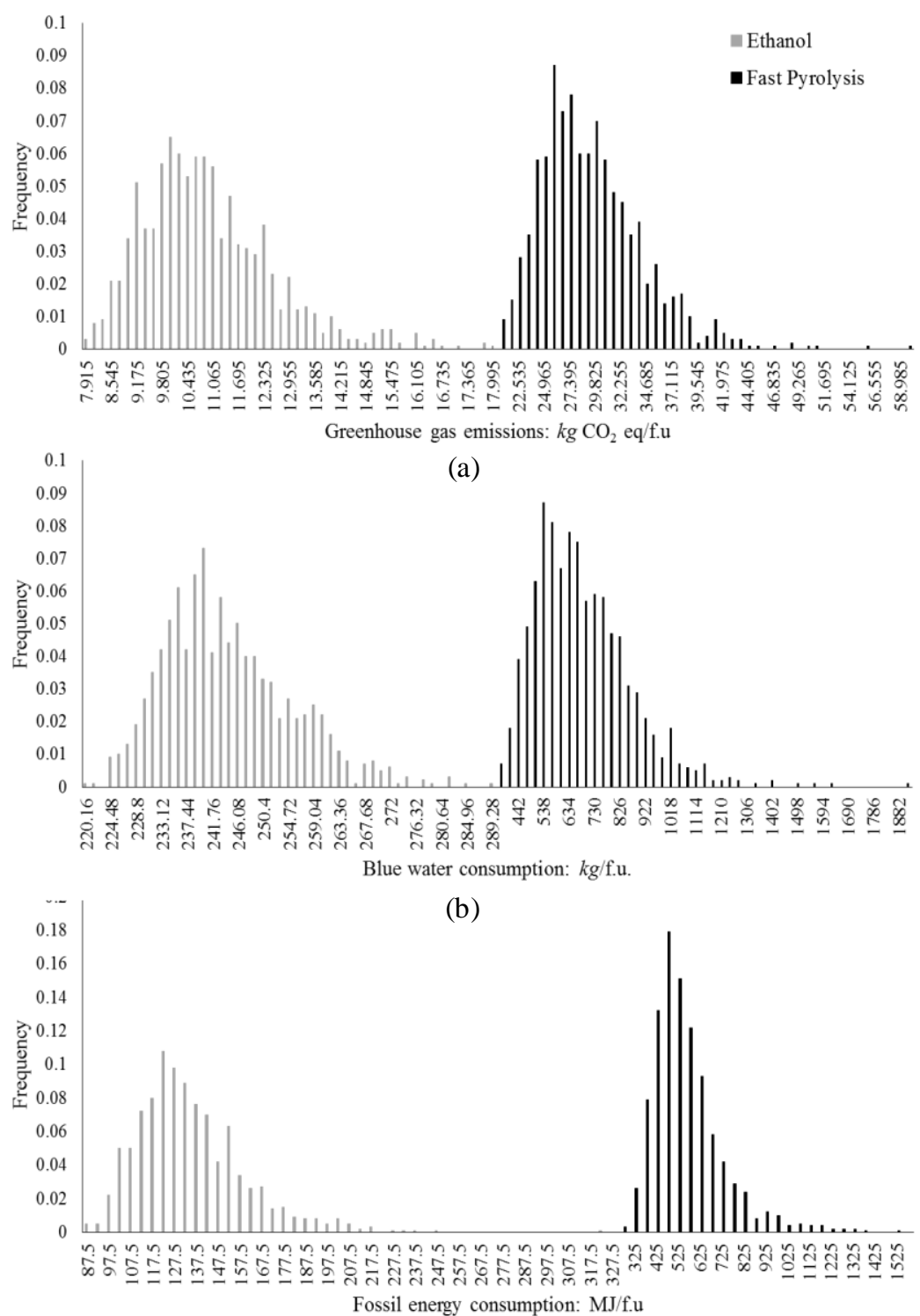

(c)

Fig. 4-3. Monte Carlo simulations of the environmental impact by bioenergy products: (a) GHG emissions, (b) blue water consumption, and (c) fossil energy consumption. 
The energy content of ethanol was almost a half of fast pyrolysis derived gasoline and diesel, but the RSP of ethanol was just slightly lower than the liquid fuels derived from fast pyrolysis. Ethanol was not easy to compete with gasoline and diesel also because of potential damage to engine (Lavelle 2010). The liquid fuels produced by fast pyrolysis were \$3/gal which was higher than the range of \$2.34-2.48/gal (Brown 2015). The operation and maintenance cost could be higher if bio-char and off-gas were not recycled (Jones and Male 2012). The sale of biochar can decrease the cost to produce liquid fuel (Shabangu et al. 2014). The amount of cost reduction will depend on the yield of bio-char and liquid fuels. The average price of crude oil in 2011 was $\$ 104.4 / \mathrm{bbl}$, but the price went down dramatically at the end of 2014 to its current price of $\$ 48 / \mathrm{bbl}$ (EIA 2015). With this uncertainty of crude oil price, it is hard to favor the biofuel production. The energy liquid fuel yield used in this study was $1.99 \mathrm{bblton}-1$ and $2.44 \mathrm{bblton}^{-1}$ for BTE and BLFP, respectively. Any improvement of conversion process would further lower the RSP. However, the RSP will also be changed according to the demand/supply of feedstock.

\subsubsection{Sensitivity of RSP}

The effect of price of biomass, liquid fuel yield and IRR on RSP were studied in sensitivity analyses. The liquid fuel yield was the most significant factor among the three factors. The reduction of liquid fuel yield significantly rose the RSP, so improvement of conversion efficiency was required to reduce the high RSP. When the liquid fuels are produced in industrial scale, the liquid fuel yield is not easy as high as in laboratory condition (Oliveira et al. 2013). Thus, a higher RSP could be expected when the liquid fuels are produced in industrial scale. The rise of biomass price could also significantly increase the RSP of liquid fuels in our study. This effect was more prominent in BTE because more biomass was required as feedstock. The price of biomass could be expected to rise through the increased use of biomass. An Austria example 
showed that the increased use of biomass has doubled the wood chip price from $7.50 € \mathrm{~m}^{-3}$ in 2005 to $16.45 € \mathrm{~m}^{-3}$ in 2012 (Kristöfel et al. 2014). IRR was sensitive in the production of liquid fuels because large proportion of total cost was investment of capital cost and a competitive price of liquid fuel could be obtained only when there is a low IRR required.

\subsubsection{LCA and Uncertainty Analysis}

The BTE presented low GHG emissions that was lower than Hsu et al.'s study (2010) because of the reduced emission in transportation and distribution. However, the energy conversion efficiency was low, thus more biomass was required than BLFP. BLFP had high water and energy consumption, of which over $90 \%$ was attributed to the conversion process. The fossil energy consumption can be reduced if the required electricity could be provided by biomass as a portion of the feedstock. However, the GHG emissions for feedstock handling would increase consequently. The bio-char from BLFP could be used for soil application to add more environmental and economic benefits if the yield of bio-char is high (Miller-Robbie et al. 2015) and the price of liquid fuels might be reduced considerably (Gerhard et al. 2014).

Emissions from biomass are usually considered as carbon neutral, but large amount of GHG emissions will increase the payback time from the regrowth of forest or grassland. In this study, the BTE resulted in higher biogenic emissions because of its requirement of relatively larger amount of biomass. Biogenic GHGs in BLFP will also increase if the fossil energy consumption is substituted by biomass energy. This increase of biogenic GHGs means high usage of biomass that leads to an increase of the environmental impact and costs in biomass supply chain.

Uncertainty is inevitable for any industrial process but it could be minimized through the robust planning and analyses. A range of liquid fuel yield for both BTE and BLFP was 
assumed based on the change of feedstock property, operation condition, facility scale (Hsu et al. 2010, Hsu 2012). Higher environmental impact could be expected if the liquid fuel yield was low. This is because more biomass need to be supplied for producing same amount of liquid fuels. Lower liquid fuel yield in BLFP also increased the expected fossil energy input which increase the possibility of negative energy output, thought the possibility is lower than $2.5 \%$.

\subsubsection{GHG Emissions Reduction}

The efficiency of GHG emissions reduction was assessed in terms of the costs, fossil energy and water consumption by reducing one $\mathrm{kg} \mathrm{CO}_{2}$ eq $\mathrm{GHG}$ emissions. BTE has higher cost efficiency than BLFP in reducing GHG emissions. It took $\$ 0.48$ for the BTE to reduce one $\mathrm{kg}$ $\mathrm{CO}_{2}$ eq GHG emissions. However, to reduce same amount of GHG emissions, more biomass was required to produce ethanol than diesel and gasoline. BLFP had much higher water and energy consumption in the comparison to BTE. The utilization of biomass was emphasized for GHG emissions reduction and energy independence. Each biomass to liquid fuel pathway in this study had its disadvantage and advantage. The proper choice largely depends on what is the major emphasize, costs, environmental impact or liquid fuels production.

\subsection{CONCLUSIONS}

The economic model was developed to maximize the profit of forest residue utilization. Fast pyrolysis derived liquid fuels cost more and require higher RSP. Ethanol had the lowest RSP. The RSP could be increased by increasing the price of biomass and decrease of IRR. Liquid fuel yield had most prominent effect on RSP, followed by IRR and price of biomass. The life cycle assessment showed the intensive water and energy consumption in BLFP. BTE had lower GHG emissions to produce same amount energy equivalent liquid fuel. The uncertainty 
analysis of LCA showed that the fossil energy consumption in BLFP could be larger than 1,000 MJ, and the possibility was lower than $2.5 \%$. The LCA study integrated with economic analysis showed that all the technologies had their advantages and disadvantages, such as the costs to produce ethanol were low but it required more biomass for same amount of product in energy.

\section{ACKNOWLEDGEMENTS}

The authors would like to thank the US Department of Agriculture National Institute of Food and Agriculture for providing funding support to this study (USDA-NIFA-AFRI-003536). We thank IBM for providing an academic version of the ILOG CPLEX solver. We are also grateful to few individuals for providing us data on biomass.

\section{REFERENCES}

Augustíno vá, J., Cvengrošová, Z., Mikulec, J., Vasillkovová, B., and Cvengroš, J. 2013. Upgrading of biooil from fast pyrolysis. In 46th International Conference on Petroleum Processing.

Boulay, A.M., Bulle, C., Bayart, J.B., Deschenes, L., and Margni, M. 2011. Regiona 1 Characterization of Freshwater Use in LCA: Modeling Direct Impact on Human Health. Environmental science \& technology 45(20): 8948-8957.

Bridgwater, A.V. 2012. Review of fast pyrolysis of biomass and product upgrading. Biomass \& Bioenergy 38: 68-94. 
Brown, T.R. 2015. A techno-economic review of thermochemical cellulosic biofuel pathways. Bioresource Technology 178: 166-176.

Cooper, J., Jackson, R., and Leigh, N.G. 2013. 14 Computational structure for linking life cycle assessment and input-output modeling: a case study on urban recycling and remanufacturing. Handbook of Industry Studies and Economic Geography: 355.

Economic Research Service, E.R. 2015. Fuel ethanol, corn and gasoline prices, by month. USDA ERS.

Edwards, R., Larive, J., Mahieu, V., and Rouveirolles, P. 2011. Well-to-wheels analysis of future automotive fuels and powertrains in the European context: WTT appendix 1 Description of individual processes and detailed input data. Version $2 \mathrm{~b}$.

EIA. 2009. Annual energy outlook 2009. Energy Information Administration, Office of Integrated Analysis and Forecasting. US Department of Energy.

EIA. 2015. Petroleum \& other liquids Available from http:/www.eia.gov/dnav/pet/hist/LeafHandler.ashx?n=pet\&s=rwtc \&f=d [accessed 6 2014].

Fan, S., Gloor, M., Mahlman, J., Pacala, S., Sarmiento, J., Takahashi, T., and Tans, P. 1998. A large terrestrial carbon sink in North America implied by atmospheric and oceanic carbon dioxide data and models. Science 282(5388): 442-446.

Fargione, J., Hill, J., Tilman, D., Polasky, S., and Hawthorne, P. 2008. Land clearing and the biofuel carbon debt. Science 319(5867): 1235-1238.

Forster, P., Ramaswamy, V., Artaxo, P., Berntsen, T., Betts, R., Fahey, D.W., Haywood, J., J., L., Lowe, D.C., Myhre, G., Nganga, J., Prinn, R., Raga, G., Schul, M., and Van Dorland, 
R. 2007. Changes in Atmospheric Constituents and in Radiative Forcing. In Climate change 2007-the physical science basis: Working group I contribution to the fourth assessment report of the IPCC. Edited by S. Solomon, D. Qin, M. Manning, Z. Chen, M. Marquis, K. B. Averyt, M. Tignor, and H. L. Miller. Cambridge University Press.

Frischknecht, R., Jungbluth, N., Althaus, H.-J., Hischier, R., Doka, G., Bauer, C., Dones, R., Nemecek, T., Hellweg, S., and Humbert, S. 2007. Implementation of life cycle impact assessment methods. Data v2. 0 (2007). Ecoinvent report No. 3. Ecoinvent Centre, Swiss Federal Laboratories for Materials Testing and Research (EMPA), Duebendorf (Switzerland).

Gecan, R., and Johansson, R. 2010. Using biofuel tax credits to achieve energy and environmental policy goals. DIANE Publishing.

Gnansounou, E., and Dauriat, A. 2010. Techno-economic analysis of lignocellulosic ethanol: A review. Bioresource Technology 101(13): 4980-4991.

Hartley, D.S. 2014. Modeling and Optimization of Woody Biomass Harvest and Logistics in the Northeastern United States. WEST VIRGINIA UNIVERSITY, Morgantown, WV.

Herrmann, I.T., Jorgensen, A., Bruun, S., and Hauschild, M.Z. 2013. Potential for optimized production and use of rapeseed biodiesel. Based on a comprehensive real-time LCA case study in Denmark with multiple pathways. International Journal of Life Cycle Assessment 18(2): 418-430.

Hertel, T.W., Golub, A.A., Jones, A.D., O'Hare, M., Plevin, R.J., and Kammen, D.M. 2010. Effects of US Maize Ethanol on Global Land Use and Greenhouse Gas Emissions: Estimating Market-mediated Responses. Bioscience 60(3): 223-231. 
Hsu, D.D. 2012. Life cycle assessment of gasoline and diesel produced via fast pyrolysis and hydroprocessing. Biomass \& Bioenergy 45: 41-47.

Hsu, D.D., Inman, D., Heath, G.A., Wolfrum, E.J., Mann, M.K., and Aden, A. 2010. Life cycle environmental impact of selected US ethanol production and use pathways in 2022. Environmental science \& technology 44(13): 5289-5297.

Jiang, M., Griffin, W.M., Hendrickson, C., Jaramillo, P., VanBriesen, J., and Venkatesh, A. 2011. Life cycle greenhouse gas emissions of Marcellus shale gas. Environmental Research Letters 6(3).

Jones, S.B., and Male, J.L. 2012. Production of Gasoline and Diesel from Biomass via Fast Pyrolysis, Hydrotreating and Hydrocracking: 2011 State of Technology and Projections to 2017. Pacific Northwest National Laboratory, Richland, Washington, U.S.

Keesom, W., Unnasch, S., Moretta, J., and Consultancy, J. 2009. Life cycle assessment comparison of North American and imported crudes. Alberta Energy Research Institute.

Kerstetter, J.D., and Lyons, J.K. 2001. Logging and agricultural residue supply curves for the Pacific Northwest. Washington State University Energy Program.Kerstetter, J.D., and Lyons, J.K. 2001. Logging and agricultural residue supply curves for the Pacific Northwest. Washington State University Energy Program.

Kocoloski, M., Griffin, W.M., and Matthews, H.S. 2011. Impact of facility size and location decisions on ethanol production cost. Energy Policy 39(1): 47-56.

Kristöfel, C., Strasser, C., Morawetz, U.B., Schmidt, J., and Schmid, E. 2014. Analysis of woody biomass commodity price volatility in Austria. Biomass \& Bioenergy 65: 112-124. 
Kumar, D., Murthy, G.S. 2012. Life cycle assessment of energy and GHG emissions during ethanol production from grass straws using various pretreatment processes. International Journal of Life Cycle Assessment, 17(4): 388-401.

Lavelle, M. 2010. Ethanol Future Looking for More Fuel. Available from $<$ http://news.nationalgeographic.com/news/2010/07/102107-energy-supply-supportdecisions-ethanol/> [accessed 6 2014].

Marano, J.J., and Ciferno, J.P. 2001. Life-cycle greenhouse-gas emissions inventory for FischerTropsch fuels. Report Prepared for the US Department of Energy, Energy and Environmental Solution, LLC, Gaithersburg, MD, USA.

Miller-Robbie, L., Ulrich, B.A., Ramey, D.F., Spencer, K.S., Herzog, S.P., Cath, T.Y., Stokes, J.R., and Higgins, C.P. 2015. Life cycle energy and greenhouse gas assessment of the coproduction of biosolids and biochar for land application. Journal of Cleaner Production 91: 118-127.

Munñz, I., Flury, K., Jungbluth, N., Rigarlsford, G., Canals, L.M.I., and King, H. 2014. Life cycle assessment of bio-based ethanol produced from different agricultural feedstocks. International Journal of Life Cycle Assessment 19(1): 109-119.

Oliveira, F.M.V., Pinheiro, I.O., Souto-Maior, A.M., Martin, C., Gonçalves, A.R., and Rocha, G.J.M. 2013. Industrial-scale steam explosion pretreatment of sugarcane straw for enzymatic hydrolysis of cellulose for production of second generation ethanol and valueadded products. Bioresource Technology 130: 168-173. 
Perlack, R.D., Wright, L.L., Turhollow, A.F., Graham, R.L., Stokes, B.J., and Erbach, D.C. 2005. Biomass as feedstock for a bioenergy and bioproducts industry: the technical feasibility of a billion-ton annual supply. DTIC Document.

Phillips, S., Aden, A., Jechura, J., Dayton, D., and Eggeman, T. 2007. Thermochemico ethanol via indirect gasification and mixed alcohol synthesis of lignocellulosic biomass. NREL.

Renewable Fuels Associatio, R.F. 2014. Renewable Fuels Association Statistics: Historic U.S. Fuel Ethanol Production. Available from www.ethanolrfa.org/pages/statistics [accessed 6 2014].

Ringer, M., Putsche, V., and Scahill, J. 2006. Large-scale pyrolysis oil production: a technology assessment and economic analysis. NETL.

Shabangu, S., Woolf, D., Fisher, E.M., Angenent, L.T., and Lehmann, J. 2014. Techno-economic assessment of biomass slow pyrolysis into different biochar and methanol concepts. Fuel 117: 742-748.

Shackley, S., Hammond, J., Gaunt, J., and Ibarrola, R. 2011. The feasibility and costs of biochar deployment in the UK. Carbon Management 2(3): 335-356.

Sharma, B., Ingalls, R.G., Jones, C.L., and Khanchi, A. 2013. Biomass supply chain design and analysis: Basis, overview, modeling, challenges, and future. Renewable \& Sustainable Energy Reviews 24: 608-627.

Snowden-Swan, L.J., and Male, J.L. 2012. Summary of Fast Pyrolysis and Upgrading GHG Analyses. Pacific Northwest National Laboratory 
Suh, S. 2004. Functions, commodities and environmental impact in an ecological-economic model. Ecological Economics 48(4): 451-467.

Sultana, A., Kumar, A., and Harfield, D. 2010. Development of agri-pellet production cost and optimum size. Bioresource Technology 101(14): 5609-5621.

USDA. 2009. Timber Products Output Map Maker (Version 1.0). U.S. Department of Agriculture, Forest Service.

US Department of State. West Virginia Weather Available. Available from http //countrystudies. us/united-states/weather/west-virginia/ [accessed 6 2014].

Wang, M. 2009. The GREET spreadsheet model: greenhouse gases and regulated emissions and energy use in transportation, Version 1.8 c. Center for Transportation Research, Energy Systems Division, Argonne National Laboratory.

Wright, M.M., Daugaard, D.E., Satrio, J.A., and Brown, R.C. 2010. Techno-economic analysis of biomass fast pyrolysis to transportation fuels. Fuel 89: S11-S19.

Wu, J., Wang, J., and Strager, M.P. 2011. A Two-Stage GIS-Based Suitability Model for Siting Biomass-to-Biofuel Plants and its Application in West Virginia, USA. International Journal of Forest Engineering 22(2): 28-38.

Wu, J.Z., Wang, J.X., Cheng, Q.Z., and DeVallance, D. 2012. Assessment of coal and biomass to liquid fuels in central Appalachia, USA. International Journal of Energy Research 36(7): 856-870. 


\section{ECONOMIC AND Life CyCle ANALySES OF BIOMASS}

\section{UTILIZATION FOR BIOENERGY AND BIOPRODUCTS ${ }^{4}$}

${ }^{4}$ Prepared for GCB Bioenergy. 


\section{AbSTRACT}

A modeling process was developed to examine the economic and environmental benefits of utilizing energy crops for biofuels and bio-products. Three energy crops (hybrid willow, switchgrass and miscanthus) that can potentially grow on marginal agricultural land or abandoned mine land in the Northeastern United States were considered in the analytical process for the production of biofuels, biopower and pellet fuel. The supply chain components for both the economic and life cycle modeling processes include feedstock establishment, harvest, transportation, storage, preprocessing, energy conversion, distribution and final usage.

Sensitivity analysis was also conducted to assess the effects of energy crop yield, transportation distance, bioproduct yield, different pretreatments, facility capacity and internal rate of return (IRR) on the production of bioenergy products. The RSPs were ranged from $\$ 7.39 / \mathrm{GJ}$ to $\$ 23.82 /$ GJ for different bioproducts. The production of biopower had the higher required selling price (RSP) where pellet fuel had the lowest. The results also indicated that bioenergy production using hybrid willow demonstrated lower RSP than the two perennial grass feedstocks. Biopower production presented the lowest GHG emissions (less than $10 \mathrm{~kg} \mathrm{CO}$ eq per 1,000 MJ) and fossil energy consumption (less than $160 \mathrm{MJ}$ per 1,000 MJ) but with the highest water consumption. The production of pellet fuel resulted in the highest GHG emissions. Sensitivity analysis indicated that bioproduct yield was the most sensitive factor to RSP and followed by transportation distance for biofuel and biopower production. Bioproduct yield and transportation distance of feedstock presented great effects on environmental impact for the production of liquid fuels and biopower. 


\subsection{INTRODUCTION}

Biomass is being considered as a carbon neutral energy resource. It is preferred to be a substitution of fossil energy resources to reduce the greenhouse gas emissions. The interest in the usage of cellulosic biomass for biofuels and bioproducts has been steadily increased due to the environmental and energy independence concerns (Paul 2009). Biomass could be used to produce different forms of bioenergy products, such as traditional firewood, pellet, electricity, ethanol, and other biofuels. However, biomass feedstock production usually requires more land cover change to provide the same amount of energy as fossil fuels (Searchiger et al. 2008). Consequently, the production cost of bioenergy from biomass is typically higher than fossil fuels (Brown 2015).

Cellulosic biomass has been traditionally combusted for heat in human history. The ash from combustion is sprayed in field as fertilizer. To improve the biomass heating efficiency, pellet was then introduced and is a product that densifies the loose biomass and becomes popular as solid biofuel (Fantozzi and Buratti2010). The densification of biomass not only improves the efficiencies in biorefinery facilities but also reduces its handling costs (Yancey et al. 2013), even though densification itself also consumes energy. Biomass fired power plants produce electricity and heat using either direct fired or gasification system (EPA 2007). The efficiency to produce electricity using biomass may be low $(<30 \%)$ but the product is easy to distribute (Perilhon et al. 2012). Biomass derived liquid fuels have been introduced in different pathways including biological and thermochemical processes. Fast pyrolysis could also produce reliable liquid fuels which can be blended with petroleum derived liquid fuels (Augustínová et al. 2013).However, the production of lignocellulosic biofuels still faces many technical, economic, environmental challenges. 
Many analyses have been conducted on biomass supply chains in terms of economic, environmental or life cycle assessments. Earlier economic analysis of biomass utilization focused on biomass-fired power plants (Kumar et al. 2003, Perilhon et al. 2012), such as optimization of plant size based on available biomass, and the cost of different sizes of pellet facilities (Sultana et al. 2010, Pirraglia et al. 2013). On the other hand, life cycle assessments (LCA) were conducted separately to analyze environmental impact of biomass utilization. For example, GHG emissions could be reduced 30-63\% through utilizing biomass pellet fuels instead of natural gas (Fantozzi and Buratti 2010), and 56-77\% from using pyrolyzed biofuels compared to fossil fuels (Snowden-Swan and Male 2012, Hsu 2012).

Although the utilization of biomass presents a lower environmental burden, the handling cost of biomass is usually higher than fossil fuels (Sharma et al. 2013, Hartley 2014). The techno-economic analysis conducted on fast pyrolysis estimated that the cost of this biofuel can range from $\$ 0.40 /$ gal to $\$ 3.07 /$ gal (Ringer et al. 2006; Wright et al. 2010). Brown (2015) recently reviewed techno-economic analyses of fast pyrolysis of biomass and found that the required selling price (RSP) varied from $\$ 1.93-\$ 3.70 /$ gal of gasoline equivalent. Similarly, a range of costs were shown using different boiler systems for biopower generation using biomass (IRENA 2012), including the capital cost of $\$ 1.8-\$ 5.7$ million/MW and operational and maintenance cost contribution $9 \%-20 \%$ of total cost. The production cost of biomass pellet also varies dramatically according to the physical location and capacity of the pellet facility, ranging from $\$ 122 /$ ton to $\$ 170 /$ ton (Sultana et al. 2010). For a 100,000 tons/year pellet facility, its production cost could be up to $\$ 199 /$ ton (Pirraglia et al. 2013). The RSP of pellet was $\$ 174 /$ ton when the biomass delivered cost was $\$ 45 /$ ton (Hunsberger and Mosey 2014). 
Energy crops such as hybrid willow and warm-season grasses on abandoned and marginal agricultural and mine lands in the Northeastern U.S. could be possibly utilized as sustainable bioenergy feedstocks in this region. These energy crops could provide flexibility for processing plants because they can be strategically deployed spatially and temporally to optimize efficiency of biofuels production (Hinchee et al. 2009). Furthermore, these crops would provide a stimulus to the regional rural economies through converting marginal agricultural and abandoned mine lands to productive and profitable uses. Energy crops usually have high growth rates, and can be genetically enhanced for robust adaptation to the biotic and abiotic stresses encountered in the region, efficient processivity, and high energy content.

There appears necessity to analyze the environmental and economic impact of utilizing bioenergy crops for major possible pathways at a regional scale. The objectives of this study were to: (1) develop an economic model to analyze biomass energy supply chains in the northeastern U.S., (2) perform a cradle-to-grave life cycle assessment (LCA) to examine the environmental impact of utilizing the energy crops for bioenergy products, and (3) conduct sensitivity analyses of the production of bioenergy products according to energy crop yield, transportation distance, bioproduct yield, facility capacity and internal rate of return (IRR). 
Table 5-1. Physical properties and requirements of three energy crops for three bioenergy

products.

\begin{tabular}{|c|c|c|c|c|c|}
\hline Name & $\begin{array}{r}\text { Moisture } \\
\text { Content (w.b.) }\end{array}$ & $\begin{array}{r}\text { Ash } \\
\text { Content }\end{array}$ & $\begin{array}{l}\text { Energy Density } \\
\text { (HHV: } \mathrm{MJ} / \mathrm{kg} \text { ) }\end{array}$ & $\begin{array}{r}\text { Yield } \\
\text { (odt } / \text { ha) }\end{array}$ & References \\
\hline Willow & $44 \%$ & $2.33 \%$ & 19 & $\begin{array}{l}10.7- \\
14.1\end{array}$ & $\begin{array}{l}\text { Fahmi et al. 2008; Stolarski et al. } \\
\text { 2013; Caputo et al.2014. } \\
\text { Bai et al.2010; Sokhansanj et al. }\end{array}$ \\
\hline Switchgrass & $34 \%$ & $4 \%$ & 18 & $\begin{array}{l}6.6-12.6 \\
10.9-\end{array}$ & $\begin{array}{l}\text { 2009; Fahmi et al. } 2008 \text {; Khanna et al. } \\
\text { 2008; Marra et al. } 2012 \\
\text { Fahmi et al. 2008; Khanna et al. 2008; }\end{array}$ \\
\hline Miscanthus & $34 \%$ & $3 \%$ & 17 & 24.7 & Brosse et al.2012. Miguez et al. 2009 \\
\hline Product & Particle Size & & \multicolumn{2}{|c|}{ Moisture Content (w.b.) } & Citation \\
\hline Biofuel & $<2 \mathrm{~mm}$ & & $<10 \%$ & & $\begin{array}{l}\text { Brown and Holmgren 2009; Jones et } \\
\text { al. } 2009 .\end{array}$ \\
\hline Biopower & $<2$ in & & $<50 \%$ & & $\begin{array}{l}\text { Mann and Spath 2001; EPA } 2007 . \\
\text { Chen 2009; Fantozzi and Buratti }\end{array}$ \\
\hline Pellet & $<1 / 4$ in & & $<10 \%$ & & 2010. \\
\hline
\end{tabular}

\subsection{MATERIALS AND MethodS}

\subsubsection{Study Area and Base Case Scenario}

The study focused on the northeastern U.S., including New York, Pennsylvania, West Virginia and other states. The regions has available marginal agricultural land of over 2.8 million ha (Graham 1994) and abandoned mine land of 0.5 million ha (Rodrigue and Burger 2004), respectively. These lands are generally categorized with rocky and sloped soils and are compatible to the development of perennial energy crops. The temperate climate in this regional so provides the conditions of producing biomass of higher yield. Annual yield from hybrid willow and miscanthus could be 10.7-14.1 odt/ha (Fahmi et al. 2008; Stolarski et al. 2013; Caputo et al. 2014) and 10.9-24.7 odt/ha (Fahmi et al. 2008; Khanna et al. 2008; Brosse et al. 2012. Miguez et al. 2009).

Three biomass feedstocks: hybrid willow, switchgrass and miscanthus were included in this study, which are being considered as the dedicated energy crops in the Northeastern U.S. 
The physical properties of these three feedstocks were described in Table 5-1.Three bioenergy products were examined: biofuel by fast pyrolysis, biopower, and pellet fuel. The preprocessing requirements of feedstocks for energy products are different according to different conversion pathways, such as particle size, energy density, moisture content and ash content (Table 5-1).The base case of the analyses primarily included the following process components: feedstock development, storage, transportation, preprocessing, conversion and final uses of the biomass energy products. The capacity was 1,000 bbl/day, $20 \mathrm{MW}$ and 180,000 dry tons per year for biofuel, biopower and pellet fuel facilities, respectively, based on a feedstock demand of 200,000 dry tons per year.

\subsubsection{Economic Modeling}

\subsubsection{Supply Chain Model Development}

A mixed integer linear programming (MILP) model was formulated with the objective to minimize the costs of delivering biomass feedstocks to the gate of a biomass energy facility. The decision variables included quantity of feedstock harvested and quantity of feedstock transported among harvest site, short-term storage, and location of bioenergy facility.

The total delivered cost $(\psi)$ that consists of the following cost components: biomass feedstock establishment $(f)$, harvest $(\eta)$, transport $(\tau)$ and storage $(\mu)$ can be formulated as follows:

$\operatorname{Min} \psi=f+\eta+\tau+\mu$

The cost of field handling system is made up of two parts: the cost of the actual harvesting operations and investment for energy crops plantation. In this model, the investment for plantation $\left(p c_{m}\right)$ was calculated as dollars per dry metric ton where $m$ was one of the energy crop $M$. Different harvest systems were considered for short rotation willow crop and perennial 
grasses, and the cost of per dry metric ton of energy crop was represented as $h c_{m}$. The feedstock establishment and harvest cost was calculated using the following equations:

$f=\sum^{T} \sum^{J} \sum^{I} \sum^{M} x_{m i j t} \times p c_{m}$

$\eta=\sum^{T} \sum^{J} \sum^{I} \sum^{M} x_{m i j t} \times h c_{m}$

Where $x_{m i j t}$ (dry metric ton) is the amount of energy crop $m$ harvested in area $i$ and transported to location $j$ at period $t$.

Transportation is a major cost element in all energy projects because of relatively low energy density of biomass and its wide spatial distribution in comparison to fossil fuels. The transportation of biomass feedstocks is affected by many factors including availability, demand and spatial distribution. It can be calculated with the following equation:

$\tau=\sum^{T} \sum^{J} \sum^{I} \sum^{M} x_{m i j t} \times t c_{m} \times d_{i j}$

Where $t c_{m}\left(\$\right.$ ton $\left.^{-1} \mathrm{~km}^{-1}\right)$ is unit transportation cost of energy crop $m$ and $d_{i j}(\mathrm{~km})$ is distance from area $i$ to candidate facility $j$.

The ability to store biomass will be a key to ensuring that a continuous, sufficient supply is available throughout the year. Uncertainty in supply of feedstock will also necessitate a certain level of storage to ensure sufficient supply during periods of reduced production. The cost of storage is calculated with equation (5):

$\mu=\sum^{J} \sum^{I} \sum^{M} \sum^{t} x s_{m i j t} \times s c_{m}$ 
Where $s c_{m}$ is storage cost of energy crop $m$ and $x s_{m i j t}$ (dry metric ton) is the amount of energy crop $m$ stored at location $j$ from area $i$ at period $t$.

The objective function developed is subject to a series of constraints such as material balance, resource availability and operational constraints. Equation (5-6) ensures that there is only one candidate location can be used for a bioenergy processing facility within a certain procurement radius. Equation (5-7) ensures no feedstock will be delivered to a location that is not open for bioenergy production. Equation (5-8) indicates that the amount of feedstock that is transported from a harvest area is less than or equal to the total available amount. Equation (5-9) represents that the feedstock shipped to a location plus the storage from previous period is equal to the amount of feedstock processed and the storage. Equation (5-10) imposes the total amount of feedstocks processed should not exceed the demand of a processing facility at a specific location.

$$
\begin{aligned}
& \sum^{J} y_{j} \leq 1 \\
& x_{m i j t} \leq C y_{j}, \forall m \in M, i \in I, j \in J \text { and } t \in T \\
& \sum^{J} x_{m i j t} \leq A_{m i t}, \forall m \in M, i \in I \text { and } t \in T \\
& \sum^{I} x_{m i j t}+x s_{m i j, t-1}=x p_{j m t}+x s_{m i j t}, \forall m \in M, j \in J \text { and } t \in T \\
& \sum^{M} x p_{j m t} \leq D_{j t}, \forall j \in J \text { and } t \in T
\end{aligned}
$$


Where $C$ is a defined positive number that is larger than any possible $x_{m i j t} . A_{m i t}$ is the amount of harvestable energy crop $m$ in area $i$ at period $t . x p_{j m t}$ is the amount of energy crop $m$ processed in location $j$ at period $t$ and $D_{j t}$ is feedstock demand of location $j$ at period $t$.

\subsubsection{Economic Model Configuration for Base Case}

Feedstock development and harvest cost of energy crops included the machine costs for land preparation, plantation, fertilizer, pesticide spray and harvest were based on the settings by Duffy (2013) and Schweier and Becker (2012). The round-trip transportation of wood chips and bales were assumed to be $\$ 0.24$ ton $^{-1} \cdot \mathrm{km}^{-1}$ (Kerstetter and Lyons 2001) in the base case. Storage cost of feedstock was assumed to be $\$ 5$ dry ton ${ }^{-1}$. The capital cost, operational and maintenance cost of fast pyrolys is were based on the results of techno-economic analyses conducted by Wright et al. (2010). Average costs of biomass fired power plant in IRENA's report (2012) were used as facility cost to produce biopower. A techno-economic analysis by Sultana et al. (2010) provided costs to operate a pellet facility. Internal rate of return was assumed $15 \%$ in base case. RSP at facility gate was calculated.

\subsubsection{Life Cycle Assessment}

\subsubsection{1. $\quad$ System Boundary and Life Cycle Inventory}

The system boundary of this cradle-to-grave LCA model (Fig. 5-1) included land preparation, plantation, harvest, transportation, storage, preprocessing, bioproduct conversion, distribution final usage and waste disposal. The environmental impact will be assessed in terms of the GHG emissions, blue water consumption, fossil fuel consumption and human health impact. The health impact considered in this study were carcinogenics, respiratory effects, ozone depletion and human toxicity. The functional unit (f.u.) was 1,000 MJ of energy equivalent bioenergy product produced in the system. 


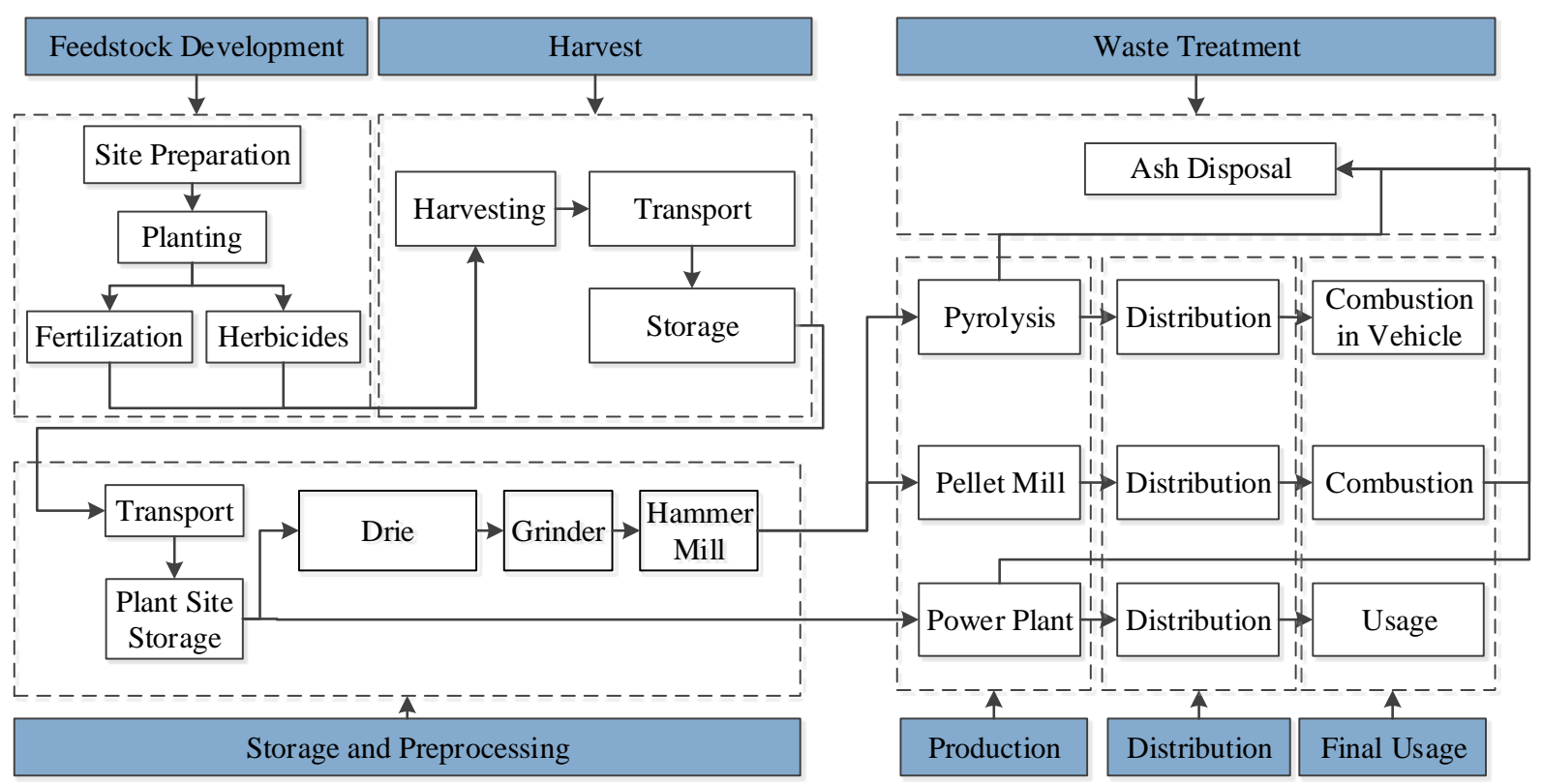

Fig. 5-1. System boundary and processes of the three energy crops for three bioenergy products.

The field operation of hybrid willow system includes 1-year land preparation and seven 3year rotations (Caputo et al. 2014) while the grass field operation system is 1-year land preparation and ten 1-year rotations (Liu and Kemmerer 2011). The grass and willow use different land preparation, planting and harvesting systems (Caputo et al. 2014; Duffy 2013; Liu and Kemmerer 2011). The procedures of land preparation for willow include mowing, plowing, disking and cultipacking. After the preparation, willow cuttings were planted by a planter. The harvest system was a single pass cut-and-chip harvester with a short rotation coppice head. A forage wagon was also included to transport biomass chips to a bigger van, the chips were then transported to a storage area. For perennial grasses, disking, harrow, and plowing are typically performed in land preparation while the harvest system includes disk mowing, tedding, raking and baling.

The data on biomass transportation were derived from the US LCI database provided by National Renewable Energy Laboratory (NETL) while energy and material usage at storage were based on the Emery and Mosier's results (2012). The energy consumptions of preprocessing 
including grinding, drying, hammer milling were based on the measurements of the Idaho National Laboratory's (INL) Process Demonstration Unit (PDU) (Kenney et al. 2013). The percentage of feedstock needs to be processed in hammer mill usually depends on the required particle size. For example, $25 \%$ of feedstock was needed to go through harmer mill if the required particle size was less than $2 \mathrm{~mm}$ and $15 \%$ if the required particle size was less than $1 / 4^{\prime \prime}$ (Kenney et al. 2013).

The LCA inventory data for fast pyrolysis and biopower generation were derived from previous studies by Hsu (2011) and Spath et al. (1999). The resource consumptions in the production of pellet fuel were based on the measurements by INL (Yancey et al. 2013). An average distribution distance of $100 \mathrm{~km}$ (62.5 miles) was assumed for bioenergy products from plants to end users. The liquid fuels were considered to be combusted in flex-fuel passenger cars (Wang 2009). The maintenance of the distribution grid for biopower generation was adapted from Jorge et al.'s results (2012). No emission was assumed for electricity in usage. Pellet was combusted in industrial boiler and the emission was derived according to the properties of the feedstock (Brassard et al. 2014). All the other related background processes were based on the SimaPro built-in database Ecoinvent 3 processes. All the detailed processes were in Appendix D.

\subsubsection{Life Cycle Impact Assessments}

The LCA model was developed using the environmental modeling tool SimaPro v8 (PRé Consultants 2014). The following indicators were assessed in terms of life cycle impact assessments. The 100-year global warming potentials of GHG (Forster et al. 2007) were calculated in carbon dioxide equivalent amount $\left(\mathrm{kg} \mathrm{CO}_{2} \mathrm{eq}\right)$. The blue water footprint $(\mathrm{kg})$ was analyzed following the Boulay et al.'s method (2011). The fossil energy consumption (MJ) was based on the results by Frischknecht et al.(2007).Carcinogenics (CTUh), respiratory effects (kg 
PM2.5 eq) and ozone depletion ( $\mathrm{kg} \mathrm{CFC}-11 \mathrm{eq}$ ) were calculated using the methods provided in TRACI (Bare 2012). The CML-IA was used to assess human toxicity (kg 1,4-DB eq). Two-way ANOVA was applied to analyze the major factors that explain the variance of life cycle impact indices. The difference of human health indices was studied by principal component analysis (PCA). All the statistical analyses were conducted in R 3.1.1 software.

Table 5-2. Parameters for base case and sensitivity analysis.

\begin{tabular}{|c|c|c|c|}
\hline Parameter & Base Case & Sensitivity Setting & Note and references \\
\hline Willow - Yield & $12.4 \mathrm{odt} / \mathrm{ha}^{1}$ & $10.7-14.1 \mathrm{odt} / \mathrm{ha}$ & Yield increases from minimum \\
\hline Switchgrass - Yield & $9.6 \mathrm{odt} / \mathrm{ha}$ & 6.6-12.6 odt/ha & to maximu $m$ yield by $10 \%$ of \\
\hline Miscanthus - Yield & $17.8 \mathrm{odt} / \mathrm{ha}$ & 10.9-24.7odt/ha & their difference. \\
\hline Transportation & 50 miles & $10-100$ miles & $\begin{array}{l}\text { The distance increases by } 10 \\
\text { miles each time. }\end{array}$ \\
\hline $\begin{array}{l}\text { Biofuel - } \\
\text { Bioproduct yield }\end{array}$ & $\begin{array}{l}0.39 \text { tons feedstock/bbl } \\
\text { of fuel }\end{array}$ & $\begin{array}{l}0.33-0.45 \mathrm{odt} \\
\text { feedstock/bblof fuel }\end{array}$ & $\begin{array}{l}\text { Amount of feedstock demand } \\
\text { increases from minimum to }\end{array}$ \\
\hline Biopower - & 0.84 tons & $0.63-1.05$ odt feedstock/ & maximu m yield by $10 \%$ of their \\
\hline Bioproduct yield & $\begin{array}{l}\text { feedstock/MWh of } \\
\text { biopower }\end{array}$ & MWh of biopower & difference. \\
\hline $\begin{array}{l}\text { Pellet - Bioproduct } \\
\text { yield }\end{array}$ & $\begin{array}{l}1.11 \text { tons feedstock/ton } \\
\text { of pellet }\end{array}$ & $\begin{array}{l}1.05-1.17 \text { tons } \\
\text { feedstock/ton of pellet }\end{array}$ & \\
\hline
\end{tabular}

\subsubsection{Sensitivity and Uncertainty Analyses}

The effects of crop yield, transportation distance, bioproduct yield, facility size and IRR on RSP were analyzed in terms of sensitivity and uncertainty (Table 5-2). Maximum and minimum yield and bioproduct yield were tested for every energy crop and bioenergy product. A range of $16-160 \mathrm{~km}(10-100$ miles) of hauling distance for feedstock were examined to test the sensitivity of RSP on transportation distance. To analyze the effect of facility capacity, 20\% larger and $20 \%$ smaller facility than the base case were examined. An IRR ranging from $10 \%$ and 20\% was also examined for its effect on the RSP. The sensitivities of the environmental impact of biomass utilization were also conducted on crop yield, biomass transportation distance and bioproduct yield (Table 5-2). 


\subsection{RESUlTS}

\subsubsection{Base Case Scenario}

The cost of each component was analyzed by feedstock and energy product (Fig. 5-2). The total costs changed from $\$ 72.64 / \mathrm{bbl}$ to $\$ 78.31 / \mathrm{bbl}$ for biofuel $(\$ 14.44 / \mathrm{GJ}-\$ 15.57 / \mathrm{GJ})$, from $\$ 73.57 / \mathrm{MWh}$ to $\$ 85.74 / \mathrm{MWh}$ for biopower (\$20.44/GJ-\$23.82/GJ) and from $\$ 125.18 /$ ton to $\$ 143.79 /$ ton for pellet $(\$ 7.36 / \mathrm{GJ}-\$ 7.99 / \mathrm{GJ})$. The percentage of cost in transportation was ranging from $13 \%-31 \%$. Percentage of capital cost for facilities to produce pellet fuel $(3.6 \%-4.1 \%)$ was lower than the other two facilities (18.5\%-22.2\%). Operation and maintenance expenses ranged from $9.54 \%$ in the production of biopower by miscanthus to $49.63 \%$ in the production of pellet fuel by willow. Operation and maintenance costs for biopower generation accounted for 10-11\% of the total cost and were lower than for biofuel and pellet production. Cost of plantation contributed $10.6 \%-27.7 \%$ of the total cost and cost of harvest contributed $5.6 \%-33.85 \%$. Willow had lower cost in plantation and harvest than the other two energy crops. Storage was a small portion of total cost, which only accounted less than $1 \%$.

The RSP ranged from $\$ 131.22 / \mathrm{bbl}$ to $\$ 136.9 / \mathrm{bbl}$ for biofuel, $\$ 160.12 / \mathrm{MWh}$ to $\$ 172.28 / \mathrm{MWh}$ for biopower, and $\$ 132.99 /$ ton to $\$ 151.6 /$ ton for pellet fuel (Table 5-3). The production of biopower presented higher RSP of $\$ 44.5 / \mathrm{GJ}-\$ 47.9 / \mathrm{GJ}$ compared to $\$ 26.1 / \mathrm{GJ}$ $\$ 27.2 / G J$ and $\$ 7.8 / G J-\$ 8.4 G J$ for the production of biofuel and pellet fuel, respectively (Table 53). For the production of the same bio-energy product, the RSP using hybrid willow was $0.5 \%$ $5.8 \%$ lower than using the other two energy crops. 


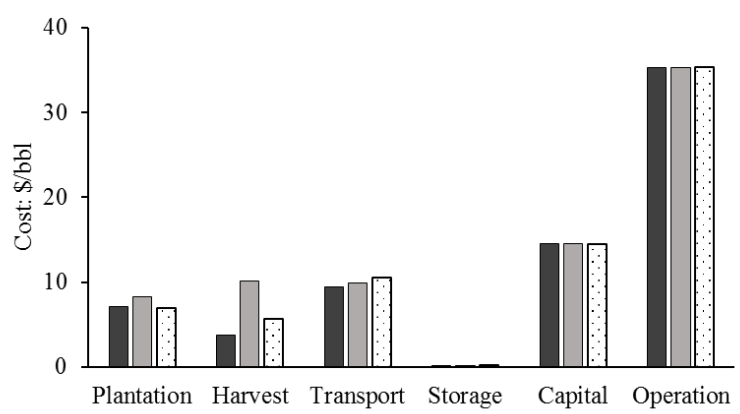

(a)

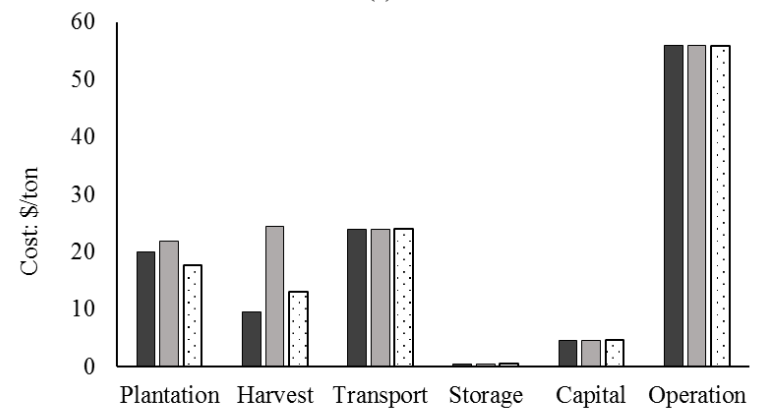

(c)

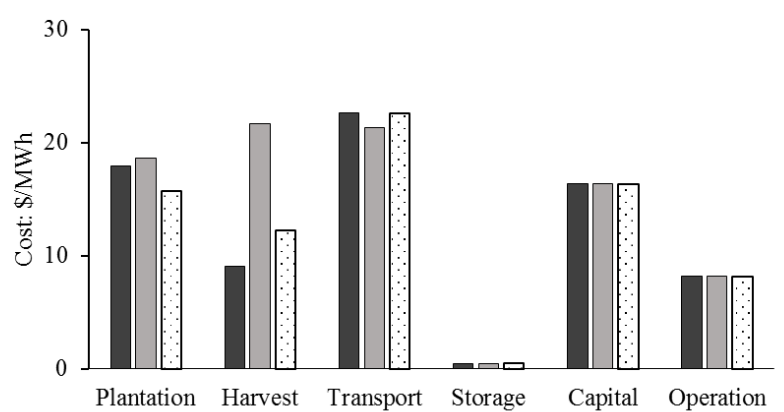

(b)

$\square$ Willow $\square$ Switchgrass $\square$ Miscanthus

Fig. 5-2. Cost components of the biomass supply chain by energy crops and bioenergy products:

(a) biofuel; (b) biopower; (c) pellet.

Table 5-3. Required selling price of bioenergy products by energy crops.

\begin{tabular}{llll}
\hline Crops & $\begin{array}{l}\text { Biofuel: } \$ / \mathrm{bbl} \\
(\$ / \mathrm{GJ})\end{array}$ & $\begin{array}{l}\text { Biopower } \$ \text { /MWh } \\
(\$ / \mathrm{GJ})\end{array}$ & Pellet: $\$ /$ ton $(\$ / \mathrm{GJ})$ \\
\hline Willow & $131.22(26.1)$ & $160.12(44.5)$ & $132.99(7.8)$ \\
Switchgrass & $136.90(27.2)$ & $172.28(47.9)$ & $151.60(8.4)$ \\
Miscanthus & $131.72(26.2)$ & $161.17(44.7)$ & $134.23(7.9)$ \\
\hline
\end{tabular}

Table 5-4. GHG emissions for the production of the three energy products by energy crops.

\begin{tabular}{llllllllll}
\hline Species & Utilization & Plantation & Harvest & $\begin{array}{l}\text { Storage and } \\
\text { preprocessing }\end{array}$ & Production & Distribution & $\begin{array}{l}\text { Final } \\
\text { Usage }\end{array}$ & $\begin{array}{l}\text { Waste } \\
\text { disposal }\end{array}$ & $\begin{array}{l}\text { Total } \\
\left(\mathrm{kg} \mathrm{CO} \mathrm{CO}_{2}\right. \\
\text { eq })\end{array}$ \\
\hline Willow & Biofuel & 0.78 & 0.19 & 13.60 & 25.00 & 0.76 & 1.60 & 0.04 & 41.43 \\
& Biopower & 2.23 & 0.56 & 1.93 & 0.00 & 1.13 & 0.00 & 0.12 & 5.46 \\
& Pellet & 0.63 & 0.13 & 7.34 & 41.79 & 0.78 & 0.46 & 0.03 & 51.02 \\
Switchgrass & Biofuel & 0.87 & 0.05 & 12.51 & 25.00 & 0.76 & 1.60 & 0.07 & 40.86 \\
& Biopower & 2.50 & 0.15 & 3.44 & 0.00 & 1.13 & 0.00 & 0.20 & 7.43 \\
& Pellet & 0.59 & 0.03 & 7.04 & 47.90 & 0.78 & 0.11 & 0.05 & 57.38 \\
Miscanthus & Biofuel & 0.49 & 0.03 & 16.20 & 25.00 & 0.76 & 1.60 & 0.05 & 44.14 \\
& Biopower & 1.42 & 0.10 & 5.82 & 0.00 & 1.13 & 0.00 & 0.16 & 8.62 \\
& Pellet & 0.33 & 0.02 & 7.96 & 47.90 & 0.78 & 0.10 & 0.04 & 58.08 \\
\hline
\end{tabular}


The most emissions occurred in the "Storage and preprocessing" and "Production" processes (Table 5-4). They together accounted for 30-60\% of the total emission for biopower generation, while for over $90 \%$ of the total emission for the production of biofuel or pellet fuel. The biopower production presented the lowest GHG emission among the three bioenergy products, with an average emission of less than $10 \mathrm{~kg} \mathrm{CO}_{2}$ eq per $1,000 \mathrm{MJ}$ of electricity produced. Among the three feedstocks, using willow shrub for biopower generation demonstrated the lowest emission at 5.96kg CO 2 eq per 1,000 MJ. The GHG emission peaked when using miscanthus to produce pellet fuel, which was $57.13 \mathrm{~kg} \mathrm{CO}_{2}$ eq per $1,000 \mathrm{MJ}$ of pellet fuel produced.

Differences of life cycle impact were more significant among the three bioenergy products than among the three energy crops (Fig. 5-3). Two-way ANOVA showed that more than $95 \%$ of the life cycle impact variance was explained by different utilizations of bioenergy products. Fossil energy consumption for biofuel production was $71 \%-73 \%$ and $6 \%-16 \%$ higher than for the production of biopower and pellet fuel, respectively. More fossil energy was needed to convert miscanthus feedstock to bioenergy products than using shrub willow and switchgrass (3.5\%-10.5\% higher). More water was consumed for biopower generation compared to the production of biofuel and pellet (47.9\%-69.7\% higher), though it required a lower input of fossil energy. The production of biofuel had higher impact on carcinogenics and ozone depletion while the production of biopower emitted the highest amount of particulate matter 2.5 (PM2.5). The highest amount of human toxicity materials were emitted when producing pellet fuel. The PCA of human health impact indices of the biomass to bio-products showed the similar results. 


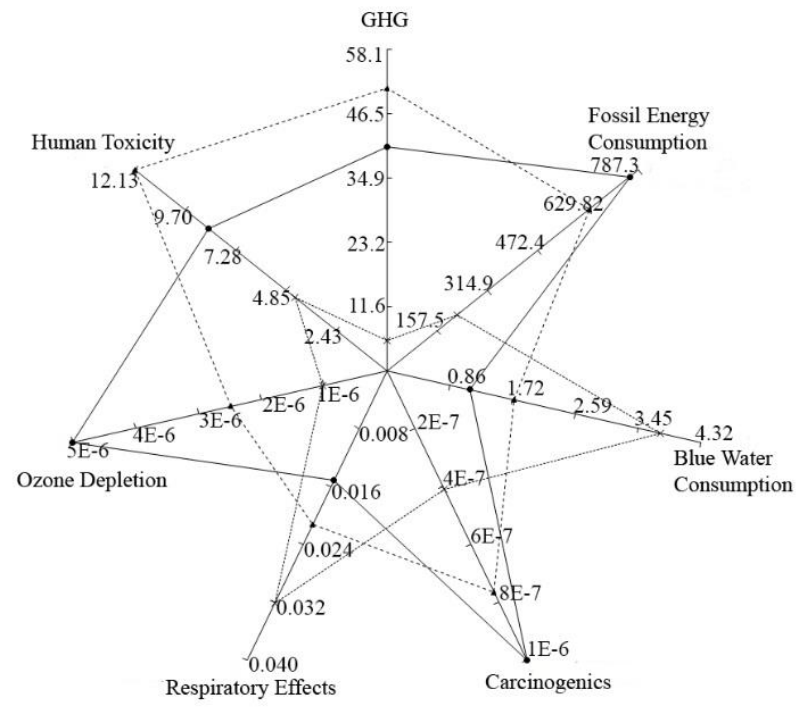

(a)

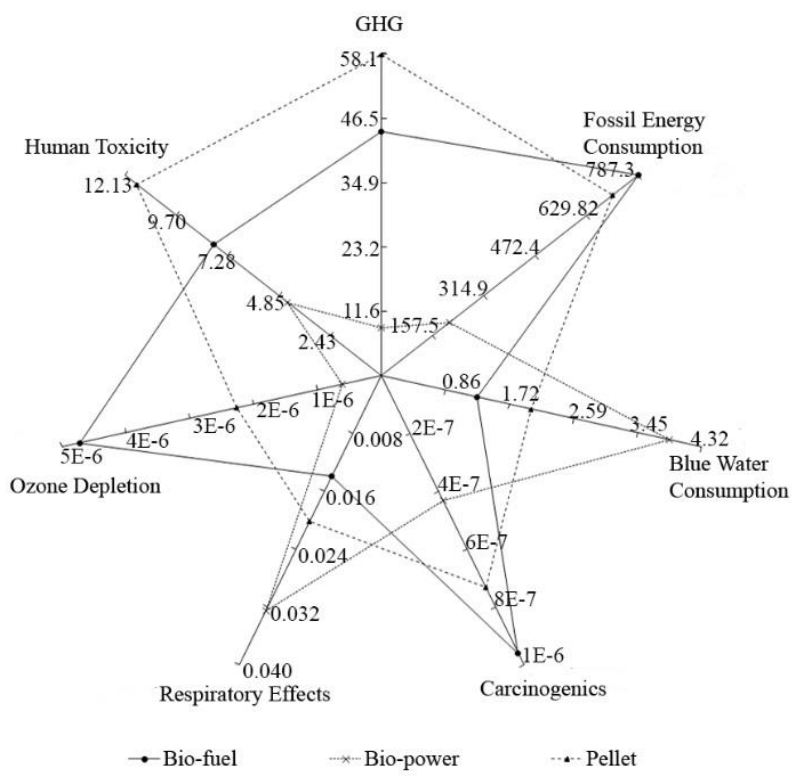

(c)

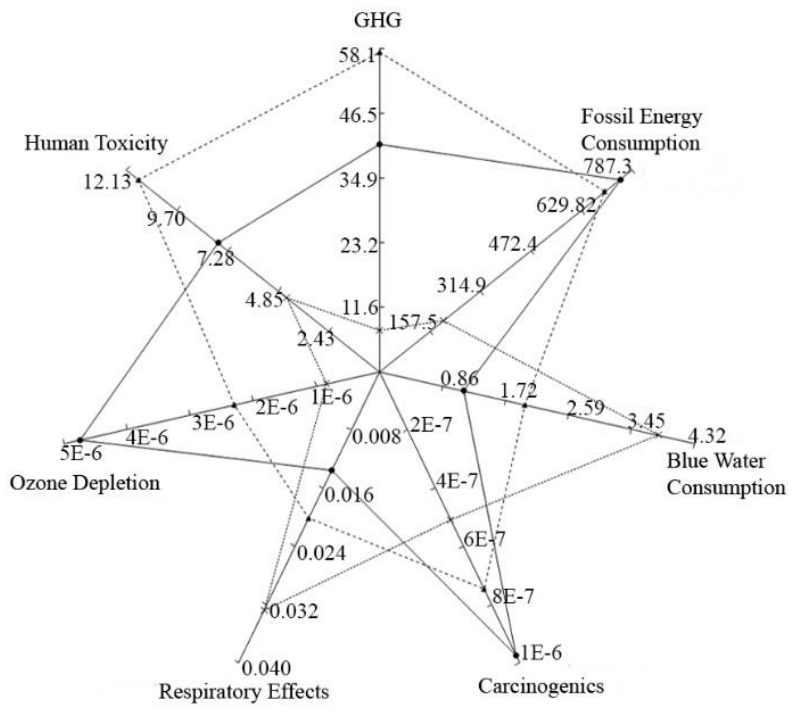

(b)

Fig. 5-3. LCA impact of GHG emissions, fossil energy consumption, blue water consumption and human health impact by energy crops: (a) willow by bioenergy products; (b) switchgrass by bioenergy products and (c) miscanthus by bioenergy products. 


\subsubsection{Sensitivity Analyses of Economic Benefit}

Several factors affect the RSP of bioenergy products including yield of energy crops, transportation distance of biomass, bioproduct yield and the required IRR (Fig. 5-4). For the production of biofuel and biopower, the RSP was very sensitive to IRR and bioproduct yield, followed by transportation distance. The RSP change of $2.6-4.2 \%$ and $2.4-3.4 \%$ was expected when IRR and bioproduct yield changed 10\%, respectively. The RSP was most sensitive to transportation distance for pellet fuel production. A 10\% change of transportation distance induced 1.9-2.1\% change of RSP. The effect of crop yield on RSP was more prominent for pellet fuel production, causing the RSP increase of $1.1-2.5 \%$ by a $10 \%$.increase of crop yield. A $20 \%$ change of plant scale could course a $0.37-1.0 \%$ change of RSP of bioproducts. The effects of these factors on RSP were similar among energy crops. However, some differences could be detected among the crops. Relatively lower effects of crop yield and bioproduct yield occurred on the RSP of bioenergy products from willow feedstock than from perennial grasses.

\subsubsection{Sensitivity of Life Cycle Impact}

The bioproduct yield was the most significant effect on the environmental impact (Fig. 55). The impact changed from $0.52 \%$ to $9.37 \%$ with $10 \%$ change of bioproduct yield from base case. However, the effect was not prominent when biomass was used for pellet fuel production, which the impact changed by $1.14 \%$ to $1.94 \%$. By increasing the transportation distance, the environmental impact was increased accordingly. The impact varied from $0.03 \%-4.73 \%$ with a $10 \%$ change of transportation distance. An increase of yield could reduce the environmental impact. By comparing the environmental impact with changing yield of energy crops by $10 \%$, it

usually had higher influence to produce biofuel $(0.13 \%-0.36 \%)$ and biopower $(0.23 \%-5.6 \%)$ than to produce pellet fuel $(0.09 \%-0.4 \%)$. However, blue water consumption did not have obvious 


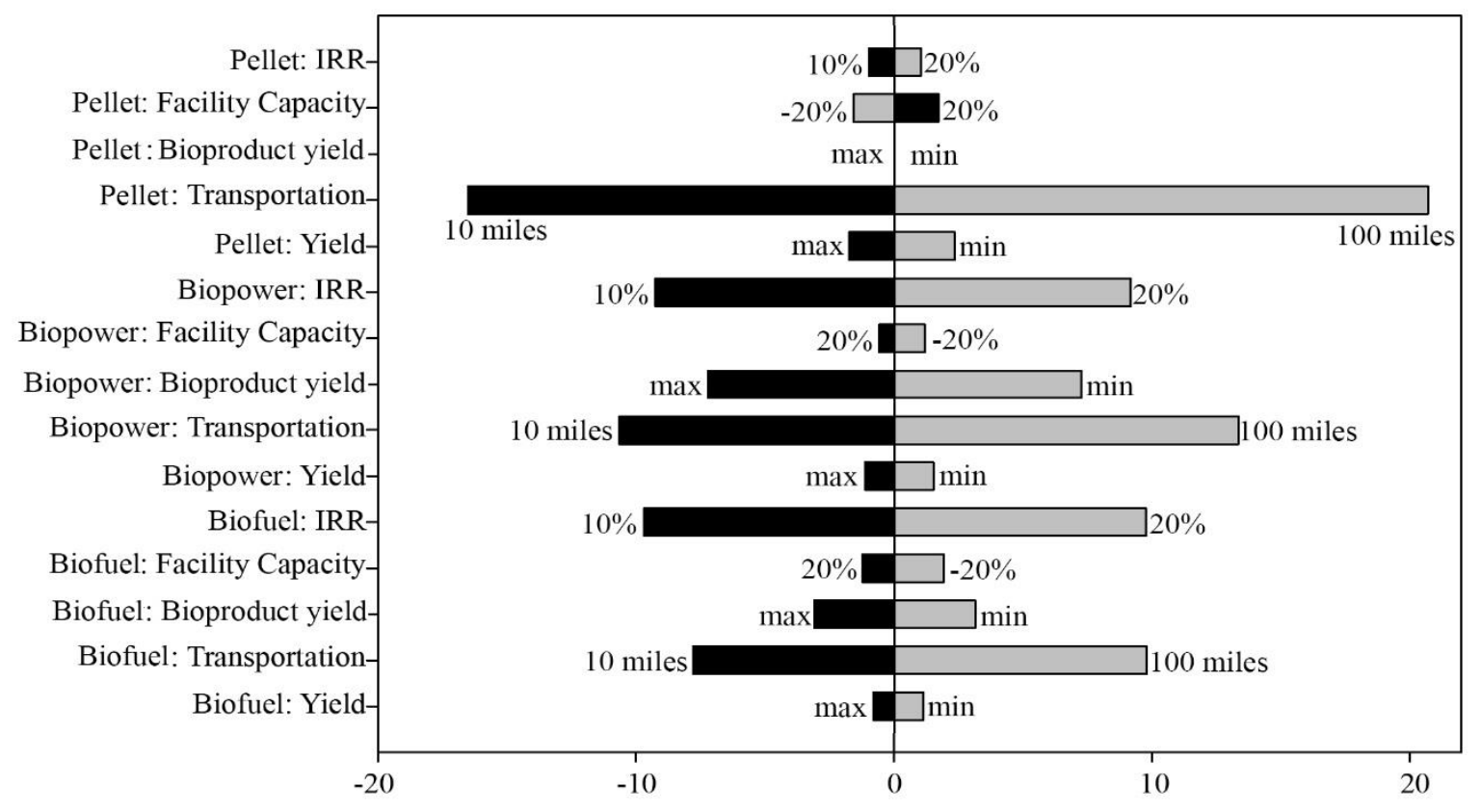

Percentage change of RSP based on basecase: \%

(a)

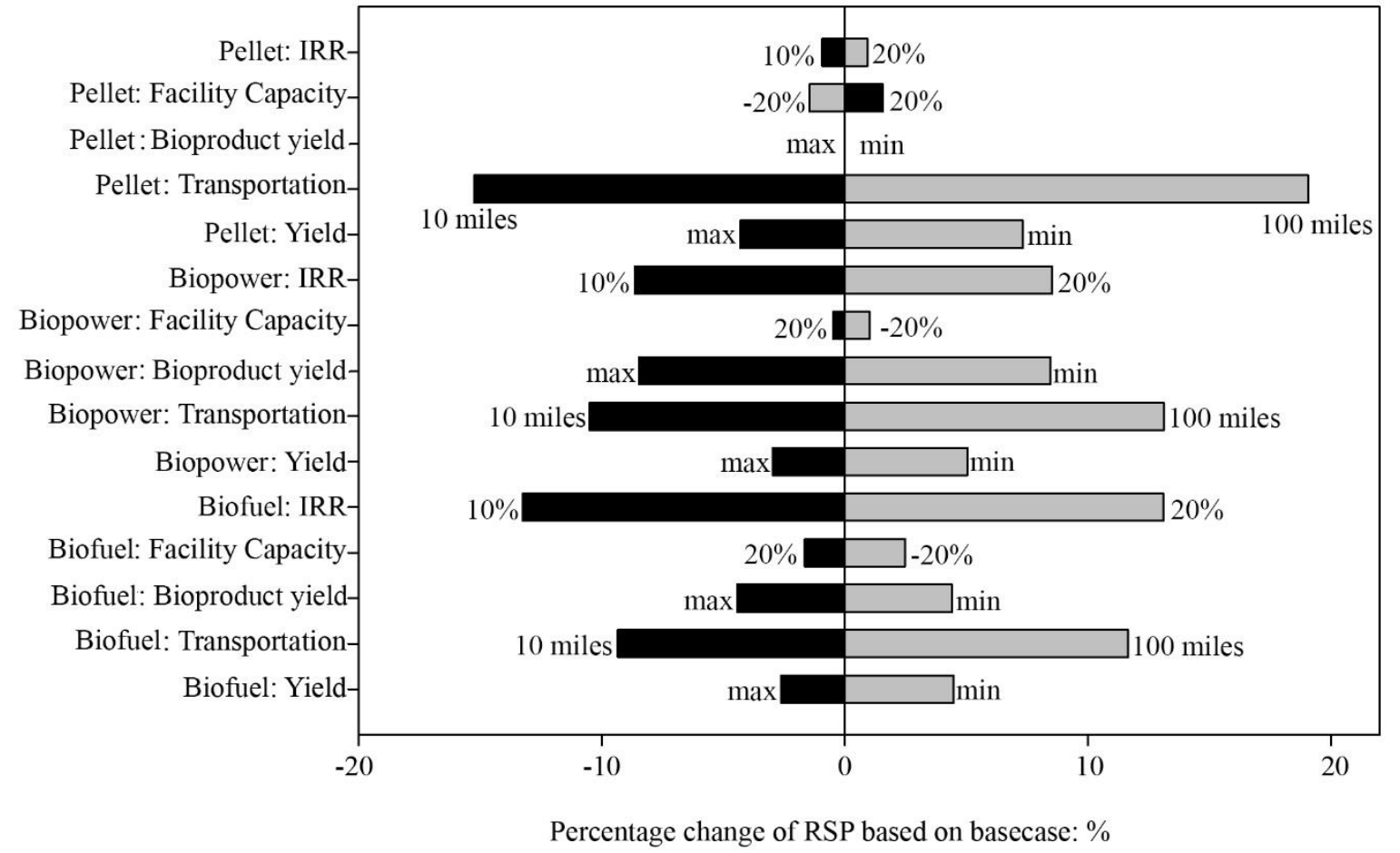

(b)

Fig. 5-4. Sensitivities of crop yield, transportation distance, facility capacity and IRR by energy

crops and bioenergy products: (a) willow; (b) switchgrass; (c) miscanthus. 


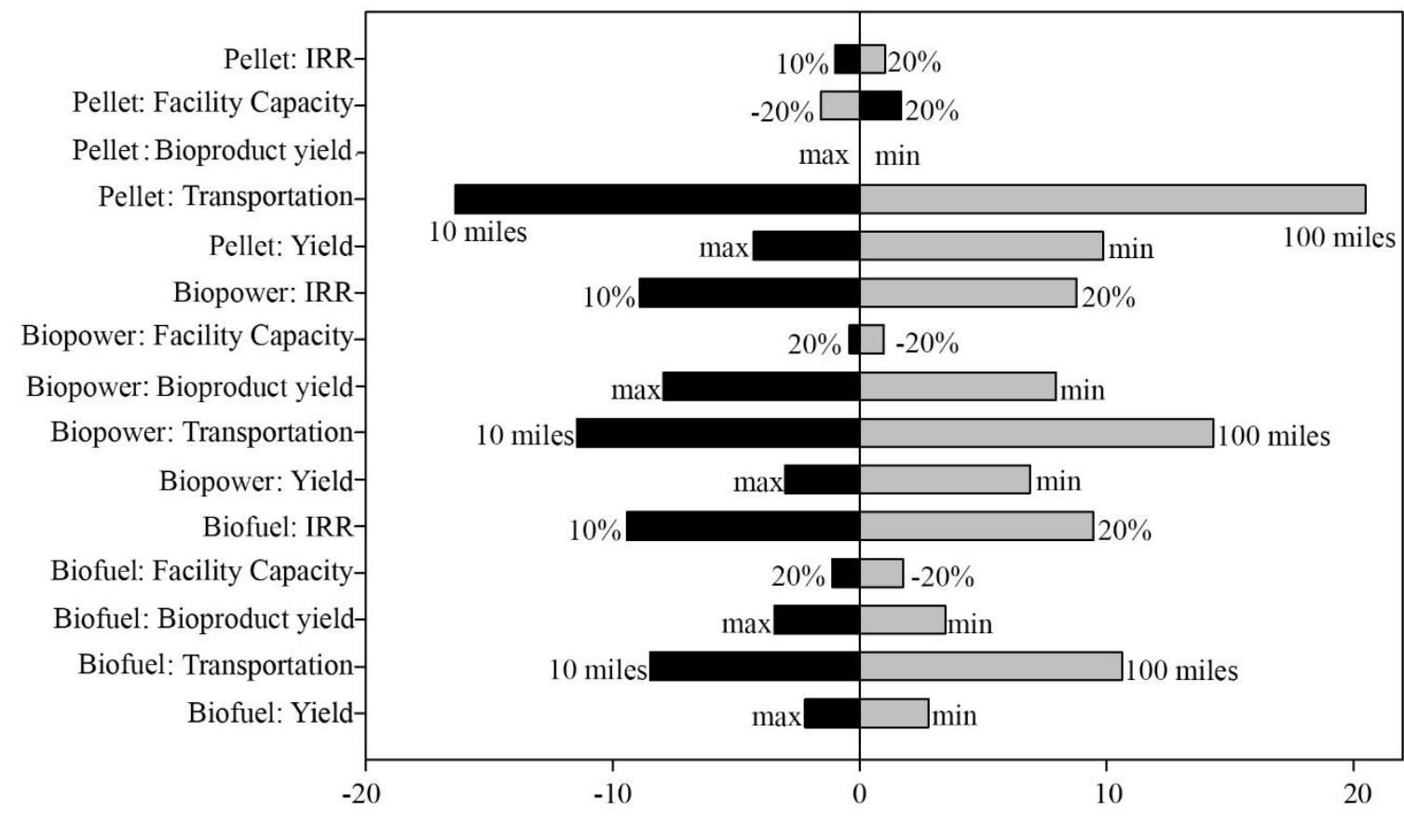

Percentage change of RSP based on basecase: \%

(c)

Fig. 5-4. Continued. 

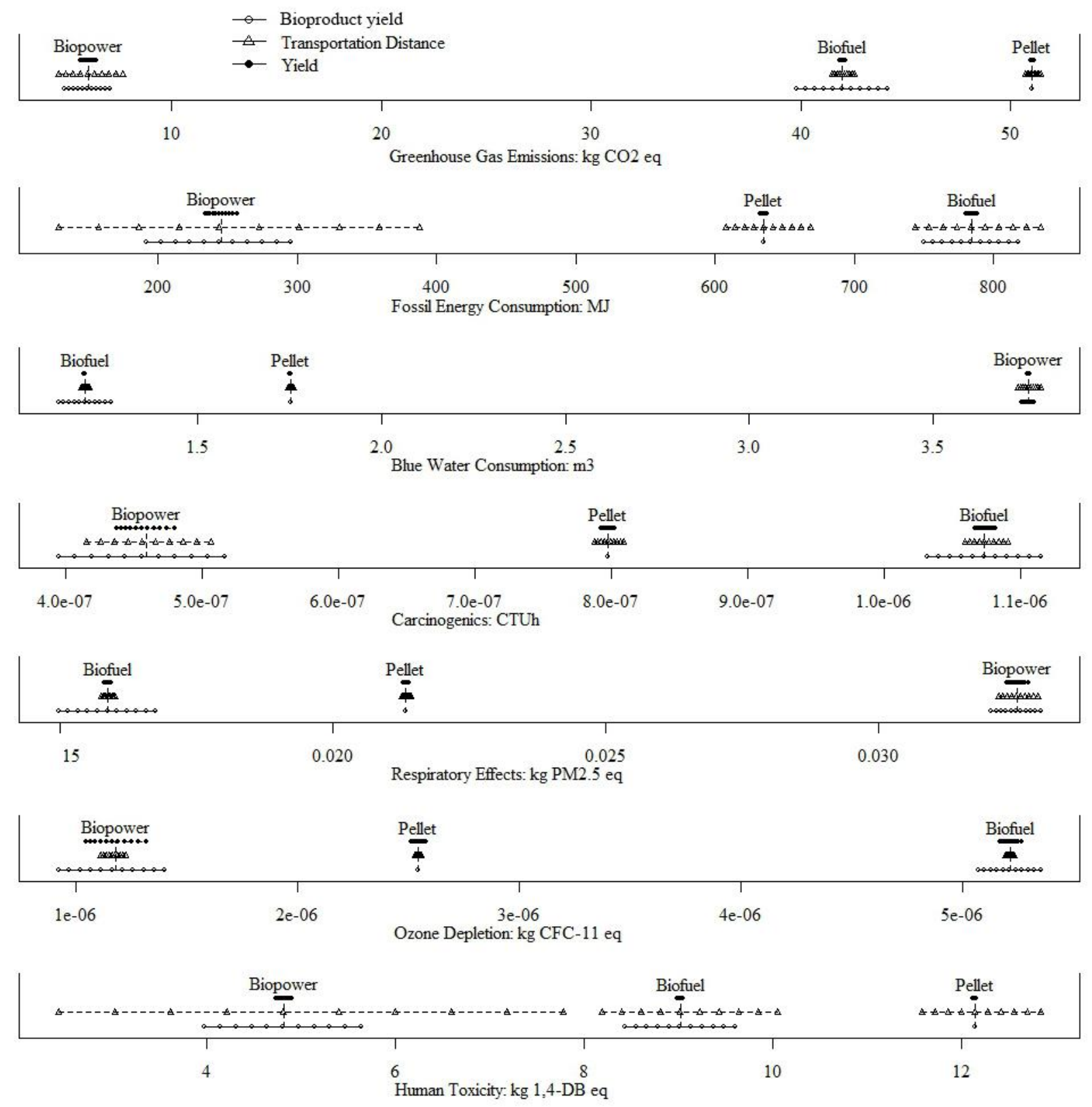

(a)

Fig. 5-5. Sensitivities of LCA impact by energy crops and bioenergy products: (a) willow; (b) switchgrass and (c) miscanthus. 

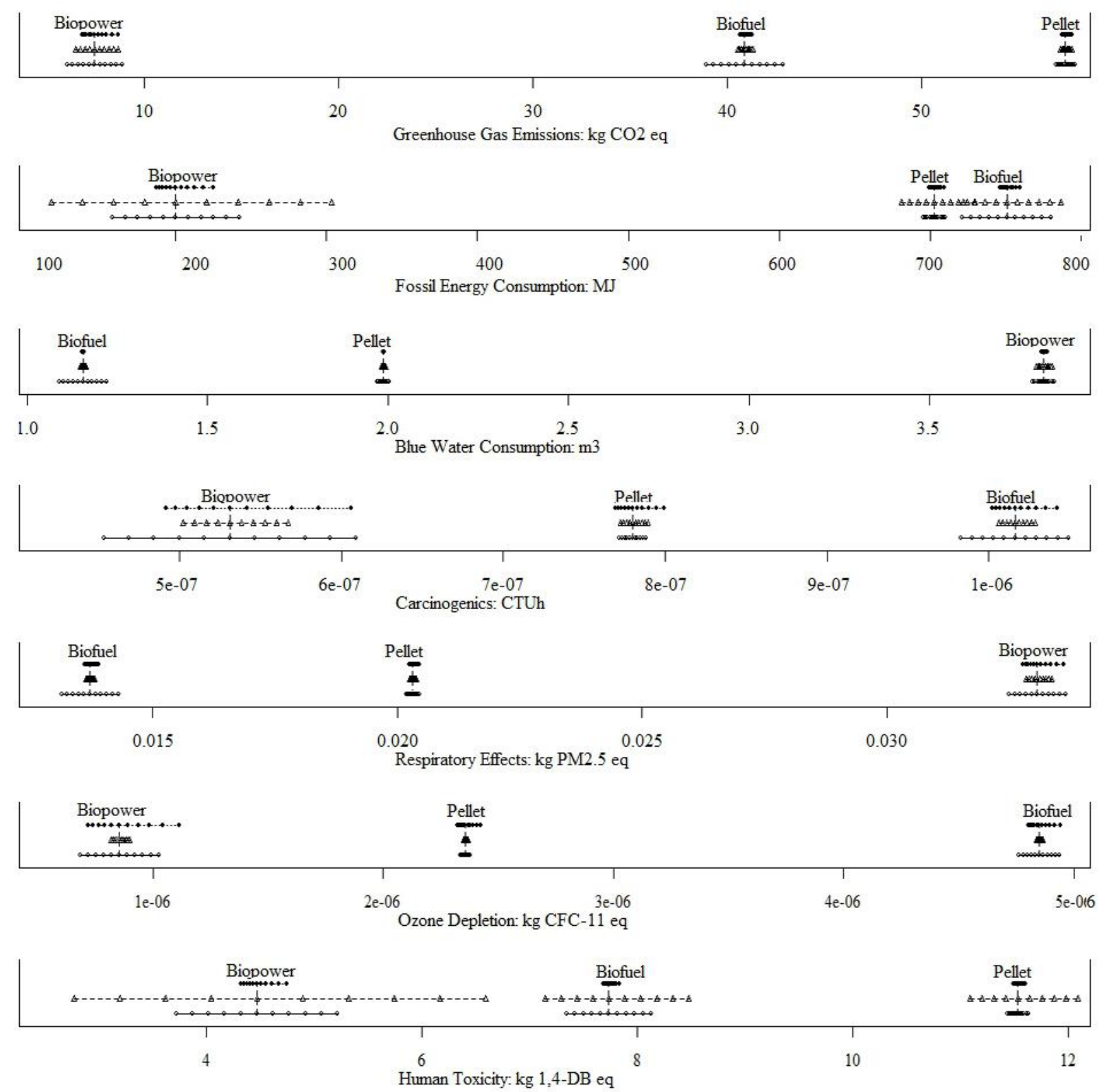

(b)

Fig. 5-5. Continued. 

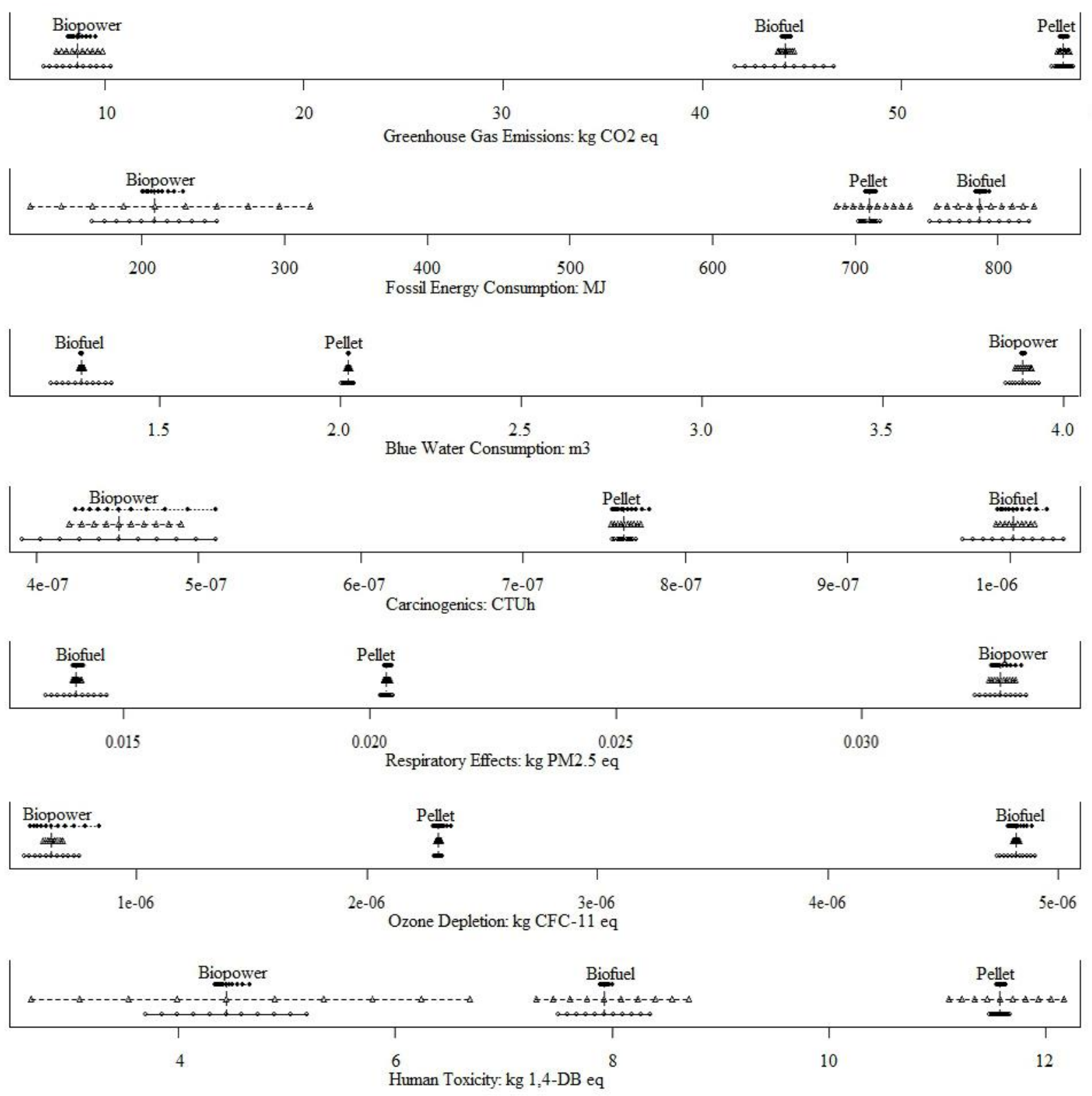

(c)

Fig. 5-5. Continued. 
change along the change of yield of crops $(0.02 \%-0.04 \%)$. The sensitivity of environmental impact on yield of crops, transportation distance and bioproduct yield were similar among all the three energy crops.

\subsection{DISCUSSION}

\subsubsection{Cost Components and RSP}

Operation and maintenance expenses were made up of up to $50 \%$ of the total cost, and followed by transportation, feedstock plantation and harvest. The production of pellet fuel required high cost for electricity consumption at facility, so the percentage of operation and maintenance cost at pellet mill was higher than other two bio-product production systems (Yancey et al. 2013). Using willow always presented lower cost than perennial grasses because of its high energy content that also leads to lower level consumption of biomass to produce the same amount of energy equivalent bioenergy product. In this study, bio-char and off-gas were recycled in the process of fast pyrolysis (Jones and Male 2012), so the operation and maintenance cost for biofuel production could be higher. Because less pretreatment of biomass was required in biopower generation, its operation and maintenance cost was mainly caused by boiler systems (IRENA 2012).

In this study, the RSP of liquid fuels produced by fast pyrolysis was $\$ 3.14-\$ 3.25 /$ gal, which is higher than a study by Brown (2015). It is hard to compete with conventional petroleum derived fuels because the low price of fossil fuels from the end of 2014 till date (EIA 2015). The price of biopower generation at $\$ 160.12 / \mathrm{MWh}-172.28 / \mathrm{MWh}$ was similar to the result by Kumar et al. (2003) after converting their results to the current dollars. The average annual price of electricity in 2013 by state in the Northeast ranged from \$78.1/MWh in West Virginia to 
\$159/MWh in Connecticut according to the EIA Electric Power Monthly Report (EIA 2015).

Our result of the RSP for biopower was a little higher than this range, so it implies the feasibility of biomass fired power plants could happen in this region if the bioproduct yield can be improved. Our study indicated that the price of pellet production could be lower due to efficient feedstock logistics, and lower capital investment for these facilities in the region.

\subsubsection{Environmental Impact}

Most of the GHG emissions occurred in the "Storage and preprocessing" and "Production" processes at facility site. The change of GHG emissions among different bioenergy products could be mostly explained by the different procedures being used at the facilities. The production of biopower emitted less GHGs than the production of biofuel or pellet fuel. This is because the heat and electricity in power plants were provided by biomass, thus more feedstock is required (Perilhon 2012). The GHG emissions were higher when produce pellet fuel because of the high electricity consumption for operating pellet mill, dryer, grinder and hammer mill. The electricity consumption was considered as fossil energy produced by coal in the LCA model. If the electricity consumed to produce biofuel and pellet fuel was generated by biomass or other renewable resources, the emissions could be reduced. Fast pyrolysis is an energy intensive process to produce biofuel, the energy consumption could be reduced through recycling byproducts, off-gas and bio-char, for preheating (Jones and Male 2012). Power plant typically needs more water for cooling, and consequently the water consumption of biopower generation is higher than the production of biofuel and pellet fuel.

More energy is required to process miscanthus than switchgrass and willow due to its properties which make it recalcitrant than other crops (Yancey et al. 2013). Willow has higher energy content than perennial grasses, as well as specific physical and chemical properties 
(Stolarski et al. 2013), allowing it to be processed or handled easily. Low ash content also ensures willow has a relatively higher energy bioproduct yield to bioenergy products (Fahmi et al. 2008). Disposal of ash is always an issue during the production of bioenergy products. However, ash may be collected and sprayed in the field as fertilizer without further negative environmental impact.

We found that most of the variations of LCA impact could be explained by different processes of three bioenergy products. Different feedstock requirements at facility required different pretreatments with different liquid fuel yield to bioenergy products. The combustion of biomass in biopower generation produced a relatively higher level of PM2.5 that could possibly cause respiratory problems of workers. The emission of smoke and dust in power industry is usually higher than in other industries (Yi et al. 2012). Fossil fuel power generation could produce high emission of human toxicity materials (Korre et al. 2010). The higher emission of human toxicity materials during the production of pellet fuel is mainly because of the usage of the fossil fuel derived electricity. The environmental impact of the production of bioenergy products did not significantly differ among the three energy crops. The differences were due primarily to the different bioproduct yield, feedstock development and harvesting systems.

\subsubsection{Sensitivity Analyses}

Yield of energy crops, transportation distance of biomass, bioproduct yield and IRR were analyzed to understand their effects on RSP. Bioproduct yield was sensitive in the production of biofuel and biopower because a little change of bioproduct yield will bring more change on demand of feedstock comparing to pellet fuel. Longer transportation distance would dramatically increase the biomass delivered cost. It is essential to reduce the transportation cost through optimizing biomass logistics (Wu et al. 2011). However, a longer procurement radius is always 
required for large scale biomass facilities. Larger facility requires more biomass which also increases the biomass handling cost which leads to high RSP (Sultana et al. 2010), so an increase of facility scale will increase RSP of bioproduct. IRR was sensitive to produce biopower because large proportion of total cost was investment of capital cost.

Sensitivity analyses on environmental impact were conducted by changing yield of energy crops, transportation distance and bioproduct yield. Prominent effects on environmental impact were obtained by changing bioproduct yield. Thus, the improvement of biomass conversion could significantly reduce GHG emission, fossil energy consumption, water consumption and human health effects because of the reduction of feedstock demand. Fossil energy consumption and human toxicity were also sensitive to transportation distance because of most of toxic emissions were contributed by transportation fuel combustion. The environmental burden of biopower showed a high sensitivity to feedstock transport distance. This is because a large amount of biomass is typically required to produce 1,000 MJ energy equivalent biopower. High biomass demand also leads to a sensitive response of environmental impact by changing the yield of energy crops. Thus, because less amount of biomass is required to produce same amount of energy equivalent pellet fuel, environmental impact in biomass to pellet fuel system was less sensitive in the change of energy crop yield than the other two bioproducts.

\subsection{CONCLUSIONS}

The economic analysis showed the RSP of different bioproducts ranged from $\$ 7.8 / \mathrm{GJ}$ to $\$ 27.2 / G J$. Biopower had the highest RSP and pellet fuel required the lowest selling price. Most of the costs were accounted by Operation and maintenance in the production of pellet fuel and biofuel. The feedstock handling system accounted the most cost in the production of biopower. 
The LCA study obtained environmental impact of different cases. Different bio-products required different specific preprocess and process procedures, so the variance of environmental burden and cost were mostly explained by the production of different bio-products. Biopower had lowest GHG emissions and fossil energy consumption, but had highest water consumption and particulate matter emission. The production of pellet fuel has highest GHG emissions.

The change of RSP had different pattern among bio-products according to different change of yield, transportation distance, bioproduct yield, facility capacity and IRR. IRR and bioproduct yield were most sensitive when producing biofuel and biopower. Transportation distance had most prominent effect on RSP when producing pellet fuel. The effects of crop yield on RSP was higher when produce pellet fuel than biopower and biofuel. An increase of facility scale would generally rise the RSP of bioproducts. The analyses of sensitivity on environmental impact showed that bioproduct yield was the most significant effect. The increase of transportation distance would increase the environmental burden accordingly. The increase of crop yield could reduce the environmental impact.

\section{ACKNOWLEDGEMENT}

This research was supported by Agriculture and Food Research Initiative Competitive Grant No. 2012-68005-19703 from the USDA National Institute of Food and Agriculture. The authors would like to thank Jacob J. Jacobson, Jaya Shankar Tumuluru, Neal Yancey, Allison E. Ray of the Idaho National Laboratory for providing useful data and thoughtful suggestions. The authors are also grateful to Drs. Peter Woodbury, Jude Liu, Larry Smart, Armen Kermaian, and Stacy Bonos for providing field dada and valuable suggestions on crop yield and field 


\section{REFERENCES}

Augustínová, J., Cvengrošová, Z., Mikulec, J., Vasilkovová, B., and Cvengroš, J. 2013.

Upgrading of biooil from fast pyrolysis. In 46th International Conference on Petroleum Processing.

Bai, Y., Luo, L., and van der Voet, E. 2010. Life cycle assessment of switchgrass-derived ethanol as transport fuel. International Journal of Life Cycle Assessment 15(5): 468-477.

Bare, J. 2012. Tool for the reduction and assessment of chemical and other environmental impact (TRACI) - user's manual. U.S. Environmental Protection Agency.

Boulay, A.M., Bulle, C., Bayart, J.B., Deschenes, L., and Margni, M. 2011. Regional Characterization of Freshwater Use in LCA: Modeling Direct Impact on Human Health. Environmental science \& technology 45(20): 8948-8957.

Brassard, P., Palacios, J.H., Godbout, S., Bussieres, D., Lagace, R., Larouche, J.P., and Pelletier, F. 2014. Comparison of the gaseous and particulate matter emissions from the combustion of agricultural and forest biomasses. Bioresource Technology 155: 300-306.

Brosse, N., Dufour, A., Meng, X.Z., Sun, Q.N., and Ragauskas, A. 2012. Miscanthus: a fastgrowing crop for biofuels and chemicals production. Biofuels Bioproducts \& BiorefiningBiofpr 6(5): 580-598.

Brown, T.R. 2015. A techno-economic review of thermochemical cellulosic biofuel pathways. Bioresource Technology 178: 166-176. 
Caputo, J., Balogh, S.B., Volk, T.A., Johnson, L., Puettmann, M., Lippke, B., and Oneil, E. 2014. Incorporating Uncertainty into a Life Cycle Assessment (LCA) Model of ShortRotation Willow Biomass (Salix spp.) Crops. Bioenergy Research 7(1): 48-59.

Chen, S. 2009. Life cycle assessment of wood pellet. In Division of environmental system analysis. Chalmers University of Technology, Göteborg, Sweden.

Duffy, M. 2013. Estimated Costs of Crop Production in Iowa, 2014. Iowa State University.

EIA. 2015. Electric power monthly with data for November 2014. U.S. Energy Information Administration.

EIA. 2015. Gasoline and diesel fuel update. Available from http://www.eia.gov/petroleum/gasdiesel/ [accessed March 24 2015].

EPA. 2007. Biomass combined heat and power catalog of technologies. U.S. Environmental Protection Agency Combined Heat and Power Partnership. Washington, DC.

Emery, I.R., and Mosier, N.S. 2012. The impact of dry matter loss during herbaceous biomass storage on net greenhouse gas emissions from biofuels production. biomass and bioenergy 39: $237-246$.

Fahmi, R., Bridgwater, A.V., Donnison, I., Yates, N., and Jones, J. 2008. The effect of lignin and inorganic species in biomass on pyrolysis oil yields, quality and stability. Fuel 87(7): 12301240.

Fantozzi, F., and Buratti, C. 2010. Life cycle assessment of biomass chains: Wood pellet from short rotation coppice using data measured on a real plant. Biomass \& Bioenergy 34(12): 1796-1804. 
Forster, P., Ramaswamy, V., Artaxo, P., Berntsen, T., Betts, R., Fahey, D.W., Haywood, J., J., L., Lowe, D.C., Myhre, G., Nganga, J., Prinn, R., Raga, G., Schulz, M., and Van Dorland, R. 2007. Changes in Atmospheric Constituents and in Radiative Forcing. In Climate change 2007-the physical science basis: Working group I contribution to the fourth assessment report of the IPCC. Edited by S. Solomon, D. Qin, M. Manning, Z. Chen, M. Marquis, K. B. Averyt, M. Tignor, and H. L. Miller. Cambridge University Press.

Frischknecht, R., Jungbluth, N., Althaus, H.-J., Hischier, R., Doka, G., Bauer, C., Dones, R., Nemecek, T., Hellweg, S., and Humbert, S. 2007. Implementation of life cycle impact assessment methods. Data v2. 0 (2007). Ecoinvent report No. 3. Ecoinvent Centre, Swiss Federal Laboratories for Materials Testing and Research (EMPA), Duebendorf (Switzerland).

Graham, R.L. 1994. An Analysis of the Potential Land Base for Energy Crops in the Conterminous United-States. Biomass \& Bioenergy 6(3): 175-189.

Hartley, D.S. 2014. Modeling and Optimization of Woody Biomass Harvest and Logistics in the Northeastern United States. WEST VIRGINIA UNIVERSITY, Morgantown, WV.

Hinchee, M., Rottmann, W., Mullinax, L., Zhang, C.S., Chang, S.J., Cunningham, M., Pearson, L., and Nehra, N. 2009. Short-rotation woody crops for bioenergy and biofuels applications. In Vitro Cellular \& Developmental Biology-Plant 45(6): 619-629.

Hsu, D.D. 2012. Life cycle assessment of gasoline and diesel produced via fast pyrolysis and hydroprocessing. Biomass \& Bioenergy 45: 41-47.

Hunsberger, R., and Mosey, G. 2014. Pre-Feasibility Analysis of Pellet Manufacturing on the Former Loring Air Force Base Site. National Technical Information Service. 
IRENA. 2012. Renewable energy technologies: cost analysis series. Volume 1 issue 1/5:

Biomass for power generation. International Renewable Energy Agency.

Jones, S.B., and Male, J.L. 2012. Production of Gasoline and Diesel from Biomass via Fast Pyrolysis, Hydrotreating and Hydrocracking: 2011 State of Technology and Projections to 2017. Pacific Northwest National Laboratory, Richland, Washington, U.S.

Jones, S.B., Valkenburg, C., Walton, C.W., Elliott, D.C., Holladay, J.E., Stevens, D.J., Kinchin, C., and Czernik, S. 2009. Production of gasoline and diesel from biomass via fast pyrolysis, hydrotreating and hydrocracking: a design case. Pacific Northwest National Laboratory Richland, WA.

Jorge, R.S., Hawkins, T.R., and Hertwich, E.G. 2012. Life cycle assessment of electricity transmission and distribution-part 1: power lines and cables. International Journal of Life Cycle Assessment 17(1): 9-15.

Kenney, K.L., Cafferty, K.G., Jacobson, J.J., Bonner, I.J., Gresham, G.L., Hess, J.R., Ovard, L.P., Smith, W.A., Thompson, D.N., Thompson, V.S., Tumuluru, J.S., and Yancey, N. 2013. Feedstock Supply System Design and Economics for Conversion of Lignocellulosic Biomass to Hydrocarbon Fuels. Idaho National Laboratory.

Kerstetter, J.D., and Lyons, J.K. 2001. Logging and agricultural residue supply curves for the Pacific Northwest. Washington State University Energy Program.

Khanna, M., Dhungana, B., and Clifton-Brown, J. 2008. Costs of producing miscanthus and switchgrass for bioenergy in Illino is. biomass and bioenergy 32(6): 482-493. 
Korre, A., Nie, Z.G., and Durucan, S. 2010. Life cycle modelling of fossil fuel power generation with post-combustion CO2 capture. International Journal of Greenhouse Gas Control 4(2): 289-300.

Kumar, A., Cameron, J.B., and Flynn, P.C. 2003. Biomass power cost and optimum plant size in western Canada. Biomass \& Bioenergy 24(6): 445-464.

Liu, J., and Kemmerer, B. 2011. Field Performance Analysis of a Tractor and a Large Square Baler. SAE Technical Paper.

Mann, M., and Spath, P. 2001. A life cycle assessment of biomass cofiring in a coal-fired power plant. Clean Products and Processes 3(2): 81-91.

Marra, M., Keene, T., Skousen, J., and Griggs, T. 2013. Switchgrass Yield on Reclaimed Surface Mines for Bioenergy Production. Journal of Environmental Quality 42(3): 696-703.

Miguez, F.E., Zhu, X., Humphries, S., Bollero, G.A., and Long, S.P. 2009. A semi mechanistic model predicting the growth and production of the bioenergy crop Miscanthus $\times$ giganteus: description, parameterization and validation. Global Change Biology Bioenergy 1(4): 282296.

Paul, A.D. 2009. A Fresh Look at Coal-Derived Liquid Fuels. Power 153(1): 46-51.

Perilhon, C., Alkadee, D., Descombes, G., and Lacour, S. 2012. Life cycle assessment applied to electricity generation from renewable biomass. Terragreen 2012: Clean Energy Solutions for Sustainable Environment (Cesse) 18: 165-176. 
Pirraglia, A., Gonzalez, R., Saloni, D., and Denig, J. 2013. Technical and economic assessment for the production of torrefied ligno-cellulosic biomass pellets in the US. Energy Conversion and Management 66: 153-164.

Ringer, M., Putsche, V., and Scahill, J. 2006. Large-scale pyrolysis oil production: a technology assessment and economic analysis. NETL.

Rodrigue, J.A., and Burger, J.A. 2004. Forest soil productivity of mined land in the midwestern and eastern coalfield regions. Soil Science Society of America Journal 68(3): 833-844.

Schweier, J., and Becker, G. 2012. New Holland forage harvester's productivity in short rotation coppice: evaluation of field studies from a German perspective. International Journal of Forest Engineering 23(2): 82-88.

Searchinger, T., Heimlich, R., Houghton, R.A., Dong, F.X., Elobeid, A., Fabiosa, J., Tokgoz, S., Hayes, D., and Yu, T.H. 2008. Use of US croplands for biofuels increases greenhouse gases through emissions from land-use change. Science 319(5867): 1238-1240.

Sharma, B., Ingalls, R.G., Jones, C.L., and Khanchi, A. 2013. Biomass supply chain design and analysis: Basis, overview, modeling, challenges, and future. Renewable \& Sustainable Energy Reviews 24: 608-627.

Snowden-Swan, L.J., and Male, J.L. 2012. Summary of Fast Pyrolysis and Upgrading GHG Analyses. Pacific Northwest National Laboratory

Sokhansanj, S., Mani, S., Turhollow, A., Kumar, A., Bransby, D., Lynd, L., and Laser, M. 2009. Large-scale production, harvest and logistics of switchgrass (Panicum virgatum L.) - current 
technology and envisioning a mature technology. Biofuels, Bioproducts and Biorefining 3(2): 124-141.

Spath, P.L., Mann, M.K., and Kerr, D.R. 1999. Life cycle assessment of coal-fired power production. National Renewable Energy Lab., Golden, CO(US).

Stolarski, M.J., Szczukowski, S., Tworkowski, J., and Klasa, A. 2013. Yield, energy parameters and chemical composition of short-rotation willow biomass. Industrial Crops and Products 46: 60-65.

Sultana, A., Kumar, A., and Harfield, D. 2010. Development of agri-pellet production cost and optimum size. Bioresource Technology 101(14): 5609-5621.

Wang, M. 2009. The GREET spreadsheet model: greenhouse gases and regulated emissions and energy use in transportation, Version 1.8 c. Center for Transportation Research, Energy Systems Division, Argonne National Laboratory.

Wright, M.M., Daugaard, D.E., Satrio, J.A., and Brown, R.C. 2010. Techno-economic analysis of biomass fast pyrolysis to transportation fuels. Fuel 89: S11-S19.

Wu, J.Z., Wang, J.X., Cheng, Q.Z., and DeVallance, D. 2012. Assessment of coal and biomass to liquid fuels in central Appalachia, USA. International Journal of Energy Research 36(7): 856-870.

Yancey, N.A., Tumuluru, J.S., and Wright, C.T. 2013. Drying, Grinding and Pelletization Studies on Raw and Formulated Biomass Feedstock's for Bioenergy Applications. Journal of Biobased Materials and Bioenergy 7(5): 549-558. 
Yi, H.H., Hao, J.M., Duan, L., Li, X.H., and Guo, X.M. 2006. Characteristics of inhalable particulate matter concentration and size distribution from power plants in China. Journal of the Air \& Waste Management Association 56(9): 1243-1251. 


\section{SuMmary}


A set of modeling techniques were applied in this dissertation to assess the economics and environmental impact of the utilization of biomass to produce bioenergy products in the northeastern United States. According to the results from the models and case scenarios, as well as sensitivity analyses, the following conclusions can be drawn:

(1) In the base case, the average sequestration potential was $0.408 \mathrm{Mg} \cdot \mathrm{ha}^{-1} \cdot \mathrm{year}^{-1}$. Several factors affected the carbon sequestration rate of the central Appalachian mixed hardwood forests. They included: permissible contiguous harvest area, carbon price, biomass price, and harvest intensity. Carbon price and harvest intensity were the two most sensitive factors. The results of the model showed that less timber would be harvested with the rising of carbon price. If forest carbon price is high enough, harvest intensity would be limited and a maximum carbon sequestration would be achieved. When the carbon to timber price ratio was low, lower harvest intensity of partial cut would allow more carbon storage compared to clear-cut. Large area limitation would be preferred when the carbon price was low. The increase of biomass price could encourage more harvest which subsequently resulted in a reduction of carbon sequestration.

(2) Economic and environmental modeling is a viable process to analyze the effects of coal and biomass utilization for the production of liquid fuels. The RSP of liquid fuels was $\$ 113.01 / \mathrm{bbl}$ with the $\mathrm{GHG}$ emissions at $93.6 \mathrm{~kg} \mathrm{CO} 2 \mathrm{eq} / 1,000 \mathrm{MJ}$ for the base case. Over $80 \%$ of the total cost was associated with the purchase of feedstock and operation and maintenance of the facilities. Most of the GHG emissions were attributed to the thermo-chemical conversion and combustion of final uses $(85.5 \%)$. Most of blue water and fossil energy were consumed in conversion process at CBTL facility. The price change of feedstock directly affected the RSP. More biomass mixed with coal and lower liquid fuel yield would rise the RSP. The highest RSP 
was $\$ 157.9 / \mathrm{bbl}$ when the biomass/coal mix ratio was 30/70 at the minimum liquid fuel yield while the lowest RSP was $\$ 104 / b b l$ when no biomass was used and at the maximum liquid fuel yield. Lower IRR would definitely allow to reduce the RSP. A $20 \%$ change of capital cost and operational and maintenance cost could result in $10-12 \%$ and $1.93-2.26 \%$ change of the RSP for different mix ratios. Sensitivity analyses conducted on LCA showed the effects of mix ratio and liquid fuel yield on GHG emissions. High biomass ratio in the feedstock and high liquid fuel yield would reduce the GHG emission.

(3) Two potential utilizations of forest residues for small scale production of bioenergy in West Virginia were analyzed for the economic and environmental effects. The RSP in base case was $\$ 90.87 / \mathrm{bbl}$ for ethanol and $\$ 126.08 / \mathrm{bbl}$ for diesel and gasoline. The sensitivity analysis showed RSP was significantly affected by liquid fuel yield and followed by IRR and price of biomass. A $10 \%$ change of liquid fuel yield would lead $5.98 \%$ and $6.94 \%$ change of RSP for BTE (biomass to ethanol) and BLFP (biomass to liquids via fast pyrolysis). The GHG emissions were $9.72 \mathrm{~kg} \mathrm{CO}_{2}$ eq and $30.5 \mathrm{~kg} \mathrm{CO}_{2}$ eq for BTE and BLFP, respectively. BLFP had more intensive water and energy consumption than BTE. The uncertainty analysis of LCA showed the possibility of negative net energy output but the possibility was lower than $2.5 \%$.

(4) The economic analysis showed the costs of bioproducts from energy crops changed from $\$ 7.36 / \mathrm{GJ}$ to $\$ 23.82 / \mathrm{GJ}$. Most of the costs in the production of biofuel and pellet fuel were accounted by operation and maintenance of facilities. The feedstock handling attributed to the most of the cost in the production of biopower. The RSP ranged from $\$ 7.8 / \mathrm{GJ}$ to $\$ 27.2 / \mathrm{GJ}$ for different bioenergy products. Biopower had the highest RSP $(\$ 26.1 / \mathrm{GJ}-\$ 27.2 / \mathrm{GJ})$ and pellet fuel required the lowest selling price $(\$ 7.8 / \mathrm{GJ}-\$ 8.4 / \mathrm{GJ})$. The environmental impact of biomass to bioenergy products were assessed by LCA model. The GHG emissions ranged from $5.96 \mathrm{~kg} \mathrm{CO}_{2}$ 
eq per $1,000 \mathrm{MJ}$ to $57.13 \mathrm{~kg} \mathrm{CO}_{2}$ eq per 1,000 MJ. Biopower had the lowest $\mathrm{GHG}$ emissions while pellet fuel bore the highest GHG emissions. Biopower also had the lowest fossil energy consumption but required the highest water consumption compared to the other two products. Different bioproducts required different specific preprocess and process procedures, so the variances of environmental burden and cost were mostly explained by the production process of different bioproducts.

Sensitivity analyses showed RSP was affected by crop yield, transportation distance, bioproduct yield, facility capacity and IRR. In the production of biofuel and biopower, a 10\% change of IRR and bioproduct yield could change RSP by $2.6-4.2 \%$ and $2.4-3.4 \%$, respectively. The RSP was most sensitive to transportation distance in the production of pellet fuel. The increase of facility capacity by $20 \%$ could only lead to a $0.37-1.0 \%$ increase of RSP. It also showed that bioproduct yield was the most significant effect. A change of $10 \%$ of bioproduct yield would change $0.52-9.37 \%$ of environmental impact. An increase of transportation distance would also result in an increase of the environmental burden accordingly. 


\section{APPEndiX A. SuPplemental InfOrmation for Chapter 2}

The difference of this model from the previous models is that it allows multiple cuts of a stand in the planning horizon. This modification will provide more options to optimize the total revenue and increase the carbon sequestration.

\section{A.1. VARIABLe In THE MODEL}

A binary variable $\boldsymbol{x}_{\boldsymbol{i t}}$ was defined to represent the harvest decision for a stand:

$x_{i t}=\left\{\begin{array}{l}1, \text { if stand } i \text { is harvested at period } t ; \\ 0, \text { otherwise. }\end{array}\right.$

Binary variable $\boldsymbol{y}_{\boldsymbol{i j t}}$ is defined to represent the virtual adjacency:

$y_{i j t}=\left\{\begin{array}{l}1, \text { if stand } i \text { and stand } j \text { are havested in same period } t \text {, and they } \\ \text { are virtual adjacency stands or } i=j \\ 0, \text { otherwise. }\end{array}\right.$

An integer variable $\boldsymbol{a}_{i t}$ represents stand age of stand $i$ at time period $t$.

A continuous variable $\mathbf{G}_{\mathbf{i t}}$ is the above-ground dry biomass in $M g$ of stand $i$ at period $t$.

A binary variable $\boldsymbol{a T e \boldsymbol { m } _ { \boldsymbol { i k t } }}(k \leq t)$ is defined as:

aTem $_{i k t}=\left\{\begin{array}{l}1, \text { if }\left(x_{i k} \neq x_{i t} \wedge x_{i t}=0\right) \vee\left(x_{i k}=1 \wedge k=t\right) \\ 0, \text { otherwise. }\end{array}\right.$ 


\section{A.2. The Parameters Used in This Model}

Table A-1. Explanation and configuration of parameters.

\begin{tabular}{|c|c|c|c|}
\hline Name & Definition & Value & Reference \\
\hline $\bar{A}$ & The area of stand $j$ (ha) & & Inventory \\
\hline$A D J$ & $\begin{array}{l}\text { describe the adjacency of every two } \\
\text { stands }\end{array}$ & & Inventory \\
\hline AgeR & The minimum permissible stand age & 40 & Sharma et al. 2011 \\
\hline$a g e_{i}$ & The initial stand age of stand $i$ & 80 & Inventory \\
\hline$a h$ & The minumum age of a stand could be hi & 20 & \\
\hline$A R$ & The maximum permissible contiguous $\mathrm{h}$ & 40 & Sharma et al. 2011 \\
\hline$f_{b i}\left(a_{i t}\right)$ & Growth function of the aboveground dry & Simulation & \\
\hline$f_{c i}\left(a_{i t}\right)$ & Stand carbon storage function of stand $i$ & Simulation & \\
\hline$G_{i 0}$ & The initial aboveground biomass of stan & & Inventory \\
\hline$r_{\mathrm{CO}_{2}}$ & $\begin{array}{l}\text { The coefficient used to convert Carbon } \\
\text { into } \mathrm{CO}_{2} \text { equivalent }\end{array}$ & 3.667 & \\
\hline$r_{d r y}$ & $\begin{array}{l}\text { The coefficient used to convert dry } \\
\text { biomass into Carbon }\end{array}$ & 0.5 & de Wit et al. 2006 \\
\hline$Y$ & The length of each period (year) & 5 & \\
\hline$\rho$ & $\begin{array}{l}\text { The percentage of biomass that is } \\
\text { economically available }\end{array}$ & 0.65 & Wu et al. 2012 \\
\hline$\delta$ & Percentage of wood product other than & $82 \%$ & \\
\hline$\eta_{B}$ & $\begin{array}{l}\text { Percentage of woody residue in total } \\
\text { above-ground biomass }\end{array}$ & $60 \%$ & \\
\hline$\eta_{T}$ & $\begin{array}{l}\text { Percentage of raw timber in total above- } \\
\text { ground biomass }\end{array}$ & $60 \%$ & \\
\hline$\Delta$ & Allowable deviation in even flow constrc & 0.15 & Goycoolea et al. 2005 \\
\hline
\end{tabular}

The parameters $\eta_{B}, \eta_{T}, \delta$ were calculated according to the results in Sharma's thesis (Sharma 2010). It said, for 66 cubic meters of timber produced, there will be approximately 66 cubic meters logging residue left in the forest and 33 cubic meters mill residue. It is also assumed that all the above-ground standing timber is harvested for a stand under clear cut scenario including $30 \%$ of long lived wood products (US DOE, 2007).

$$
\begin{aligned}
& \eta_{B}=\frac{66(\text { logging residue })+33(\text { mill residue })}{66+66+33} \times 100 \%=60 \% \\
& \eta_{T}=\frac{66(\text { timber produced })+33(\text { mill residue })}{66+66+33} \times 100 \%=60 \%
\end{aligned}
$$


$\delta=1-\frac{66(\text { timber produced }) \times 30 \%}{66+66+33} \times 100 \%=82 \%$

The coefficient $r_{\mathrm{CO}_{2}}$ was used to convert Carbon into $\mathrm{CO}_{2}$ equivalent. This is because the percentage of Carbon in $\mathrm{CO}_{2}$ is $\frac{12}{44} \times 100 \%=27.27 \%$. Then $\frac{1}{27.27 \%}=3.667$. 


\section{A.3. JAVA Code to Solve the Problem}

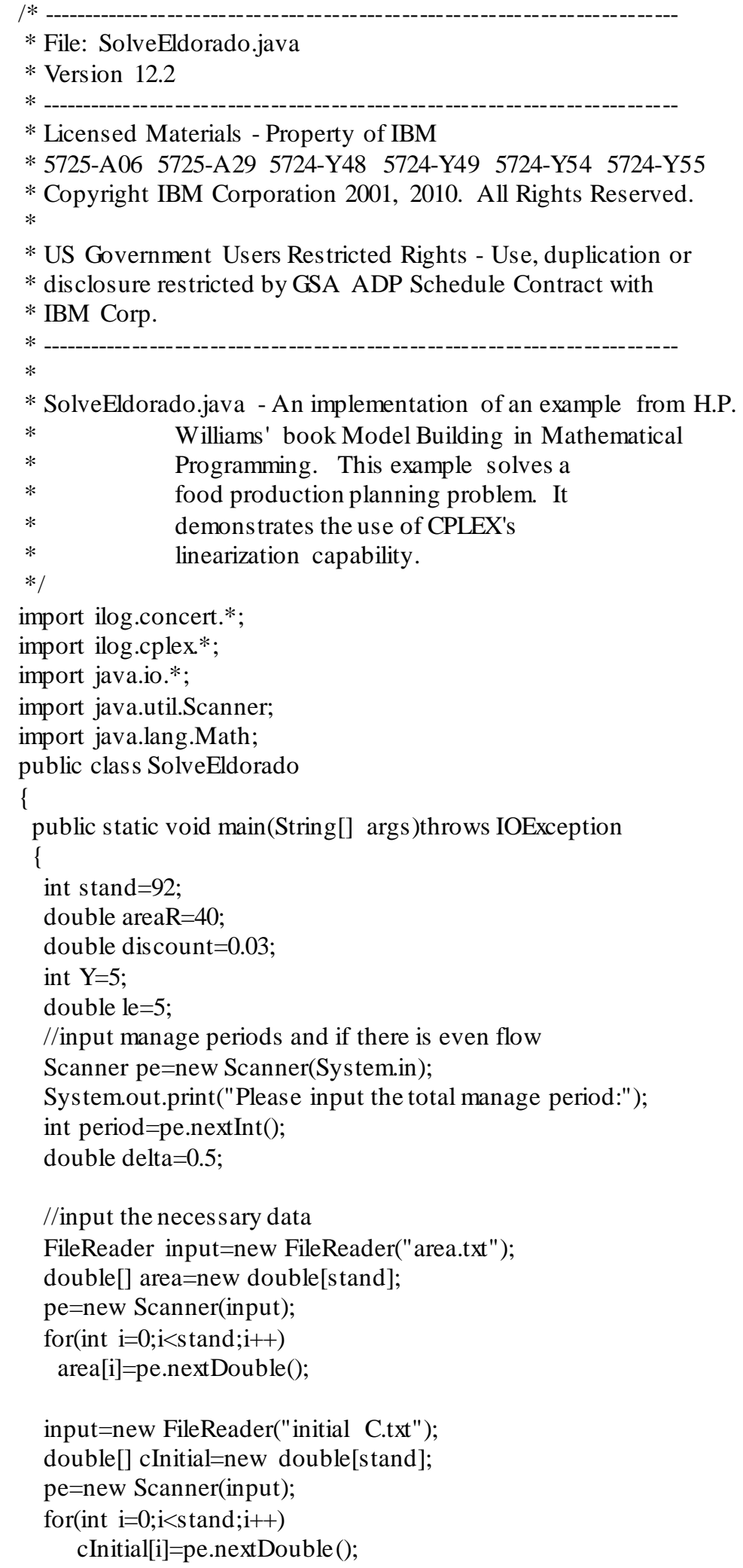




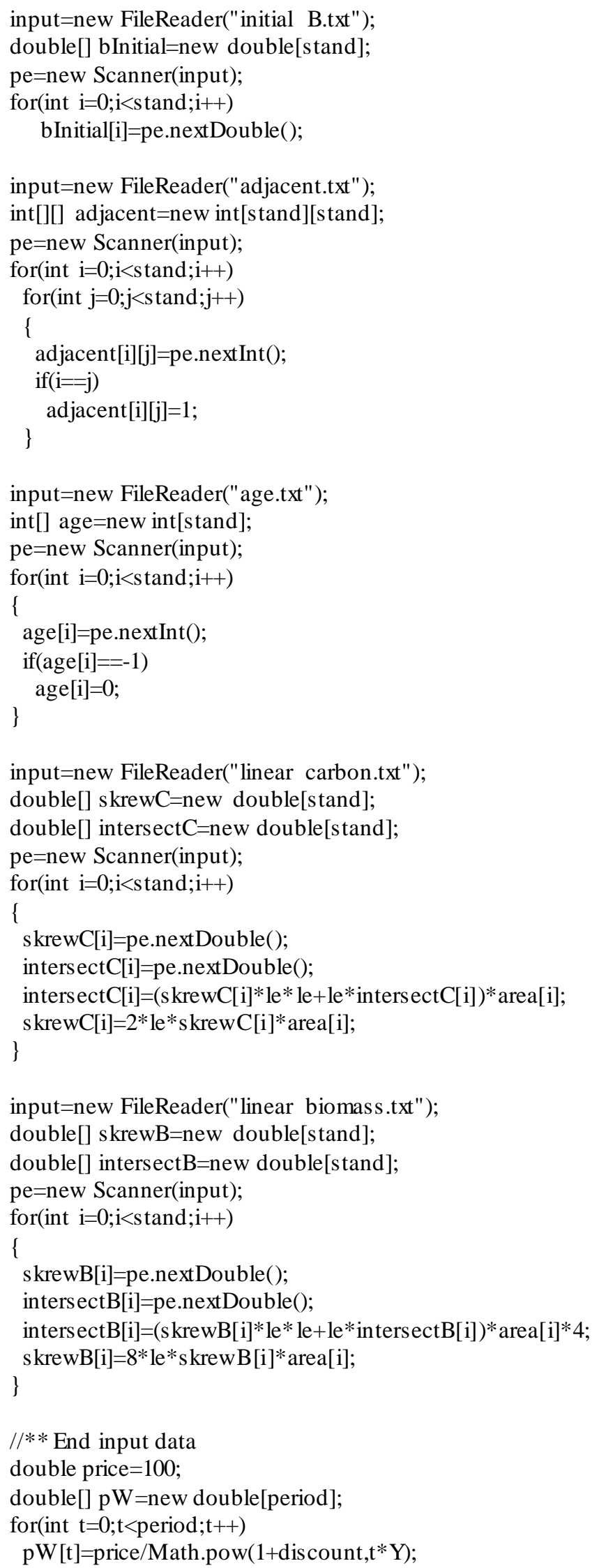




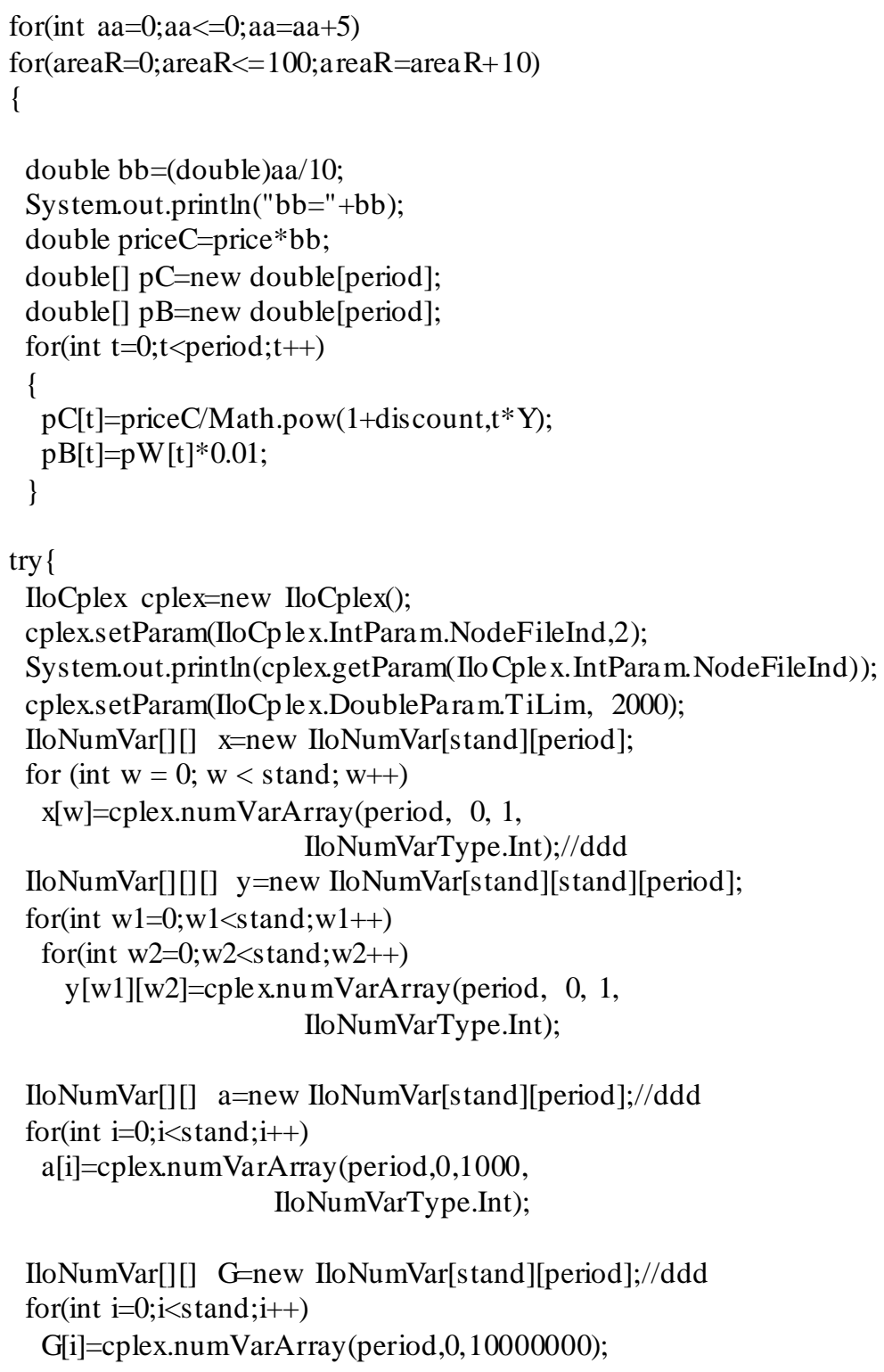

IloNumVar[][][] aTemp=new IloNumVar[stand][period][period];//ddd

IloNumExpr[][] objvalsC=new IloNumExpr[stand][period];

IloNumExpr[][] objvals B=new IloNumExpr[stand][period];

IloNumExpr[][] objvals $\mathrm{C} 0=$ new IloNumExpr[stand][period];

IloNumExpr[][] objvals T0=new IloNumExpr[stand][period];

IloNumExpr[][] objvals T=new IloNumExpr[stand][period];

//The total revenue includes three components: carbon, timber and biomass (residue).

//The raw merchantable timber is 0.6 of the total timber calculated here.

//The residue include logging residue and mill residue are 0.6 of the total.

for(int $\mathrm{k}=0 ; \mathrm{k}<\mathrm{stand} ; \mathrm{k}++)$

for(int $\mathrm{m}=0 ; \mathrm{m}<$ period; $\mathrm{m}++$ ) 
\{

if $(m>0)$

objvals T0[k][m]=cplex.sum(cplex.sum $(\mathrm{G}[\mathrm{k}][\mathrm{m}-1], \mathrm{cplex} \cdot \operatorname{prod}(-$

$1, \mathrm{G}[\mathrm{k}][\mathrm{m}]))$,cple x.sum(intersectB[k],cplex.prod(skrewB[k],a $[\mathrm{k}][\mathrm{m}-1]))$ );

else

objvals $\mathrm{T} 0[\mathrm{k}][\mathrm{m}]=$ cplex.prod $\left(\mathrm{x}[\mathrm{k}][\mathrm{m}], \mathrm{bInit} i a l[\mathrm{k}]^{*}\right.$ area[k]);//biomass is wet weight;

objvals $\mathrm{C} 0[\mathrm{k}][\mathrm{m}]=\mathrm{cp}$ lex.prod(3.667,cplex.sum(cplex.sum(intersectC[k],cplex.prod(skrewC[k],a $[\mathrm{k}][\mathrm{m}]))$,cplex.prod($0.82 / 4$, objvals T0[k][m])));

objvals $\mathrm{C}[\mathrm{k}][\mathrm{m}]=$ cplex.prod(pC[m],objvals $\mathrm{C} 0[\mathrm{k}][\mathrm{m}])$;

objvals $\mathrm{T}[\mathrm{k}][\mathrm{m}]=\mathrm{cple}$.pprod $\left(\mathrm{pW}[\mathrm{m}]^{*} 0.6, \mathrm{objvalsT} \mathrm{T}[\mathrm{k}][\mathrm{m}]\right)$;

objvals $B[\mathrm{k}][\mathrm{m}]=$ cple $x . \operatorname{prod}(\mathrm{pB}[\mathrm{m}] * 0.6, \mathrm{objvals} \mathrm{T} 0[\mathrm{k}][\mathrm{m}])$;

\}

IloNumExpr[] lwvC=new IloNumExpr[stand];

IloNumExpr[] lwvT=new IloNumExpr[stand];

IloNumExpr[] lwvB=new IloNumExpr[stand];

for(int $\mathrm{i}=0 ; \mathrm{i}<$ stand $; \mathrm{i}++$ )

\{

$\operatorname{lwv} C[i]=$ cple $x . \operatorname{sum}($ objvals $\mathrm{C} 0[\mathrm{i}])$;

lwvB[i] =cple x.sum(objvals T0[i]);

lwvT $[\mathrm{i}]=$ cple $\mathrm{x} . \operatorname{sum}($ objvals TO[i]);

\}

IloNumExpr[] 12=new IloNumExpr[stand];

for(int $\mathrm{i}=0 ; \mathrm{i}<$ stand; $\mathrm{i}++)$

\{

12[i]=cplex.su m(cplex.sum(objvals C[i]),cplex.sum(objvals B[i]),cplex.sum(objvals T[i])); \}

cplex.addMaximize(cplex.sum(12));//objective function;

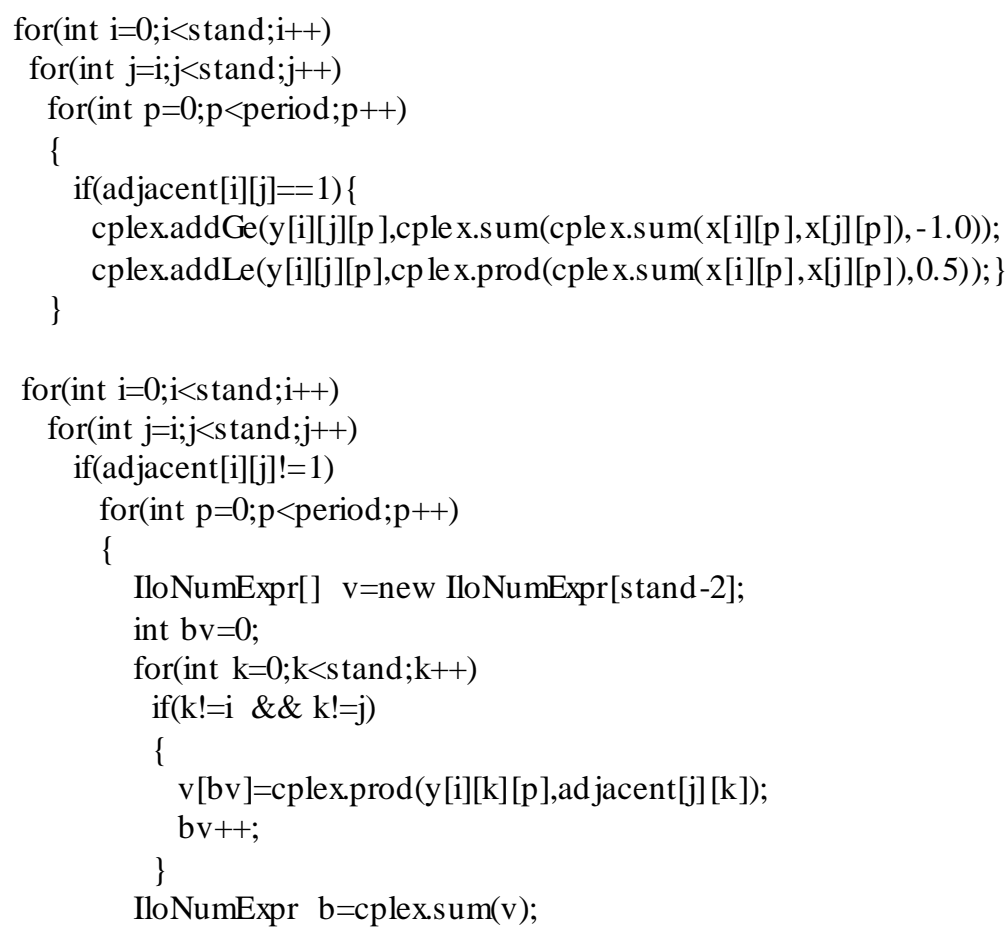




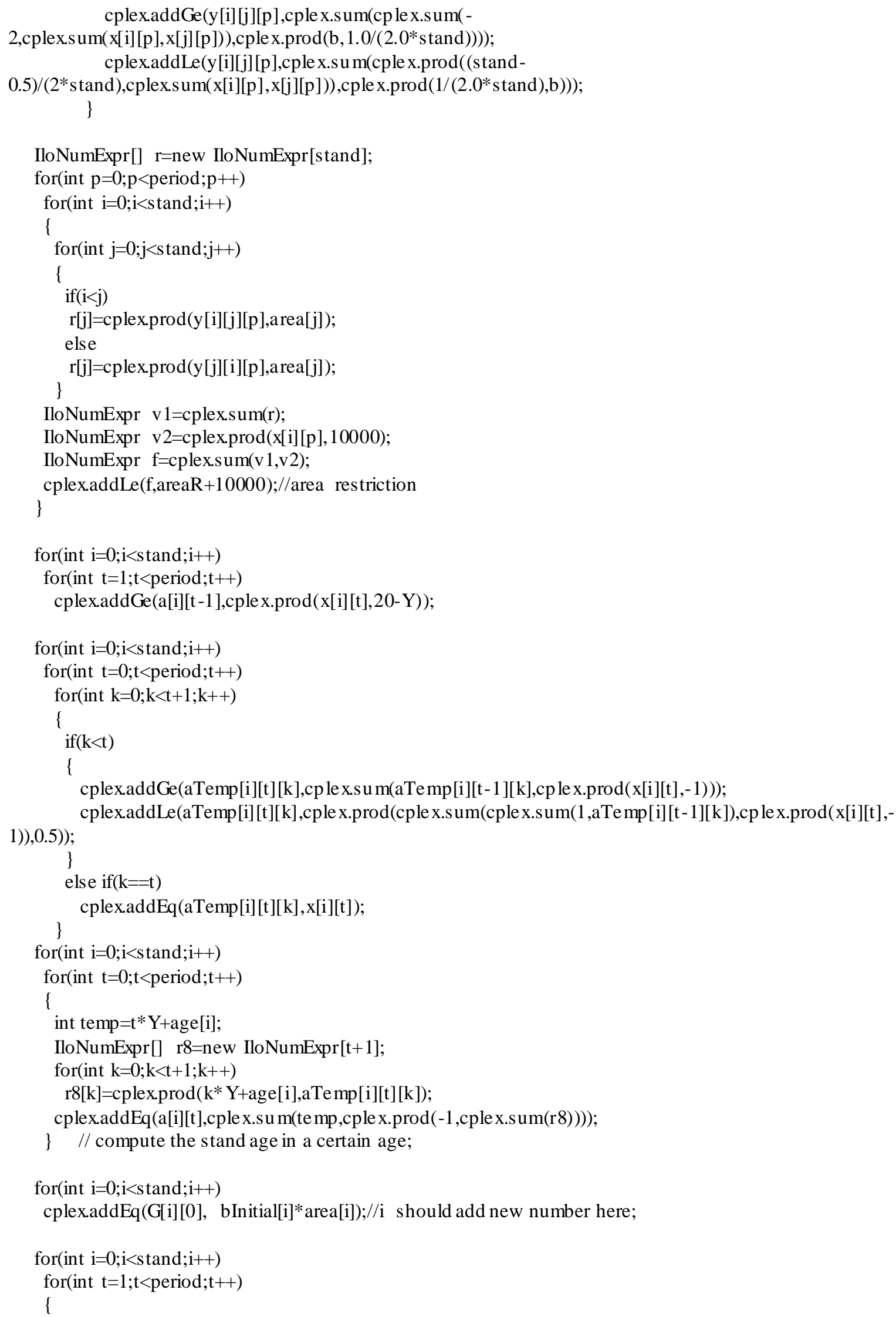


cplex.addLe(G[i][t],cplex.prod(cplex.su m(1,cplex.prod(-1,x[i][t])),Math.pow(10,15)));

cplex.addLe(G[i][t],cplex.su m(G[i][t-1],cplex.sum(intersectB[i],cplex.prod(a[i][t-1],skrewB[i]))));

cplex.addGe(G[i][t],cplex.sum(cplex.sum(G[i][t-1],cplex.sum(intersectB[i],cplex.prod(a[i] [t-

1],skrewB[i]))),cplex.prod(-1*Math.pow(10,15),x[i][t])));

\}

if(true)

\{

for(int $\mathrm{t}=1 ; \mathrm{t}<$ period; $\mathrm{t}++$ )

\{

if $(\mathrm{t}==1)$

\{

IloNumExpr[] rl=new IloNumExpr[stand];

for(int $\mathrm{i}=0 ; \mathrm{i}<$ stand; $\mathrm{i}++)$

r1[i]=cplex.prod(x[i][t-1],bInitial[i]);

IloNumExpr[] r2=new IloNumExpr[stand];

for(int $\mathrm{i}=0 ; \mathrm{i}<$ stand; $i++)$

r2[i]=cplex.sum(cplex.sum(G[i][t-1],cplex.prod(-1,G[i][t])),cplex.sum(cplex.prod(a[i] [t-

$1]$,skrewB[i]), intersectB[i]));

cplex.addLe(cplex.prod(1-delta,cplex.sum(r1)),cplex.sum(r2));

cplex.addGe(cplex.prod(1+delta,cple x.su m(r1)),cplex.sum(r2));

\}

else

\{

IloNumExpr[] rl=new IloNumExpr[stand];

for(int $\mathrm{i}=0 ; \mathrm{i}<\mathrm{stand} ; \mathrm{i}++)$

r1[i]=cplex.sum(cplex.sum(G[i][t-2],cplex.prod(-1,G[i][t-1])),cplex.sum(cplex.prod(a[i] [t-

2],skrewB[i]),intersectB[i]));

IloNumExpr[] r2=new IloNumExpr[stand];

for(int $\mathrm{i}=0 ; \mathrm{i}<$ stand; $i++)$

r2[i]=cplex.sum(cplex.sum(G[i][t-1],cplex.prod(-1,G[i][t])),cplex.sum(cplex.prod(a[i] [t-

1],skrewB[i]), intersectB[i]));

cplex.addLe(cplex.prod(1-delta,cplex.sum(r1)), cplex.sum(r2));

cplex.addGe(cplex.prod(1+delta,cplex.su m(r1)),cplex.sum(r2));

\}

\} J//flow constraint

IloNumExpr[] r3=new IloNumExpr[stand];

for(int $\mathrm{i}=0 ; \mathrm{i}<$ stand; $\mathrm{i}++)$

\{

IloNumExpr[] r4=new IloNumExpr[period+1];

for(int $\mathrm{p}=0 ; \mathrm{p}<$ period; $\mathrm{p}++)$

$\mathrm{r} 4[\mathrm{p}]=\operatorname{cplex} \cdot \operatorname{prod}(\mathrm{x}[\mathrm{i}][\mathrm{p}],(\mathrm{p} *$ Y+age $[\mathrm{i}]))$;

$\mathrm{r} 4\left[\right.$ period] $=$ cplex.prod(period* ${ }^{*}+$ age $[\mathrm{i}]$, cplex.sum $\left.(1, \operatorname{cplex} \cdot \operatorname{prod}(-1, \operatorname{cplex} \cdot \operatorname{sum}(\mathrm{x}[\mathrm{i}])))\right)$;

$\mathrm{r} 3[\mathrm{i}]=$ cplex.su $\mathrm{m}(\mathrm{r} 4)$;

r3[i]=cplex.prod(area[i],r3[i]);

\}

double sumArea $=0$;

for(int $b=0 ; b<$ stand $; b++)$

sumArea+=area[b];

cplex.addGe(cplex.sum(r3),40.0* sumArea);//age restriction

if(cplex.solve())

\{

System.out.println("Solution status="+cplex.getStatus());

System.out.println("Solution value="+cplex.getObjValue()); 
System.out.println("this is the price of timber "+price+" this is carbon price "+priceC);

System.out.println("total C "+cplex.getValue(cple x.sum(lwv C)));

System.out.println("total B "+cplex.getValue(cplex.sum(lwv B)));

System.out.println();

String rr=Double.toString $(\mathrm{bb})+"{ }^{\prime}++$ Double.toString $(\operatorname{areaR})$;

rr+=".txt";

PrintWriter re=new PrintWriter(rr);

double gap $=100 *$ (cplex.getBestObjValue()-cplex.getObjValue())/cplex.getBestObjValue();

re.println("total carbon $(\mathrm{Mg})$ total timber $(\mathrm{Mg})$ Total Residue(Mg) total revenue (\$)");

re.println(cplex.getValue(cplex.sum(lwv C) $)+" \quad+0.6^{*}$ cplex.getValue(cplex.sum(lwvT) $)+"$

"+0.6*cplex.getValue(cplex.su m(lwvB))+" "+cplex.getObjValue()+" " +gap+"\%");

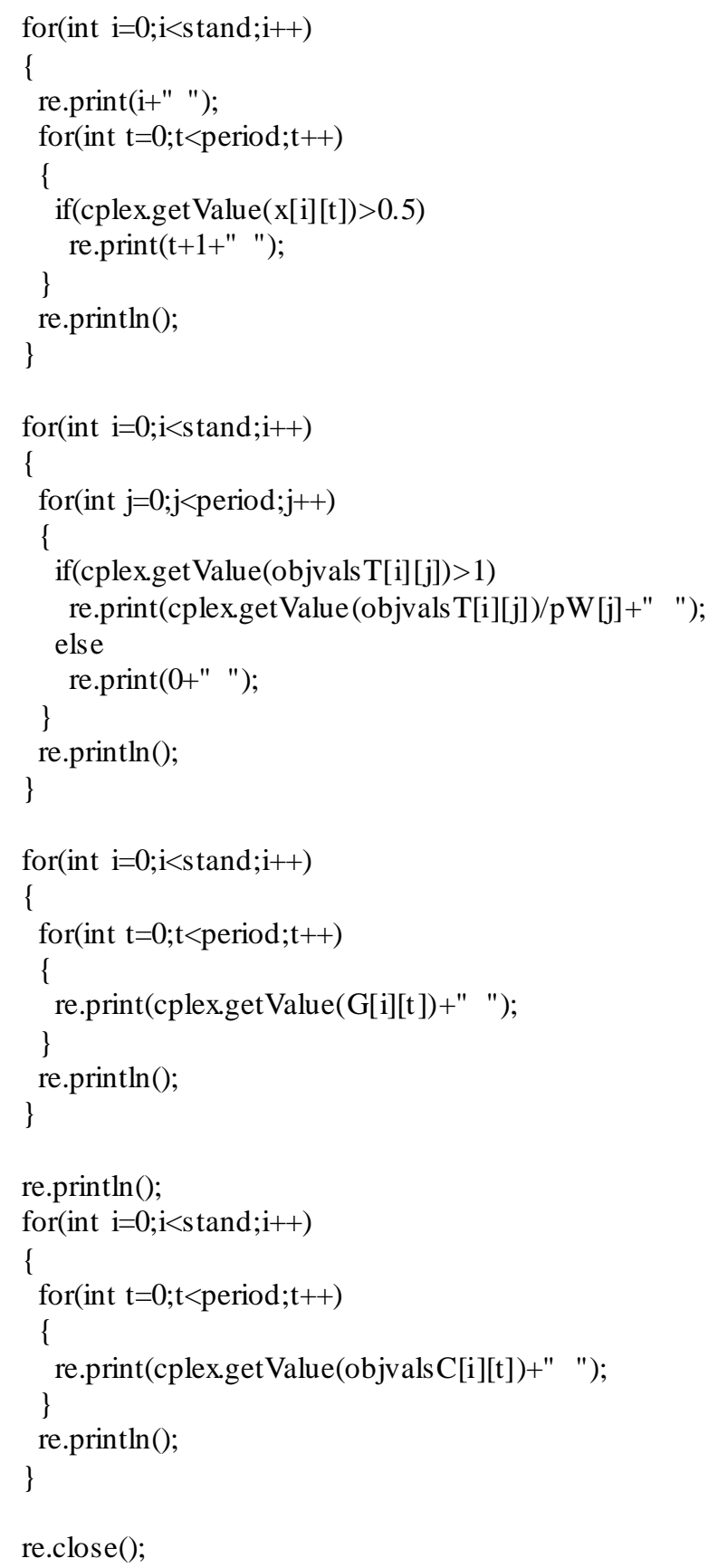




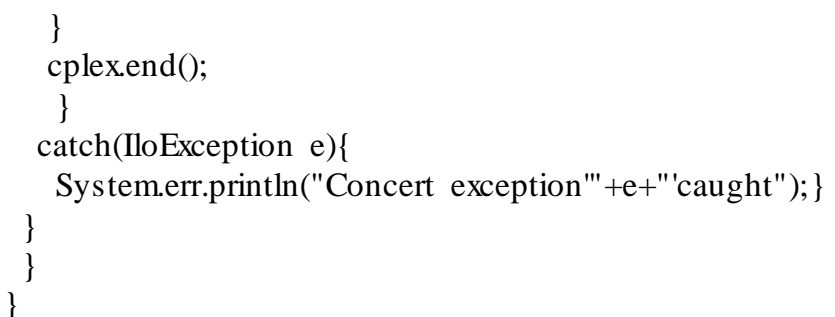




\section{APPENDIX B. SUPPLEMENTAL INFORMATION FOR CHAPTER 3}

\section{B.1. VARIAB LES AND PARAMETERS IN THE ECONOMIC MODEL}

Table B-1. Data Sets and Descriptions.

\begin{tabular}{cl}
\hline Set & Description \\
\hline$C$ & Set of coal mines, $|\mathrm{C}|=954 ;$ \\
$I$ & Set of logging sites $|\mathrm{I}|=196 ;$ \\
$L$ & Set of possible plant scale levels, $|\mathrm{L}|=12 ;$ \\
$P$ & Set of plant candidates, $|\mathrm{P}|=22 ;$ \\
$S$ & Set of sawmills, $|\mathrm{S}|=171 ;$ \\
$T$ & Set of operation periods, $|\mathrm{T}|=30$. \\
\hline
\end{tabular}

Table B-2. Parameters and Descriptions.

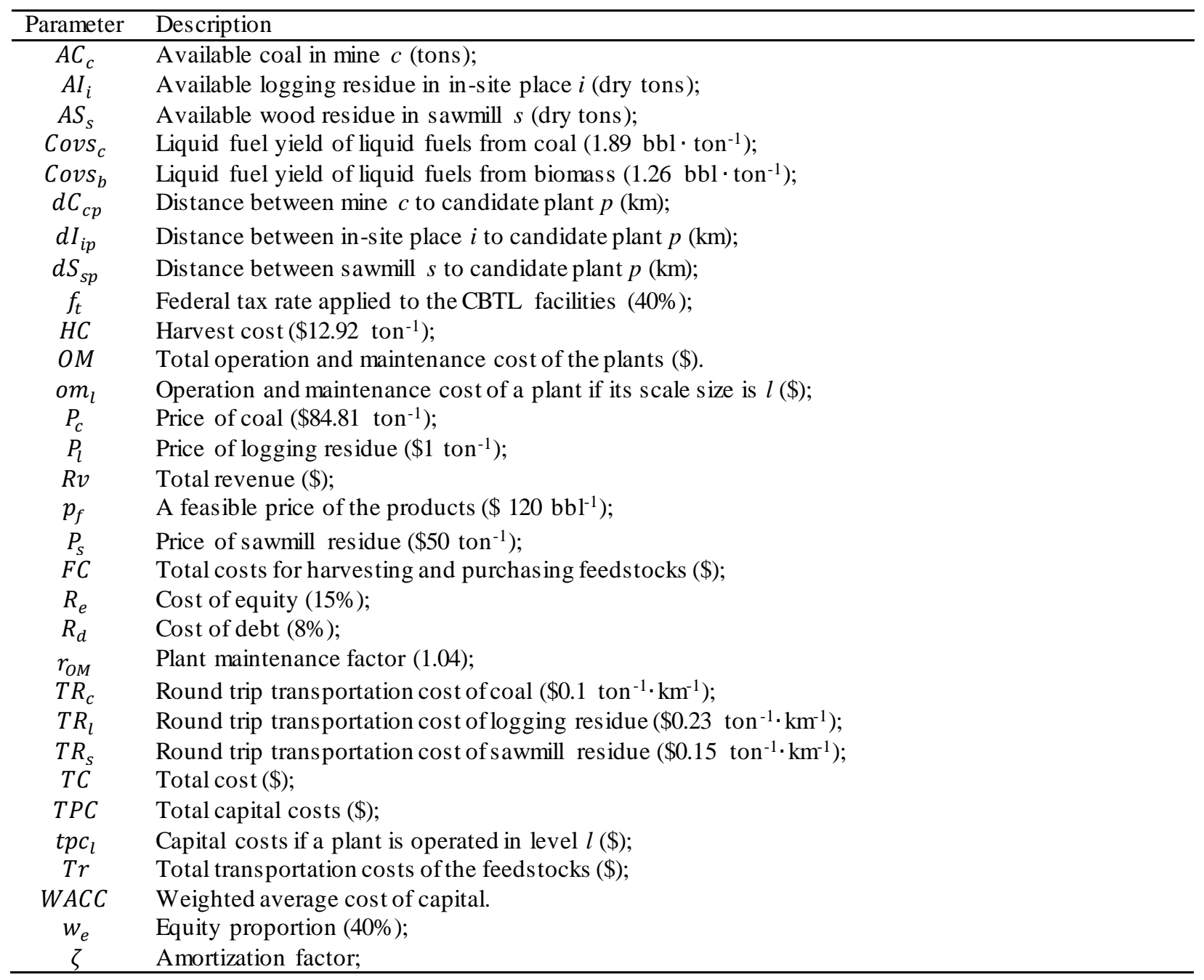




\begin{tabular}{cl}
\hline Parameter & Description \\
\hline$\eta$ & Biomass and coal mix ratio $(0 / 100,8 / 92,15 / 85,20 / 80,25 / 75,30 / 70,35 / 65) ;$ \\
$\psi$ & Sum of plant maintenance factor; \\
\hline
\end{tabular}

Table B-3. Variables and Descriptions.

\begin{tabular}{cl}
\hline Variable & Description \\
\hline$x C_{c p t}$ & Quantity of coal transported from mine $c$ to plant $p$ in period $t$ (tons); \\
$x I_{i p t}$ & Quantity of logging residue transported from place $i$ to plant $p$ in period $t$ (dry ton); \\
$x S_{s p t}$ & Quantity of wood residue transported from sawmills to plant $p$ in period $t$ (dry ton); \\
$o_{p l}$ & Binary variable decides if the plant $p$ operated in level $l$. \\
\hline
\end{tabular}




\section{B.2. LCA ProcesSES in SimaPro}

Table B-4. Processes involved in on the CBTL LCA model ${ }^{\text {a }}$.

\begin{tabular}{ll}
\hline Process Name & Table Number \\
\hline Loaded and transported to Prep Plant & B-5 \\
Coal (dried, stored) & B-6 \\
Grinding (Coal) & B-7 \\
Preprocessed coal, at conversion facility & B-8 \\
Grapple Skidder & B-9 \\
Grapple Loader & B-10 \\
Chipper & B-11 \\
Forest residues processed and loaded at the landing & B-12 \\
Forest residue (dried, stored) & B-13 \\
Preprocessed residue, at conversion facility & B-14 \\
CBTL (Syngas) & B-15 \\
CBTL (Diesel) & B-16 \\
Distribution, 60 miles & B-17 \\
Liquid fuels pumped into vehicle & B-18 \\
Transmission of Electricity & B-19 \\
Gasoline Combustion & B-20 \\
Diesel Combustion & B-21 \\
\hline
\end{tabular}

${ }^{a}$ The numbers of all the processes are calculated in the mix ratio is $8 / 92$.

Table B-5. Process "Loaded and transported to Prep Plant".

\begin{tabular}{ll}
\hline Products and co-product & \\
\hline Loaded and transported to Prep Plant & 1 ton \\
\hline Materials/fuels & 8 tkm \\
\hline Transport, lorry 16-32t, EURO5/RER U & 1 ton \\
Bituminous Coal, at mine & \\
\hline
\end{tabular}

${ }^{a}$ Ecoinvent 2.2;

b US-LCI.

Table B-6. Process "Coal (dried, stored)”.

\begin{tabular}{ll}
\hline Products and co-product & \\
\hline Coal (dried, stored) & \\
\hline Materials/fuels & 0.98 ton \\
\hline Loaded and transported to Prep Plant & 1 ton \\
Transport, freight, rail, dies el/US U & $29.68 \mathrm{tkm}$ \\
Fodder loading, by self-loading trailer/CH with US & $2.27 \mathrm{~m}^{3}$ \\
electricity US & \\
\hline
\end{tabular}

a Assuming 2\% dry coal loss;

b Ecoinvent 2.2. 
Table B-7. Process "Grinding (Coal)”.

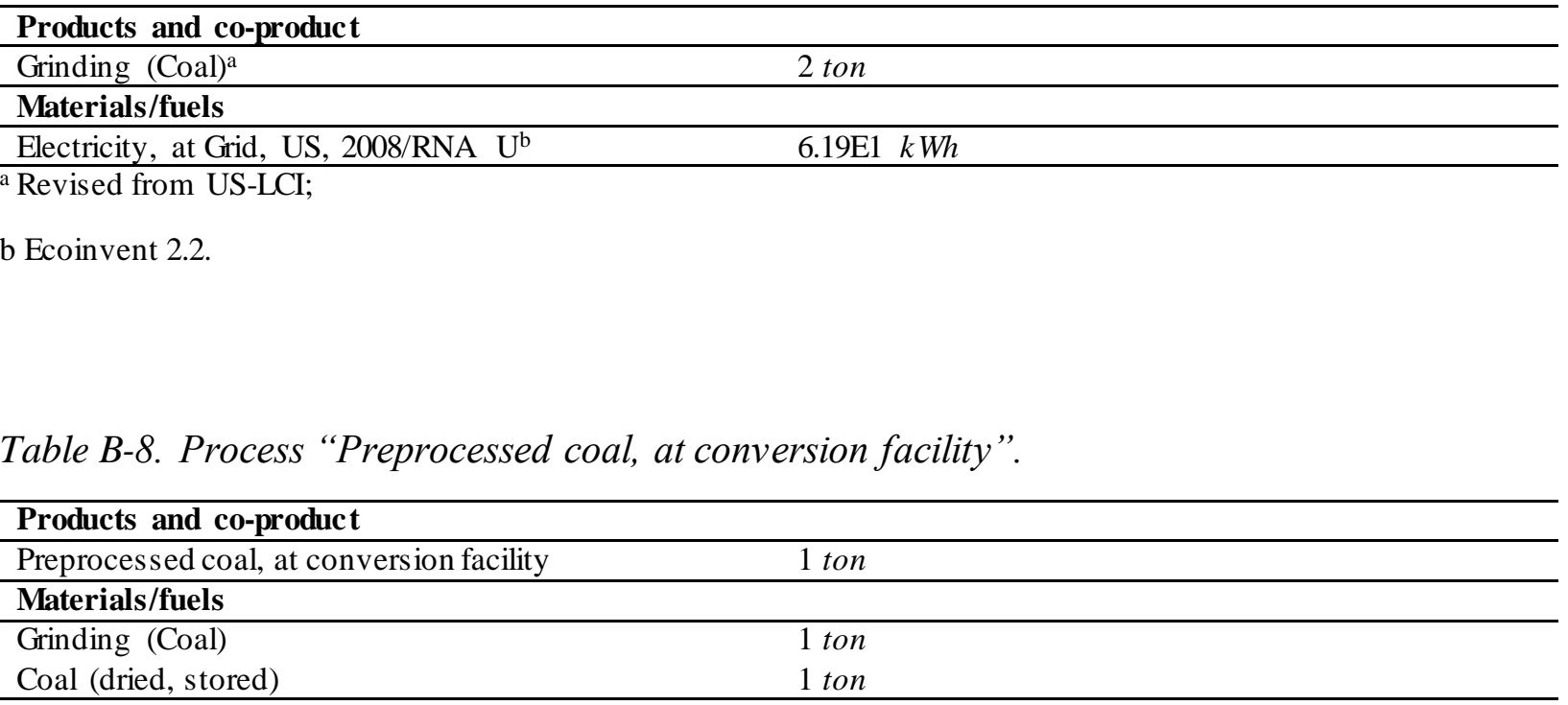

Table B-9. Process “Grapple Skidder”.

\begin{tabular}{ll}
\hline Products and co-product & \\
\hline Grapple Skidder $^{\mathrm{a}}$ & 24 ton \\
\hline Materials/fuels & \\
\hline Diesel, combusted in industrial equipment/US & $13.758 \mathrm{gal}$ \\
Lubricant oil $(1)^{\mathrm{b}}$ & $0.247644 \mathrm{gal}$
\end{tabular}

${ }^{a} \mathrm{Wu}$, Jinzhuo, Wang, Jingxin, Cheng, Qingzheng, DeVallance, David. 2011. Asses sment of coal and biomass to liquid fuels in central Appalachia, USA. International Journal of Energy Research. 36(7): 856-870;

b Ecoinvent 2.2.

Table B-10. Process “Grapple Loader".

\begin{tabular}{ll}
\hline Products and co-product & \\
\hline Grapple Loader & 24 ton \\
\hline Materials/fuels & \\
\hline Diesel, combusted in industrial equipment/US ${ }^{\mathrm{b}}$ & $6.54 \mathrm{gal}$ \\
Lubricant oil (1) & $0.1172 \mathrm{gal}$ \\
\hline${ }^{\mathrm{a}} \mathrm{Wu}$ et al. 2011; & \\
${ }^{\mathrm{b}}$ Ecoinvent 2.2. &
\end{tabular}


Table B-11. Process "Chipper”.

\begin{tabular}{ll}
\hline Products and co-product & \\
\hline Chipper $^{\mathrm{a}}$ & 24 ton \\
\hline Materials/fuels & \\
\hline Diesel, combusted in industrial equipment/US & $14.52 \mathrm{gal}$ \\
Lubricant oil $(1)^{\mathrm{b}}$ & $0.26136 \mathrm{gal}$ \\
\hline
\end{tabular}

a Wu et al. 2011;

b Ecoinvent 2.2.

Table B-12. Process "Forest residues processed and loaded at the landing”.

\begin{tabular}{ll}
\hline Products and co-product & \\
\hline Forest residues processed and loaded at the landing ${ }^{\mathrm{a}}$ & 1 ton \\
\hline Natural Resources & \\
\hline Carbon dioxide, in air & $942 \mathrm{~kg}$ \\
Energy, from biomass & $8561 \mathrm{MJ}$ \\
\hline Materials/fuels & 1 ton \\
\hline Grapple Skidder & 1 ton \\
Grapple Loader & 1 ton \\
Chipper & \\
\hline
\end{tabular}

a Revised from "Hsu, David D., Inman, Daniel, Heath, Garvin A., Wolfrum, Edward J., Mann, Margaret K., Aden, Andy. 2010. Life cycle environmental impact of selected U.S. ethanolproduction and use pathway in 2022. Environmental Science and Technology.44: 5289-5297”;

Table B-13. Process "Forest residues (dried, stored)".

\begin{tabular}{ll}
\hline Products and co-product & \\
\hline Forest residue (dried, stored) & 0.772 ton \\
\hline Materials/fuels & \\
\hline Forest residues processed and loaded at the landing & 0.62 ton \\
Transport, lorry 16-32t, EURO5/RER U & 148.73 tkm \\
Dried roughage store, non ventilated/CH/I Ub & $9.75 \mathrm{E}-8 \mathrm{~m}^{3}$ \\
Conveyor belt, at plant/RER/I U & $3.47 \mathrm{E}-5 \mathrm{~m}$ \\
Fodder loading, by self-loading trailer/CH with US & $2.27 \mathrm{~m}^{3}$ \\
electricity US & \\
Sawmill Residue & 0.16 ton \\
\hline
\end{tabular}

a Revised from "Hsu et al. 2010";

b Ecoinvent 2.2. 
Table B-14. Process "Preprocessed residue, at conversion facility".

\begin{tabular}{ll}
\hline Products and co-product & \\
\hline Preprocessed residue, at conversion facility & 1 ton \\
\hline Materials/fuels & 1 ton \\
\hline Forest residue (dried, stored) & $20 \mathrm{tkm}$ \\
Transport, lorry 16-32t, EURO5/RER U &
\end{tabular}

a Revised from "Hsu et al. 2010";

${ }^{\mathrm{b}}$ Ecoinvent 2.2.

Table B-15. Thermal-conversion Process "CBTL (Syngas)".

\begin{tabular}{|c|c|}
\hline \multicolumn{2}{|l|}{ Products and co-product } \\
\hline Syncrude $^{\mathrm{a}}$ & $165.41 \mathrm{~kg}$ \\
\hline Light Gases ${ }^{a}$ & $24.81 \mathrm{~kg}$ \\
\hline \multicolumn{2}{|l|}{ Natural Resources } \\
\hline Water, unspecified natural origin $/ \mathrm{kg}^{\mathrm{b}}$ & $183.85 \mathrm{~kg}$ \\
\hline \multicolumn{2}{|l|}{ Materials/fuels } \\
\hline Preprocessed coal, at conversion facility & $500 \mathrm{~kg}$ \\
\hline Preprocessed residue, at conversion facility & $43.3 \mathrm{~kg}$ \\
\hline Thermochemical conversion plant ${ }^{\mathrm{b}}$ & $5.95 \mathrm{E}-9 \mathrm{p}$ \\
\hline \multicolumn{2}{|l|}{ Emissions to air } \\
\hline Carbon dioxide, fossil & $41.5 \mathrm{~kg}$ \\
\hline Carbon dioxide, biogenic & $23.3 \mathrm{~kg}$ \\
\hline \multicolumn{2}{|c|}{$\begin{array}{l}\text { a Simulation based on Aspen Plus: Jiang, Yuan, Bhattacharyya, Debangsu. 2015. Modeling and Analysis of an } \\
\text { Indirect Coal Biomass to Liquids Plant Integrated with a Combined Cycle Plant and } \mathrm{CO}_{2} \text { Capture and Storage } \\
\text { Energy and Fuels, } 29 \text { (8): 5434-5451. }\end{array}$} \\
\hline
\end{tabular}

Table B-16. Thermal-conversion Process "CBTL (Diesel)".

\begin{tabular}{|c|c|}
\hline Products and co-product & \\
\hline CBTL $\left(\right.$ Diesel) ${ }^{\mathrm{a}}$ & $88.067 \mathrm{~kg}$ \\
\hline CBTL (Gasoline) ${ }^{\mathrm{a}}$ & $52.966 \mathrm{~kg}$ \\
\hline Electricity_CBTL & $122.54 \mathrm{MJ}$ \\
\hline \multicolumn{2}{|l|}{ Natural Resources } \\
\hline Water, unspecified natural origin $/ \mathrm{kg}^{\mathrm{b}}$ & $65.83 \mathrm{~kg}$ \\
\hline \multicolumn{2}{|l|}{ Materials/fuels } \\
\hline $\begin{array}{l}\text { Syncrude } \\
\text { a }\end{array}$ & $165.41 \mathrm{~kg}$ \\
\hline Light Gases ${ }^{\mathrm{a}}$ & $24.81 \mathrm{~kg}$ \\
\hline \multicolumn{2}{|l|}{ Emissions to air } \\
\hline Carbon dioxide, fossil & $26.9 \mathrm{~kg}$ \\
\hline Carbon monoxide, fossil & $1.51 \mathrm{~kg}$ \\
\hline \multicolumn{2}{|c|}{$\begin{array}{l}\text { Simulation based on Aspen Plus: Jiang, Yuan, Bhattacharyya, Debangsu. 2015. Modeling and Analysis of an } \\
\text { Indirect Coal Biomass to Liquids Plant Integrated with a Combined Cycle Plant and } \mathrm{CO}_{2} \text { Capture and Storage } \\
\text { Energy and Fuels, } 29 \text { (8): 5434-5451. }\end{array}$} \\
\hline
\end{tabular}


Table B-17. Process "Distribution, 60 miles".

\begin{tabular}{ll}
\hline Products and co-product & \\
\hline Distribution, 60 miles $^{\text {a }}$ & $1 \mathrm{gal}$ \\
\hline Emissions to air & $28.29 \mathrm{~g}$ \\
\hline Carbon dioxide, fossil & $0.0015 \mathrm{~g}$ \\
Methane & $0.0009 \mathrm{~g}$ \\
Dinitrogen monoxide & $0.1389 \mathrm{~g}$ \\
Sulfur oxides & $0.1223 \mathrm{~g}$ \\
Nitrogen oxides & $0.1638 \mathrm{~g}$ \\
Carbon monoxide, fossil & $0.0011 \mathrm{~g}$ \\
VOC, volatile organic compounds & $0.0235 \mathrm{~g}$ \\
Particulates, unspecified & \\
\hline
\end{tabular}

a Revised from "Marano and Ciferno 2001".

Table B-18. Process "Liquid fuels pumped into vehicle".

\begin{tabular}{ll}
\hline Products and co-product & \\
\hline Liquid fuels pumped into vehicle $^{\mathrm{a}}$ & $0.2973 \mathrm{gal}$ \\
\hline Electricity/heat & \\
\hline Electricity, low voltage, at grid/US U & \\
Liquid storage tank, chemicals, organics/CH/I U & $0.0026495 \mathrm{kWh}$ \\
Distribution, 60 miles & $9.4 \mathrm{e}-12 \mathrm{p}$ \\
Rubber and plastics hose and belting & 0.297348 gal \\
Measuring and dispensing pumps & $7.49 \mathrm{E}-12$ USD \\
\hline
\end{tabular}

a Revised from "Hsu et al. 2010";

b Ecoinvent 2.2.

Table B-19. Process "Transmission of Electricity".

\begin{tabular}{ll}
\hline Products and co-product & \\
\hline Electricity, Transmission and dis tribution $^{\mathrm{a}}$ & $1,000 \mathrm{MJ}$ \\
\hline Electricity/heat & \\
\hline Zinc, primary, at regional storage/RER with US & \\
electricity U & $0.000267 \mathrm{~kg}$ \\
Glass tube plant/DE/I with US electricity U & $2.26 \mathrm{E}+08 \mathrm{p}$ \\
Cement, unspecified, at plant/CH with US electricity U & $4.17 \mathrm{E}-06 \mathrm{~kg}$ \\
Steel & $1.37 \mathrm{E}-06 \mathrm{~kg}$ \\
Electricity_CBTL & $1.00 \mathrm{E}+03 \mathrm{MJ}$ \\
\hline
\end{tabular}

a Revised from Jorge, R.S., Hawkins, T.R., Hertwich, E.G. 2011. Life cycle assessment of electricity transmission and distribution power lines and cables. International Journal of Life Cycle Assessment, 17 (1): 9-15. 
Table B-20. Process "Gasoline Combustion".

\begin{tabular}{ll}
\hline Products and co-product & \\
\hline Gasoline Combustion $^{\mathrm{a}}$ & $52.966 \mathrm{~kg}$ \\
\hline Eectricity/heat & \\
\hline CBTL (Gasoline) & $52.966 \mathrm{~kg}$ \\
Liquid fuels pumped into vehicle & $2.12 \mathrm{E}+01$ \\
\hline Emissions to air & \\
\hline Carbon dioxide, fossil & $1.56 \mathrm{E}+02 \mathrm{~kg}$ \\
Carbon dioxide, biogenic & $8.78 \mathrm{E}+00 \mathrm{~kg}$ \\
Carbon monoxide, fossil & $2.35 \mathrm{E}+00 \mathrm{~kg}$ \\
Nitrogen oxides & $7.41 \mathrm{E}-02 \mathrm{~kg}$ \\
Sulfur oxides & $2.76 \mathrm{E}-03 \mathrm{~kg}$ \\
Methane & $4.27 \mathrm{E}-03 \mathrm{~kg}$ \\
\hline
\end{tabular}

a Revised from "Marano and Ciferno 2001".

Table B-21. Process "Diesel Combustion".

\begin{tabular}{ll}
\hline Products and co-product & \\
\hline Diesel Combustion $^{\mathrm{a}}$ & $88.067 \mathrm{~kg}$ \\
\hline Eectricity/heat & \\
\hline CBTL (Diesel) & $88.067 \mathrm{~kg}$ \\
Liquid fuels pumped into vehicle & $2.12 \mathrm{E}+01$ \\
\hline Emissions to air & \\
\hline Carbon dioxide, fossil & $2.55 \mathrm{E}+02 \mathrm{~kg}$ \\
Carbon dioxide, biogenic & $1.43 \mathrm{E}+01 \mathrm{~kg}$ \\
Carbon monoxide, fossil & $6.23 \mathrm{E}-01 \mathrm{~kg}$ \\
Nitrogen oxides & $1.42 \mathrm{E}-01 \mathrm{~kg}$ \\
Methane & $4.27 \mathrm{E}-03 \mathrm{~kg}$ \\
\hline
\end{tabular}

a Revised from "Marano and Ciferno 2001". 


\section{APPENDiX C. SuPPlemental Information For Chapter 4}

\section{C.1. VARIAB LeS AND PARAMETERS IN THE ECONOMIC MODEL}

Table C-1. Data Sets and Descriptions.

\begin{tabular}{cl}
\hline Set & Description \\
\hline$I$ & Set of county $|\mathrm{I}|=54 ;$ \\
$L$ & Set of possible plant scale levels, $|\mathrm{L}|=8$ for fast pyrolysis and $|\mathrm{L}|=19$ for ethanol; \\
$J$ & Set of plant candidates, $|\mathrm{J}|=22 ;$ \\
$M$ & Set of operation periods, $|\mathrm{M}|=12$. \\
\hline
\end{tabular}

Table C-2. Parameters and Descriptions.

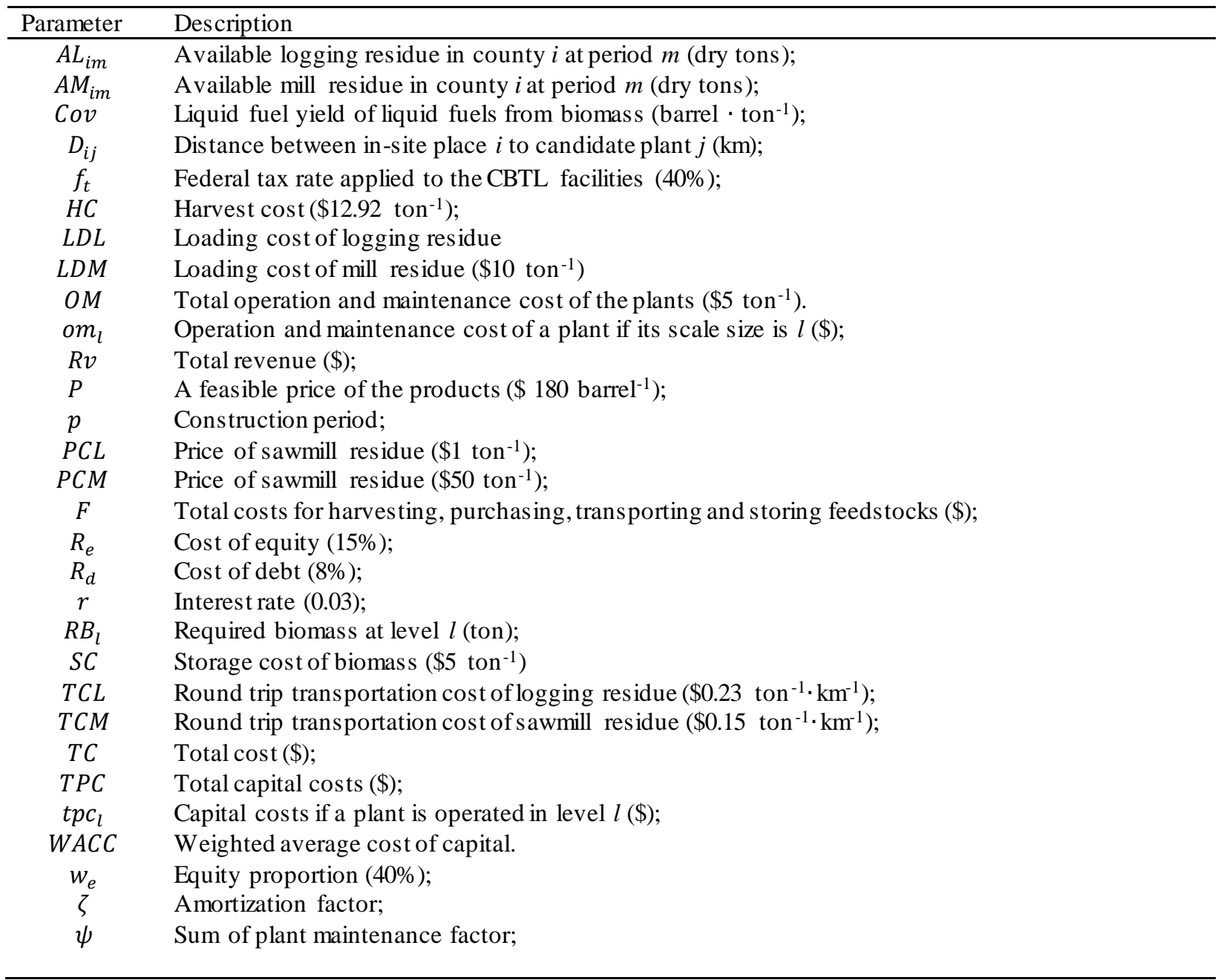


Table C-3. Variables and Descriptions.

\begin{tabular}{cl}
\hline Variable & Description \\
\hline$x L_{i j m}$ & Quantity of logging residue transported from county $i$ to plant $j$ at period $m$ (dry tons); \\
$x M_{i j m}$ & Quantity of mill residue transported from county $i$ to plant $j$ at period $m$ (dry ton); \\
$x P_{j m}$ & Quantity of biomass processed in plant $j$ at period $m$ (dry ton); \\
$x S_{j m}$ & Quantity of wood residue stored in plant $j$ at period $m$ (dry ton); \\
$y_{j l}$ & Binary variable decides if the plant $j$ operated in level $l$. \\
\hline
\end{tabular}




\section{C.2. LCA Processes in SimaPro}

Table C-1. Processes involved in on the LCA model.

\begin{tabular}{ll}
\hline Process Name & Table Number \\
\hline Grapple Skidder & C-5 \\
Grapple Loader & C-6 \\
Chipper & C-7 \\
Forest residues processed and loaded at the landing & C-8 \\
Forest residues (dried, stored) & C-9 \\
Preprocessed residue, at conversion facility & C-10 \\
Thermochemical conversion plant & C-11 \\
Indirect heated softwood & C-12 \\
Dry wood residue combustion & C-13 \\
Residue Dried & C-14 \\
Denatured ethanol & C-15 \\
Distribution, 60 miles & C-16 \\
Ethanol, forest residue, at blending terminal & C-17 \\
Liquid fuels pumped into vehicle & C-18 \\
Ethanol combustion & C-19 \\
Bio-oil & C-20 \\
Upgrade & C-21 \\
Gasoline combustion & C-22 \\
Diesel combustion & C-23 \\
\hline
\end{tabular}

Table C-5. Process "Grapple Skidder".

\begin{tabular}{ll}
\hline Products and co-product & \\
\hline Grapple Skidder $^{\mathrm{a}}$ & 24 ton \\
\hline Materials/fuels & \\
\hline Diesel, combusted in industrial equipment/US & $13.758 \mathrm{gal}$ \\
Lubricant oil $(1)^{\mathrm{b}}$ & $0.247644 \mathrm{gal}$ \\
\hline
\end{tabular}

${ }^{a} \mathrm{Wu}$, Jinzhuo, Wang, Jingxin, Cheng, Qingzheng, DeVallance, David. 2011. Asses sment of coal and biomass to liquid fuels in central Appalachia, USA. International Journal of Energy Research. 36(7): 856-870;

b Ecoinvent 2.2.

Table C-6. Process "Grapple Loader".

\begin{tabular}{ll}
\hline Products and co-product & \\
\hline Grapple Loader $^{\mathrm{a}}$ & $24 \mathrm{ton}$ \\
\hline Materials/fuels & \\
\hline Diesel, combusted in industrial equipment/US & \\
Lubricant oil $(1)^{\mathrm{b}}$ & $6.54 \mathrm{gal}$ \\
\hline
\end{tabular}

${ }^{\mathrm{a}} \mathrm{Wu}$ et al. 2011;

b Ecoinvent 2.2. 
Table C-7. Process “Chipper”.

\begin{tabular}{ll}
\hline Products and co-product & \\
\hline Chipper $^{\mathrm{a}}$ & 24 ton \\
\hline Materials/fuels & \\
\hline Diesel, combusted in industrial equipment/US & \\
Lubricant oil $(1)^{\mathrm{b}}$ & $14.52 \mathrm{gal}$ \\
\hline
\end{tabular}

a Wu et al. 2011;

b Ecoinvent 2.2.

Table C-8. Process "Forest residues processed and loaded at the landing”.

\begin{tabular}{ll}
\hline Products and co-product & \\
\hline Forest residues processed and loaded at the landing ${ }^{\mathrm{a}}$ & 1 ton \\
\hline Natural Resources & \\
\hline Carbon dioxide, in air & $942 \mathrm{~kg}$ \\
Energy, from biomas & $8561 \mathrm{MJ}$ \\
\hline Materials/fuels & 1 ton \\
\hline Grapple Skidder & 1 ton \\
Grapple Loader & 1 ton \\
Chipper & Wolfrum Edward Mann, Margaret K, Aden,
\end{tabular}

a Revised from "Hsu, David D., Inman, Daniel, Heath, Garvin A., Wolfrum, Edward J., Mann, Margaret K., Aden, Andy. 2010. Life cycle environmental impact of selected U.S. ethanolproduction and use pathway in 2022.

Environmental Science and Technology.44: 5289-5297”;

Table C-9. Process "Forest residues (dried, stored)".

\begin{tabular}{ll}
\hline Products and co-product & \\
\hline Forest residue (dried, stored) & \\
\hline Materials/fuels & 0.772 ton \\
\hline Forest residues processed and loaded at the landing & 0.62 ton \\
Transport, lorry 16-32t, EURO5/RER U & 148.73 tkm \\
Dried roughage store, non ventilated/CH/I U & $9.75 \mathrm{E}-8 \mathrm{~m}^{3}$ \\
Conveyor belt, at plant/RER/I U & $3.47 \mathrm{E}-5 \mathrm{~m}^{\mathrm{b}}$ \\
Fodder loading, by self-loading trailer/CH with US electricity & $2.27 \mathrm{~m}^{3}$ \\
US & 0.16 ton \\
Sawmill Residue &
\end{tabular}

a Revised from "Hsu et al. 2010";

b Ecoinvent 2.2. 
Table C-10. Process "Preprocessed residue, at conversion facility".

\begin{tabular}{ll}
\hline Products and co-product & \\
\hline Preprocessed residue, at conversion facility ${ }^{\mathrm{a}}$ & 1 ton \\
\hline Materials/fuels & 1 ton \\
\hline Forest residue (dried, stored) & $20 \mathrm{tkm}$ \\
Transport, lorry 16-32t, EURO5/RER U &
\end{tabular}

a Revised from "Hsu et al. 2010";

${ }^{\mathrm{b}}$ Ecoinvent 2.2.

Table C-11. Process "Thermochemical conversion plant".

\begin{tabular}{ll}
\hline Products and co-product & \\
\hline Thermochemical conversion plant ${ }^{\mathrm{a}}$ & $1 \mathrm{p}$ \\
\hline Materials/fuels & $39100 \mathrm{~m}^{3}$ \\
\hline Concrete, sole plate and foundation, at plant/CH U & $526000 \mathrm{~kg}$ \\
Steel, low-alloyed, at plant/RER U & $1240000 \mathrm{~kg}$ \\
Steel, converter, unalloyed, at plant/RER U & $456000 \mathrm{~kg}$ \\
Chromium steel 18/8, at plant/RER U & $271000 \mathrm{~kg}$ \\
Zinc, primary, at regional storage/RER U & $113000 \mathrm{~kg}$ \\
Copper, at regional storage/RER U & $10100 \mathrm{~kg}$ \\
Nickel, 99.5\%, at plant/GLO U & $3140000 \mathrm{~kg}$ \\
Transport, lorry 20-28t, fleet average/CH U & $1570000 \mathrm{tkm}$ \\
Transport, freight, rail/CH U & $3.84 \mathrm{E}+05 \mathrm{MJ}$ \\
Diesel, burned in building machine/GLO U & $4.65 \mathrm{E}+04 \mathrm{kWh}$ \\
Electricity, medium voltage, at grid/US U & $1.67 \mathrm{E}+05 \mathrm{MJ}$ \\
\hline Emissions to air & $8.59 \mathrm{E}+07 \mathrm{MJ}$ \\
\hline Heat, waste & \\
\hline Waste Treatment & \\
\hline Disposal, building, concrete gravel, to final disposal/CH S & \\
\hline Revised from "Hsu et al. 2010";
\end{tabular}

a Revised from "Hsu et al. 2010";

Table C-12. Process "Indirect heated softwood".

\begin{tabular}{ll}
\hline Products and co-product & \\
\hline Indirect heated softwood, plywood drying ${ }^{\mathrm{a}}$ & $411 \mathrm{~kg}$ \\
\hline Materials/fuels & $0.159 \mathrm{~kg}$ \\
\hline Particulates, unspecified & $1.27 \mathrm{E}-02 \mathrm{~kg}$ \\
Carbon monoxide, biogenic
\end{tabular}

a Revised from "Hsu et al. 2010"; 
Table C-13. Process "Dry wood residue combustion".

\begin{tabular}{ll}
\hline Products and co-product & \\
\hline Dry wood residue combustion $^{\mathrm{a}}$ & $1055 \mathrm{MJ}$ \\
\hline Emissions to air & $45.5 \mathrm{~g}$ \\
\hline Particulates & $33.6 \mathrm{~g}$ \\
Particulates, < $10 \mathrm{um}$ & $29.5 \mathrm{~g}$ \\
Particulates, $<2.5 \mathrm{um}$ & $222 \mathrm{~g}$ \\
Nitrogen oxides & $11.4 \mathrm{~g}$ \\
Sulfur dioxide & $272 \mathrm{~g}$ \\
Carbon monoxide, biogenic & $8.63 \mathrm{~g}$ \\
Hydrogen chloride & $9.53 \mathrm{E}+00 \mathrm{~g}$ \\
Methane, biogenic & $1.77 \mathrm{E}+01 \mathrm{~g}$ \\
Organic substances, unspecified & $7.72 \mathrm{E}+00 \mathrm{~g}$ \\
VOC, volatile organic compounds & $5.90 \mathrm{E}+00 \mathrm{~g}$ \\
\hline Nitrous acid &
\end{tabular}

a Revised from "Hsu et al. 2010";

Table C-14. Process "Residue Dried".

\begin{tabular}{ll}
\hline Products and co-product & \\
\hline Forest residue (dried) & $1055 \mathrm{MJ}$ \\
\hline Materials/fuels & \\
\hline Dried roughage store, non ventilated/CH/I U & $0.00 \mathrm{~m}^{3}$ \\
Sawmill Residue & $0.16 \mathrm{ton}$ \\
Fodder loading, by self-loading trailer/CH with US electricity & \\
U & $2.27 \mathrm{~m}^{3}$ \\
Conveyor belt, at plant/RER/I with US electricity U & $0.00 \mathrm{~m}^{3}$ \\
Forest residues processed and loaded at the landing & $0.62 \mathrm{ton}$ \\
Transport, lorry 16-32t, EURO5/RER U & $148.73 \mathrm{tkm}$ \\
\hline
\end{tabular}




\section{Table C-15. Process "Denatured ethanol".}

\begin{tabular}{|c|c|}
\hline Products and co-product & \\
\hline Ethanol, denatured, (from forest residues via thermochemical) ${ }^{a}$ & $21202 \mathrm{~kg}$ \\
\hline Mixed alcohols (from thermochemical) & $3791 \mathrm{~kg}$ \\
\hline Sulfur (from thermochemical) & $53.6 \mathrm{~kg}$ \\
\hline Resources & \\
\hline Oxygen, in air & $77634 \mathrm{~kg}$ \\
\hline Nitrogen, in air & $253790 \mathrm{~kg}$ \\
\hline Water, cooling, unspecified natural origin $/ \mathrm{kg}$ & $74002 \mathrm{~kg}$ \\
\hline Water, process, unspecified natural origin $/ \mathrm{kg}$ & $13348 \mathrm{~kg}$ \\
\hline Materials/fuels & \\
\hline Silica sand, at plant/DE U & $244 \mathrm{~kg}$ \\
\hline Thermochemical conversion plant & 5.95E-06 p \\
\hline Magnesium oxide, at plant/RER $U$ & $3.16 \mathrm{~kg}$ \\
\hline Zeolite, powder, at plant/RER $S$ & $45.4 \mathrm{~kg}$ \\
\hline Chemicals inorganic, at plant/GLO U & $4.63 \mathrm{E}+01 \mathrm{~kg}$ \\
\hline Monoethanolamine, at plant/RER U & $2.72 \mathrm{E}+01 \mathrm{~kg}$ \\
\hline Hydrochloric acid, $30 \%$ in $\mathrm{H} 2 \mathrm{O}$, at plant/RER $\mathrm{U}$ & $0.4 \mathrm{~kg}$ \\
\hline Sodium hydroxide, $50 \%$ in $\mathrm{H} 2 \mathrm{O}$, production mix, at plant/RER & \\
\hline $\mathrm{U}$ & $0.4 \mathrm{~kg}$ \\
\hline Sulphite, at plant/RER U & $4.00 \mathrm{E}-01 \mathrm{~kg}$ \\
\hline Chemicals inorganic, at plant/GLO U & 4.54E-01 kg \\
\hline Diesel, low-sulphur, at regional storage/RER U & $3.13 \mathrm{E}+01 \mathrm{~kg}$ \\
\hline Dry wood residue combustion, EPA AP-42 & 3.90E+05 MJ \\
\hline Indirect heated softwood, plywood drying & $41768 \mathrm{~kg}$ \\
\hline Forest residue (dried) Ethanol & $1.13 \mathrm{E}+05 \mathrm{~kg}$ \\
\hline Petrol, unleaded, at regional storage/RER with US electricity $U$ & $276 \mathrm{~kg}$ \\
\hline Emissions to air & \\
\hline Ammonia & $0.454 \mathrm{~kg}$ \\
\hline Carbon dioxide, biogenic & $107598 \mathrm{~kg}$ \\
\hline Nitrogen & $2.64 \mathrm{E}+05 \mathrm{~kg}$ \\
\hline Oxygen & $1.20 \mathrm{E}+04 \mathrm{~kg}$ \\
\hline Water & $6.31 \mathrm{E}+04 \mathrm{~kg}$ \\
\hline Nitrogen dioxide & $8.40 \mathrm{E}+01 \mathrm{~kg}$ \\
\hline Sulfur dioxide & $3.91 \mathrm{E}+01 \mathrm{~kg}$ \\
\hline Waste treatment & \\
\hline Disposal, wood ash mixture, pure, $0 \%$ water, to sanitary & \\
\hline landfill/CH U & $1.10 \mathrm{E}+03 \mathrm{~kg}$ \\
\hline Disposal, inert material, $0 \%$ water, to sanitary landfill/CH U & $4.54 \mathrm{E}+01 \mathrm{~kg}$ \\
\hline Treatment, sewage, unpolluted, to wastewater treatment, class & \\
\hline $3 / \mathrm{CH} \mathrm{U}$ & $797 \mathrm{~kg}$ \\
\hline
\end{tabular}

a Revised from "Hsu et al. 2010"; 
Table C-16. Process "Distribution, 60 miles".

\begin{tabular}{ll}
\hline Products and co-product & \\
\hline Distribution, 60 miles $^{\mathrm{a}}$ & $1 \mathrm{gal}$ \\
\hline Emissions to air & \\
\hline Carbon dioxide, fossil & $28.29 \mathrm{~g}$ \\
Methane & $0.0015 \mathrm{~g}$ \\
Dinitrogen monoxide & $0.0009 \mathrm{~g}$ \\
Sulfur oxides & $0.1389 \mathrm{~g}$ \\
Nitrogen oxides & $0.1223 \mathrm{~g}$ \\
Carbon monoxide, fossil & $0.1638 \mathrm{~g}$ \\
VOC, volatile organic compounds & $0.0011 \mathrm{~g}$ \\
Particulates, unspecified & $0.0235 \mathrm{~g}$ \\
\hline
\end{tabular}

a Revised from "Marano and Ciferno 2001".

Table C-17. Process "Ethanol, forest residue, at blending terminal".

\begin{tabular}{ll}
\hline Products and co-product \\
\hline Ethanol, forest residue, at blending terminal ${ }^{\mathrm{a}}$ & \\
\hline Electricity/heat & $0.81 \mathrm{~kg}$ \\
\hline Ethanol, denatured,(from forest residues via & \\
thermochemical)_Ethanol & $0.81 \mathrm{~kg}$ \\
Electricity, medium voltage, at grid/US U & $8.60 \mathrm{E}-04 \mathrm{kWh}$ \\
Liquid storage tank, chemicals, organics/CH/I U & $8.50 \mathrm{E}-11 \mathrm{p}$ \\
\hline a Revised from "Hsu et al. 2010";
\end{tabular}

a Revised from "Hsu et al. 2010";

Table C-18. Process "Liquid fuels pumped into vehicle".

\begin{tabular}{ll}
\hline Products and co-product & \\
\hline Liquid fuels pumped into vehicle $^{\mathrm{a}}$ & $0.2973 \mathrm{gal}$ \\
\hline Eectricity/heat & \\
\hline Electricity, low voltage, at grid/US Ub & $0.0026495 \mathrm{kWh}$ \\
Liquid storage tank, chemicals, organics/CH/I Ub & $9.4 \mathrm{e}-12 \mathrm{p}$ \\
Distribution, 60 miles & $0.297348 \mathrm{gal}$ \\
Rubber and plastics hose and belting & $7.49 \mathrm{E}-12 \mathrm{USD}$ \\
Measuring and dispensing pumps & $9.17 \mathrm{E}-15 \mathrm{USD}$ \\
Eth, forest residue, at blending terminal & $1 \mathrm{~kg}$ \\
\hline
\end{tabular}

a Revised from "Hsu et al. 2010";

${ }^{\mathrm{b}}$ Ecoinvent 2.2. 
Table C-19. Process “Ethanol combustion”.

\begin{tabular}{ll}
\hline Products and co-product & \\
\hline Ethanol combustion $^{\mathrm{a}}$ & $0.080135 \mathrm{~kg}$ \\
\hline Eectricity/heat & \\
\hline Carbon dioxide, biogenic & $2.14 \mathrm{E}+02 \mathrm{~g}$ \\
Methane & $6.80 \mathrm{E}-03 \mathrm{~g}$ \\
Nitrous acid & $7.52 \mathrm{E}-03 \mathrm{~g}$ \\
\hline a Revised from "Hsu et al. 2010";
\end{tabular}

a Revised from "Hsu et al. 2010";

Table C-20. Process "Bio-oil".

\begin{tabular}{|c|c|}
\hline \multicolumn{2}{|l|}{ Products and co-product } \\
\hline Bio-oil (from wood via pyrolysis) ${ }^{\mathrm{a}}$ & $68038.8 \mathrm{~kg}$ \\
\hline \multicolumn{2}{|l|}{ Resources } \\
\hline Water, process, unspecified natural origin $/ \mathrm{kg}$ & $6000 \mathrm{lb}$ \\
\hline Air & $350000 \mathrm{lb}$ \\
\hline Water, cooling, uns pecified natural origin $/ \mathrm{kg}$ & $180000 \mathrm{lb}$ \\
\hline Water, unspecified natural origin $/ \mathrm{kg}$ & $84800 \mathrm{lb}$ \\
\hline \multicolumn{2}{|l|}{ Materials/fuels } \\
\hline Electricity, medium voltage, at grid/US U & $12000 \mathrm{kWh}$ \\
\hline Hydrochloric acid, $30 \%$ in $\mathrm{H} 2 \mathrm{O}$, at plant/RER U & $0.667 \mathrm{lb}$ \\
\hline \multicolumn{2}{|l|}{ Sodium hydroxide, $50 \%$ in $\mathrm{H} 2 \mathrm{O}$, production mix, at plant/RER } \\
\hline $\mathrm{U}$ & $0.667 \mathrm{lb}$ \\
\hline Sulphite, at plant/RER U & $0.667 \mathrm{lb}$ \\
\hline Chemicals inorganic, at plant/GLO U & $1 \mathrm{lb}$ \\
\hline Thermochemical conversion plant & 5.95E-06 p \\
\hline Forest residue (dried) & $2.83 \mathrm{E}+05 \mathrm{lb}$ \\
\hline \multicolumn{2}{|l|}{ Emissions to air } \\
\hline Oxygen & $24400 \mathrm{lb}$ \\
\hline Nitrogen & $270000 \mathrm{lb}$ \\
\hline Water & $180000 \mathrm{lb}$ \\
\hline Hydrogen & $2.01 \mathrm{lb}$ \\
\hline Carbon dioxide, biogenic & $88100 \mathrm{lb}$ \\
\hline Carbon monoxide, biogenic & $504 \mathrm{lb}$ \\
\hline Water & $1.28 \mathrm{E}+05 \mathrm{lb}$ \\
\hline Water & $2.01 \mathrm{E}+04 \mathrm{lb}$ \\
\hline Water & $3.20 \mathrm{E}+04 \mathrm{lb}$ \\
\hline Water & $1.20 \mathrm{E}+03 \mathrm{lb}$ \\
\hline \multicolumn{2}{|l|}{ Waste treatment } \\
\hline \multirow{2}{*}{$\begin{array}{l}\text { Disposal, wood ash mixture, pure, } 0 \% \text { water, to sanitary } \\
\text { landfill/CH U } \\
\text { Treatment, sewage, unpolluted, to wastewater treatment, class } \\
\text { 3/CH U }\end{array}$} & $3.60 \mathrm{E}+03 \mathrm{lb}$ \\
\hline & $2.18 \mathrm{E}+00 \mathrm{~m}^{3}$ \\
\hline
\end{tabular}

a Revised from "Hsu 2011”; 
Table C-21. Process "Upgrade".

\begin{tabular}{ll}
\hline Products and co-product & \\
\hline Gasoline (from bio-oil via upgrading) & $28600 \mathrm{lb}$ \\
Diesel (from bio-oil via upgrading) & $38400 \mathrm{lb}$ \\
\hline Resources & \\
\hline Water, cooling, unspecified natural origin/kg & $6070 \mathrm{lb}$ \\
Water, unspecified natural origin/kg & $56400 \mathrm{lb}$ \\
Air & $230000 \mathrm{lb}$ \\
\hline Materials/fuels & \\
\hline Natural gas, high pressure, at consumer/RER U & $374000 \mathrm{MJ}$ \\
Zeolite, powder, at plant/RER S & $85 \mathrm{lb}$ \\
Zeolite, powder, at plant/RER S & $0.371 \mathrm{lb}$ \\
Zeolite, powder, at plant/RER S & $3.27 \mathrm{lb}$ \\
Electricity, medium voltage, at grid/US U & $12600 \mathrm{MJ}$ \\
Bio-oil (from wood via pyrolysis) & $68038.8 \mathrm{~kg}$ \\
Refinery/RER/I U & $3.30 \mathrm{E}-06 \mathrm{p}$ \\
\hline Emissions to air & \\
\hline Water & $2.90 \mathrm{E}+04 \mathrm{lb}$ \\
Nitrogen & $1.76 \mathrm{E}+05 \mathrm{lb}$ \\
Oxygen & $9.74 \mathrm{E}+03 \mathrm{lb}$ \\
Water & $6.83 \mathrm{E}+01 \mathrm{lb}$ \\
Hydrogen & $1.23 \mathrm{E}+02 \mathrm{lb}$ \\
Carbon dioxide, biogenic & $1.75 \mathrm{E}+03 \mathrm{lb}$ \\
Carbon dioxide, biogenic & $6.71 \mathrm{E}+02 \mathrm{lb}$ \\
Ethane & $4.02 \mathrm{E}+02 \mathrm{lb}$ \\
Propane & $3.39 \mathrm{E}+02 \mathrm{lb}$ \\
Isobutane & $3.01 \mathrm{E}+02 \mathrm{lb}$ \\
Heptane & $3.76 \mathrm{E}+02 \mathrm{lb}$ \\
Cyclohexane, propyl- & $7.24 \mathrm{E}+00 \mathrm{lb}$ \\
Hydrocarbons, aliphatic, alkanes, unspecified & $1.52 \mathrm{E}+00 \mathrm{lb}$ \\
Hydrocarbons, alkanes, cyclo-, C6 & $2.87 \mathrm{E}+00 \mathrm{lb}$ \\
Xylene & $1.08 \mathrm{E}+00 \mathrm{lb}$ \\
Water & $6.07 \mathrm{E}+03 \mathrm{lb}$ \\
Water & $3.41 \mathrm{E}+02 \mathrm{lb}$ \\
Water & $-3.45 \mathrm{E}+02 \mathrm{lb}$ \\
Carbon dioxide, biogenic & $8.39 \mathrm{E}+04 \mathrm{lb}$ \\
\hline Revised “Ho &
\end{tabular}

a Revised from "Hsu 2011"; 
Table C-22. Process "Gasoline combustion".

\begin{tabular}{ll}
\hline Products and co-product & \\
\hline Gasoline combustion & $0.112 \mathrm{~kg}$ \\
\hline Materials/fuels & \\
\hline Gasoline (from bio-oil via upgrading) & $0.112 \mathrm{~kg}$ \\
Liquid fuels pumped into vehicle & $0.038638215 \mathrm{gal}$ \\
\hline Emissions to air & \\
\hline Carbon dioxide, biogenic & $3.43 \mathrm{E}+02 \mathrm{~g}$ \\
Methane, biogenic & $1.00 \mathrm{E}-02 \mathrm{~g}$ \\
Dinitrogen monoxide & $1.20 \mathrm{E}-02 \mathrm{~g}$ \\
VOC, volatile organic compounds & $1.51 \mathrm{E}-01 \mathrm{~g}$ \\
Carbon monoxide & $3.48 \mathrm{E}+00 \mathrm{~g}$ \\
Nitrogen oxides & $6.90 \mathrm{E}-02 \mathrm{~g}$ \\
Particulates, < 10 um & $2.90 \mathrm{E}-02 \mathrm{~g}$ \\
Particulates, $<2.5$ um & $1.40 \mathrm{E}-02 \mathrm{~g}$ \\
Sulfur oxides & $6.00 \mathrm{E}-03 \mathrm{~g}$ \\
\hline Revised from "Hsu 2011"; &
\end{tabular}

Table C-23. Process "Diesel combustion".

\begin{tabular}{ll}
\hline Products and co-product & \\
\hline Diesel combustion & $0.0944 \mathrm{~kg}$ \\
\hline Materials/fuels & \\
\hline Diesel (from bio-oil via upgrading) & $0.0944 \mathrm{~kg}$ \\
Liquid fuels pumped into vehicle & $2.8 \mathrm{E}-02 \mathrm{gal}$ \\
\hline Emissions to air & \\
\hline Carbon dioxide, biogenic & $3.02 \mathrm{E}+02 \mathrm{~g}$ \\
Methane, biogenic & $3.08 \mathrm{E}-03 \mathrm{~g}$ \\
Dinitrogen monoxide & $1.23 \mathrm{E}-02 \mathrm{~g}$ \\
VOC, volatile organic compounds & $6.16 \mathrm{E}-02 \mathrm{~g}$ \\
Carbon monoxide & $5.48 \mathrm{E}-01 \mathrm{~g}$ \\
Nitrogen oxides & $8.22 \mathrm{E}-02 \mathrm{~g}$ \\
Particulates, < 10 um & $3.08 \mathrm{E}-02 \mathrm{~g}$ \\
Particulates, < 2.5 um & $1.54 \mathrm{E}-02 \mathrm{~g}$ \\
Sulfur oxides & $2.05 \mathrm{E}-03 \mathrm{~g}$ \\
\hline a Revised from "Hsu 2011"; &
\end{tabular}




\section{APPENDIX D. SUPPLEMENTAL INFORMATION FOR CHAPTER 5}

\section{D.1. LCA ProcesSES in SimAPro}

Table D-1. Processes involved in on the LCA model.

\begin{tabular}{ll}
\hline Process Name & Table Number \\
\hline Plow & D-2 \\
Disk & D-3 \\
Cultipacker & D-4 \\
Seeder & D-5 \\
Site Preparation & D-6 \\
Planter & D-7 \\
Sprayer & D-8 \\
Herbicides & D-9 \\
Fertilization & D-10 \\
Blower & D-11 \\
Cut \& Chip Harvester & D-12 \\
Forage Wagon & D-13 \\
New Holland FR series forage harvester & D-14 \\
Transport, truck & D-15 \\
Wheel Loader L150G & D-16 \\
Plant site storage & D-17 \\
Active Drier, MC<10\%, Willow & D-18 \\
Grinder, Particle size<2mm, Willow & D-19 \\
Hammer Mill, Particle size<2mm, Willow & D-20 \\
Preprocess, Pyrolysis, Willow & D-21 \\
Grinder, Particle size<1/4", Willow & D-22 \\
Hammer Mill, Particle size<1/4", Willow & D-23 \\
Preprocess, Pellet & D-24 \\
Cooling & D-25 \\
Power Plant, Biomass & D-26 \\
Pellet Mill, Willow & D-27 \\
Pellet, distribution & D-28 \\
Disk, Grass & D-29 \\
Lorrow, New Holland T1530 & D-30 \\
\hline & D-31 \\
Praration, Miscanthus 60 kW engine & D-32 \\
D-33 \\
\hline
\end{tabular}




\begin{tabular}{ll}
\hline Process Name & Table Number \\
\hline Fertilizing, Grass & D-34 \\
Transplanter, Miscanthus & D-35 \\
Herbicides, Grass & D-36 \\
Baler & D-37 \\
Disk Mowing, New Holland H6740 & D-38 \\
Harvest, Grass & D-39 \\
Rake, New Holland H5920 & D-40 \\
Tedder, New Holland H5270 & D-41 \\
Tractor with Wagon & D-42 \\
Land Preparation, Switchgrass & D-43 \\
Hopper, Switchgrass & D-44 \\
\hline
\end{tabular}

\section{Table D-2. Process "Plow”.}

\begin{tabular}{ll}
\hline Products and co-product & \\
\hline Plow $^{\mathrm{a}}$ & $1 \mathrm{ha}$ \\
\hline Materials/fuels & \\
\hline Diesel, at regional storage/CH with US electricity U & $2.707566 \mathrm{~kg}$ \\
Lubricating oil, at plant/RER with US electricity U & $0.042926 \mathrm{~kg}$ \\
\hline
\end{tabular}

a Caputo, J, Balogh, S.B., Volk, T.A., Johnson, L., Puettmann, M., Lippke, B., Oneil, E. 2014 Icorporation uncertainty into a life cylccle as sessment model of short rotation willow biomass crops. Biomass and Bioenrgy, 7:48-59;

Table D-3. Process “Disk”.

\begin{tabular}{ll}
\hline Products and co-product & \\
\hline Disk $^{\mathrm{a}}$ & $1 \mathrm{ha}$ \\
\hline Materials/fuels & \\
\hline Diesel, at regional storage/CH with US electricity U & $2.22976 \mathrm{~kg}$ \\
Lubricating oil, at plant/RER with US electricity U & $0.035323 \mathrm{~kg}$ \\
\hline
\end{tabular}

${ }^{a}$ Caputo, J, Balogh, S.B., Volk, T.A., Johnson, L., Puettmann, M., Lippke, B., Oneil, E. 2014 Icorporation uncertainty into a life cylccle assessment model of short rotation willow biomass crops. Biomass and Bioenrgy, 7:48-59; 
Table D-4. Process “Cultipacker”.

\begin{tabular}{ll}
\hline Products and co-product & \\
\hline Cultipacker & $1 \mathrm{ha}$ \\
\hline Materials/fuels & \\
\hline Diesel, at regional storage/CH with US electricity U & $1.130331 \mathrm{~kg}$ \\
Lubricating oil, at plant/RER with US electricity U & $0.017899 \mathrm{~kg}$ \\
\hline
\end{tabular}

${ }^{a}$ Caputo, J, Balogh, S.B., Volk, T.A., Johnson, L., Puettmann, M., Lippke, B., Oneil, E. 2014 Icorporation uncertainty into a life cylccle as sessment model of short rotation willow biomass crops. Biomass and Bioenrgy, 7:48-59;

Table D-5. Process “Seeder”.

\begin{tabular}{ll}
\hline Products and co-product & \\
\hline Seeder & $1 \mathrm{ha}$ \\
\hline Materials/fuels & \\
\hline Diesel, at regional storage/CH with US electricity U & $0.159269 \mathrm{~kg}$ \\
Lubricating oil, at plant/RER with US electricity U & $0.002519 \mathrm{~kg}$ \\
\hline
\end{tabular}

a Caputo, J, Balogh, S.B., Volk, T.A., Johnson, L., Puettmann, M., Lippke, B., Oneil, E. 2014 Icorporation uncertainty into a life cylccle assessment model of short rotation willow biomass crops. Biomass and Bioenrgy, 7:48-59;

Table D-6. Process "Site Preparation”.

\begin{tabular}{ll}
\hline Products and co-product & \\
\hline Site Preparation $^{\mathrm{a}}$ & $1 \mathrm{ha}$ \\
\hline Materials/fuels & $1 \mathrm{ha}$ \\
\hline Disk & $1 \mathrm{ha}$ \\
Plow & $1 \mathrm{ha}$ \\
Cultipacker & $1 \mathrm{ha}$ \\
Seeder & \\
\hline
\end{tabular}

${ }^{a}$ Caputo, J, Balogh, S.B., Volk, T.A., Johnson, L., Puettmann, M., Lippke, B., Oneil, E. 2014 Icorporation uncertainty into a life cylccle assessment model of short rotation willow biomass crops. Biomass and Bioenrgy, 7:48-59;

Table D-7. Process "Planter".

\begin{tabular}{|c|c|}
\hline \multicolumn{2}{|l|}{ Products and co-product } \\
\hline Planter $^{\mathrm{a}}$ & $1 \mathrm{ha}$ \\
\hline \multicolumn{2}{|l|}{ Materials/fuels } \\
\hline Willow Step planter 1 ha US U & $0.142857 \mathrm{ha}$ \\
\hline Site Preparation & $1 \mathrm{ha}$ \\
\hline
\end{tabular}


Table D-8. Process "Sprayer".

\begin{tabular}{ll}
\hline Products and co-product & \\
\hline Sprayer & \\
\hline Materials/fuels & $1 \mathrm{p}$ \\
\hline Diesel, at regional storage/CH with US electricity U & $0.832 \mathrm{~kg}$ \\
Lubricating oil, at plant/RER with US electricity U & $0.013179 \mathrm{~kg}$ \\
\hline
\end{tabular}

${ }^{a}$ Caputo, J, Balogh, S.B., Volk, T.A., Johnson, L., Puettmann, M., Lippke, B., Oneil, E. 2014 Icorporation uncertainty into a life cylccle as sessment model of short rotation willow biomass crops. Biomass and Bioenrgy, 7:48-59;

Table D-9. Process "Herbicides".

\begin{tabular}{ll}
\hline Products and co-product & \\
\hline Herbicides $^{\mathrm{a}}$ & $1 \mathrm{ha}$ \\
\hline Materials/fuels & \\
\hline Sprayer & $0.957143 \mathrm{p}$ \\
Glyphosate, at regional storehouse/CHwith US electricity U & $0.357143 \mathrm{~kg}$ \\
\hline
\end{tabular}

${ }^{a}$ Caputo, J, Balogh, S.B., Volk, T.A., Johnson, L., Puettmann, M., Lippke, B., Oneil, E. 2014 Icorporation uncertainty into a life cylccle assessment model of short rotation willow biomass crops. Biomass and Bioenrgy, 7:48-59;

Table D-10. Process “Fertilization”.

\begin{tabular}{lc}
\hline Products and co-product & \\
\hline Fertilization $^{\mathrm{a}}$ & $1 \mathrm{p}$ \\
\hline Materials/fuels & $2.81 \mathrm{p}$ \\
\hline Sprayer & $100 \mathrm{~kg}$ \\
Ammonium sulphate, as N, at regional storehouse/RER with US & \\
electricity U & \\
\hline
\end{tabular}

${ }^{a}$ Caputo, J, Balogh, S.B., Volk, T.A., Johnson, L., Puettmann, M., Lippke, B., Oneil, E. 2014 Icorporation uncertainty into a life cylccle assessment model of short rotation willow biomass crops. Biomass and Bioenrgy, 7:48-59;

Table D-11. Process "Blower".

\begin{tabular}{ll}
\hline Products and co-product & \\
\hline Blower $^{\mathrm{a}}$ & $1 \mathrm{ha}$ \\
\hline Materials/fuels & \\
\hline Diesel, at regional storage/CH with US electricity U & $5.408 \mathrm{~kg}$ \\
Lubricating oil, at plant/RER with US electricity U & $0.085694 \mathrm{~kg}$ \\
\hline
\end{tabular}

${ }^{a}$ Caputo, J, Balogh, S.B., Volk, T.A., Johnson, L., Puettmann, M., Lippke, B., Oneil, E. 2014 Icorporation uncertainty into a life cylccle assessment model of short rotation willow biomass crops. Biomass and Bioenrgy, 7:48-59; 
Table D-12. Process “Cut \& Chip Harvester”.

\begin{tabular}{lc}
\hline Products and co-product & \\
\hline Cut \& Chip Harvester & 1 ha \\
\hline Materials/fuels & 1 ha \\
\hline New Holland FR series forage harvester & 1 ha \\
Blower & \\
\hline
\end{tabular}

${ }^{a}$ Caputo, J, Balogh, S.B., Volk, T.A., Johnson, L., Puettmann, M., Lippke, B., Oneil, E. 2014 Icorporation uncertainty into a life cylccle as sessment model of short rotation willow biomass crops. Biomass and Bioenrgy, 7:48-59;

Table D-13. Process “Forage Wagon”.

\begin{tabular}{ll}
\hline Products and co-product & \\
\hline Forage Wagon $^{\mathrm{a}}$ & $1 \mathrm{ha}$ \\
\hline Materials/fuels & $10.816 \mathrm{~kg}$ \\
\hline Diesel, at regional storage/CH with US electricity U & $0.171072 \mathrm{~kg}$ \\
\hline Lubricating oil, at plant/RER with US electricity U &
\end{tabular}

a Caputo, J, Balogh, S.B., Volk, T.A., Johnson, L., Puettmann, M., Lippke, B., Oneil, E. 2014 Icorporation uncertainty into a life cylccle assessment model of short rotation willow biomass crops. Biomass and Bioenrgy, 7:48-59;

Table D-14. Process "New Holland FR series forage harvester".

\begin{tabular}{ll}
\hline Products and co-product & \\
\hline New Holland FR series forage harvester ${ }^{\mathrm{a}}$ & $1 \mathrm{ha}$ \\
\hline Materials/fuels & $101.1712 \mathrm{~kg}$ \\
\hline Diesel, at regional storage/CH with US electricity U & $1 \mathrm{ha}$ \\
Fertilization & $1 \mathrm{ha}$ \\
Herbicides & $1 \mathrm{ha}$ \\
Planter & $1.59984 \mathrm{~kg}$ \\
Lubricating oil, at plant/RER with US electricity U
\end{tabular}

${ }^{a}$ Caputo, J, Balogh, S.B., Volk, T.A., Johnson,L., Puettmann, M., Lippke, B., Oneil, E. 2014 Icorporation uncertainty into a life cylccle assessment model of short rotation willow biomass crops. Biomass and Bioenrgy, 7:48-59; 
Table D-15. Process "Transport, truck".

\begin{tabular}{ll}
\hline Products and co-product & \\
\hline Transport, truck & \\
\hline Materials/fuels & $80 \mathrm{~km}$ \\
\hline Transport, combination truck, diesel powered NREL /US & $80 \mathrm{tkm}$ \\
Forage Wagon & 0.080645 ha \\
Cut \& Chip Harvester & 0.080645 ha \\
Wheel Loader L150G & 1 ton \\
\hline
\end{tabular}

${ }^{a}$ Caputo, J, Balogh, S.B., Volk, T.A., Johnson,L., Puettmann, M., Lippke, B., Oneil, E. 2014 Icorporation

uncertainty into a life cylccle assessment model of short rotation willow biomass crops. Biomass and Bioenrgy, 7:48-59;

Table D-16. Process “Wheel Loader L150G”.

\begin{tabular}{ll}
\hline Products and co-product & \\
\hline Wheel Loader L150G & 270000 ton \\
\hline Materials/fuels & \\
\hline Sheet rolling, aluminium/RER U & $266 \mathrm{~kg}$ \\
Glass fibre, at plant/RER with US electricity U & $3240 \mathrm{~kg}$ \\
Polyethylene, LDPE, granulate, at plant/RER with US electricity & \\
U & $102 \mathrm{~kg}$ \\
Heavy fuel oil, at regional storage/RER with US electricity U & $2992 \mathrm{~kg}$ \\
Paper, woodfree, uncoated, at regional storage/RER with US & \\
electricity U & $246 \mathrm{~kg}$ \\
Wire drawing, steel/RER with US electricity U & $1800 \mathrm{~kg}$ \\
Synthetic rubber, at plant/RER with US electricity U & $6960 \mathrm{~kg}$ \\
Crude oil, at production/NG with US electricity U & $450491 \mathrm{~kg}$ \\
Hard coal, at regional storage/RNA with US electricity U & $5545.23 \mathrm{~kg}$ \\
Lignite coal, combusted in industrial boiler NREL /US & $5733 \mathrm{~kg}$ \\
Natural gas, production mix, at service station/CH U & $44743 \mathrm{~kg}$ \\
Peat, at mine/NORDEL with US electricity U & $33 \mathrm{~kg}$ \\
\hline
\end{tabular}

a Salman, O., Chen, Y. 2013. Comparative environmental analysis of conventional and hybrid wheel loader technologies. Master of Science Thesis, Stockholm. 
Table D-17. Process "Plant site storage”.

\begin{tabular}{ll}
\hline Products and co-product & \\
\hline Plant site storage $^{\mathrm{a}}$ & 1 ton \\
\hline Materials/fuels & \\
\hline Conveyor belt, at plant/RER/I with US electricity U & $3.47 \mathrm{E}-05 \mathrm{~m}$ \\
Transport, truck & $80.40201 \mathrm{tkm}$ \\
Electricity, medium voltage, at grid/US with US electricity U & $20 \mathrm{MJ}$ \\
\hline
\end{tabular}

a Jirjis, R. 1994. Storage and drying of wood fuel. Biomass and Bioenergy, 9(1):181-190.

Table D-18. Process "Active Drier, MC $<10 \%$, Willow".

\begin{tabular}{ll}
\hline Products and co-product & \\
\hline Active Drier, MC<10\%, Willow ${ }^{\mathrm{a}, \mathrm{b}}$ & $2.865 \mathrm{ton}$ \\
\hline Materials/fuels & \\
\hline Electricity, medium voltage, at grid/US with US electricity U & $350 \mathrm{kWh}$ \\
Transport, truck & $208.3636 \mathrm{tkm}$ \\
Plant site storage & $0.289394 \mathrm{ton}$ \\
\hline
\end{tabular}

a Nordhagen, E. 2011. Drying of wood chips with surplus heat from two hydroelectric plants in Norway. FORMEC, Austria.

b INL PDU.

Table D-19. Process “Grinder, Particle size $<2 m m$, Willow”.

\begin{tabular}{ll}
\hline Products and co-product & \\
\hline Grinder, Particle size $<2 \mathrm{~mm}, \quad$ Willow ${ }^{\mathrm{a}}$ & $1 \mathrm{ton}$ \\
\hline Materials/fuels & $3.47 \mathrm{E}-05 \mathrm{~m}$ \\
\hline Conveyor belt, at plant/RER/I with US electricity U & $72 \mathrm{tkm}$ \\
Transport, truck & $0.1 \mathrm{ton}$ \\
Plant site storage & $45.89 \mathrm{kWh}$ \\
Electricity, medium voltage, at grid/US with US electricity U & \\
\hline
\end{tabular}

a INL PDU.

Table D-20. Process "Hammer Mill, Particle size<2mm, Willow”.

\begin{tabular}{ll}
\hline Products and co-product & \\
\hline Hammer Mill, Particle size<2mm, Willow ${ }^{\mathrm{a}}$ & 1 ton \\
\hline Materials/fuels & $34.51 \mathrm{kWh}$ \\
\hline Electricity, medium voltage, at grid/US with US electricity U & 1 ton \\
Grinder, Particle size<2mm, Willow & $3.47 \mathrm{E}-05 \mathrm{~m}$ \\
\hline Conveyor belt, at plant/RER/I with US electricity U
\end{tabular}

a INL PDU. 
Table D-21. Process "Preprocess, Pyrolysis, Willow”.

Products and co-product

Preprocess, Pyrolysis, Willow ${ }^{\text {a }}$ 1 ton

Materials/fuels

Hammer Mill, Particle size<2mm, Willow 0.25 ton

Grinder, Particle size $<2 \mathrm{~mm}$, Willow

0.75 ton

a INL PDU.

Table D-22. Process “Grinder, Particle size <1/4", Willow”.

\begin{tabular}{ll}
\hline Products and co-product & \\
\hline Grinder, Particle size<1/4", Willow ${ }^{\mathrm{a}}$ & $1 \mathrm{ton}$ \\
\hline Materials/fuels & $3.47 \mathrm{E}-05 \mathrm{~m}$ \\
\hline Conveyor belt, at plant/RER/I with US electricity U & $72 \mathrm{tkm}$ \\
Transport, truck & $0.1 \mathrm{ton}$ \\
Plant site storage & $12.3 \mathrm{kWh}$ \\
Electricity, medium voltage, at grid/US with US electricity U
\end{tabular}

${ }^{\mathrm{a}}$ INL PDU.

Table D-23. Process "Hammer Mill, Particle size<1/4", Willow".

\begin{tabular}{ll}
\hline Products and co-product & \\
\hline Hammer Mill, Particle size<1/4", Willow ${ }^{\mathrm{a}}$ & 1 ton \\
\hline Materials/fuels & \\
\hline Electricity, medium voltage, at grid/US with US electricity U & $9.8 \mathrm{kWh}$ \\
Grinder, Particle size<2mm, Willow & 1 ton \\
Conveyor belt, at plant/RER/I with US electricity U & $3.47 \mathrm{E}-05 \mathrm{~m}$ \\
\hline
\end{tabular}

a INL PDU.

Table D-24. Process "Preprocess, Pellet".

\begin{tabular}{ll}
\hline Products and co-product & \\
\hline Preprocess, Pellet $^{\mathrm{a}}$ & 1 ton \\
\hline Materials/fuels & \\
\hline Hammer Mill, Particle size<1/4", Willow & 0.15 ton \\
Grinder, Particle size<1/4", Willow & 0.85 ton \\
\hline
\end{tabular}


Table D-25. Process “Cooling”.

\begin{tabular}{lc}
\hline Products and co-product & $1 \mathrm{ton}$ \\
\hline Cooling $^{\mathrm{a}}$ & \\
\hline Materials/fuels & $0.34 \mathrm{kWh}$ \\
\hline Electricity, medium voltage, at grid/US with US electricity U & $0.56 \mathrm{kWh}$ \\
Electricity, medium voltage, at grid/US with US electricity U & . \\
\hline a Fantozzi, F., Buratti, C. 2010. Life cycle assessment of biomas chains: Wood pellet from short rotation coppice \\
using data measured on a real plant. Biomass and Bioenergy, 34(12): $1796-1804$.
\end{tabular}

Table D-26. Process "Power Plant, Biomass".

\begin{tabular}{ll}
\hline Products and co-product & \\
\hline Power Plant, Biomas s ${ }^{\text {a }}$ & $1,000 \mathrm{MJ}$ \\
\hline Resources & \\
\hline Preprocess, Power Plant & 0.234 ton \\
Water, cooling, unspecified natural origin/m3 & $3.5 \mathrm{~m}^{3}$ \\
\hline Materials/fuels & $6 \mathrm{~kg}$ \\
\hline Water, completely softened, at plant/RER with US electricity U & $150 \mathrm{~kg}$ \\
Water, decarbonised, at plant/RER with US electricity U & \\
\hline Emissions to air & $585 \mathrm{~g}$ \\
\hline Carbon dioxide, biogenic & $389 \mathrm{~g}$ \\
Carbon monoxide, biogenic & $779 \mathrm{~g}$ \\
Nitrogen dioxide & $214 \mathrm{~g}$ \\
VOC, volatile organic compounds & $97 \mathrm{~g}$ \\
Particulates & $389 \mathrm{~g}$ \\
Sulfur dioxide & \\
\hline
\end{tabular}

a Spath, P.L., Mann, M.K., Kerr, D.R. 1999. Life cycle as ses sment applied to electricity generation from renewable biomass \& Life Cycle Assessment of Coal-fired Power Production (NREL). NREL/TP-570-25119.

Table D-27. Process "Pellet Mill, Willow".

\begin{tabular}{ll}
\hline Products and co-product & \\
\hline Pellet Mill, Willow ${ }^{\mathrm{a}}$ & $1 \mathrm{ton}$ \\
\hline Materials/fuels & \\
\hline Electricity, medium voltage, at grid/US with US electricity U & $50 \mathrm{kWh}$ \\
Cooling & $1 \mathrm{ton}$ \\
\hline
\end{tabular}

${ }^{\mathrm{a}}$ INL PDU. 
Table D-28. Process “Pellet, distribution".

\begin{tabular}{ll}
\hline Products and co-product & \\
\hline Pellet, distribution ${ }^{\mathrm{a}}$ & 1 ton \\
\hline Materials/fuels & 1 ton \\
\hline Wheel Loader L150G & $100 \mathrm{tkm}$ \\
Transport, combination truck, diesel powered/US & \\
\hline
\end{tabular}

a INL PDU.

Table D-29. Process "Pellet, combustion, Willow".

\begin{tabular}{ll}
\hline Products and co-product & \\
\hline Pellet, combustion, Willow ${ }^{\mathrm{a}}$ & $1 \mathrm{~kg}$ \\
\hline Materials/fuels & $0.035 \mathrm{~g}$ \\
\hline Methane, biogenic & $12.57 \mathrm{~g}$ \\
Carbon monoxide, biogenic & $1059 \mathrm{~g}$ \\
Carbon dioxide, biogenic & $0.002 \mathrm{~g}$ \\
Ammonia & $0.643 \mathrm{~g}$ \\
Nitrogen dioxide & $0.028 \mathrm{~g}$ \\
Dinitrogen monoxide & $4.226 \mathrm{~g}$ \\
Sulfur dioxide & $0.063 \mathrm{~g}$ \\
Particulates & \\
\hline Waste treatment & $0.033535 \mathrm{~kg}$ \\
\hline Disposal, wood ash mixture, pure, 0\% water, to sanitary & \\
landfill/CH with US electricity U & \\
\hline a Brassard, P., Palacios, J.H., Godbout, S., Bussières, D., Lagacé, R., Larouche, J.P., Pelletier, F. 2014. Comparis on \\
of the gaseous and particulate matter emis sions from the combustion of agricultural and forest biomas es. \\
Bioresource Technology, 155: 300-306.
\end{tabular}

Table D-30. Process “Disk, Grass”.

\begin{tabular}{lc}
\hline Products and co-product & $1 \mathrm{ha}$ \\
\hline Disk, Gras s $^{\mathrm{a}}$ & \\
\hline Materials/fuels & $15.60832 \mathrm{~kg}$ \\
\hline Diesel, at regional storage/CH with US electricity U & $0.36 \mathrm{~kg}$ \\
Lubricating oil, at plant/RER with US electricity U & \\
\hline a Adjusted from: Caputo, J, Balogh, S.B., Volk, T.A., Johnson, L., Puettmann, M., Lippke, B., Oneil, E. 2014 \\
Icorporation uncertainty into a life cylccle as ses sment model of short rotation willow biomass crops. Biomas s and \\
Bioenrgy, 7:48-59;
\end{tabular}


Table D-31. Process "Horrow, New Holland T1530".

\begin{tabular}{ll}
\hline Products and co-product & \\
\hline Horrow, New Holland T1530 & $1 \mathrm{ha}$ \\
\hline Materials/fuels & $10.45824 \mathrm{~kg}$ \\
\hline Diesel, at regional storage/CH with US electricity U & $0.2 \mathrm{~kg}$ \\
Lubricating oil, at plant/RER with US electricity U & \\
\hline
\end{tabular}

a Adjusted from: Caputo, J, Balogh, S.B., Volk, T.A., Johnson, L., Puettmann, M., Lippke, B., Oneil, E. 2014 Icorporation uncertainty into a life cylccle assessment model of short rotation willow biomass crops. Biomass and Bioenrgy, 7:48-59;

Table D-32. Process "Land Preparation, Miscanthus".

\begin{tabular}{ll}
\hline Products and co-product & \\
\hline Land Preparation, Miscanthus & 1 ha \\
\hline Materials/fuels & 0.1 ha \\
\hline Disking & 0.1 ha \\
Transplanter, Miscanthus & 0.1 ha \\
Horrow, New Holland T1530 & 0.1 ha \\
Plow, Grass, $60 \mathrm{~kW}$ engine & \\
\hline
\end{tabular}

Table D-33. Process "Plow, Grass, $60 \mathrm{~kW}$ engine".

\begin{tabular}{ll}
\hline Products and co-product & \\
\hline Plow, Grass, 60 kW engine ${ }^{\mathrm{a}}$ & $1 \mathrm{ha}$ \\
\hline Materials/fuels & $18.95296 \mathrm{~kg}$ \\
\hline Diesel, at regional storage/CH with US electricity U & $0.36 \mathrm{~kg}$ \\
\hline Lubricating oil, at plant/RER with US electricity U & A
\end{tabular}

a Adjusted from: Caputo, J, Balogh, S.B., Volk, T.A., Johnson, L., Puettmann, M., Lippke, B., Oneil, E. 2014 Icorporation uncertainty into a life cylccle assessment model of short rotation willow biomass crops. Biomass and Bioenrgy, 7:48-59;

Table D-34. Process "Fertilizing, Grass".

\begin{tabular}{lc}
\hline Products and co-product & $1 \mathrm{ha}$ \\
\hline Fertilizing, Grass ${ }^{\mathrm{a}}$ & \\
\hline Materials/fuels & $2.33792 \mathrm{~kg}$ \\
\hline Diesel, at regional storage/CH with US electricity U & $0.04 \mathrm{~kg}$ \\
Lubricating oil, at plant/RER with US electricity U & $100 \mathrm{~kg}$ \\
Ammonium sulphate, as N, at regional storehouse/RER with US & \\
electricity U & \\
\hline a Adjusted from: Caputo, J, Balogh, S.B., Volk, T.A., Johnson, L., Puettmann, M., Lippke, B., Oneil, E. 2014 \\
Icorporation uncertainty into a life cylccle assessment model of short rotation willow biomas s crops. Biomas and \\
Bioenrgy, 7:48-59;
\end{tabular}


Table D-35. Process "Transplanter, Miscanthus".

\begin{tabular}{ll}
\hline Products and co-product & \\
\hline Transplanter, Miscanthus $^{\mathrm{a}}$ & $1 \mathrm{ha}$ \\
\hline Materials/fuels & $1.23968 \mathrm{~kg}$ \\
\hline Diesel, at regional storage/CH with US electricity U & $0.02 \mathrm{~kg}$ \\
Lubricating oil, at plant/RER with US electricity U & \\
\hline
\end{tabular}

a Adjusted from: Caputo, J, Balogh, S.B., Volk, T.A., Johnson, L., Puettmann, M., Lippke, B., Oneil, E. 2014 Icorporation uncertainty into a life cylccle assessment model of short rotation willow biomass crops. Biomass and Bioenrgy, 7:48-59;

Table D-36. Process "Herbicides, Grass".

\begin{tabular}{ll}
\hline Products and co-product & \\
\hline Herbicides, Gras s $^{\text {a }}$ & $1 \mathrm{ha}$ \\
\hline Materials/fuels & \\
\hline Diesel, at regional storage/CH with US electricity U & $0.796343 \mathrm{~kg}$ \\
Lubricating oil, at plant/RER with US electricity U & $0.012614 \mathrm{~kg}$ \\
Glyphosate, at regional storehouse/CH with US electricity U & $0.357143 \mathrm{~kg}$ \\
\hline
\end{tabular}

a Adjusted from: Caputo, J, Balogh, S.B., Volk, T.A., Johnson, L., Puettmann, M., Lippke, B., Oneil, E. 2014 Icorporation uncertainty into a life cylccle assessment model of short rotation willow biomass crops. Biomass and Bioenrgy, 7:48-59;

Table D-37. Process "Baler".

\begin{tabular}{ll}
\hline Products and co-product & \\
\hline Baler $^{\mathrm{a}}$ & $1 \mathrm{ha}$ \\
\hline Materials/fuels & $13.8528 \mathrm{~kg}$ \\
\hline Diesel, at regional storage/CH with US electricity U & $0.26 \mathrm{~kg}$ \\
Lubricating oil, at plant/RER with US electricity U & \\
\hline
\end{tabular}

${ }^{a}$ Liu, J., Kemmerer, B. 2011. Field performance analys is of a tractor and a large square baler. SAE Technical Paper. 2011-01-2302. 
Table D-38. Process "Disk Mowing, New Holland H6740".

\begin{tabular}{|c|c|}
\hline Products and co-product & \\
\hline Disk Mowing, New Holland H6740 ${ }^{\mathrm{a}}$ & $1 \mathrm{ha}$ \\
\hline Materials/fuels & \\
\hline Diesel, at regional storage/CH with US electricity $\mathrm{U}$ & $5.05856 \mathrm{~kg}$ \\
\hline Land Preparation, Switchgrass & $1 \mathrm{ha}$ \\
\hline Fertilizing, Grass & $1 \mathrm{ha}$ \\
\hline Herbicides, Grass & $1 \mathrm{ha}$ \\
\hline Lubricating oil, at plant/RER with US electricity $U$ & $0.1 \mathrm{~kg}$ \\
\hline $\begin{array}{l}\text { a Adjusted from: Caputo, J, Balogh, S.B., Volk, T.A., } \\
\text { Icorporation uncertainty into a life cylccle assessment } \\
\text { Bioenrgy, 7:48-59; }\end{array}$ & $\begin{array}{l}\text { ettmann, } \mathrm{M} \text {. } \\
\text { rotation will }\end{array}$ \\
\hline Table D-39. Process "Harvest, Grass". & \\
\hline Products and co-product & \\
\hline Harvest, Grass & $1 \mathrm{ha}$ \\
\hline Materials/fuels & \\
\hline Baler & $1 \mathrm{ha}$ \\
\hline Disk Mowing, New Holland H6740 & 1 ha \\
\hline Rake, New Holland H5920 & 1 ha \\
\hline Tractor with Wagon & 1 ha \\
\hline Wheel Loader L150G Switchgrass & 17.8 ton \\
\hline Tedding, New Holland H5270 & $1 \mathrm{ha}$ \\
\hline
\end{tabular}

Table D-40. Process "Rake, New Holland H5920".

\begin{tabular}{ll}
\hline Products and co-product & \\
\hline Rake, New Holland H5920 & $1 \mathrm{ha}$ \\
\hline Materials/fuels & \\
\hline Diesel, at regional storage/CH with US electricity U & $2.76224 \mathrm{~kg}$ \\
Lubricating oil, at plant/RER with US electricity U & $0.05 \mathrm{~kg}$ \\
\hline
\end{tabular}

a Adjusted from: Caputo, J, Balogh, S.B., Volk, T.A., Johnson, L., Puettmann, M., Lippke, B., Oneil, E. 2014

Icorporation uncertainty into a life cylccle assessment model of short rotation willow biomass crops. Biomass and Bioenrgy, 7:48-59;

Table D-41. Process "Tedder, New Holland H5270".

\begin{tabular}{ll}
\hline Products and co-product & \\
\hline Tedder, New Holland H5270 & $1 \mathrm{ha}$ \\
\hline Materials/fuels & $3.22816 \mathrm{~kg}$ \\
\hline Diesel, at regional storage/CH with US electricity U & $0.06 \mathrm{~kg}$ \\
Lubricating oil, at plant/RER with US electricity U & \\
\hline
\end{tabular}

a Adjusted from: Caputo, J, Balogh, S.B., Volk, T.A., Johnson,L., Puettmann, M., Lippke, B., Oneil, E. 2014 Icorporation uncertainty into a life cylccle assessment model of short rotation willow biomass crops. Biomass and Bioenrgy, 7:48-59; 
Table D-42. Process "Tractor with Wagon".

\begin{tabular}{ll}
\hline Products and co-product & \\
\hline Tractor with Wagon $^{\mathrm{a}}$ & $1 \mathrm{ha}$ \\
\hline Materials/fuels & $10.816 \mathrm{~kg}$ \\
\hline Diesel, at regional storage/CH with US electricity U & $0.057182 \mathrm{~kg}$ \\
Lubricating oil, at plant/RER with US electricity U &
\end{tabular}

a Adjusted from: Caputo, J, Balogh, S.B., Volk, T.A., Johnson, L., Puettmann, M., Lippke, B., Oneil, E. 2014 Icorporation uncertainty into a life cylccle assessment model of short rotation willow biomass crops. Biomass and Bioenrgy, 7:48-59;

Table D-43. Process "Land Preparation, Switchgrass".

\begin{tabular}{ll}
\hline Products and co-product & \\
\hline Land Preparation, Switchgrass & $1 \mathrm{ha}$ \\
\hline Materials/fuels & \\
\hline Disking & $0.1 \mathrm{ha}$ \\
Hopper, Switchgrass & $0.1 \mathrm{ha}$ \\
Horrow, New Holland T1530 & $0.1 \mathrm{ha}$ \\
Plow, Grass, 60 kW engine & $0.1 \mathrm{ha}$ \\
\hline
\end{tabular}

Table D-44. Process "Hopper, Switchgrass".

\begin{tabular}{ll}
\hline Products and co-product & \\
\hline Hopper, Switchgrass ${ }^{a}$ & 1 ha \\
\hline Materials/fuels & $1.23968 \mathrm{~kg}$ \\
\hline Diesel, at regional storage/CH with US electricity U & $0.02 \mathrm{~kg}$ \\
Lubricating oil, at plant/RER with US electricity U &
\end{tabular}

${ }^{a}$ Adjusted from: Caputo, J, Balogh, S.B., Volk, T.A., Johnson, L., Puettmann, M., Lippke, B., Oneil, E. 2014 Icorporation uncertainty into a life cylccle assessment model of short rotation willow biomass crops. Biomass and Bioenrgy, 7:48-59; 


\section{D.2. StatistiCal ANALYSIS}

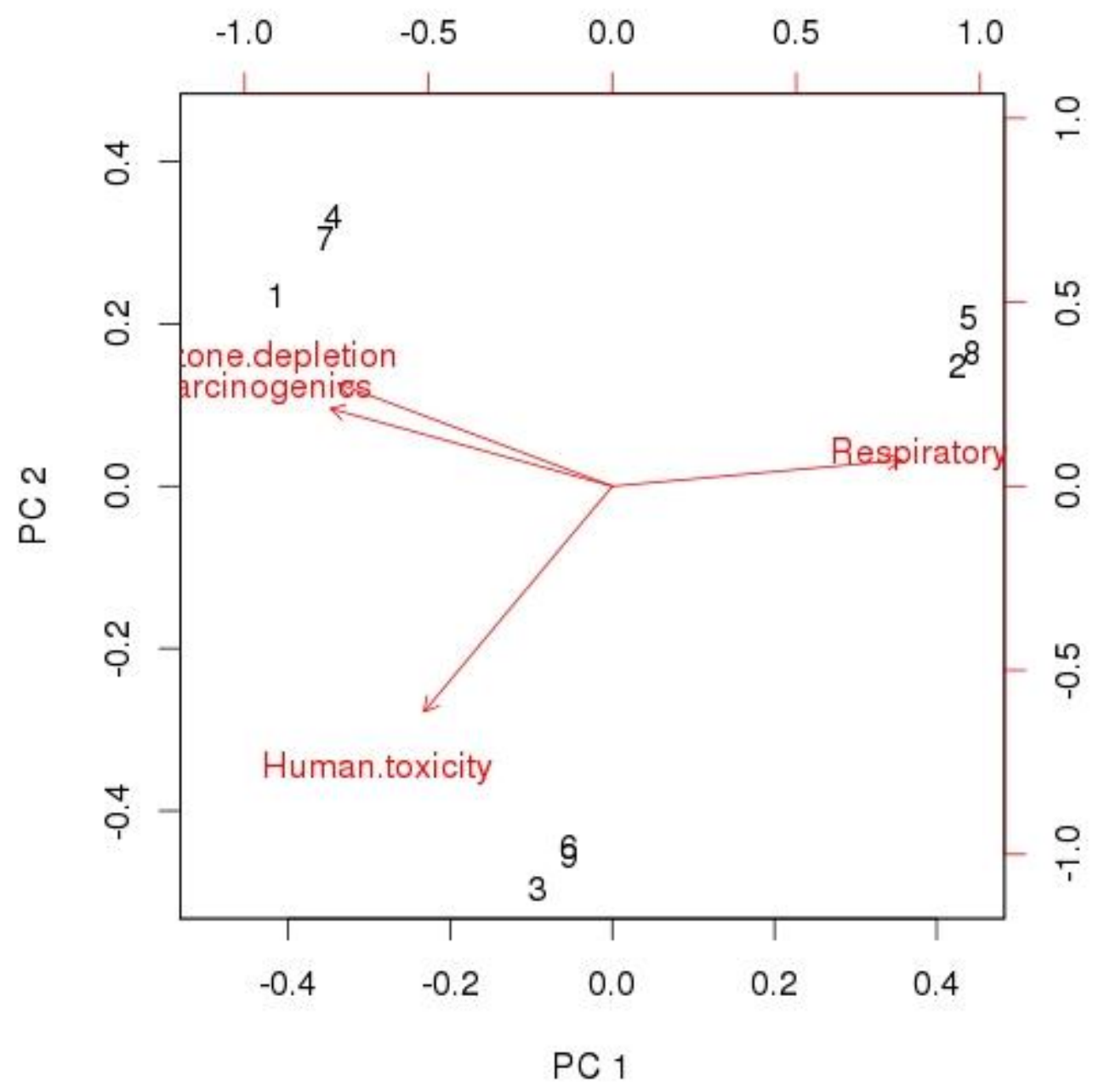

Fig. D-1. PCA of human health impact.

\section{Result of PCA}

$>\operatorname{pca}(x[, 6: 9])$

$\$$ pca.var

[1] 3.16240 .78450 .03690 .0163

\$var.p

[1] 0.79060 .19610 .00920 .0041 


$$
\begin{aligned}
& \text { \$pca.scores } \\
& \begin{array}{ccccc}
\text { V1 } & \text { V2 } & \text { V3 } & \text { V4 } \\
1 & -0.4127 & 0.2355 & -0.7007 & -0.0534 \\
2 & 0.4255 & 0.1474 & 0.0221 & -0.8195 \\
3 & -0.0904 & -0.4952 & -0.3471 & -0.0063 \\
4 & -0.3444 & 0.3332 & 0.4570 & 0.0206 \\
5 & 0.4382 & 0.2071 & -0.0530 & 0.4906 \\
6 & -0.0540 & -0.4436 & 0.2574 & 0.0489 \\
7 & -0.3534 & 0.3062 & 0.2399 & 0.0157 \\
8 & 0.4460 & 0.1638 & -0.0876 & 0.2856 \\
9 & -0.0548 & -0.4543 & 0.2120 & 0.0178
\end{array}
\end{aligned}
$$

\$pca.coeff

$\begin{array}{lrrrr} & \mathrm{V} 1 & \mathrm{~V} 2 & \mathrm{~V} 3 & \mathrm{~V} 4 \\ & & & \\ \text { Carcinogenics } & -0.9579 & 0.2635 & -0.0710 & 0.0888 \\ \text { Respiratory.effects } & 0.9834 & 0.0884 & -0.1586 & -0.0067 \\ \text { Ozone.depletion } & -0.9317 & 0.3482 & -0.0495 & -0.0905 \\ \text { Human.toxicity } & -0.6400 & -0.7655 & -0.0653 & -0.0114\end{array}$

\$pca.corr

$\begin{array}{cccccc} & \text { V1 } & \text { V2 } & \text { V3 } & \text { V4 } & \\ \text { Carcinogenics } & & -0.9579 & 0.2635 & -0.0710 & 0.0888\end{array}$

Respiratory.effects $0.9834 \quad 0.0884-0.1586-0.0067$

Ozone.depletion $\quad-0.9317 \quad 0.3482-0.0495-0.0905$

Human.toxicity $\quad-0.6400-0.7655-0.0653-0.0114$ 